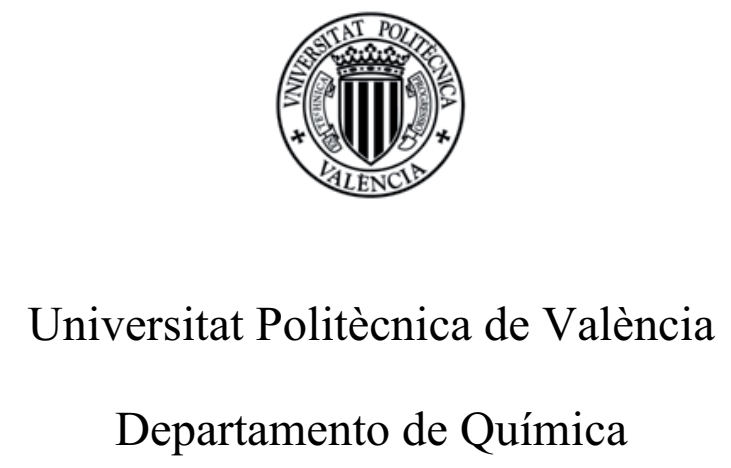

Tesis Doctoral

\title{
SÍNTESIS DE INMUNORREACTIVOS PARA LA DETERMINACIÓN DE SULFONAMIDAS Y TETRACICLINAS EN ALIMENTOS
}

\author{
Memoria presentada por Nuria Pastor Navarro \\ para optar al grado de Doctor \\ por la Universitat Politècnica de València
}

Directores:

Dra. Rosa Puchades Pla

Dr. Ángel Maquieira Catalá

Valencia, Septiembre 2011 



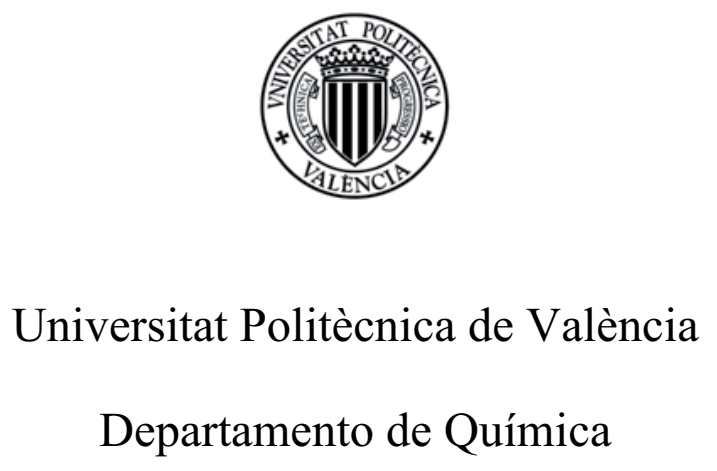

Rosa Puchades Pla,

Catedrática de Química Analítica de la Universidad Politécnica de Valencia,

Ángel Maquieira Catalá, Catedrático de Química Analítica de la Universidad Politécnica de Valencia,

CERTIFICAN: Que las investigaciones recogidas en la presente memoria "Síntesis de inmunorreactivos para la determinación de sulfonamidas y tetraciclinas en alimentos", que presenta $D^{\mathbf{a}}$. Nuria Pastor Navarro, Licenciada en Ciencias Químicas, han sido realizadas bajo nuestra dirección y cumplen con las normas en vigor en cuanto a calidad científica y volumen de trabajo. Por ello, autorizamos su presentación para ser defendida como Tesis Doctoral.

En Valencia a 15 de Septiembre de 2011.

Fdo. Rosa Puchades Pla

Fdo. Ángel Maquieira Catalá 


Al finalizar el presente trabajo quiero expresar mi agradecimiento a todas las personas que, de una forma u otra, han ayudado a que esta tesis sea una realidad.

En primer lugar a mis directores, Rosa Puchades Pla y Ángel Maquieira Catalá, por su capacidad de enseñar, apoyo, dedicación y sobretodo, por lo pendiente que han estado todo este tiempo, animándome y alentándome para que pudiera terminarla. Gracias por confiar en mí para este proyecto y por apoyarme cada vez que lo necesitaba.

Al Departamento de Química de la Universitat Politècnica de València donde se ha realizado este trabajo. En especial, a los profesores y compañeros de la Unidad Docente de Química Analítica por su incondicional apoyo.

A todos los compañeros del laboratorio y a todos mis amigos que a lo largo de estos años me han demostrado su amistad. En especial a Sergi, por haber trabajado conmigo todo el tiempo necesario con una entrega y dedicación absoluta, además de sus inestimables aportaciones profesionales y personales.

A mis padres, por todo su apoyo, confianza y cariño, estoy donde estoy gracias a ellos. A mis hermanos y a Carlos, por las risas, apoyo, consejos y paciencia que han tenido. A mi sobrina Laura, por el tiempo y los juegos que ha compartido con su teta Irene durante la escritura de esta Tesis.

Pero especialmente quisiera darle las gracias a una persona que siempre ha confiado en mí, que realmente sabía lo importante que era para mi este esfuerzo de investigación, y que me ha apoyado incondicionalmente, con mucho cariño y comprensión, mi marido David. Gracias a Irene, nuestra hija, que espero llegue a entender algún día el motivo por el que durante tantas horas no he podido dedicarle la atención que merecía.

Muchas gracias a todos, una parte de esta Tesis es también vuestra. 



\section{RESUMEN}

La presencia de residuos de antibióticos en alimentos de origen animal es uno de los problemas más importantes y actuales en seguridad alimentaria. Los medicamentos son utilizados en la producción animal con fines terapéuticos y como promotores del crecimiento. El problema surge cuando residuos de estos antibióticos llegan al consumidor a través de la cadena alimentaria a niveles perjudiciales para su salud, ya que tienen efectos secundarios al destruir las bacterias comensales de nuestro intestino y al provocar reacciones alérgicas, además de contribuir a la aparición de bacterias resistentes.

A efectos normativos, en el reglamento CE No 470/2009 se establecen procedimientos comunitarios para la fijación de los límites máximos de residuos (LMR) de las sustancias farmacológicamente activas en los alimentos de origen animal. Así, para la mayoría de los antibióticos usados con fines veterinarios y dependiendo del tejido, el LMR varía entre 5 y $600 \mu \mathrm{g} / \mathrm{kg}$.

Actualmente, la determinación de tetraciclinas y sulfonamidas se lleva a cabo, principalmente, mediante cromatografía liquida (HPLC) con detección fluorescente, UV o por espectrometría de masas (MS). El método es complicado y sobre todo caro. Además, la etapa de preparación y purificación de muestra requerida para obtener un alto grado de pureza es laboriosa, lo que unido a la baja capacidad de trabajo y el coste de los análisis, hacen que esta metodología sea poco adecuada para implementar programas de vigilancia y control que aseguren la inocuidad de los alimentos. Los métodos de barrido son los utilizados comúnmente para detectar residuos de antibióticos en alimentos previamente al análisis confirmativo. Estos métodos deben ser semicuantitativos, rápidos, robustos y relativamente baratos. Entre los métodos de barrido (screening) utilizados para detectar residuos de antibióticos se encuentran principalmente los cromatográficos, los microbiológicos y los inmunológicos.

Esta Tesis se ha centrado en el desarrollo de inmunorreactivos y sistemas analíticos de barrido basados en métodos inmunoquímicos (ELISA), dirigida a la detección de residuos de antibióticos en alimentos, concretamente sulfonamidas y tetraciclinas. Las técnicas puestas a punto permitirán conocer el nivel de residuos de estos analitos de forma rápida, sensible, económica y fiable, con un tratamiento de muestra mínimo y por personal no cualificado. 
En primer lugar, se abordó la síntesis de haptenos para la obtención de anticuerpos contra distintos compuestos de la familia de las sulfonamidas y tetraciclinas. Así, se sintetizaron diferentes moléculas manteniendo la estructura base de cada grupo de antibióticos (región constante) y se funcionalizaron con grupos carboxilo con el fin de obtener los inmunógenos, los conjugados de tapizado y los trazadores enzimáticos, disponiéndose de los reactivos necesarios para poner a punto los ensayos. En todos los casos se procedió a obtener anticuerpos policlonales por inmunización de conejos, que han demostrado ser efectivos y de fácil obtención, tanto en lo que respecta a la técnica operativa como a los tiempos de respuesta.

Los sueros obtenidos se caracterizaron (sensibilidad y selectividad) mediante ELISA, estableciendo las concentraciones óptimas de inmunorreactivos y los formatos de ensayo. Después de la puesta a punto de varios ensayos se seleccionaron los más específicos, dos para sulfonamidas, (sulfatiazol, STZ y sulfasalazina, SSZ) y uno para tetraciclinas (clortetraciclina, CTC).

Por otro lado, se obtuvieron inmunorreactivos genéricos (baja selectividad) hacia algunas de las sulfonamidas y tetraciclinas de mayor uso, lo que permitió desarrollar dos inmunoensayos multirresiduo.

Posteriormente se optimizaron los factores físico-químicos que pueden influir en la interacción antígeno-anticuerpo como la fuerza iónica del medio, tiempo de incubación, $\mathrm{pH}$ y concentración de tensoactivos. Los inmunoensayos específicos más sensibles presentaron valores de $\mathrm{IC}_{50}$ de $1,6 \mu \mathrm{g} / \mathrm{L}$ para STZ, $0,51 \mu \mathrm{g} / \mathrm{L}$ para SSZ y $36,40 \mu \mathrm{g} / \mathrm{L}$ para CTC, mientras que en los genéricos la $\mathrm{IC}_{50}$ fue $1,32 \mu \mathrm{g} / \mathrm{L}$ expresada como equivalentes de STZ y $6,5 \mu \mathrm{g} / \mathrm{L}$ expresada como tetraciclina. Todos los ELISAs desarrollados para sulfonamidas y tetraciclinas presentaron buena sensibilidad, a niveles de $\mu \mathrm{g} / \mathrm{L}$, siendo inferiores a los LMRs establecidos por la legislación.

Finalmente, se evaluó el potencial analítico de los inmunoensayos desarrollados mediante su aplicación a la determinación de residuos de sulfonamidas y tetraciclinas en miel. Los resultados mostraron recuperaciones excelentes (recuperación media, 97\%), resultando una metodología muy interesante para la implementación de Planes de Vigilancias, con tratamiento de muestra mínimo. 


\section{RESUM}

La presència de residus d'antibiòtics en aliments d'origen animal és un dels problemes més importants i d'actualitat en seguretat alimentària. Els medicaments són utilitzats en la producció animal per a ús terapèutic, però també com a promotors del creixement. El problema sorgeix quan residus d'aquests antibiòtics arriben al consumidor per mitjans de la cadena alimentària, a nivells perjudicials per a la salut, ja que tenen efectes secundaris en destruir els bacteris comensals del nostre intestí i en provocar reaccions al·lèrgiques, a més de contribuir a l'aparició de bacteris resistents.

A efectes normatius, en el reglament CE núm. 470/2009 s'estableixen procediments comunitaris per a fixar els límits màxims de residus (LMR) de les substàncies farmacològicament actives en els aliments d'origen animal. Així, per a la major part dels antibiòtics usats amb finalitats veterinàries i, depenent del teixit, el LMR varia entre 5 i $600 \mu \mathrm{g} / \mathrm{kg}$.

Actualment, la determinació de tetraciclines i sulfonamides es porta a terme, principalment, mitjançant cromatografia de líquids d'alta pressió (HPLC) amb detecció fluorescent, UV o per espectrometria de masses (MS). El mètode és complicat i sobretot car. A més, l'etapa de preparació i purificació de la mostra requerida per obtenir un grau alt de puresa és laboriosa, la qual cosa unit a la baixa capacitat de treball i el cost de les anàlisis fan que aquesta metodologia siga poc adequada per a implementar programes de vigilància i control que asseguren la innocuïtat dels aliments. Els mètodes de cribratge són els utilitzats comunament per a detectar residus d'antibiòtics en aliments prèviament a l'anàlisi confirmativa. Aquests mètodes han de ser semiqüantitatius, ràpids, robustos i relativament barats. Entre els mètodes de cribratge (screening) utilitzats per a detectar residus d'antibiòtics es troben principalment els cromatogràfics, els microbiològics i els immunològics.

Aquesta tesi s'ha centrat en el desenvolupament d'immunoreactius i sistemes analítics de cribratge basats en mètodes immunoquímics (ELISA), dirigits a detectar residus d'antibiòtics en aliments, concretament sulfonamides i tetraciclines. Les tècniques posades a punt permetran conèixer el nivell de residus d'aquests anàlits d'una manera ràpida, sensible, econòmica i fiable, amb un tractament de mostra mínim i fet per personal no qualificat. 
En primer lloc, es va abordar la síntesi d'haptens per a obtenir anticossos contra diferents compostos de la família de les sulfonamides i tetraciclines. Així, es van sintetitzar diferents molècules però se'n va mantenir l'estructura base de cada grup d'antibiòtics (regió constant) i es van funcionalitzar amb grups carboxil amb la finalitat d'obtenir els immunògens, els conjugats de tamisatge i els traçadors enzimàtics, tot disposant dels reactius necessaris per a posar a punt els assajos. En tots els casos es va procedir a obtenir anticossos policlonals per immunització de conills, els quals han demostrat ser efectius i fàcils d'obtenir, tant pel que fa a la tècnica operativa com pel que fa als temps de resposta.

Els sèrums obtinguts es van caracteritzar (sensibilitat i selectivitat) mitjançant ELISA $i$ es van establir les concentracions òptimes d'immunoreactius i els formats d'assaig. Després de la posada a punt de diversos assajos, es van seleccionar els més específics, dos per a sulfonamides (sulfatiazole, STZ i sulfasalazina, SSZ) i un per a tetraciclines (clortetraciclina, CTC).

D'altra banda, es van obtenir immunoreactius genèrics (baixa selectivitat) cap a algunes de les sulfonamides i tetraciclines més utilitzades, fet que va permetre desenvolupar dos immunoassajos multiresidu.

Posteriorment, es van optimitzar els factors fisicoquímics que poden influir en la interacció antigen-anticòs com ara la força iònica del mitjà, el temps d'incubació, el pH i la concentració de tensoactius. Els immunoassajos específics més sensibles van presentar valors d' $\mathrm{IC}_{50}$ d' $1,6 \mu \mathrm{g} / \mathrm{L}$ per a STZ, $0,51 \mu \mathrm{g} / \mathrm{L}$ per a SSZ i $36,40 \mu \mathrm{g} / \mathrm{L}$ per a CTC, mentre que en els genèrics la $\mathrm{IC}_{50}$ va ser $1,32 \mu \mathrm{g} / \mathrm{L}$ expressada com a equivalents de STZ, i $6,5 \mu \mathrm{g} / \mathrm{L}$ expressada com tetraciclina. Tots els ELISA desenvolupats per a sulfonamides i tetraciclines van presentar bona sensibilitat, a nivells de $\mu \mathrm{g} / \mathrm{L}$, i van ser inferiors als LMR establits per la legislació.

Finalment, es va avaluar el potencial analític dels immunoassajos desenvolupats mitjançant la seua aplicació a determinar els residus de sulfonamides i tetraciclines en mel. Els resultats van mostrar recuperacions excel·lents (recuperació mitjana, 97\%); per tant, és una metodologia molt interessant per a la implementació de plans de vigilàncies, amb tractament de mostra mínim. 


\section{SUMMARY}

The presence of antibiotic residues in food from animal origin is one of the most important and contemporary problems in food quality and safety control. Medicines are employed in animal production for therapeutic use and, as growing promoters. The problem arises when antibiotic residues reaches to the consumer through food chain, at health harmful levels, since they have secondary effect, they destroying synergic bacteria in our intestine and provoking allergic reactions. These effects contribute to the raising of resistant bacteria.

Regarding regulations, in CE regulation No. 470/2009, community procedures for fixing the maximal residual limits (LMR) of active drug substances in commodities from animal origin are established. Thus, for most of the employed veterinary antibiotics, and depending on the tissue, LMR ranges from 5 to 600 $\mu \mathrm{g} / \mathrm{kg}$.

Currently, tetracycline and sulfonamide determination is carried out mainly by means of liquid chromatography (HPLC) with fluorescent, UV or mass spectrometry (MS) detection. The method is complicated and expensive. Furthermore, the step of sample preparation and clean-up required for obtaining a high purity degree is laborious, and that together with the low rate and high cost of analyses, imply that this methodology is little adequate for carrying out survey and control programs that guarantee food safety. Screening methods are commonly used for detecting residues of antibiotics in food prior to the confirmatory analysis. These methods must be semiquantitative, rapid, robust and relatively cheap. Among screening methods employed for detecting antibiotic residues, chromatographic, microbiologic and immunologic ones are current.

This Thesis has been focused on the development of immunoreagents and screening analytical systems based on immunochemical methods (ELISA), addressed to detect antibiotic residues, concretely sulfonamides and tetracyclines, in food. The set-up techniques will allow to know the level of these substances in a rapid, sensitive, cost-effective and reliable way, with a minimal sample treatment and without the need of qualified personnel.

The work was focused first in the synthesis of haptens for raising antibodies against the different compounds from the sulfonamide and tetracycline families. Thus, different molecules were synthesized maintaining the structural basis for each antibiotic group (constant region), and they were functionalized with 
carboxylic acid groups in order to obtain immunogens, coating conjugates and enzyme tracers, to be used for assays setting-up. In all cases, polyclonal antibodies that have demonstrated to be effective and easy to obtain regarding to both operative technique and response time, were raised by immunizing rabbits.

The obtained sera were characterized (sensitivity and selectivity) by means of ELISA, establishing the optimal immunoreagent concentration and assay formats. After setting up different assays, the most specific ones were selected, two for sulfonamides (sulfatiazole, STZ and sulfasalazine, SSZ) and one for tetracyclines (chlortetracycline, CTC).

On the other hand, generic (low selectivity) immunoreagents were raised for some of the most employed sulfonamides and tetracyclines, allowing for the development of two multiresidue immunoassays.

Furthermore, the physico-chemical factors that have influence on antigenantibody interaction, such as medium ionic strength, incubation time, $\mathrm{pH}$ and surfactant concentration, were optimized. The most sensitive specific immunoassays showed $\mathrm{IC}_{50}$ values of $1,6 \mu \mathrm{g} / \mathrm{L}$ for STZ, $0,51 \mu \mathrm{g} / \mathrm{L}$ for SSZ and $36,40 \mu \mathrm{g} / \mathrm{L}$ for CTC, while in generic assays $\mathrm{IC}_{50}$ was $1,32 \mu \mathrm{g} / \mathrm{L}$ expressed as $\mathrm{STZ}$ equivalent, and $6,5 \mu \mathrm{g} / \mathrm{L}$ expressed as tetracycline equivalent. All the developed ELISAs for sulfonamides and tetracyclines showed good sensitivity, at $\mu \mathrm{g} / \mathrm{L}$ level, this being lower than LMRs established in regulations.

Finally, the analytical potential of the developed immunoassays was evaluated by applying them to the determination of sulfonamide and tetracycline residues in honey. Results showed excellent recoveries (mean recovery 97\%), what makes this methodology interesting for implementing Survey Plans, with minimal sample treatment. 
$\delta$

${ }^{13} \mathrm{C}-\mathrm{RMN}$

${ }^{1}$ H-RMN

$\mathrm{A}_{0}$

$\mathrm{Ab}$

ABA

AcOEt

AEMA

AESAN

Ag

aq

ar

as

ATC

BSA

BTG

CB

cBSA

CDI

CFI

CONA

conc

cOVA

CS

CTC

$\mathrm{CV}$

d

D2

D4

D5

DAD

DCC

DMAP

DMC
Desplazamiento químico

Resonancia magnética nuclear de carbono-13

Resonancia magnética nuclear de protón

Absorbancia máxima

Anticuerpo

Aminobenzoico

Acetato de etilo

Agencia europea de medioambiente

Agencia española de seguridad alimentaria y nutrición

Antígeno

Acuoso

Aromático

Asimétrica

Anhidrotetraciclina

Seroalbúmina bovina

Tiroglobulina bovina

Tampón carbonato/bicarbonato sódico 50 mM, pH 9,6

BSA cationizada

Carboxidiimida

Cloroformiato de isobutilo

Conalbúmina

Concentrado

OVA cationizada

Ácido 4-(4-amino-bencenosulfonilamino)benzoico

7-Clortetraciclina

Coeficiente de variación

Doblete

Ácido 6-(4-amino-bencenosulfonilamino)nicotínico

Ácido 6-(4-amino-bencenosulfonilamino)hexanoico

Ácido 4-(4-amino-bencenosulfonilamino)butanoico

Diode array detector / detector de diodos integrados en fila

$N, N$ '-diciclohexilcarbodiimida

4-Dimetilaminopiridina

Demeclociclina 


\begin{tabular}{|c|c|}
\hline DMF & $N, N$ '-dimetilformamida \\
\hline DMSO & Dimetilsulfóxido \\
\hline DR & Daunorubicina \\
\hline $\mathrm{DXC}$ & Doxiciclina \\
\hline DXR & Doxorubicina \\
\hline EDTA & Ácido etilendiaminotetracético \\
\hline EFSA & Autoridad europea de seguridad alimentaria \\
\hline ELISA & $\begin{array}{l}\text { Enzyme-linked immunosorbent assay / inmunoensayo } \\
\text { enzimático en fase heterogénea }\end{array}$ \\
\hline $\mathrm{EtOH}$ & Etanol \\
\hline FAO & $\begin{array}{l}\text { Organización de las naciones unidas para la agricultura y } \\
\text { la alimentación }\end{array}$ \\
\hline FLD & Fluorescent daylight / luz fluorescente \\
\hline GAR-HRP & $\begin{array}{l}\text { Inmunoglobulina } \mathrm{G} \text { de cabra anti-conejo marcada con } \\
\text { HRP }\end{array}$ \\
\hline $\mathrm{GC}$ & Gas chromatography / cromatografía de gases \\
\hline $\mathrm{HCH}$ & Hemocianina del cangrejo de herradura \\
\hline HPLC & $\begin{array}{l}\text { High performance liquid chromatography / cromatografía } \\
\text { líquida de alta eficacia }\end{array}$ \\
\hline HRP & Enzima peroxidasa de rábano picante \\
\hline $\mathrm{IC}_{50}$ & $\begin{array}{l}\text { Concentración de analito que inhibe } 50 \% \text { de los sitios } \\
\text { específicos de unión del anticuerpo }\end{array}$ \\
\hline IE & Impacto electrónico \\
\hline IR & Infrarrojo \\
\hline $\mathrm{J}$ & Constante de acoplamiento (RMN) \\
\hline KLH & $\begin{array}{l}\text { Keyhole limped hemocyanin / hemocianina del molusco } \\
\text { Megathura crenulata }\end{array}$ \\
\hline LC & Liquid chromatography / cromatografía líquida \\
\hline LD & Límite de detección \\
\hline LMR & Límite máximo de residuo \\
\hline LPH & Hemocianina de Limulus polyphemus \\
\hline $\mathrm{m}$ & Multiplete \\
\hline $\mathrm{m} / \mathrm{z}$ & Relación masa/carga \\
\hline Abs & Anticuerpos monoclonales \\
\hline
\end{tabular}




$\begin{array}{ll}\text { MC } & \text { Metaciclina } \\ \text { MeOH } & \text { Metanol } \\ \text { MNC } & \text { Minociclina } \\ \text { Mr } & \text { Masa molecular relativa } \\ \text { MRPL } & \text { Límites mínimos de funcionamiento exigido } \\ \text { MS } & \text { Espectrometría de masas } \\ \text { NCS } & N \text {-clorosuccinimida } \\ \text { NHS } & N \text {-hidroxisuccinimida } \\ \text { NS } & \text { 4-Amino- } N \text {-(4-nitro-fenil)-bencenosulfonamida } \\ \text { OIE } & \text { Organización mundial de la sanidad animal } \\ \text { OMS } & \text { Organización mundial de la salud } \\ \text { OPD } & o \text {-Fenilendiamina } \\ \text { OTC } & \text { Oxitetraciclina } \\ \text { OVA } & \text { Ovoalbúmina } \\ \text { pAbs } & \text { Anticuerpos policlonales } \\ \text { PBS } & \text { Tampón fosfato salino (10 mM fosfato, 137 mM NaCl, } \\ \text { PBS-T } & 2,7 \text { mM KCl, pH 7,4) } \\ \text { ppm } & \text { PBS conteniendo 0,05\% v/v de Tween 20 } \\ \text { PS } & \text { Partes por millón } \\ \text { PSTZ } & \text { Ácido 3- }\{3 \text {-[6-(4-amino-bencenosulfonilamino)-4-metil- } \\ \text { q } & \text { piridin-3-ilazo]-4-hidroxi-fenil }\} \text { propiónico } \\ \text { quint } & N^{4} \text {-ftalilsulfatiazol } \\ \text { R } & \text { Cuadruplete } \\ \text { rAbs } & \text { Quintuplete } \\ \text { RC } & \text { Recuperación } \\ \text { RD } & \text { Anticuerpos recombinantes } \\ \text { R } & \text { Reactividad cruzada } \\ \text { RIAs } & \text { Intervalo de trabajo } \\ \text { RM } & \text { Factor de retención } \\ \text { RMN } & \text { Radioinmunoensayos } \\ \text { RSA } & \text { Relación molar } \\ \text { RTC } & \text { Resonancia magnética nuclear } \\ & \end{array}$


$\mathrm{S}$

SA1

SA2

SA3

SA4

SA5

SA6

SAM

SAN

SCP

SDM

SDX

SDZ

SG

sim

SIM

SMM

SMP

SMR

SMT

SMX

SMZ

SOX

SP

SPE

SPR

SPFIA

SQX
Singlete

Ácido 5-[6-(4-aminobencenosulfonilamino)piridin-3-il]-2metilpentanoico

Ácido 5-[4-(amino)fenilsulfonamida]-5-oxopentanoico Ácido 5-(4-\{[(4-clorofenil)amino $]$ sulfonil $\}$ fenil $)$ pentanoico Ácido 5-[(4-\{[(4,6-dimetilpirimidin-2-il)amino]sulfonil $\}$ fenil)amino]-5-oxopentanoico Ácido 5-[(4-\{[(6-cloropiridazin-3-il)amino $]$ sulfonil $\}$ fenil $)$ amino]-5-oxopentanoico Ácido 5-oxo-5-(4-\{[(piridin-2-ilamino)sulfonil $]$ fenil $\}$ amino)pentanoico

Sulfacetamida

Sulfanilamida

Sulfacloropiridazina

Sulfadimetoxina

Sulfadoxina

Sulfadiazina

Sulfaguanidina

Simétrica

Sulfisomidina

Sulfamonometoxina

Sulfametoxipiridazina

Sulfamerazina

Sulfametizol

Sulfametoxazol

Sulfametazina o sulfadimidina

Sulfisoxazol

Sulfapiridina

Solid phase extraction / extracción en fase sólida

Surface plasmon resonante / resonancia de plasmón

superficial

Solid-phase fluorescence immunoassay / inmunoensayo

fluorescente en fase sólida

Sulfaquinoxalina 
SSZ

STI

STZ

$\mathrm{t}$

TBA

$\mathrm{TC}$

TFA

TFAA

TLC

$\mathrm{t}_{\mathrm{R}}$

TS

Tween 20

UV-VIS

$v$
Sulfasalazina

Inhibidor de tripsina de soja

Sulfatiazol

Triplete

Tributilamina

Tetraciclina

Ácido trifluoroacético

Anhídrido trifluoroacético

Thin layer chromatography / cromatografía en capa fina

Tiempo de retención

Ácido [2-(4-amino-bencenosulfonilamino)-1,3-tiazol-4-

il]acético

Polioxietilensorbitan monolaurato

Ultravioleta visible

Frecuencia de estiramiento 

1.1. CARACTERÍSTICAS GENERALES DE LOS ANTIBIÓTICOS 3

1.1.1. Clasificación 4

1.2. CARACTERÍSTICAS GENERALES DE LAS SULFONAMIDAS 8

1.2.1. Propiedades y estructura general 9

1.2.2. Clasificación 10

1.3. CARACTERÍSTICAS GENERALES DE LAS TETRACICLINAS 11

1.3.1. Propiedades y estructura general 12

$\begin{array}{ll}\text { 1.3.2. Clasificación } & 14\end{array}$

1.4. EMPLEO DE ANTIBIÓTICOS EN VETERINARIA 16

1.4.1. Utilización de antibióticos en zootecnia 16

1.4.2. Consecuencias del empleo de antibióticos en animales de 17 abasto

1.4.2.1. Consecuencias para la salud humana 18

1.4.2.2. Problemas tecnológicos y analíticos 19

1.4.2.3. Problemas medioambientales 20

1.5. LEGISLACIÓN Y CONTROL DE RESIDUOS DE

MEDICAMENTOS VETERINARIOS EN LOS ALIMENTOS DE 22

ORIGEN ANIMAL

1.6. MÉTODOS ANALÍTICOS PARA LA DETERMINACIÓN DE SULFONAMIDAS Y TETRACICLINAS

1.6.1. Métodos de confirmación o referencia 28

1.6.2. Métodos de barrido $\quad 29$

1.6.2.1. Métodos cromatográficos $\quad 30$

1.6.2.2. Métodos microbiológicos 31

1.6.2.3. Métodos inmunoquímicos (ELISA) 32

1.6.3. Determinación de sulfonamidas y tetraciclinas mediante 33

ELISA

1.6.3.1. Sintesis de haptenos para sulfonamidas 34

1.6.3.2. Sintesis de haptenos para tetraciclinas $\quad 39$

1.6.3.3. Determinación de sulfonamidas en alimentos mediante ELISA 
3.1. SÍNTESIS ORGÁNICA

3.1.1. Técnicas generales $\quad 59$

3.1.1.1. Técnicas cromatográficas $\quad 59$

3.1.1.2. Técnicas espectroscópicas $\quad 60$

3.1.2. Reactivos $\quad 60$

3.1.3. Síntesis de haptenos para sulfonamidas 61

3.1.3.1. Haptenos tipo I 61

3.1.3.2. Haptenos tipo II 71

3.1.3.3. Haptenos tipo III 74

3.1.4. Síntesis de haptenos para tetraciclinas $\quad 81$

3.1.4.1. Haptenos tipo I 81

3.1.4.2. Haptenos tipo II 83

3.2. DESARROLLO DE INMUNOENSAYOS 86

3.2.1. Instrumentación 86

$\begin{array}{ll}\text { 3.2.2. Reactivos y disoluciones } & 87\end{array}$

3.2.3. Protocolos generales $\quad 88$

3.2.3.1. Preparación de conjugados hapténicos, trazadores y reactivos auxiliares. Protocolos de conjugación $\quad 88$

3.2.3.2. Determinación de la relación hapteno/proteina 93

3.2.3.3. Protocolo de inmunización y obtención de anticuerpos 93 policlonales

3.2.4. Ensayos inmunoenzimáticos. ELISAs 94

3.2.4.1. ELISAs no competitivos 94

3.2.4.2. ELISAs competitivos 95

3.2.4.3. Optimización de los ensayos ELISA 97

3.2.4.4. Estudio de la selectividad de los ensayos 97 
3.2.4.5. Efecto de los disolventes orgánicos 100

3.2.4.6. Análisis de muestras reales 100

4. RESULTADOS Y DISCUSIÓN 107

4.1. DISEÑO Y SÍNTESIS DE HAPTENOS 109

4.1.1. Diseño y síntesis de haptenos para sulfonamidas $\quad 110$

4.1.1.1. Haptenos tipo I 112

4.1.1.2. Haptenos tipo II 119

4.1.1.3. Haptenos tipo III 121

4.1.2. Diseño y síntesis de haptenos para tetraciclinas 126

4.1.2.1. Haptenos tipo I 130

4.1.2.2. Haptenos tipo II 132

4.2. DESARROLLO DE INMUNOENSAYOS 138

4.2.1. Caracterización y selección de los antisueros 138

4.2.1.1. Selección de antisueros para sulfonamidas 138

4.2.1.2. Selección de antisueros para tetraciclinas $\quad 140$

4.2.2. ELISAs competitivos para sulfonamidas 141

4.2.2.1. Optimización y estudio de la selectividad de los ensayos 145

4.2.2.2. Ensayos para $S T Z$

4.2.2.3. Ensayo para SSZ 151

4.2.2.4. ELISAs Genérico I 154

4.2.3. ELISAs competitivos para tetraciclinas 159

4.2.3.1. Optimización y estudio de la selectividad de los ensayos 159

4.2.3.2. Ensayo para TCs 160

4.2.3.3. Ensayo para CTC 164

4.2.4. Análisis de muestras 167

4.2.4.1. Ensayo para STZ 167

4.2.4.2. Ensayo para SSZ 169

4.2.4.3. ELISA Genérico I 175

4.2.4.4. Ensayo para TCs 181

5. CONCLUSIONES 185 
APÉNDICE I: ESPECTROS RMN, IR Y MS

APÉNDICE II: PUBLICACIONES DERIVADAS DE ESTA TESIS

DOCTORAL

APÉNDICE III: PUBLICACIONES BASADAS EN

INMUNORREACTIVOS DESARROLLADOS EN ESTA TESIS

251

DOCTORAL 
Tabla 1. Clasificación de los antibióticos según la estructura química

Pag.

Tabla 2. Sulfonamidas de uso generalizado 11

Tabla 3. Clasificación de las tetraciclinas según su descubrimiento 15

Tabla 4. Límites máximos de residuos establecidos para sulfonamidas y tetraciclinas en diferentes tejidos y productos de origen 24 animal

Tabla 5. Sustancias detectadas del grupo B1 de acuerdo a la clasificación establecida en la Directiva 96/23/CE en el año 2009

Tabla 6. Características de los ELISAs desarrollados para la determinación de residuos de una única sulfonamida en alimentos

Tabla 7. Características de los ELISAs desarrollados para la determinación de residuos de varias sulfonamidas en alimentos

Tabla 8. Características de los ELISAs desarrollados para la determinación de residuos de tetraciclinas en alimentos

Tabla 9. Valores de $\mathrm{IC}_{50}$ de los ensayos competitivos directos para sulfonamidas

Tabla 10. Valores de $\mathrm{IC}_{50}$ de los ensayos competitivos indirectos para sulfonamidas

Tabla 11. Resultados de la optimización de los ELISAs para STZ en formato directo

Tabla 12. Resultados de la optimización de los ELISAs para STZ en formato indirecto

Tabla 13. Parámetros analíticos de los ELISAs para STZ

Tabla 14. Selectividad de los ELISAs para STZ en formato directo 150

Tabla 15. Selectividad de los ELISAs para STZ en formato indirecto 150

Tabla 16. Resultados de la optimización del ELISA para SSZ en formato indirecto

Tabla 17. Parámetros analíticos del ELISA desarrollado para SSZ 153

Tabla 18. Selectividad del ELISA para SSZ 
Tabla 19. Resultados de la optimización de los ELISAs Genérico I para STZ

Tabla 20. Parámetros analíticos de los ELISAs Genérico I desarrollados para STZ

Tabla 21. Selectividad de los ELISAs Genérico I para sulfonamidas

Tabla 22. Valores de $\mathrm{IC}_{50}$ de los ensayos competitivos indirectos para tetraciclinas

Tabla 23. Resultados de la optimización del ELISA para TCs en formato indirecto

Tabla 24. Parámetros analíticos del ELISA desarrollado para TCs 162

Tabla 25. Selectividad del ELISA para TCs 163

Tabla 26. Resultados de la optimización del ELISA para CTC en formato indirecto

Tabla 27. Parámetros analíticos del ELISA desarrollado para CTC 165

Tabla 28. Selectividad del ELISA para CTC 166

Tabla 29. Determinación de STZ mediante ELISA en miel 169

Tabla 30. Determinación de SSZ mediante ELISA en suero fisiológico 171

Tabla 31. Parámetros analíticos para el ELISA de SSZ 172

Tabla 32. Determinación de SSZ mediante ELISA en plasma humano 174

Tabla 33. Parámetros analíticos de los ELISAs desarrollados para STZ 177

Tabla 34. Determinación de STZ mediante ELISA en miel 179

Tabla 35. Composición de las muestras de miel fortificadas 180

Tabla 36. Recuperaciones obtenidas en el análisis de muestras de miel comercial dopadas con una mezcla de STZ, SMP, SP, SMT, 180 SSZ y PSTZ

Tabla 37. Determinación de residuos de tetraciclinas mediante ELISA en miel 
Figura 1. Esquema de las estructuras bacterianas (pared, membrana, ribosoma y ácidos nucleicos) y ejemplos de antibióticos que 5 actúan a dichos niveles

Figura 2. Estructura genérica de las sulfonamidas 9

Figura 3. Estructura genérica de las tetraciclinas 13

Figura 4. Principales fuentes y rutas de entrada de los medicamentos en el medioambiente

Figura 5. Etapas de la determinación de residuos de antibióticos utilizando métodos de barrido y métodos de confirmación

Figura 6. Haptenos de sulfonamidas recogidos en la literatura 39

Figura 7. Inmunógenos y conjugados de tapizado de tetraciclina recogidos en la literatura

Figura 8. Estructura general de las sulfonamidas

Figura 9. Estructura genérica de los haptenos tipo I para sulfonamidas

Figura 10. Estructura genérica de los haptenos tipo II para sulfonamidas

Figura 11. Estructura genérica de los haptenos tipo III para sulfonamidas

Figura 12. Estructura general de las tetraciclinas

Figura 13. Estructura genérica de los haptenos tipo I para tetraciclinas

Figura 14. Estructura genérica de los haptenos tipo II para tetraciclinas

Figura 15. Esquema del método del éster activo para la conjugación de haptenos a proteínas

Figura 16. Esquema del método del anhídrido mixto para la conjugación de haptenos a proteínas

Figura 17. Esquema del método para el acoplamiento de alcoholes a proteínas

Figura 18. Esquema del método de condensación de Mannich para la conjugación de haptenos a proteínas

Figura 19. Estructura de las sulfonamidas utilizadas en los estudios de selectividad

Figura 20. Estructura de las tetraciclinas utilizadas en los estudios de selectividad 
Figura 21. Esquema del proceso de extracción de sulfonamidas en miel 101

Figura 22. Esquema del proceso de extracción de SSZ en plasma humano

Figura 23. Esquema del proceso de precipitación de proteínas en plasma humano

Figura 24. Clasificación de los haptenos para sulfonamidas según la ubicación del brazo espaciador

Figura 25. Estructura química de los haptenos tipo I para sulfonamidas

Figura 26. Esquema sintético seguido para la obtención de los haptenos S2 y S9

Figura 27. Esquema general de fragmentación de las sulfonamidas

Figura 28. Esquema sintético seguido para la obtención de los haptenos S3 y S4

Figura 29. Estructura química de los haptenos tipo II para sulfonamidas

Figura 30. Esquema sintético seguido para la obtención de los haptenos S7 y S8

Figura 31. Estructura química de los haptenos tipo III para sulfonamidas

Figura 32. Esquema sintético seguido para la obtención de los haptenos S10, S12 y S13

Figura 33. Esquema sintético seguido para la obtención del hapteno S11

Figura 34. Reacción secundaria descrita por Deng et al.

Figura 35. Esquemas sintéticos ensayados en la obtención de haptenos para tetraciclinas

Figura 36. Esquema sintético seguido para la obtención de 4hidrazono-4-dedimetilaminotetraciclina

Figura 37. Clasificación de los haptenos para tetraciclinas según la ubicación del brazo espaciador

Figura 38. Estructura química de los haptenos tipo I para tetraciclinas

Figura 39. Esquema sintético seguido para la obtención de los haptenos CTC-2 y OTC-2 
Figura 40. Estructura química de los haptenos tipo II para tetraciclinas

Figura 41. Esquema sintético seguido para la obtención de los haptenos OTC-3, CTC-3 y TC-4

Figura 42. Espectros de absorción UV-VIS del patrón de OTC (línea roja) y del sólido a purificar (línea azul)

Figura 43. Cromatogramas obtenidos para (a) Patrón de OTC de 10 mg/L, (b) Hapteno OTC-3 purificado

Figura 44. Curvas de competición para STZ (a) formato directo y (b) formato indirecto (media y desviación de tres réplicas)

Figura 45. Curva de competición para SSZ (media y desviación de tres réplicas)

Figura 46. Curvas de competición para STZ (media y desviación de tres réplicas)

Figura 47. Curva de competición para TC (media y desviación de tres réplicas)

Figura 48. Curva de competición para CTC (media y desviación de tres réplicas)

Figura 49. Curvas de calibrado de STZ en PBS-T y en miel diluida 1:100 (p/v) (media y desviación de tres réplicas)

Figura 50. Curvas de calibrado de SSZ en PBS-T y suero fisiológico al $20 \% \mathrm{v} / \mathrm{v}$ (media y desviación de tres réplicas)

Figura 51. Tolerancia al metanol del inmunoensayo para SSZ

Figura 52. Curvas de calibrado de SSZ en PBS-T y PBS-T/MeOH al $10 \% \mathrm{v} / \mathrm{v}$ (media y desviación de tres réplicas)

Figura 53. Curvas de calibrado de SSZ en plasma humano utilizando diferentes tratamientos de muestra (media y desviación de tres réplicas)

Figura 54. Tolerancia a disolventes orgánicos del inmunoensayo para STZ

Figura 55. Curvas de calibrado de STZ en PBS-T y PBS-T/MeOH al $10 \% \mathrm{v} / \mathrm{v}$ (media y desviación de tres réplicas)

Figura 56. Efecto matriz en la señal y sensibilidad del ensayo 



\section{INTRODUCCIÓN}





\subsection{CARACTERÍSTICAS GENERALES DE LOS ANTIBIÓTICOS}

El empleo de agentes farmacológicos en el tratamiento de infecciones se remonta al siglo V a.C., cuando en China se utilizó la cáscara enmohecida de la soja en el tratamiento de carbuncos, forúnculos e infecciones similares. En el año 1877, Pasteur y Joubert reconocieron las potencialidades clínicas de los microorganismos como agentes terapéuticos. Ehrlich fue el primero en formular los principios de la toxicidad selectiva y en reconocer las relaciones químicas específicas entre los parásitos y los medicamentos, el desarrollo de resistencia a medicamentos en los parásitos y el papel de la terapéutica combinada para combatir dicha resistencia. Los experimentos de Ehrlich en la primera década del siglo XIX condujeron al descubrimiento de las arsfenaminas, primer triunfo importante de la quimioterapia planeada. Este descubrimiento influyó posteriormente en Alexander Fleming, el cual en 1928 descubrió la penicilina.

La terapéutica antimicrobiana moderna se inicia en 1934 con la descripción de Domagk sobre la efectividad de la primera sulfonamida en el tratamiento de las infecciones experimentales por estreptococos.

El progreso más significativo se produjo cuando Ron Waksman aisló la actinomicina, la estreptotricina (1942) y la estreptomicina (1944), bautizando estos compuestos como antibióticos. Puede decirse que la "Edad de Oro" de los antibióticos comienza en 1941 con la producción de la penicilina a gran escala y su utilización con buenos resultados en ensayos clínicos ${ }^{l}$. A partir de este momento se inicia el desarrollo de un numeroso grupo de compuestos que actúan como antimicrobianos.

Desde los años 80, la industria farmacéutica se dedica a modificar moléculas ya conocidas con el fin de cambiar su espectro de acción y cualidades farmacológicas (absorción oral, vida media más prolongada, mejor distribución, etc.).

El estado actual de la terapia antimicrobiana indica que, a pesar de la variedad de productos desarrollados, aún existen dificultades serias para el manejo de las infecciones bacterianas producidas por microorganismos resistentes a los mismos, necesitándose nuevos compuestos capaces de superar dichas resistencias.

Según la definición de la Real Academia Española, un antibiótico es una sustancia química producida por un ser vivo o fabricada por síntesis, capaz de paralizar el desarrollo de ciertos microorganismos patógenos debido a su acción 
bacteriostática, o de causar la muerte de los mismos debido a su acción bactericida. Posteriormente, este término se amplió para incluir compuestos sintéticos, como las sulfonamidas y las quinolonas, que presentan también actividad antibacteriana ${ }^{2,3}$. La antigua clasificación, que aún no ha sido abandonada, reserva el término "antibiótico" a compuestos naturales o semisintéticos que actúan sobre los organismos patógenos por muy distintos mecanismos, mientras que denomina "quimioterápicos" a los compuestos de origen sintético que presentan actividad antibacteriana ${ }^{4}$. La terminología aquí empleada será la de denominar "antibiótico" a cualquier compuesto farmacéutico que actúe contra las bacterias.

El número de antibióticos conocidos se ha visto incrementado desde cerca de quinientos en 1960, hasta más de once mil en 1994; además, cada año se detectan aproximadamente 300 nuevas sustancias con actividad antibiótica ${ }^{5}$, aunque en clínica solo se usa un $1 \%$ de los descubiertos.

De acuerdo con los datos recogidos por la Organización Mundial de la Salud (OMS), cada año se producen alrededor de 28 millones de kilos de antibióticos, de los cuales aproximadamente la mitad (52\%) están destinados al consumo humano y el resto se emplea para el ganado. La Unión Europea junto con Estados Unidos, concentra casi la mitad de la demanda de antibióticos mundial. Una simple proyección indica, en el caso de España, un consumo diario cercano a los 330 kilos $^{6}$.

\subsubsection{Clasificación}

Los antibióticos están constituidos por grupos muy diversos de compuestos y su clasificación se realiza principalmente en función de su mecanismo de acción, origen y estructura química.

En base a su mecanismo de acción los antibióticos se agrupan en:

Inhibidores de la síntesis de la pared celular. En este grupo se encuentran los agentes que son capaces de inhibir la síntesis del peptidoglicano, componente de la pared celular que le confiere estabilidad estructural. Forman parte de este grupo los antibióticos $\beta$-lactámicos, glucopéptidos (vancomicina, teicoplanina y avoparcina), bacitracina y estreptograminas (virginiamicina, quinupristina-dalfopristina).

Modificadores de la función de la membrana celular. Los antibióticos de este grupo se fijan a nivel de los fosfolípidos de la membrana celular, formando 
microporos y permeabilizando la membrana, con fuga del material intracelular y posterior lisis de la bacteria ${ }^{2}$.

Inhibidores de la síntesis proteica. Dentro de este grupo de antibióticos podemos destacar aquellos que alteran la funcionalidad de las subunidades ribosómicas $30 \mathrm{~S}$ y $50 \mathrm{~S}$, causando una inhibición reversible de la síntesis proteica (cloranfenicol, tetraciclinas, eritromicina y clindamicina), y aquellos que se unen a la subunidad $30 \mathrm{~S}$, alterando la síntesis proteica y produciendo la muerte celular (aminoglucósidos).

Inhibidores de la síntesis o función de los ácidos nucleicos. Ejemplos de este grupo son la rifampicina, las quinolonas o los antivirales, que pueden actuar a través de tres mecanismos diferentes: interfiriendo la replicación de ADN, impidiendo la transcripción, o inhibiendo la síntesis de metabolitos esenciales. También pertenecen a este grupo las sulfonamidas y el trimetoprim, cuya acción como antimetabolitos impiden la síntesis de purinas.

En la Figura 1 se muestran los antibióticos más comunes y sus lugares de acción dentro de la estructura microbiana.

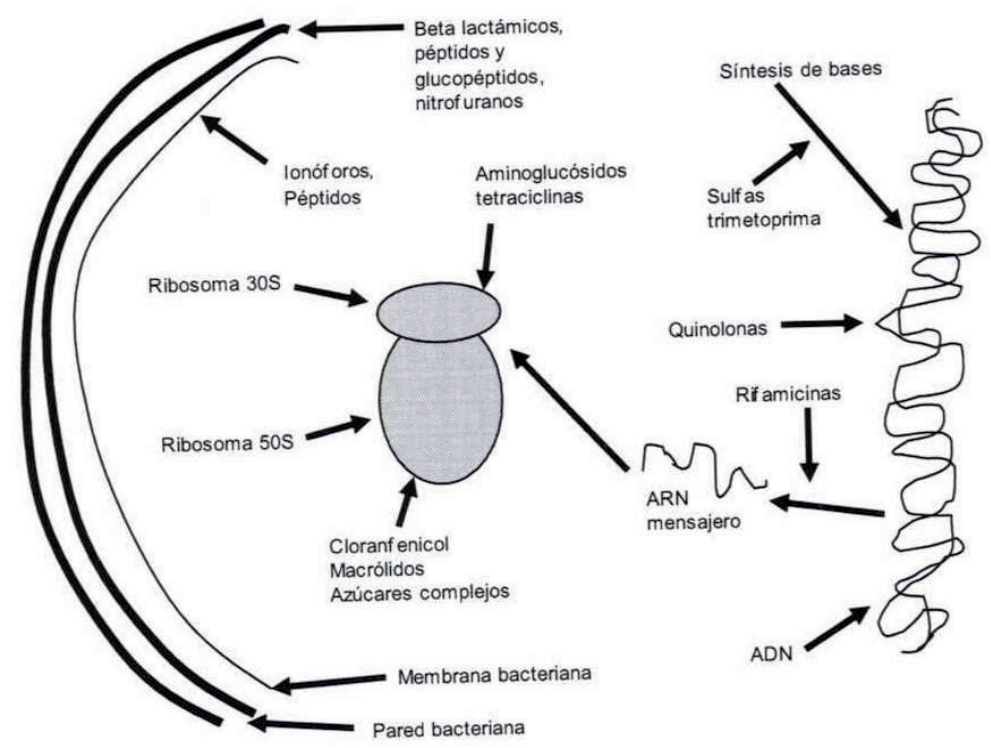

Figura 1. Esquema de las estructuras bacterianas (pared, membrana, ribosoma y ácidos nucleicos) y ejemplos de antibióticos que actúan a dichos niveles ${ }^{7}$ 
De acuerdo a su origen $^{8}$, los antibióticos se clasifican en tres categorías:

Biológicos: son producidos por microorganismos, lo que permite subdividirlos a su vez en antimicrobianos -elaborados por bacterias típicas (polimixinas por Bacillus polimixa)-, actinomicetos (tetraciclina por Streptomyces) y hongos (penicilina por Penicillium notatum).

Sintéticos: son producidos exclusivamente por síntesis química (nitrofuranos, quinolonas y sulfonamidas).

Semisintéticos: son producidos por síntesis parcial, ya que sobre el núcleo básico del antibiótico se introducen radicales obtenidos por síntesis (cefalosporinas). En la actualidad constituyen el grupo más numeroso e importante.

La clasificación más utilizada en la literatura científica, es la fundamentada en la similitud química de algunos antibióticos según los núcleos base de sus estructuras, los cuales les confieren cierta semejanza en sus propiedades físicoquímicas y farmacológicas.

La Tabla 1 recoge una clasificación de los antibióticos en función de su estructura química 9 . Dicha Tabla presenta los antibióticos $\beta$-lactámicos, aminoglucósidos, macrólidos, quinolonas, tetraciclinas y sulfonamidas, dividiéndolos en las diferentes familias, así como los fármacos que los componen. 
Tabla 1. Clasificación de los antibióticos según la estructura química

\begin{tabular}{|c|c|c|}
\hline Grupos & Familias & Antibióticos \\
\hline \multicolumn{3}{|c|}{ ק-lactámicos: Poseen en su estructura el anillo $\beta$-lactámico } \\
\hline Penicilinas & $\begin{array}{l}\text { Naturales } \\
\text { Aminopenicilinas } \\
\text { Resistentes a } \beta \text {-lactamasas } \\
\text { Amplio espectro }\end{array}$ & $\begin{array}{l}\text { Penicilina } \mathrm{G} \text {, penicilina } \mathrm{V} \\
\text { Amoxicilina, ampicilina } \\
\text { Oxacilina, cloxacilina, dicloxaciclina, nafcilina } \\
\text { Ticarcilina, carbencilina }\end{array}$ \\
\hline Cefalosporinas & $\begin{array}{l}\text { Primera generación } \\
\text { Segunda generación } \\
\text { Tercera generación } \\
\text { Cuarta generación }\end{array}$ & $\begin{array}{l}\text { Cefalotina cefapirina, cefalexina, cefadroxil, } \\
\text { Cefuroxima, ceforanida, cefamandol, cefoxitina } \\
\text { Ceftiofur, ceftriaxona, cefotaxima, cefoperazona } \\
\text { Cefepima, cefquinoma }\end{array}$ \\
\hline Otros & $\begin{array}{l}\text { Carbapenems } \\
\text { Monobactamas } \\
\text { Ácido clavulánico }\end{array}$ & $\begin{array}{l}\text { Imipenem } \\
\text { Aztreonam }\end{array}$ \\
\hline
\end{tabular}

Aminoglucósidos: Consisten en azúcares aminados y un anillo denominado aminociclitol

Espectro reducido

Amplio espectro

Diversos
Estreptomicina, dihidroestreptomicina

Neomicina, canamicina, gentamicina, tobramicina Apramicina

Macrólidos: Poseen en su estructura un anillo lactónico con azúcares aminados

Anillo de 12 constituyentes Sin uso en práctica clínica

Anillo de 14 constituyentes Eritromicina, oleandomicina, troleandomicina

Anillo de 16 constituyentes Tilosina, espiramicina, josamicina

Quinolonas: Poseen en su estructura el anillo 4-oxo-1,4-dihidroquinoleina

Primera generación

Segunda generación

Tercera generación
Ácidos nalidíxico, pipemídico y oxocínico

Flumequina, ciprofloxacina, norfloxacina

Enrofloxacina, danofloxacina, sarafloxacina

Tetraciclinas: Poseen en su estructura el anillo naftaceno (4 anillos)

Acción corta

Acción intermedia

Acción prolongada
Tetraciclina, oxitetraciclina, clortetraciclina Demetilclortetraciclina, metaciclina Doxiciclina, minociclina

Sulfonamidas: El núcleo básico es p-amino-bencenosulfonamida

Uso habitual

Muy solubles (urinarias)

Poco solubles (entéricas)

Potenciadas

Uso tópico
Sulfatiazol, sulfametazina, sulfadiazina

Sulfisoxazol, sulfasomidina

Sulfaguanidina, succinilsulfatiazol

Sulfonamidas + diaminopirimidinas

Sulfacetamida, sulfadiazina de plata

Fuente: Roca, Marugán, M.I. (2008) Termoestabilidad de sustancias antimicrobianas en la leche. Molina, Pons, M.P. dir. ; Lisandro, Althaus, R. dir. 


\subsection{CARACTERÍSTICAS GENERALES DE LAS SULFONAMIDAS}

El éxito en la lucha contra las infecciónes bacterianas es uno de los grandes logros históricos de la química médica ${ }^{10}$.

El descubrimiento de las sulfonamidas se produjo en 1908, cuando Gelmo preparó la sulfanilamida (SAN) como parte de un programa de investigación de colorantes azoicos, aunque no fue hasta 1932 cuando Domagk estudió las propiedades antimicrobianas del Prontosil y observó que éstas sólo se apreciaban in vivo. Por estas investigaciones Domagk recibió el premio Nobel en 1938. En 1935, un grupo de investigadores del Instituto Pasteur de Paris bajo la dirección de Fourneau, demostró que el grupo azo del Prontosil se reduce in vivo por acción enzimática formando SAN, demostrando que ésta es el auténtico metabolito activo $^{11}$.

La SAN fue el origen de toda una gran variedad de derivados. En 1938 se conoció la sulfapiridina (SP), con un mayor espectro, e indicada en neumonías, meningitis, gonococias e infecciones estafilocócicas, pero tuvo graves efectos adversos y fue rápidamente rechazada. Hasta 1942 surgieron nuevos fármacos como sulfatiazol (STZ), sulfacetamida (SAM), sulfadiazina (SDZ) y sulfametazina o sulfadimidina (SMZ), muchos de los cuales aparecieron ante la necesidad de salvar vidas durante la Segunda Guerra Mundial. La SDZ, introducida en 1941, fue ampliamente utilizada por su escasa toxicidad. La sulfaguanidina (SG) se empleó en las disenterías bacilares durante las campañas del Oriente Medio y Lejano. En los años anteriores a la generalización del uso de la penicilina, las sulfonamidas fueron los agentes fundamentales de la quimioterapia antibacteriana, evitando millones de muertes ${ }^{12}$.

Actualmente, y a causa del efecto sinérgico que presentan combinadas con el Trimetoprim, las sulfonamidas han recuperado aplicaciones importantes en quimioterapia antibacteriana. Así, encontramos sulfonamidas utilizadas en el tratamiento de infecciones urinarias, oftalmológicas, intestinales o dermatológicas, entre otras ${ }^{13}$. 


\subsubsection{Propiedades y estructura general}

El término sulfonamida se utiliza como nombre genérico para derivados de la $p$ aminobencenosulfonamida (sulfanilamida). Por lo general, son sólidos cristalinos, blancos o amarillentos, de sabor amargo. La mayoría de las sulfonamidas son relativamente insolubles en agua, pero sus sales sódicas son bastante solubles; suelen ser solubles en disolventes orgánicos polares como etanol, acetona, acetonitrilo y $N, N$ '-dimetilformamida, e insolubles en disolventes apolares como cloroformo y dietiléter. Son sustancias de naturaleza anfótera, ya que mientras el grupo amino les confiere carácter básico, el grupo sulfonamido $\left(-\mathrm{SO}_{2} \mathrm{NH}_{2}\right)$ les otorga características ácidas ${ }^{13,14}$. La estructura general de las sulfonamidas se presenta en la Figura 2.

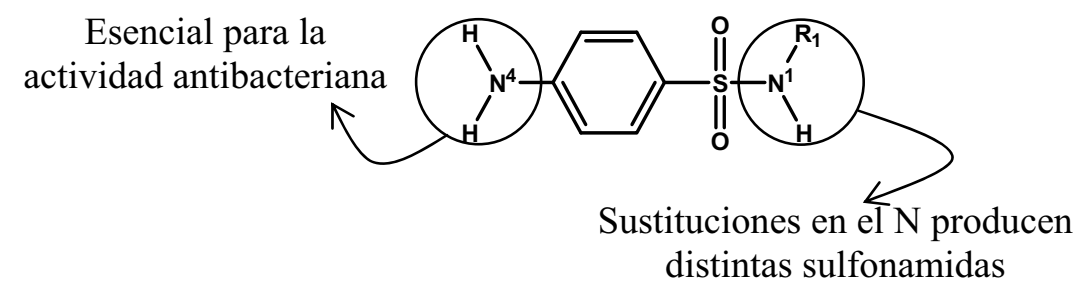

Figura 2. Estructura genérica de las sulfonamidas

Los requisitos estructurales mínimos para que una sulfonamida tenga actividad antimicrobiana se pueden resumir en la propia SAN. El grupo $p-\mathrm{NH}_{2}$ (cuyo nitrógeno se ha denominado $\mathrm{N}^{4}$ ) es esencial y puede sustituirse únicamente por radicales que se transformen in vivo en un grupo amino libre. La acetilación de este grupo produce la pérdida de la actividad antimicrobiana. El grupo $-\mathrm{SO}_{2}$ no es esencial en sí, pero la característica importante es que el azufre está ligado directamente al anillo bencénico. Las sustituciones en este grupo modifican las características farmacocinéticas, pero no la actividad antibacteriana. Las sustituciones en el grupo amida (designado como $\mathrm{N}^{1}$ ) originan efectos variables en la actividad antibacteriana de la molécula. No obstante, la sustitución del núcleo aromático heterocíclico en $\mathrm{N}^{1}$ genera compuestos extraordinariamente activos ${ }^{13,15}$.

En cuanto a su actividad antimicrobiana, su espectro de acción es amplio, abarca la mayoría de los microorganismos Gram+ y muchos Gram-, aunque 
actualmente abundan cepas bacterianas que han desarrollado mecanismos de resistencia como resultado de los más de cincuenta años de utilización.

Las sulfonamidas se metabolizan principalmente en el hígado, aunque también se dan procesos de transformación en otros órganos. Las reacciones mayoritarias que tienen lugar son la $N$-acetilación, glucuronidación e hidroxilación. La acetilación transforma la sulfonamida en un compuesto más tóxico e inactivo; la glucuronidación también la inactiva, pero reduce su toxicidad por su mayor solubilidad $^{13}$.

\subsubsection{Clasificación}

Las sulfonamidas poseen la estructura general presentada en la Figura 2. Este núcleo es la base de numerosos derivados, obtenidos por sustitución de los hidrógenos aminados por radicales. Así, podemos efectuar la siguiente clasificación en función de su estructura química:

Sulfanilamida o $p$-aminobencenosulfonamida, caracterizada por poseer átomos de hidrogeno tanto en el nitrógeno anilínico $\left(\mathrm{N}^{4}\right)$ como en el sulfamídico $\left(\mathrm{N}^{1}\right)$ :

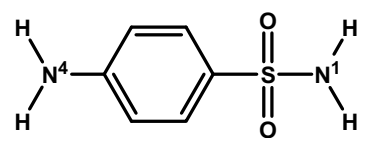

Derivados obtenidos por la sustitución del hidrógeno del nitrógeno sulfamídico, generalmente por un heterociclo aromático nitrogenado:<smiles>[R7]NS(=O)(=O)c1ccc(N([2H])[2H])cc1</smiles>

Derivados obtenidos por la sustitución de átomos de hidrógeno en el nitrógeno anilínico y sulfamídico, conjuntamente:<smiles>[R9]N([2H])c1ccc(S(=O)(=O)N([R])[2H])cc1</smiles> 
Derivados de tipo azoico, obtenidos por la formación de la sal de diazonio y la posterior copulación con diversos reactivos:

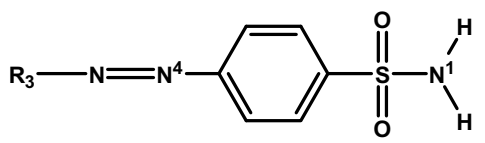

En la Tabla 2 se presentan las sulfonamidas más utilizadas en la industria farmacéutica y veterinaria.

Tabla 2. Sulfonamidas de uso generalizado

\begin{tabular}{lll}
\hline Nombre genérico & Siglas & Nombre químico \\
\hline Sulfacetamida & SAM & $N$-Acetil-4-amino-bencenosulfonamida \\
Sulfadiazina & SDZ & 4-Amino- $N$-pirimidin-2-il-bencenosulfonamida \\
Sulfadimetoxina & SDM & 4-Amino- $N$-(2,6-dimetoxi-pirimidin-4-il)-bencenosulfonamida \\
Sulfadimidina o & SMZ & 4-Amino- $N$-(4,6-dimetil-pirimidin-2-il)-bencenosulfonamida \\
sulfametazina & SG & 4-Amino- $N$-diaminometileno-bencenosulfonamida \\
Sulfaguanidina & SMT & 4-Amino- $N$-(5-metil-[1,3,4]tiadiazol-2-il)-bencenosulfonamida \\
Sulfametizol & SMX & 4-Amino- $N$-(5-metil-isoxazol-3-il)-bencenosulfonamida \\
Sulfametoxazol & SMP & 4-Amino- $N$-(6-metoxi-piridazin-3-il)-bencenosulfonamida \\
Sulfametoxipiridazina & SAN & 4-Amino-bencenosulfonamida \\
Sulfanilamida & SP & 4-Amino- $N$-piridin-2-il-bencenosulfonamida \\
Sulfapiridina & SSZ & Ácido 2-hidroxi-5-[4-(piridin-2-ilsulfamoil)-fenilazo]-benzoico \\
Sulfasalazina & STZ & 4-Amino- $N$-tiazol-2-il-bencenosulfonamida \\
Sulfatiazol & SOX & 4-Amino- $N$-(3,4-dimetil-isoxazol-5-il)-bencenosulfonamida \\
Sulfisoxazol & &
\end{tabular}

\subsection{CARACTERÍSTICAS GENERALES DE LAS TETRACICLINAS}

El origen de este grupo de antibióticos se remonta a las investigaciones llevadas a cabo por el profesor Duggar de la Universidad de Wisconsin, en colaboración con los Laboratorios Lederle de Pearl River. Con el fin de hallar un compuesto más 
seguro que la estreptomicina para el tratamiento de la tuberculosis, el profesor Duggar analizó una gran variedad de muestras de suelos procedentes de distintas partes del mundo. Así, en el verano de 1945, Duggar aisló un actinomiceto dorado con actividad antibacteriana, al que nombró Streptomyces aureofaciens. El antibiótico aislado de este microorganismo recibió el nombre de aureomicina y pudo observarse que se trataba de un compuesto con un amplio espectro de actividad. En 1948 empezó la producción a gran escala de este compuesto. Sin embargo, hasta 1952 no pudo establecerse su estructura química y la aureomicina recibió el nombre de clortetraciclina (CTC) ${ }^{16}$.

En 1950, tras el análisis de gran cantidad de muestras de suelos, se aisló la oxitetraciclina (OTC) a partir de Streptomices rimosus, con características y propiedades similares a la CTC. En 1953, mediante la eliminación del átomo de cloro de la CTC se obtuvo la tetraciclina (TC). La demeclociclina (DMC) fue aislada en 1957 de una cepa mutante de Streptomices aureofaciens.

Entre los años 1960-1972 se realizaron modificaciones químicas de las moléculas naturales, obteniendo generalmente antibióticos semisintéticos con una mayor liposolubilidad relativa (metaciclina (MC) en 1961; doxiciclina (DXC) en 1966 y minociclina (MNC) en 1972). Estas modificaciones mejoraron las características farmacocinéticas y la eficacia de este grupo de antibióticos, cambiando el perfil y algunos aspectos toxicológicos de los mismos.

En la década de los 90, aparecieron un nuevo tipo de representantes, las glicilciclinas (1993), que constituyen la última generación de tetraciclinas descubiertas tras modificar la posición 9 del anillo tetracíclico (Figura 3). La tigeciclina es un derivado semi-sintético de la MNC y es el primer antibiótico de la nueva generación de tetraciclinas disponible en clínica $^{17,18}$.

\subsubsection{Propiedades y estructura general}

Las tetraciclinas son sustancias cristalinas, ligeramente amarillas, sin olor y levemente amargas; son anfóteras (el grupo amino les confiere carácter básico, mientras que el hidroxilo les otorga características ácidas) y muchas de ellas forman sales solubles en agua, tanto con ácidos como con bases fuertes. La mayoría de las tetraciclinas son solubles en ácidos, bases y alcoholes, pero son bastante insolubles en disolventes orgánicos como cloroformo. Son estables en 
forma de polvo pero no en disolución acuosa, siendo particularmente inestables a $\mathrm{pH}$ superiores a 7. Se destruyen en medio ácido a pHs inferiores a 2. A pH ácido son poco solubles, pero pueden combinarse con el ión sodio o ácido clorhídrico aumentando la solubilidad. Debido a la presencia de grupos que pueden formar varios puentes de hidrógeno intramoleculares, las tetraciclinas tienen propiedades quelantes y forman complejos insolubles con sales de hierro, calcio, magnesio o aluminio $^{19,20}$.

Tal como su nombre genérico indica, se trata de un grupo de antibióticos de estructura tetracíclica, compuesta por cuatro anillos fusionados (designados A, B, C y D), siendo $R_{1}, R_{2}, R_{3}, R_{4}$ y $R_{5}$ los radicales que dan lugar a los diferentes compuestos que constituyen la familia (Figura 3). Los requerimientos estructurales mínimos para que una tetraciclina pueda llevar a cabo su actividad biológica coinciden con su estructura básica, es decir, el núcleo policíclico de naftacenocarboxamida y un grupo dimetilamino en posición 4 .

Región periférica superior

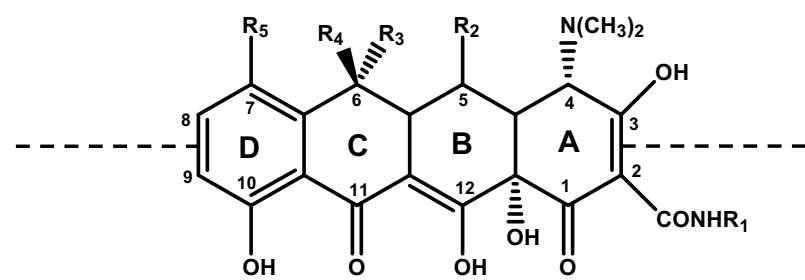

Región periférica inferior

Figura 3. Estructura genérica de las tetraciclinas

Las tetraciclinas poseen dos regiones bien diferenciadas, denominadas región periférica inferior y superior (Figura 3). En la región inferior de la molécula las tetraciclinas bioactivas poseen grupos funcionales a base de oxígeno: un grupo fenol en el $\mathrm{C}_{10}$ del anillo aromático $\mathrm{D}$, un sistema diceto-enólico en los carbonos $\mathrm{C}_{11}-\mathrm{C}_{12}$ entre los anillos $\mathrm{C}$ y $\mathrm{B}, \mathrm{y}$ un grupo hidroxilo terciario en posición 12a en la unión de los anillos BA. La mayoría de las modificaciones sintéticas a lo largo de esta región implican una pérdida de la actividad biológica. Sin embargo, las modificaciones sintéticas realizadas en la región periférica superior de la molécula dan lugar a nuevos compuestos con una mayor actividad biológica y, en algunos 
casos, con capacidad de inhibir el crecimiento de bacterias resistentes a otras tetraciclinas. Además, la alteración de los grupos funcionales de esta región puede inducir cambios en el tamaño, forma, carga, densidad electrónica y polaridad. Dichas modificaciones estructurales producen cambios en la solubilidad, lipofilia e incluso en la afinidad con sus moléculas diana. Sin embargo, las tetraciclinas con actividad antibacteriana, en general, sólo difieren entre ellas por sus características farmacocinéticas ${ }^{21}$.

Las tetraciclinas se metabolizan en el hígado en diferentes proporciones dependiendo del tipo de tetraciclina. Sin embargo, en la mayor parte de los casos, el compuesto detectado con más frecuencia en heces, orina y tejidos es la tetraciclina original, siendo mínimo el grado de biotransformación.

\subsubsection{Clasificación}

Aunque inicialmente las tetraciclinas se clasificaban especialmente por la duración de su acción (corta, intermedia o larga), la aparición de las glicilciclinas ha conducido a una nueva clasificación por "generaciones", dependiendo del orden de su descubrimiento. En la Tabla 3 se muestra una clasificación de las tetraciclinas según dicho criterio.

La primera generación de tetraciclinas abarca desde 1948 hasta 1963, y está constituida principalmente por un grupo de productos naturales. Farmacocinéticamente se caracterizan por su reducida absorción y químicamente son menos lipofílicos que las nuevas moléculas. Antimicrobianos de este grupo son: clortetraciclina, oxitetraciclina, tetraciclina, demeclociclina, rolitetraciclina, limeciclina, clomociclina y metaciclina. Los antibióticos de la primera generación se han utilizado muy a menudo, ya que son antibacterianos de bajo costo y alta disponibilidad. Hoy en día, una gran cantidad de bacterias presentan resistencia a estos medicamentos.

La segunda generación comprende desde 1965 hasta 1972, y está constituida principalmente por un grupo de productos semisintéticos. Durante ese período, los investigadores trataron de mejorar las propiedades farmacológicas de los antibióticos, obteniendo moléculas con mejor absorción y más lipofílicas que las de la primera generación. Antibióticos de este grupo son: doxiciclina y minociclina. 
Sin embargo, también abundan cepas bacterianas que han desarrollado mecanismos de resistencia como resultado de su extensiva utilización.

Tabla 3. Clasificación de las tetraciclinas según su descubrimiento

\begin{tabular}{lll}
\hline Generación & Nombre genérico & Origen \\
\hline Primera (1948-1963) & $\begin{array}{l}\text { Clortetraciclina } \\
\text { Oxitetraciclina }\end{array}$ & $\begin{array}{l}\text { Producidas por dos } \\
\text { especies diferentes de } \\
\text { Streptomyces; descubiertas } \\
\text { a finales de los años 1940 }\end{array}$ \\
& $\begin{array}{l}\text { Tetraciclina } \\
\text { Demeclociclina }\end{array}$ & $\begin{array}{l}\text { Obtenidas a partir de } \\
\text { Streptomyces en la década } \\
\text { de 1950 }\end{array}$ \\
& $\begin{array}{l}\text { Rolitetraciclina } \\
\text { Limeciclina } \\
\text { Clomociclina }\end{array}$ & $\begin{array}{l}\text { Derivados semisintéticos } \\
\text { caracterizados por su } \\
\text { hidrosolubilidad }\end{array}$ \\
& Metaciclina & \\
\hline Segunda (1965-1972) & $\begin{array}{l}\text { Doxiciclina } \\
\text { Minociclina }\end{array}$ & $\begin{array}{l}\text { Derivados semisintéticos } \\
\text { de las primeras }\end{array}$ \\
\hline Tercera (1993-) & Glicilciclinas (tigeciclina) & $\begin{array}{l}\text { Derivados semisintéticos } \\
\text { de MNC }\end{array}$ \\
& Aminometilciclinas & En desarrollo experimental \\
\hline
\end{tabular}

Fuente: Vicente, D., Pérez-Trallero, E. (2010) Tetraciclinas, sulfamidas y metronidazol. Enferm. Infecc. Microbiol. Clin., 28, 122-130.

Fue difícil encontrar nuevos miembros de la familia de las tetraciclinas, pues a menudo presentaban efectos secundarios indeseables. Todo ello cambió en 1993 con el descubrimiento de las glicilciclinas, que constituyen la tercera generación de esta familia. Estos fármacos son análogos semisintéticos obtenidos tras modificar la posición 9 del anillo tetracíclico de los compuestos de las generaciones anteriores. La tigeciclina es el 9-tert-butil-glicilamido derivado de la MNC, cuya comercialización fue aprobada en los años 2005 y 2006 por la Administración de Medicamentos y Alimentos de EE.UU., y por la Agencia Europea de Medicamentos, respectivamente ${ }^{22}$. Además de las glicilciclinas, en esta tercera generación se incluyen nuevos compuestos en desarrollo, como las 
aminometilciclinas, de cuyo grupo ya ha pasado a experimentación humana la PTK 0796 para administración oral e intravenosa en una sola dosis diaria. Hasta la fecha, las glicilciclinas resultan sensibles a un gran número de bacterias resistentes a otras tetraciclinas ${ }^{23}$.

\subsection{EMPLEO DE ANTIBIÓTICOS EN VETERINARIA}

Los antibióticos se empezaron a utilizar en medicina veterinaria poco después de su aplicación en medicina humana. Hoy en día, la gran variedad de antibióticos existente permite el tratamiento de infecciones bacterianas que afectan de un modo frecuente tanto a animales como a humanos.

El impacto ejercido por los antibióticos en el sector de la salud animal es tan importante como en el de la medicina. Para los veterinarios, los nuevos fármacos supusieron el primer recurso farmacéutico realmente eficaz para tratar o bien prevenir infecciones. Los antibióticos han tenido un efecto muy positivo no sólo en la salud de los animales, sino también en los niveles de bienestar de los mismos.

\subsubsection{Utilización de antibióticos en zootecnia}

El uso de los antibióticos en la farmacoterapia se ha convertido en uno de los eventos más exitosos de la medicina moderna. Los sistemas actuales de explotación intensiva de los animales de producción favorecen la aparición de procesos infecciosos y parasitarios que requieren la utilización de fármacos con fines terapéuticos y/o profilácticos. En ambos casos, los antibióticos deben ser suministrados bajo el control de un veterinario y la normativa vigente exige la prescripción de la receta veterinaria. Asimismo, los antibióticos pueden ser empleados fraudulentamente en producción animal como promotores del crecimiento, para reducir el estrés, evitar muertes durante el transporte de los animales al matadero y mejorar la calidad del producto final ${ }^{24}$.

La propiedad de los antibióticos de mejorar las tasas de crecimiento animal se conoce desde finales de los años cuarenta, cuando se observó que las aves alimentadas con productos procedentes de la fermentación de Streptomyces aureofaciens mejoraban su desarrollo. Se identificó el factor de crecimiento en dichos extractos como residuos de $\mathrm{CTC}^{25}$. Posteriormente se confirmó esta 
propiedad en múltiples antibióticos y para diversas especies animales. Como promotores de crecimiento, los antibióticos se han empleado a dosis subterapéuticas durante largos períodos de la vida del animal, produciendo una ganancia de peso estimada alrededor del 5\%. Sin embargo, la preocupación por el desarrollo de resistencias y la transferencia de estos genes de animales a la microbiota humana, llevó a retirar la autorización del uso de antibióticos como promotores del crecimiento en la Unión Europea desde el 1 de enero de 2006.

El uso global de las diferentes sustancias medicamentosas administradas a los animales de producción se desconoce. Los datos disponibles acerca del consumo de los distintos antibióticos se refieren más al volumen de ventas que al consumo efectivo. Disponer de esta información sería esencial para reducir el uso y mal uso de los antibióticos en la producción animal ${ }^{26}$.

\subsubsection{Consecuencias del empleo de antibióticos en animales de abasto}

Como ya se ha comentado anteriormente, la administración de antibióticos a animales de abasto destinados al consumo humano facilita el control de enfermedades infecciosas y permite una mejora en la producción. Sin embargo, hay que tener en cuenta los riesgos asociados a una mala práctica, tanto de índole sanitario, tecnológico, analítico y medioambiental. Por ejemplo, la contaminación de suelos y aguas debido a las excreciones procedentes de las explotaciones ganaderas o la presencia de residuos de estos fármacos en distintos tejidos utilizados como alimento o destinados a la obtención de los mismos ${ }^{27,28}$, dependiendo del tiempo transcurrido entre la administración de un antibiótico y el sacrificio.

Durante el año 2007, España tuvo un puesto destacado en la aparición de residuos de sustancias medicamentosas en productos de origen animal, en parte por su fuerte peso específico en la ganadería Europea. Así, los residuos de mayor relevancia fueron cloranfenicol y penicilina en leche, nicarbazina en huevos, y sulfadiazinas y tetraciclinas en carne de conejo ${ }^{29}$. 


\subsubsection{Consecuencias para la salud humana}

Los residuos de antibióticos en alimentos presentan un amplio abanico de riesgos para la salud humana, que dependen de la frecuencia y grado de exposición $^{30}$. La utilización de algunos antibióticos en animales de producción puede provocar en el consumidor efectos adversos relacionados con la propia toxicidad del compuesto suministrado. Los efectos tóxicos son, en general, poco probables, ya que los residuos estarán presentes en pequeñas cantidades. Sin embargo, se han descrito casos de reacciones alérgicas ${ }^{31,32}$ en individuos especialmente sensibilizados a algún tipo de antibiótico.

Todos estos efectos son de vital importancia para la salud del consumidor, pero sin duda alguna la principal preocupación en la actualidad es el desarrollo de resistencias a los antibióticos que pueden, por supuesto, dar lugar a fallos terapéuticos en tratamientos veterinarios, y al riesgo de transferencia de bacterias resistentes de los animales al hombre, o de genes portadores de información que codifica resistencia de bacterias de animales a bacterias humanas.

Investigaciones realizadas en los últimos años demuestran la relación entre el consumo de antibióticos por animales y la aparición de bacterias resistentes, tanto en los propios animales como en los consumidores de alimentos procedentes de los $\operatorname{mismos}^{33,34}$.

Durante la última década, la OMS y la Organización Mundial de la Sanidad Animal (OIE), junto a la Organización de las Naciones Unidas para la Agricultura y la Alimentación (FAO), y la Comisión del Codex Alimentarius, han valorado el riesgo potencial de aparición de resistencias, derivado del uso de antibióticos, en el tratamiento y la prevención de enfermedades en animales destinados a la producción de alimentos.

Concretamente, el hecho de que se empleen en gran medida las mismas clases de antibióticos en humanos y animales, y de que se hayan elaborado muy pocos medicamentos nuevos para sustituir a los relativamente ineficaces a causa de las resistencias, ha dado lugar a un acuerdo sobre la necesidad de adoptar ciertas medidas, como el uso responsable y prudente de los antibióticos, o la vigilancia de la aparición de resistencias a estos agentes en medicina humana y veterinaria. 
Por estos motivos, las distintas organizaciones han ido desarrollando una serie de actividades y procesos de armonización internacional, enfocados a la contención de aparición de resistencias a los antimicrobianos transmitida por los alimentos ${ }^{35}$.

Estas actividades han abordado con especial énfasis el uso racional de antibióticos como fármacos en producción animal, incluyendo en ellos programas de farmacovigilancia de resistencias bacterianas con el fin de disminuir el riesgo de transmisión a la población humana, controlar la eficacia terapéutica de estos agentes en las especies de destino, y asegurar que los productos originados de animales tratados con fármacos lleguen sin residuos a la población humana.

\subsubsection{Problemas tecnológicos y analíticos}

A nivel industrial, la producción de productos fermentados es la más afectada por la presencia de residuos de antibióticos, provocando grandes pérdidas en calidad y, por tanto, económicas.

Los residuos de antibióticos en materias primas pueden provocar fermentaciones anormales en embutidos y otros productos cárnicos, así como en leches fermentadas, quesos y otros productos lácteos, pudiendo ralentizar la acidificación, dificultando el cuajado y la maduración. Por ejemplo, las bacterias empleadas en la fabricación de yoghurt, L. bulgaricus y Strep. termophillus, resultan ser unas de las más sensibles a los antibióticos. Las bacterias, por efecto de los antibióticos, presentan cambios morfológicos y pueden darse situaciones en que los cultivos iniciadores sean reemplazados por microorganismos indeseables, lo que provocan el rechazo del producto o que se convierta en peligroso para su consumo ${ }^{36}$.

Además de los efectos en los productos fermentados, la industria se ve perjudicada en el control de calidad a la que es sometida su producción. Muchos residuos de antibióticos son capaces de inhibir el desarrollo de la flora microbiana que ha podido contaminar un alimento $\mathrm{y}$, de esta forma, cuando se realiza el análisis bacteriológico podría pasar desapercibida la presencia de patógenos. 


\subsubsection{Problemas medioambientales}

El desarrollo tecnológico e industrial ha procurado a la humanidad prosperidad y bienestar, pero ha traído consigo un alarmante deterioro del medioambiente. Desde hace décadas el mercado europeo de productos farmacéuticos registra un constante crecimiento, al igual que el impacto medioambiental de las sustancias activas que componen dichos productos; toneladas de sustancias biológicamente activas, sintetizadas para su uso en la agricultura, la medicina (uso humano y veterinario), la industria, etc., fueron y son vertidas al medioambiente sin reparar en las posibles consecuencias. A pesar de la existencia de diversos informes que advierten sobre el problema de la contaminación que producen este tipo de sustancias, la importancia de esta realidad ha pasado, y en gran medida aún lo hace, inadvertida.

Recientemente, la Agencia Europea de Medioambiente (AEMA) en su informe "Los medicamentos en el Medioambiente", advierte de las consecuencias de la diseminación de sustancias activas provenientes de productos farmacéuticos en el medioambiente. Según la AEMA, es necesario tomar medidas urgentes por parte de la industria, las autoridades públicas y los pacientes que utilicen este tipo de sustancias.

En los últimos años, ha aumentado la concienciación y el número de proyectos de investigación financiados por la Unión Europea (KNAPPE, Aquaterra, ERAPharm, etc.) y por otros países, lo que ha permitido conocer mejor aspectos tales como exposición, destino, acumulación, uso, e impacto de los productos farmacéuticos en el medioambiente. Además, la mejora en las técnicas analíticas y el interés de algunos grupos de investigación que han detectado la presencia ubicua de medicamentos en suelos agrícolas ${ }^{37,38}$, aguas ${ }^{39}$, y otras muestras ambientales ${ }^{40}$, han despertado el interés por el estudio de este tipo de sustancias.

La preocupación creciente sobre los posibles riesgos ambientales de los medicamentos se ha ido incorporando progresivamente en el marco legislativo europeo y se ha transpuesto a nuestra legislación mediante la Ley 29/2006 del medicamento. En esta normativa legal, se incluye la evaluación de riesgos ambientales de los medicamentos como complemento a las evaluaciones de seguridad para pacientes, aplicadores y consumidores; se confiere a los 
profesionales sanitarios la responsabilidad de esta evaluación y se incluyen los riesgos ambientales en los programas de farmacovigilancia.

Los fármacos alcanzan el medioambiente a través de múltiples vías (Figura 4). Los medicamentos, así como los desinfectantes empleados en medicina, entran en los sistemas de depuración llegando finalmente a las aguas continentales. Los fármacos de uso veterinario empleados en las granjas de explotación ganadera son excretados, metabolizados o no, y llegan al suelo, generalmente como enmiendas agrícolas (purines y estiércoles). Según las propiedades físico-químicas de los fármacos y sus metabolitos, los productos de degradación, y las características de los suelos, estas sustancias pueden llegar a alcanzar las aguas subterráneas ${ }^{41}$ y contaminar los acuíferos, o bien quedar retenidas en el suelo y acumularse, pudiendo afectar al ecosistema y a los humanos a través de la cadena trófica ${ }^{37}$. Por otro lado, los medicamentos empleados en acuicultura se vierten directamente a las aguas de los ríos y al mar. Además, muchos medicamentos se eliminan completamente inalterados, mientras que otros se eliminan en forma de metabolitos y/o conjugados (glucurónidos, sulfatos, etc.), que contienen la molécula del fármaco intacta y que aumenta su solubilidad en agua; estos conjugados pueden fácilmente liberar el fármaco en los tratamientos de aguas residuales en las estaciones depuradoras y ser vertidos posteriormente al medio acuático en el efluente.

Los estudios de monitorización realizados en las últimas décadas han demostrado que este tipo de compuestos son muy ubicuos, detectándose en efluentes ganaderos, aguas superficiales, aguas subterráneas y suelos, a concentraciones de ppt y ppb.

Por todo ello, la situación actual demanda el desarrollo de un sistema de farmacovigilancia ambiental conjunto, humano, agrícola y veterinario, que abarque tanto la caracterización de los residuos ambientales como los niveles de resistencia, por su incidencia directa a corto o medio plazo sobre la salud pública. 


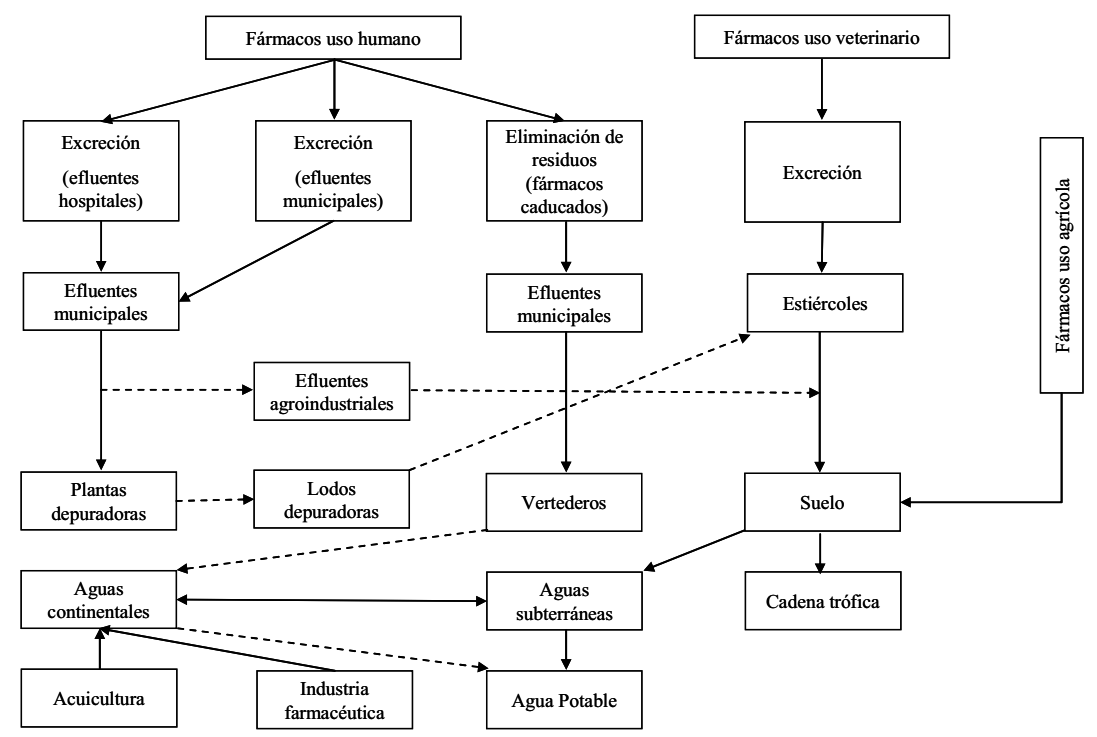

Figura 4. Principales fuentes y rutas de entrada de los medicamentos en el medioambiente

\subsection{LEGISLACIÓN Y CONTROL DE RESIDUOS DE MEDICAMENTOS VETERINARIOS EN LOS ALIMENTOS DE ORIGEN ANIMAL}

A efectos normativos de calidad y seguridad alimentaria, existe la necesidad de controlar los niveles de residuos de fármacos en alimentos de origen animal. La Comunidad Europea ha establecido una regulación coherente y exigente para garantizar la seguridad y calidad de los alimentos. En líneas generales, dicha regulación se basa en controlar todas las etapas del proceso productivo, así como del producto final. En este sentido, el Reglamento 178/2002 fija los principios generales de la legislación alimentaria y crea la Autoridad Europea de Seguridad Alimentaria (EFSA), un organismo que constituye la referencia científica para el control y la evaluación de los alimentos.

A finales de 1981, la Comunidad Económica Europea presentó las primeras Directivas en relación a los medicamentos de uso veterinario y, en 1990, apareció en Europa el primer Reglamento 2377/90/CE que fijó los criterios para establecer 
los LMRs de diferentes compuestos en los distintos tejidos y partes comestibles de los animales destinados al consumo humano, incluyendo huevos, leche y miel. Actualmente, dicha Directiva ha sido derogada por el nuevo Reglamento 470/2009/CE, por el que se establecen procedimientos comunitarios para la fijación de los límites de residuos de las sustancias farmacológicamente activas en los alimentos de origen animal.

El LMR de una sustancia se define como "la concentración máxima de un residuo de una sustancia farmacológicamente activa que puede permitirse en los alimentos de origen animal". Los valores están expresados en $\mathrm{mg} / \mathrm{kg}$ o en $\mu \mathrm{g} / \mathrm{kg}$ sobre la base del peso fresco. Los cálculos de estos valores (LMR) se basan en el tipo y cantidad de residuos que no constituyen ningún riesgo toxicológico significativo para la salud humana.

En España y al amparo del Real Decreto 731/2007, se establecen las medidas de control aplicables a determinadas sustancias y sus residuos presentes en los animales vivos, y en los productos de ellos derivados. Así, para las sulfonamidas, el LMR se fija en $100 \mu \mathrm{g} / \mathrm{kg}$ para todas las "especies productoras de alimentos". En el caso de las tetraciclinas y dependiendo del tejido analizado, el LMR varía entre $100-600 \mu \mathrm{g} / \mathrm{kg}$. La Tabla 4 muestra los LMRs para residuos de sulfonamidas y tetraciclinas que aparecen en el nuevo Reglamento.

Además, teniendo en cuenta el incremento en el número de exportaciones y para evitar trabas comerciales, deben considerarse los límites establecidos en otros países. Por ejemplo, en Canadá ${ }^{42}$ y EE.UU. ${ }^{43}$ el LMR para sulfonamidas es de 100 $\mu \mathrm{g} / \mathrm{kg}$, mientras que en Japón ${ }^{44}$ disminuye hasta $20 \mu \mathrm{g} / \mathrm{kg}$. Sin embargo, en EE.UU. ${ }^{43}$ el LMR para tetraciclinas varía entre $2-12 \mathrm{mg} / \mathrm{kg}$, dependiendo del tejido analizado.

El Reglamento 470/2009/CE, además de establecer procedimientos comunitarios para la fijación de nuevos límites de residuos de las sustancias farmacológicamente activas en los alimentos de origen animal, consta de 4 anexos heredados del antiguo Reglamento 2377/90/CE. En el anexo I se indican las sustancias que tienen establecido un LMR, en el II las sustancias que por su inocuidad no precisan de un LMR, en el III las que tienen establecido un LMR con carácter temporal, y en el IV las prohibidas, para las cuales, debido a su toxicidad, no se puede establecer un LMR. 
Tabla 4. Límites máximos de residuos establecidos para sulfonamidas y tetraciclinas en diferentes tejidos y productos de origen animal

\begin{tabular}{llll}
\hline \multicolumn{1}{c}{ Sustancia } & \multicolumn{1}{c}{ Especie animal } & $\begin{array}{c}\text { LMR } \\
(\mu \mathbf{g} / \mathbf{k g})\end{array}$ & $\begin{array}{c}\text { Tejido } \\
\text { diana }^{a}\end{array}$ \\
\hline Todas las sulfonamidas & $\begin{array}{l}\text { Todas las especies } \\
\text { productoras de alimentos }\end{array}$ & 100 & $\mathrm{M}, \mathrm{G}, \mathrm{H}, \mathrm{R}$ \\
& Bovinos, ovinos, caprinos & 100 & $\mathrm{~L}$ \\
\hline Clortetraciclina & Todas las especies & 100 & $\mathrm{M}, \mathrm{L}$ \\
Oxitetraciclina & productoras de alimentos & 300 & $\mathrm{Hv}$ \\
Tetraciclina & & 600 & $\mathrm{H}$ \\
& & 100 & $\mathrm{M}$ \\
& Bovinos & 300 & $\mathrm{H}$ \\
& & 600 & $\mathrm{R}$ \\
Doxiciclina & & 100 & $\mathrm{M}$ \\
& & 300 & $\mathrm{G}, \mathrm{P}, \mathrm{H}$ \\
& & 600 & $\mathrm{R}$ \\
\hline
\end{tabular}

${ }^{a} \mathrm{M}$ : músculo, G: grasa, H: hígado, R: riñón, L: leche, Hv: huevos, P: piel

Las medidas de control y los planes de vigilancia que deben aplicarse para la detección de determinadas sustancias y residuos potencialmente tóxicos para el consumidor, en animales vivos o productos de origen animal destinados a consumo humano, están definidas en la Directiva del Consejo 96/23/CE. Esta Directiva clasifica los residuos en dos grupos en función de su efecto en la salud humana. Por un lado, las sustancias con efecto anabolizante y otras sustancias no autorizadas (grupo A), y por otro, los medicamentos veterinarios y otros contaminantes (grupo B), ambos especificados en el anexo I. Dicha Directiva establece que los distintos estados miembros deben realizar planes nacionales de control de residuos, detallados en el anexo II, así como establecer la frecuencia, cantidad de muestra, tipo de matriz a muestrear y laboratorios de referencia autorizados para dicho control, designados en el anexo V. En España, el organismo oficial responsable del plan nacional de control de residuos es la Agencia Española de Seguridad Alimentaria y Nutrición (AESAN). A lo largo del año 2009 se notificaron un total 
de 74 alertas, efectuadas en el marco de gestión de la detección de sustancias prohibidas y/o medicamentos veterinarios por encima de los límites legalmente establecidos. En la Tabla 5 se recogen algunas alertas según las sustancias detectadas del grupo B1, de acuerdo a la clasificación establecida en la Directiva 96/23/CE. Se destacan las alertas de algunos de los residuos de sulfonamidas y tetraciclinas.

La Decisión de la Comisión 2002/657/CE implementa la anterior Directiva y establece los criterios y procedimientos para la validación de los métodos analíticos, con el fin de asegurar la calidad y la posibilidad de comparar los resultados generados por los distintos laboratorios de referencia. Además, establece un criterio común para la interpretación de los resultados, e introduce un procedimiento para establecer los límites mínimos de funcionamiento exigido (MRPL), es decir, la menor concentración de un residuo que pueda ser detectada y confirmada por un laboratorio de control oficial. Estos valores son particularmente importantes para los compuestos que no están autorizados o que están específicamente prohibidos (grupo A). La Decisión de la Comisión 2002/657/CE está en continua modificación por nuevas Decisiones. Una de las últimas modificaciones fue la Decisión 2009/800/CE por la que se aprobaron planes de vigilancia de residuos presentados por terceros países, de conformidad con la Directiva 96/23/CE del Consejo.

La Decisión de la Comisión 97/747/CE es una normativa adicional para determinados productos de origen animal como leche, huevos y miel. Además, el Reglamento 178/2002/CE reconoce la necesidad de detectar residuos en la cadena de producción de los alimentos, desde las materias primas hasta los productos elaborados a disposición del consumidor. Este Reglamento obliga también a que todos los responsables del proceso de producción garanticen la trazabilidad y adecuación de sus productos.

Completando la legislación comunitaria en materia de higiene alimentaria, el Reglamento 882/2004 del Parlamento Europeo y del Consejo reorganiza los controles oficiales en piensos y alimentos, de modo que estén integrados en todas las etapas y en todos los sectores de la producción. Define las tareas que incumben a la Unión Europea en cuanto a la organización de estos controles oficiales, así como las disposiciones que deben observar las autoridades nacionales encargadas de efectuarlos, incluidas las medidas de ejecución que deben tomarse si se 
incumple la legislación comunitaria. Además, los titulares de las explotaciones tienen la obligación de llevar registros de todos los datos relativos a la protección sanitaria. Con ello se pretende ofrecer el máximo nivel de protección a los consumidores en términos de seguridad y calidad de los productos, reducir la incidencia de las enfermedades y prevenir la transmisión de las mismas.

Tabla 5. Sustancias detectadas del grupo B1 de acuerdo a la clasificación establecida en la Directiva 96/23/CE en el año 2009

\begin{tabular}{llc}
\hline Sustancia & Especie animal & $\begin{array}{c}\mathbf{N}^{\mathbf{0}} \text { de } \\
\text { notificaciones }\end{array}$ \\
\hline Sulfaquinoxalina & Gallina & 1 \\
Sulfatiazol & Miel & 3 \\
Sulfadiazina & Ovino & 1 \\
\hline \multirow{2}{*}{ Doxiciclina } & Porcino & 2 \\
& Bovino & 1 \\
\hline Clortetraciclina & Oollo & 2 \\
\hline Sulfadiazina & Ovino & 8 \\
\hline \multirow{3}{*}{ Antibióticos } & Porcino & 13 \\
& Ovino & 2 \\
\hline Sulfametazina & Porcino & 1 \\
& Pollo & 1 \\
\hline
\end{tabular}

Fuente: adaptación de la memoria anual 2009 de la AESAN 


\subsection{MÉTODOS ANALÍTICOS PARA LA DETERMINACIÓN DE SULFONAMIDAS Y TETRACICLINAS}

El análisis de residuos de antibióticos en productos alimenticios suele presentar fundamentalmente dos tipos de problemas: el primero es debido a la complejidad y diversidad de las matrices en las que suelen determinarse y, el segundo, es el derivado de las bajas concentraciones en que se encuentran generalmente estos productos. Esta problemática obliga a utilizar métodos de análisis que presenten una adecuada selectividad, que permita efectuar el análisis sin que interfieran los numerosos contaminantes presentes en la matriz, y una alta sensibilidad para poder determinar cantidades de analito a nivel de trazas.

Existen metodologías de referencia (HPLC, LC-MS y LC/MS/MS) para la determinación de sulfonamidas y tetraciclinas, que por sus características intrínsecas son poco adecuadas para llevar a cabo programas de vigilancia y control, si bien deben usarse como técnicas de confirmación.

Por ello, es aconsejable el empleo de métodos alternativos, principalmente de barrido. Entre estos, tienen especial relevancia por sus excelentes prestaciones, los métodos inmunoquímicos.

Como se ha comentado previamente, en la Decisión 2002/657/CE se establecen los procedimientos a emplear y los criterios que deben aplicarse a los métodos de análisis para poder ser utilizados por los estados miembros para el control de residuos. Dependiendo del tipo de residuo, es necesario desarrollar un método analítico que demuestre ser adecuado para su determinación cuantitativa en matrices concretas, asegurando que su concentración no sobrepasa los límites permitidos. Para considerar que el método es válido, debe documentarse que satisface criterios de aceptabilidad o de evaluación tales como: selectividad, exactitud, precisión, límites de detección y cuantificación, recuperaciones, robustez, linealidad e intervalo de trabajo.

La Comisión de las Comunidades Europeas en su informe Eur 15127-EN, publicado con el título Veterinary Drug Residues ${ }^{45}$, incluye una serie de métodos analíticos para el análisis de residuos de medicamentos de uso veterinario, haciendo una separación entre métodos de confirmación y métodos de barrido. 


\subsubsection{Métodos de confirmación o referencia}

Las técnicas cromatográficas son, sin duda, las más utilizadas para la determinación de antibióticos. El gran potencial de éstos métodos estriba en su capacidad para llevar a cabo determinaciones multianalito, en su selectividad, exactitud, precisión, reproducibilidad, así como en su excelente sensibilidad. Estas características han facilitado la implantación de los métodos cromatográficos como métodos de referencia para la detección de residuos de antibióticos en muestras biológicas, medioambientales, preparados farmacéuticos, etc.

La técnica cromatográfica más utilizada para el análisis de antibióticos es la cromatografía líquida de alta eficacia (HPLC). No obstante, aunque en menor medida, también se han desarrollado métodos basados en cromatografía de gases (GC) para la determinación de sulfonamidas y tetraciclinas. Estos métodos requieren normalmente la extracción previa con disolventes orgánicos o su purificación mediante extracción en fase sólida (SPE).

Existen en la literatura multitud de publicaciones y revisiones donde se emplean estas técnicas para el análisis de residuos de medicamentos veterinarios y/o agentes promotores de crecimiento en alimentos, ${ }^{46,47}$ incluyendo la determinación de sulfonamidas $^{48,49}$ y tetraciclinas ${ }^{50,51}$.

Los sistemas de detección acoplados a la cromatografía líquida (LC) son, habitualmente, la espectroscopia ultravioleta-visible (UV-VIS) ${ }^{52,53}$, el detector de diodos integrados en fila (DAD) $)^{54,55}$ y la fluorescencia (FLD) ${ }^{56,57}$. Mención especial merece debido a su poder intrínseco de caracterización, la espectrometría de masas $\mathrm{MS}^{58}$ o MS/MS ${ }^{59,60}$ acoplada a LC, que se ha convertido en la técnica de referencia para el análisis de compuestos farmacéuticos, sulfonamidas y tetraciclinas.

Debido a la naturaleza polar, no volátil y termosensible de los antibióticos, la GC no es la técnica más adecuada para el análisis de estos compuestos, a no ser que se recurra a un proceso de derivatización que hace aumentar el tiempo total de análisis y su complejidad. Por estas razones, cuando se emplea la cromatografía de gases acoplada a la espectrometría de masas, las sulfonamidas requieren una derivatización previa para la formación de compuestos metilados o acetilados de modo que se aumente su volatilidad y se originen fragmentos de peso molecular válidos para el análisis de trazas en muestras biológicas ${ }^{61,62}$. Debido a la gran 
inestabilidad térmica que presentan las tetraciclinas ${ }^{63,64}$, la bibliografía que recoge su determinación mediante GC es escasa.

A pesar de ser considerados los métodos de confirmación por excelencia, los métodos cromatográficos no están exentos de inconvenientes, destacando la dificultad de analizar grandes volúmenes de muestras en tiempos reducidos -indispensable para llevar a cabo programas de vigilancia y control efectivos-. A ello se han de añadir los elevados costes del sistema y su mantenimiento. Por otro lado, el proceso de análisis es laborioso, ya que se requiere una etapa previa de tratamiento de muestra, o bien una derivatización de los compuestos, lo que incrementa el tiempo de análisis y su coste. Por ello, para muchas situaciones en las que se requiere detectar la presencia de residuos, la eficacia de un tratamiento, la idoneidad de las dosis o vías de aplicación, los métodos cromatográficos son poco adecuados, por lo que es necesario desarrollar nuevos métodos más simples y rápidos.

\subsubsection{Métodos de barrido}

Cuando es necesario analizar un gran número de muestras, resulta conveniente utilizar métodos de barrido (screening) que permitan descartar las muestras negativas, de modo que solo sea necesario confirmar las positivas mediante métodos de referencia. En la Figura 5 se muestra el esquema de análisis utilizando métodos de barrido y confirmación.

Un método de barrido debe ser semicuantitativo, rápido, robusto y relativamente barato. Además, debe requerir poco instrumental o equipos simples $\mathrm{y}$, a ser posible, procesar varias muestras simultáneamente. La técnica debe ser suficientemente selectiva y sensible para permitir la identificación de las muestras que contienen los residuos de interés, en concentraciones del orden de los LMRs establecidos.

Entre los métodos de screening utilizados para detectar residuos de antibióticos se encuentran principalmente los cromatográficos, los microbiológicos y los inmunológicos. 


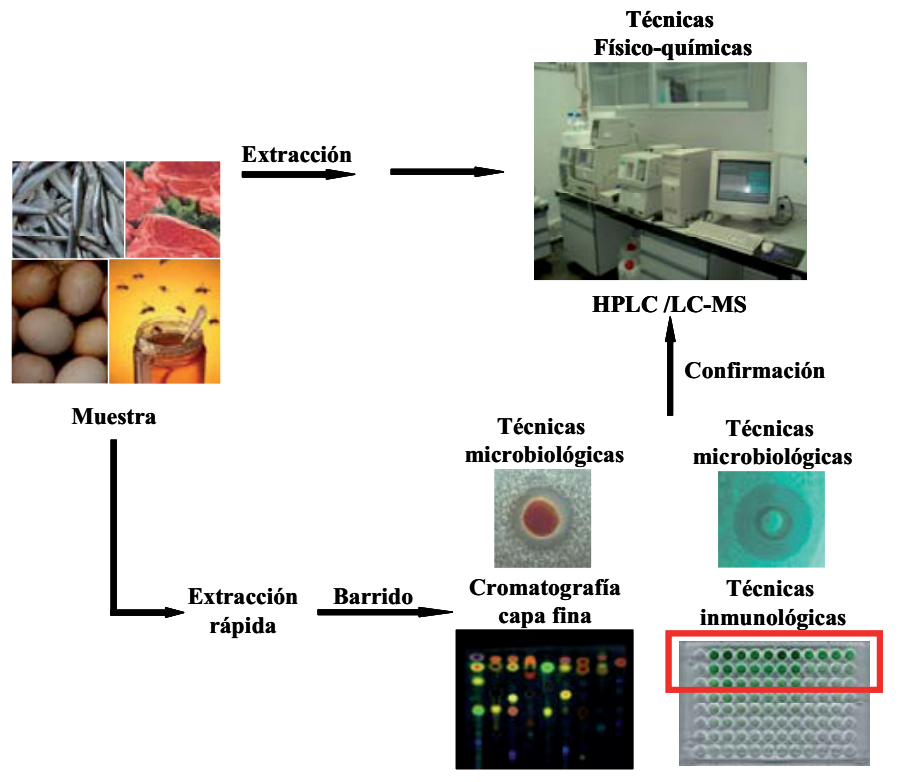

Figura 5. Etapas de la determinación de residuos de antibióticos utilizando métodos de barrido y métodos de confirmación

\subsubsection{Métodos cromatográficos}

La cromatografía en capa fina (TLC) ha sido tradicionalmente empleada como técnica de screening, ya que permite analizar simultáneamente varias muestras sobre la misma placa. Tiene un coste relativamente bajo, presentando una selectividad y sensibilidad aceptables. Aplicando esta técnica, Petkovska et al. ${ }^{65}$ han desarrollado un método para la determinación de TC, OTC, CTC en muestras de leche por debajo del LMR permitido. Otro ejemplo de detección de antibióticos mediante cromatografía en capa fina es el trabajo de Babic et al. ${ }^{66}$ que determinan SMZ, SDZ, SG y trimetoprim, alcanzando un límite de cuantificación de 100 $\mathrm{ng} /$ mancha para sulfonamidas y $200 \mathrm{ng} /$ mancha para trimetoprim.

A pesar de la sensibilidad alcanzada, ésta metodología requiere laboriosas etapas de tratamiento de muestra y purificación con el fin de evitar interferencias, lo que incrementa el tiempo de realización del análisis y su coste. 


\subsubsection{Métodos microbiológicos}

Los métodos microbiológicos se clasifican, en función del formato, en ensayos de inhibición bacteriana y ensayos de receptores.

Los ensayos de inhibición bacteriana se han desarrollado y utilizado tradicionalmente para la detección de residuos de antibióticos o sustancias antimicrobianas en productos alimenticios, especialmente leche y tejidos animales. Estos métodos se basan en el grado de inhibición del crecimiento microbiano producido por los fluidos o extractos tisulares. Se han publicado numerosas revisiones bibliográficas en las que se describen la mayor parte de las técnicas microbiológicas empleadas para la detección de residuos de antibióticos en $\operatorname{alimentos}^{67,68}$. Existen en el mercado kits microbiológicos para realizar determinaciones individuales o para screening de un amplio número de antibióticos de uso frecuente. Así, el kit PremiTest (DSM, Holanda), con detección colorimétrica, está diseñado para la determinación semicuantitativa de tetraciclinas, macrólidos, aminoglicósidos, sulfonamidas y $\beta$-lactámicos en carne, pescado, miel y huevos. Este test se basa en la inhibición del crecimiento del Bacillus Stearothermophilus, muy sensible a la mayoría de antibióticos, incluyendo las sulfonamidas. Sin embargo, la presentación de resultados es lenta y el límite de detección (LD) medio superior a $100 \mu \mathrm{g} / \mathrm{kg}^{69}$.

En España, la empresa Microkit S.L. dispone de un kit cualitativo (microkit antibiotic test) para la determinación de inhibidores en leche, carne, huevos, miel, pescado, etc. El ensayo utiliza también Bacillus Stearothermophilus, var. Calidolactis, y un indicador de pH. Al germinar las esporas, la acidificación consecuente al metabolismo produce un viraje de color (violeta-amarillo). En presencia de inhibidores, la espora no germina y el color del medio no varía. La sensibilidad depende del antibiótico, y oscila entre 100, 200 y $150 \mu \mathrm{g} / \mathrm{kg}$ para TC, OTC y CTC, respectivamente ${ }^{70}$.

Así pues, los ensayos de inhibición microbiana pueden utilizarse para screening, aunque no son específicos y su precisión es variable. Además, la presencia de sustancias inhibidoras interferentes afecta a la exactitud del análisis. En este sentido, está demostrado que la presencia de inhibidores como el agua oxigenada -sustancia presente naturalmente en mieles en determinados estados de 
maduración- interfiere negativamente en el resultado de los ensayos, invalidándolos como métodos de control.

Los kits microbiológicos requieren un buen control de la temperatura de incubación y tiempos de desarrollo del orden de tres a cuatro horas. Informan sobre la presencia de inhibidores del crecimiento del microorganismo base del ensayo, por lo que no son selectivos (muestras que contienen inhibidores diferentes a los antibióticos dan con frecuencia falsos negativos). Por otro lado, es frecuente tener que efectuar ensayos basados en diferentes cepas para detectar el tipo de compuesto deseado. Además, presentan fallos cuando la muestra contiene microorganismos que compiten con el inóculo base del ensayo. A este respecto, los tests de inhibición microbiológicos son, en general, menos específicos y sensibles que los basados en técnicas inmunoquímicas; teóricamente, todo tipo de sustancia con carácter y actividad antibacteriana puede producir la inhibición del crecimiento de bacterias, dando lugar a falsos positivos.

En los últimos quince años, y paralelamente a los ensayos tradicionales de inhibición microbiana, se ha producido un incremento notable en el desarrollo de métodos microbiológicos basados en la utilización de receptores proteicos. Estos ensayos se basan en la unión del antibiótico a una proteína específica, alojada en la matriz de una membrana o situada en células microbianas. Se trata de métodos más versátiles que los ensayos de inhibición y, en principio, se pueden aplicar a la determinación de diferentes residuos de antibióticos en una gran variedad de matrices. Existe una gran diversidad de kits comerciales basados en este tipo de reconocimiento, como el SNAP Tetracycline Test (IDEXX Laboratories, Inc., Maine), que permite detectar TC, CTC y OTC en leche de vaca por debajo del nivel de tolerancia establecido por la US.FDA $(300 \mu \mathrm{g} / \mathrm{kg})^{71}$.

\subsubsection{Métodos inmunoquímicos (ELISA)}

El método más comúnmente usado en inmunoensayo para el análisis de residuos es el ELISA (Enzyme-Linked Immunosorbent Assay); un ensayo en fase heterogénea con el anticuerpo o el antígeno fijado sobre el soporte de microtitulación y que utiliza marcaje enzimático. En general, se lleva a cabo en placas de poliestireno de 96 pocillos o en tubos individuales. 
El principio básico del ELISA radica en la competición que se establece entre el analito sin marcar y el analito marcado por los sitios específicos de unión de un anticuerpo específico. La medida de la señal proporcionada por el marcador está relacionada inversamente con la cantidad de analito presente en la muestra. Las principales características de estos métodos son su sensibilidad, selectividad, sencillez, rapidez y bajo coste. Es precisamente la alta sensibilidad de muchos de los inmunoensayos desarrollados hasta la fecha lo que constituye uno de los mayores puntos de apoyo de esta metodología, habiéndose alcanzado límites de detección por debajo de $0,1 \mu \mathrm{g} / \mathrm{kg}^{72}$, con gran selectividad y tratamiento de muestra mínimo.

Otra característica de los inmunoensayos es su carácter portátil y su sencillez operativa, pudiendo realizar ensayos en los puntos de producción o líneas de fabricación, lo que favorece su consolidación en el campo agroalimentario para el análisis de residuos. Buena prueba de ello es que importantes compañías (Ohmicron, Randox, Riedel-de Häen, Cosmo, Hangzhou Nankai Biotech, Abraxis o Neógeno Europa) se hayan implicado en el desarrollo y posterior comercialización de inmunoensayos para este tipo de residuos.

\subsubsection{Determinación de sulfonamidas y tetraciclinas mediante ELISA}

El desarrollo de métodos inmunoquímicos aplicables a la determinación de residuos de sulfonamidas y tetraciclinas en alimentos, debe tener en cuenta la incidencia de los principales tratamientos farmacológicos aplicados, la heterogeneidad de normativas e intereses, y la necesidad de disponer de formatos prácticos de análisis.

El desarrollo de nuevos ensayos inmunoquímicos requiere resolver satisfactoriamente distintos aspectos como la síntesis de haptenos y la obtención de inmunorreactivos, para desarrollar formatos con prestaciones concretas. La síntesis de haptenos es uno de los puntos más criticos con que se encuentran las técnicas inmunoquímicas. Así, para el caso de las sulfonamidas y debido a sus diferencias estructurales, la obtención de anticuerpos e inmunorreactivos que puedan detectar simultáneamente los principales compuestos es compleja. Sin embargo, en el caso de las tetraciclinas, dada su similitud estructural, la obtención de anticuerpos e inmunorreactivos específicos es especialmente difícil. Por ello, se hace necesario 
estudiar nuevas estrategias de síntesis de haptenos que conduzcan a la obtención de anticuerpos tanto genéricos como específicos.

\subsubsection{Síntesis de haptenos para sulfonamidas}

La bibliografía recoge diversas estrategias de síntesis de haptenos para la obtención de anticuerpos, tanto monoclonales (mAbs), policlonales (pAbs) y recombinantes (rAbs) contra sulfonamidas. La vía más sencilla para la síntesis de haptenos inmunizantes específicos consiste en la unión directa de una sulfonamida a una proteína inmunogénica a través del grupo amino aromático común a todas ellas. Esta vía puede llevarse a cabo mediante diazotación, o por la introducción de un brazo espaciador como glutaraldehído o un grupo succinil. Así, autores como Muldoon y Lee ${ }^{73,74}$ obtuvieron el inmunógeno diazotizando la sulfonamida deseada (SDM y STZ) y acoplándola a tiroglobulina bovina (BTG) para la producción de mAbs. Sin embargo, el resto de inmunorreactivos necesarios los prepararon siguiendo el procedimiento descrito por Dixon et al. ${ }^{75}$ utilizando STZ, SMZ y SDM como sulfonamidas base. Siguiendo esta misma estrategia varios autores describieron la obtención de anticuerpos policlonales para distintas sulfonamidas $(\mathrm{SMZ}, \mathrm{STZ})^{76,77,78,79,80,81}$. Utilizando glutaraldehído como cross-linker, se ha descrito la obtención de anticuerpos monoclonales y policlonales para sulfametazina, preparando el inmunógeno por acoplamiento directo de SMZ a seroalbúmina bovina $(\mathrm{BSA})^{75}$. Siguiendo el mismo procedimiento la SMZ se conjugó a la enzima peroxidasa de rábano picante (HRP) y a albúmina de suero de conejo (RSA), para la obtención de los trazadores y conjugados, respectivamente. Otros autores aplicaron dicha estrategia a la obtención de pAbs para SMZ, SDZ y $\mathrm{SMP}^{82,83}$.

Utilizando un grupo succinil como brazo espaciador, se han preparado inmunógenos para SMZ, sulfamerazina (SMR), SDZ, sulfadoxina (SDX), sulfacloropiridazina (SCP), sulfaquinoxalina (SQX), SP, SDM, SMP, SG y SAN, con el fin de obtener pAbs. Para ello, cada sulfonamida fue succinilada y posteriormente conjugada a ovoalbúmina (OVA) mediante el método de la carboxidiimida $(\mathrm{CDI})^{84}$. Siguiendo el mismo procedimiento, Haasnoot et al. ${ }^{85}$ obtuvieron anticuerpos policlonales contra SMZ utilizando como proteína carrier BSA. 
Otra vía para la obtención de anticuerpos genéricos es mantener la región constante de la sulfonamida invariable, por lo que el hapteno inmunizante debe estar funcionalizado a través de la región variable, conservando así la estructura del analito. Por lo general, las sustituciones en el grupo amida ( $\mathrm{N}$ designado como $\mathrm{N}^{1}$ ) no poseen un grupo funcional adecuado para poder acoplar covalentemente el compuesto a una proteína, haciendo necesaria su funcionalización. Las primeras síntesis de haptenos para sulfonamidas fueron llevadas a cabo por Sheth y Sporns ${ }^{86}$ en 1991. Ellos diseñaron una ruta sintética que constaba de tres etapas para la obtención de dos haptenos, un derivado de sulfatiazol (ácido [2-(4-aminobencenosulfonilamino)-1,3-tiazol-4-il]acético, TS) y el ácido 4-(4-aminobencenosulfonilamino)benzoico (CS). En primer lugar llevaron a cabo la formación del correspondiente éster metílico y, a continuación, condensaron los ésteres con cloruro de $\mathrm{N}$-acetilsulfanililo. Por último, realizaron una hidrólisis con hidróxido de sodio para obtener los haptenos deseados. Además, sintetizaron el hapteno 4amino- $N$-(4-nitro-fenil)-bencenosulfonamida (NS) directamente desde $p$ nitroanilina y cloruro de $N$-acetilsulfanililo. Spinks et al. ${ }^{87}$ llevaron a cabo un estudio de modelización molecular sobre las distintas estructuras del hapteno de inmunización para la obtención de anticuerpos genéricos contra sulfonamidas. De dicho estudio se concluyó que podrían obtenerse anticuerpos con una amplia reactividad cruzada (RC) utilizando como hapteno una sulfonamida con una estructura lo más plana posible (SAM) o una gran curvatura (SCP). Sin embargo, la inmunización con dichas sulfonamidas no dio lugar a la obtención de un antisuero genérico, concluyendo que la modelización molecular en este caso no era capaz de solventar el problema y que era necesario continuar con la síntesis de nuevos haptenos. Muldoon et al. ${ }^{88}$ obtuvieron el hapteno CS planteando una ruta sintética corta (2 etapas de síntesis). Para ello, una mezcla de ácido 4-aminobenzoico y cloruro de $N$-acetilsulfanililo se hizo reaccionar durante toda una noche a temperatura ambiente; posteriormente, el grupo acetilo se eliminó mediante hidrólisis básica para obtener el producto final. Assil et al. ${ }^{89}$ obtuvieron pAbs inmunizando con ácido 3-\{3-[6-(4-amino-bencenosulfonilamino)-4-metil-piridin-3ilazo]-4-hidroxi-fenil\}propiónico (PS) unido a hemocianina de Limulus polyphemus (LPH). La síntesis del hapteno (PS) se abordó haciendo reaccionar la 2-amino-4-metil-5-nitropiridina con cloruro de $\mathrm{N}$-acetilsulfanililo en piridina seca. Posteriormente, el grupo nitro del producto de condensación se redujo a amino con 
dióxido de platino e hidrógeno. El intermedio obtenido permitió disponer del hapteno buscado mediante una reacción de diazotación, seguida de un acoplamiento con el ácido 3-(4-hidroxifenil)propanoico y posterior desacetilación básica. Así, Haasnoot et al. ${ }^{90,91}$ obtuvieron mAbs utilizando los mismos derivados de sulfonamidas que Sheth y Sporns ${ }^{86}$, y Assil et al. ${ }^{89}$. De la misma manera, utilizando derivados de sulfonamidas previamente sintetizados ${ }^{86}$, Korpimäki et $a l .{ }^{92,93,94}$ han descrito la obtención de anticuerpos recombinantes.

Durante la realización de esta tesis doctoral, Franek et al. ${ }^{95}$ desarrollaron otra alternativa para la producción de anticuerpos genéricos contra sulfonamidas, basada en la síntesis de haptenos fragmentarios que contienen la región constante de la estructura general de dichos antibióticos. Para el estudio se emplearon siete haptenos que mantenían la estructura común de la familia de las sulfonamidas, de los cuales cuatro de ellos eran haptenos fragmentarios con brazos espaciadores de distinta longitud, pero en ningún caso describieron el procedimiento sintético. La mayor respuesta genérica se obtuvo cuando se utilizó como inmunógeno el hapteno CS descrito previamente por Sheth y Sporns ${ }^{86}$. Además, se estudió la influencia del grupo sulfonamido $\left(-\mathrm{SO}_{2} \mathrm{NH}_{2}\right)$ sobre la especificidad de los anticuerpos; para ello se utilizó el ácido $p$-aminobenzoico conjugado a una proteína como inmunógeno. Los anticuerpos generados contra dicho hapteno no reconocieron ninguna sulfonamida, concluyendo que el grupo sulfonamido es fundamental para la obtención de una respuesta inmune.

Posteriormente, Zhang et al. ${ }^{96}$ optimizaron el proceso de síntesis para cinco derivados de sulfonamidas previamente descritos por nuestro grupo de trabajo ${ }^{97} \mathrm{y}$ por Sheth y Sporns ${ }^{86}$. Además, proporcionaron un procedimiento general para la síntesis de haptenos que conservan la estructura general de las sulfonamidas. En los trabajos previos, estos haptenos se sintetizaron utilizando una ruta sintética que constaba de tres etapas: esterificación de compuestos ácidos carboxílicos, condensación con cloruro de $\mathrm{N}$-acetilsulfanililo y por último, hidrólisis básica para obtener el compuesto deseado. Zhang et al. ${ }^{96}$ modificaron la ruta sintética evitando la etapa de purificación intermedia, reduciendo los tiempos de reacción y alcanzando mayores rendimientos sintéticos.

Recientemente, se han obtenido anticuerpos con mayor reactividad cruzada utilizando como hapteno de inmunización el ácido 4-(4-aminobencenosulfonilamino)butanoico (D5) ${ }^{98}$. La síntesis de este hapteno fue descrita 
previamente por Eremin et al. ${ }^{99}$. Para la preparación de los inmunógenos y conjugados de tapizado, el haptenos D5 se conjugó a OVA y al inhibidor de tripsina de soja (STI). De los resultados se pudo concluir que el mejor antisuero se obtuvo con D5 acoplado a STI, reconociendo once sulfonamidas.

Por último, Adrián et al. ${ }^{100}$ han desarrollado anticuerpos e inmunorreactivos para sulfonamidas, con el objetivo de determinar simultáneamente varios antibióticos de dicha familia administrados en el sector veterinario. La estrategia se basó en la obtención de anticuerpos policlonales contra dos haptenos diseñados mediante modelización para un reconocimiento genérico. De esta manera, el hapteno denominado SA1 (ácido 5-[6-(4-aminobencenosulfonilamino)piridin-3-il]2-metilpentanoico) se sintetizó en cuatro etapas a partir de metilo 5-(4-amino-3piridinil)-2-metil-4-pentenoato, mediante una reacción de Heck en condiciones de Jeffery. La reacción consiste en un acoplamiento $\mathrm{sp}^{2}-\mathrm{sp}^{2}$ entre un compuesto yodoaromático, en este caso el 2-amino-5-yodopiridina, y un grupo alqueno, el metil-2-metil-4-pentenoato, utilizando acetato de paladio como catalizador, cloruro de tetrabutilamonio y formiato de potasio. La mezcla obtenida se hidrogenó y, posteriormente, se purificó por HPLC para obtener el compuesto deseado. Posteriormente, la sulfonamida se formó por reacción del grupo amino con cloruro de $N$-acetilsulfanililo. La hidrólisis simultánea del grupo acetilo y el éster metílico, en condiciones básicas, permitió obtener el hapteno SA1.

Por otro lado, la síntesis del ácido 5-[4-(amino)fenilsulfonamida]-5oxopentanoico (SA2) se llevó a cabo por reacción de $N$-4[(aminosulfonil)fenil]acetamida con metil 4-(cloroformil)butirato, seguido de la hidrólisis del éster y el grupo acetilo. Ambos haptenos, SA1 y SA2, fueron acoplados covalentemente a través de sus grupos carboxílicos a los residuos de lisina de la proteína hemocianina del cangrejo de herradura $(\mathrm{HCH})$, siguiendo el método del éster activo, y empleados para la inmunización. Asimismo, ambos haptenos fueron conjugados a BSA, conalbúmina (CONA) y OVA para su uso como conjugados de tapizado. Además, sintetizaron los siguientes competidores: ácido 5-(4-\{[(4-clorofenil)amino]sulfonil $\}$ fenil)pentanoico (SA3), ácido 5-[(4$\{[(4,6$-dimetilpirimidin-2-il)amino]sulfonil $\}$ fenil)amino]-5-oxopentanoico (SA4), ácido 5-[(4-\{[(6-cloropiridazin-3-il)amino]sulfonil\} fenil)amino]-5-oxopentanoico (SA5) y ácido 5-oxo-5-(4-\{[(piridin-2-ilamino)sulfonil]fenil $\}$ amino)pentanoico (SA6). Todos ellos se caracterizan por estar funcionalizados por el grupo amino 
aromático, exponiendo la región variable de las sulfonamidas. Para la síntesis de SA4, SA5 y SA6 partieron de las sulfonamidas comerciales, SMZ, SCP y SP, respectivamente. Por otra parte, en un intento de encontrar mayor heterogeneidad, sintetizaron el competidor SA3 sin la anilina común que poseen todos los congéneres de las sulfamidas. Además, sintetizaron los competidores SA7-SA10, que se identifican por tener el grupo amino aromático libre, ya que están funcionalizados a través de la región variable utilizando brazos espaciadores de distinta longitud. En resumen, el hapteno SA1 fue el más adecuado para fines de inmunización. Tanto el hapteno SA1 como el SA2 poseen una estructura similar, ya que comparten el resto aminobencenosulfonilamino, pero se diferencian en que el hapteno SA2 es un hapteno fragmentario, mientras que el SA1 posee la estructura completa de la sulfonamida, demostrando que la presencia de los heterocíclicos y los grupos electrón-atrayentes juegan un papel importante en el reconocimiento de los anticuerpos. Por otra parte, el conjugado SA2-OVA fue el mejor para el tapizado de microplacas.

La Figura 6 muestra las estructuras químicas de los haptenos más utilizados por los diferentes autores en la bibliografía. 
Estructura química
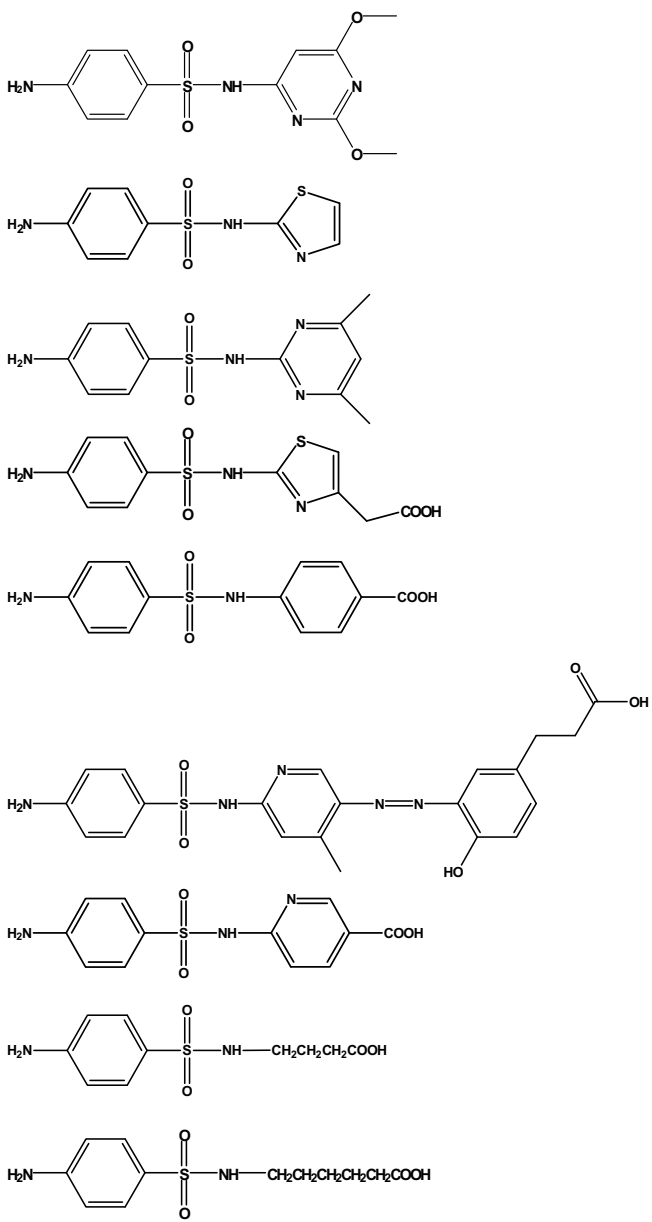

Nombre (IUPAC)

4-Amino- $N$-(2,6-dimetoxi-pirimidin-4-il) bencenosulfonamida (SDM)

4-Amino- $N$-(1,3-tiazol-2-il) bencenosulfonamida (STZ)

4-Amino- $N$-(4,6-dimetil-pirimidin-2-il) bencenosulfonamida (SMZ)

Ácido [2-(4-amino-bencenosulfonilamino)-1,3tiazol-4-il]acético (TS)

Ácido 4-(4-amino-bencenosulfonilamino) benzoico (CS)

Ácido 3-\{3-[6-(4-amino-bencenosulfonilamino) -4-metil-piridin-3-ilazo]-4-hidroxi-fenil\} propiónico (PS)

Ácido 6-(4-amino-bencenosulfonilamino) nicotínico (D2)

Ácido 4-(4-amino-bencenosulfonilamino) butanoico (D5)

Ácido 6-(4-amino-bencenosulfonilamino) hexanoico (D4)

Figura 6. Haptenos de sulfonamidas recogidos en la literatura

\subsubsection{Síntesis de haptenos para tetraciclinas}

En el caso de las tetraciclinas, y dada su similitud estructural, en la bibliografía se recoge un planteamiento general basado en la obtención de haptenos por derivatización de un único compuesto (tetraciclina), con resultados aceptables tanto para la obtención de anticuerpos monoclonales como de policlonales. La mayoría de los trabajos llevan a cabo la preparación de los inmunógenos y conjugados de 
tapizado uniendo directamente el antibiótico tetraciclina a una proteína carrier, mediante condensación de Mannich utilizando aldehídos homobifuncionales ${ }^{101,102,103}$, el método de la $\mathrm{CDI}^{103,104,105}$, o por diazotación ${ }^{105}$. Otros autores, han sintetizado derivados de TC para acoplarlos químicamente a diferentes proteínas carrier ${ }^{105}$. Las estructuras químicas de los inmunógenos y conjugados de tapizado más utilizados en la bibliografía se muestran en la Figura 7.

\section{Estructura química}
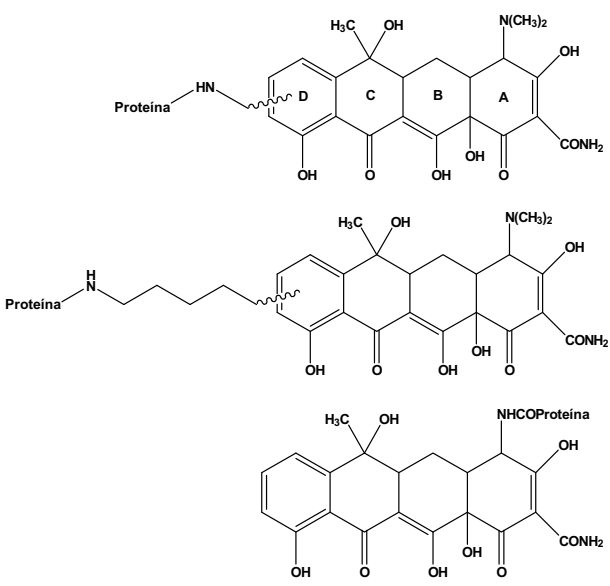

Proteina
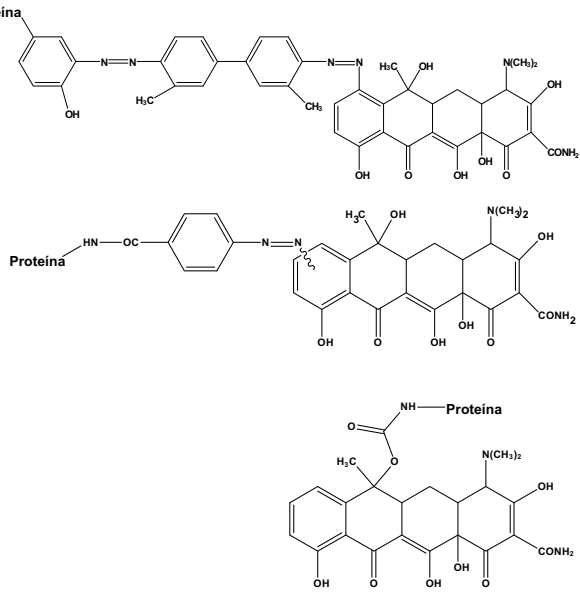

\section{Abreviatura}

TC-Proteína

TC- $\left(\mathrm{CH}_{2}\right)_{5}$-Proteína

4-TC-Proteína

TC-o-tolidina-Proteína

TC-ABA-Proteína

TC-CDI-Proteína

Figura 7. Inmunógenos y conjugados de tapizado de tetraciclina recogidos en la literatura 
Faraj y Lang ${ }^{101,102}$ fueron los primeros en obtener un inmunógeno (TC-Proteína) de TC por acoplamiento -vía Mannich- de la TC con BSA, utilizando formaldehído como cross-linker. Más tarde, Goldring et al. ${ }^{103}$ presentaron un estudio interesante en el cual evaluaron la obtención de anticuerpos contra la TC y DXC en pollos. Para ello, los conjugados de inmunización (TC- $\left(\mathrm{CH}_{2}\right)_{5}$-Proteína) fueron preparados por acoplamiento directo de TC o DXC a RSA, usando en este caso glutaraldehído. Sin embargo, los conjugados de tapizado se prepararon mediante el método de la carboxidiimida utilizando la correspondiente tetraciclina, OVA y carbonildiimidazol, ya que resultó ser un método de acoplamiento más eficiente que con glutaraldehído. En base a los resultados obtenidos, se concluyó que la obtención de anticuerpos contra TCs mediante la inmunización de pollos era de gran potencial, ya que los rendimientos fueron elevados y además, los anticuerpos se aislaron fácilmente de la yema de huevo.

Posteriormente, Everest et al. ${ }^{104}$ obtuvieron anticuerpos anti-TC derivatizando la molécula de tetraciclina. La derivatización consistió en la introducción de un grupo hidrazina en posición 4 del anillo "A", permitiendo la conjugación a OVA mediante el método de la CDI (4-TC-Proteína). Esta estrategia evita la epimerización que generalmente ocurre sobre el $\mathrm{C}_{4}$ en muchas transformaciones químicas. Siguiendo el mismo procedimiento prepararon el conjugado TC-HRP. Este enfoque permitió la obtención de anticuerpos con reactividad cruzada hacia las tetraciclinas (TC, OTC y CTC) más utilizadas en ganadería.

Durante el transcurso de esta tesis doctoral Zhang et al. ${ }^{105}$ sintetizaron tres inmunógenos, TC-o-tolidina-BSA, ácido TC-4-aminobenzoico(ABA)-BSA cationizada (cBSA) y TC-CDI-cBSA, para la obtención de anticuerpos anti-TC. El primer conjugado (TC-o-tolidina-BSA) fue sintetizado utilizando tolidina, un agente de reticulación homobifuncional, como puente entre la TC y la BSA, mediante una conjugación simple de un solo paso de reacción. Para ello, los dos grupos amino presentes en la tolidina se diazotizaron para obtener un derivado bisdiazonio. A continuación, dicho derivado fue acoplado por un lado a la TC en posición para al grupo hidroxilo aromático y, por otro, a la proteína BSA en posición orto del residuo de tirosina, formando el derivado azoico correspondiente. Siguiendo el mismo procedimiento se preparó también un conjugado de TCtolidina-OVA. El segundo inmunógeno de TC, TC-ABA-cBSA, se sintetizó diazotizando el ABA y acoplándolo a TC para introducir un grupo carboxílico, el 
cual mediante el método de la CDI fue acoplado a cBSA, obteniendo así el conjugado deseado. Siguiendo un método análogo se sintetizó el conjugado TCABA-OVA cationizada (cOVA). Los últimos conjugados fueron sintetizados utilizando el método de la CDI, obteniendo así los conjugados TC-CDI-cBSA y TC-CDI-cOVA. Los resultados mostraron que el antisuero obtenido del inmunógeno TC-CDI-cBSA, utilizando TC-ABA-cOVA como conjugado de tapizado, dio los mejores resultados tanto en términos de afinidad como de especificidad.

\subsubsection{Determinación de sulfonamidas en alimentos mediante ELISA}

El estado actual de los inmunoensayos descritos para la determinación de una única sulfonamida en alimentos se resume en la Tabla 6. Se observa que el mayor número de inmunoensayos desarrollados corresponden a sulfametazina ${ }^{77,79,81,106}$, debido a las reacciones alérgicas o tóxicas y a su uso generalizado. Asimismo, se han descrito inmunoensayos sensibles para SMZ con un límite de detección por debajo de $10 \mu \mathrm{g} / \mathrm{L}$. En general, la reactividad cruzada para SMZ ha sido relativamente alta con la sulfamerazina o su metabolito acetilado. Diversos tipos de muestras, tales como hígado, músculo, leche y plasma porcino han sido analizados, siendo los procedimientos de extracción y purificación para ELISA más simples que para métodos instrumentales. También se han establecido inmunoensayos para otras sulfonamidas, tales como sulfatiazol ${ }^{74,78,107}$, sulfamerazina ${ }^{108}$, sulfadimetoxina $^{109}$, sulfacloropiridazina ${ }^{110}$, y sulfametoxipiridazina ${ }^{111}$. La mayoría de los inmunoensayos desarrollados utilizan anticuerpos policlonales en formato ELISA directo e indirecto, con sistemas homólogos. Las características de estos ensayos se muestran en la Tabla 6.

Considerando que el número de sulfonamidas utilizadas en producción animal está aumentando, una estrategia muy interesante consiste en disponer de un único inmunoensayo capaz de detectar simultáneamente diferentes sulfonamidas. Como consecuencia de ello, se han invertido muchos esfuerzos en el desarrollo de métodos multirresiduo. En esta línea, la Tabla 7 muestra la información disponible para la determinación simultánea de residuos de varias sulfonamidas. 
.

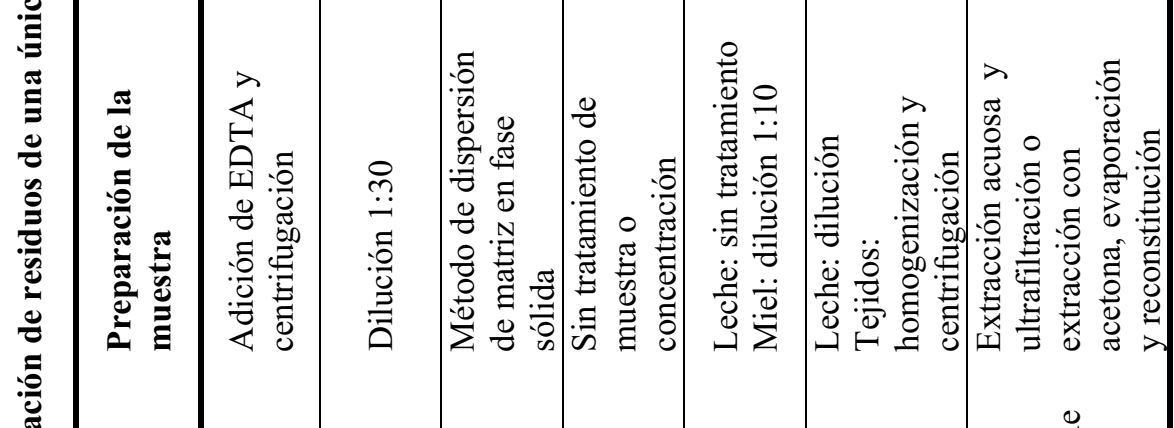




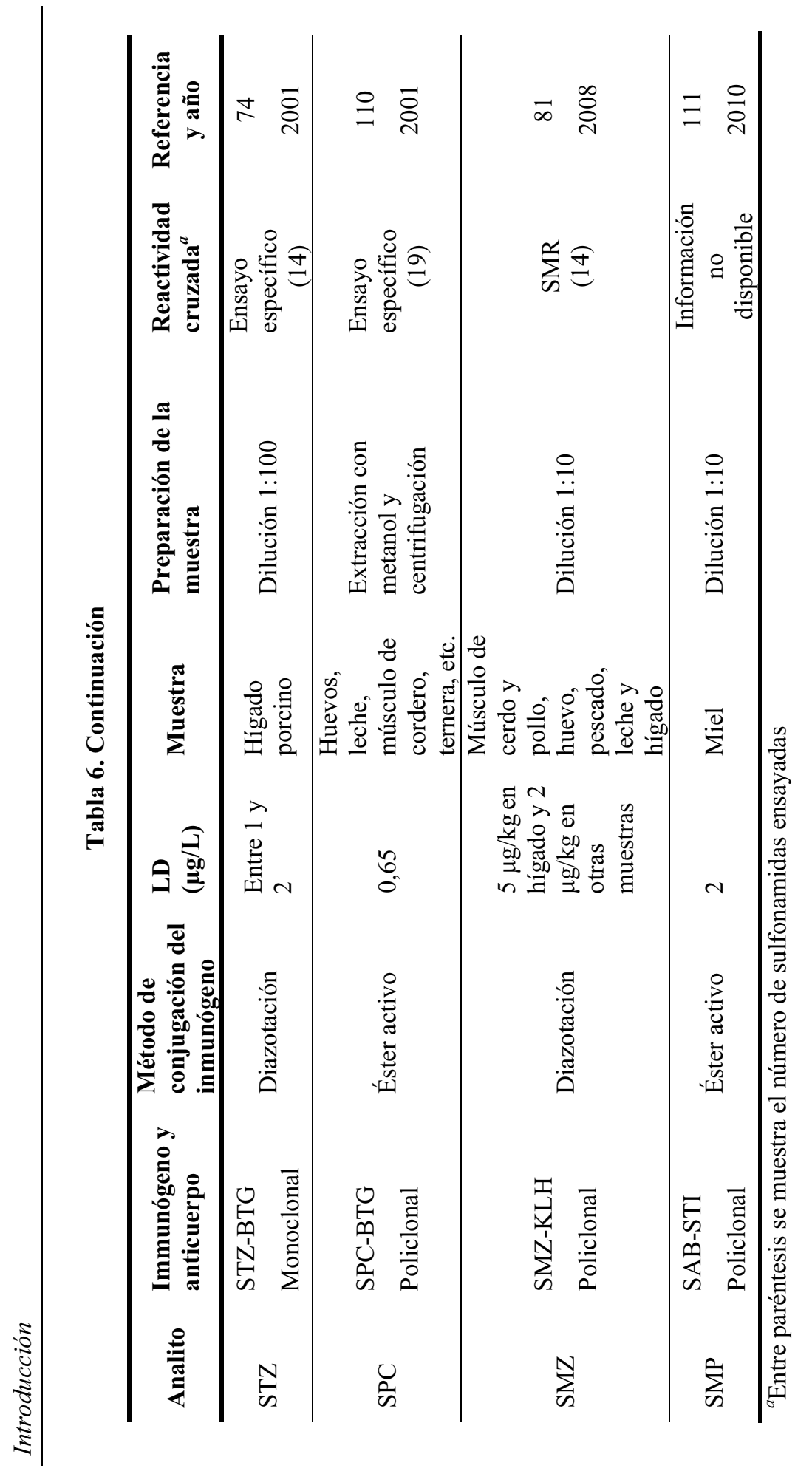




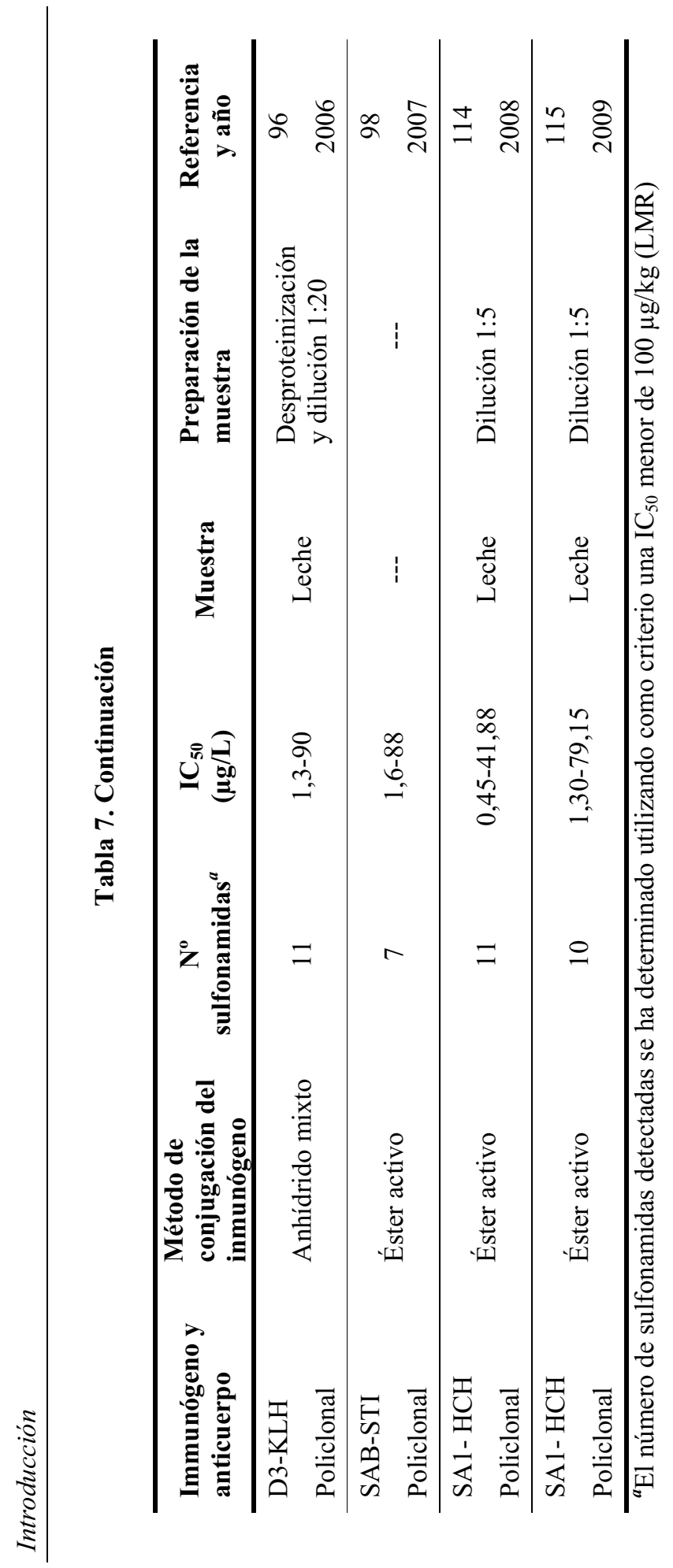


Otras alternativas disponibles para la determinación multianalito son los ensayos comercializados por Biacore $\mathrm{AB}$ (Qflex ${ }^{\circledR}$ Kit sulfonamidas) y Charm Sciences Inc. (Charm II test). Ambas propuestas pueden ser clasificadas como técnicas instrumentales, distintas de los métodos estándar en placa ELISA, porque requieren diversos equipos, incluidos detectores específicos. Qflex ${ }^{\circledR}$ kit se basa en el principio de la inmunoquímica y permite la detección de veinte sulfonamidas con una sensibilidad que oscila entre 8,5 y 101,7 $\mu \mathrm{g} / \mathrm{L}$, utilizando la tecnología de resonancia de plasmón superficial. El ensayo Charm II se aplica tanto para sulfonamidas -Sulfa Drug Test- como tetraciclinas -Tetracycline Test-. Ambos radioinmunoensayos (RIAs) utilizan centelleo líquido como técnica de detección y permiten determinar dichos antibióticos en leche, miel, huevos, etc., con buena sensibilidad $(\mathrm{LD}<\mathrm{LMR})^{116}$. Sin embargo, necesitan instrumentación específica (resonancia de plasmón superficial (SPR) y contador de centelleo), relativamente costosa $(\approx 50.000 €$ ) y no frecuente en laboratorios agroalimentarios, lo que reduce la competitividad de éstos.

\subsubsection{Determinación de tetraciclinas en alimentos mediante ELISA}

Hasta el momento son pocos los inmunoensayos tipo ELISA sensibles desarrollados para la detección de residuos de tetraciclinas. La Tabla 8 recoge las características de los distintos métodos inmunoquímicos recogidos en la bibliografía hasta la fecha.

En 1992, Lang et al. ${ }^{102}$ desarrollaron un inmunoensayo enzimático indirecto para la detección de $\mathrm{TC}$ en leche, usando un inmunógeno obtenido por acoplamiento -vía reacción Mannich- de la TC con BSA. Las muestras de leche fueron desnatadas por centrifugación, diluidas 1:30 (p/v) en tampón fosfato salino (PBS), y directamente analizadas por ELISA, alcanzando un LD de $5 \mu \mathrm{g} / \mathrm{L}$. Aunque no se trata de un inmunoensayo genérico, éste mostró elevada RC con CTC, MNC y rolitetraciclina (RTC).

En otro trabajo ${ }^{104}$, se describe la producción de anticuerpos policlonales en ovejas mediante el acoplamiento directo de un producto intermedio de la TC (4hidrazono-4-dedimetilaminotetraciclina) con la proteína carrier; el inmunoensayo desarrollado permitió detectar residuos de CTC, OTC y TC en riñón y leche, con un $\mathrm{LD}$ de $50 \mu \mathrm{g} / \mathrm{kg}$ y $15 \mu \mathrm{g} / \mathrm{L}$, respectivamente. El inmunoensayo directo no requirió ninguna etapa previa de tratamiento de muestra. 


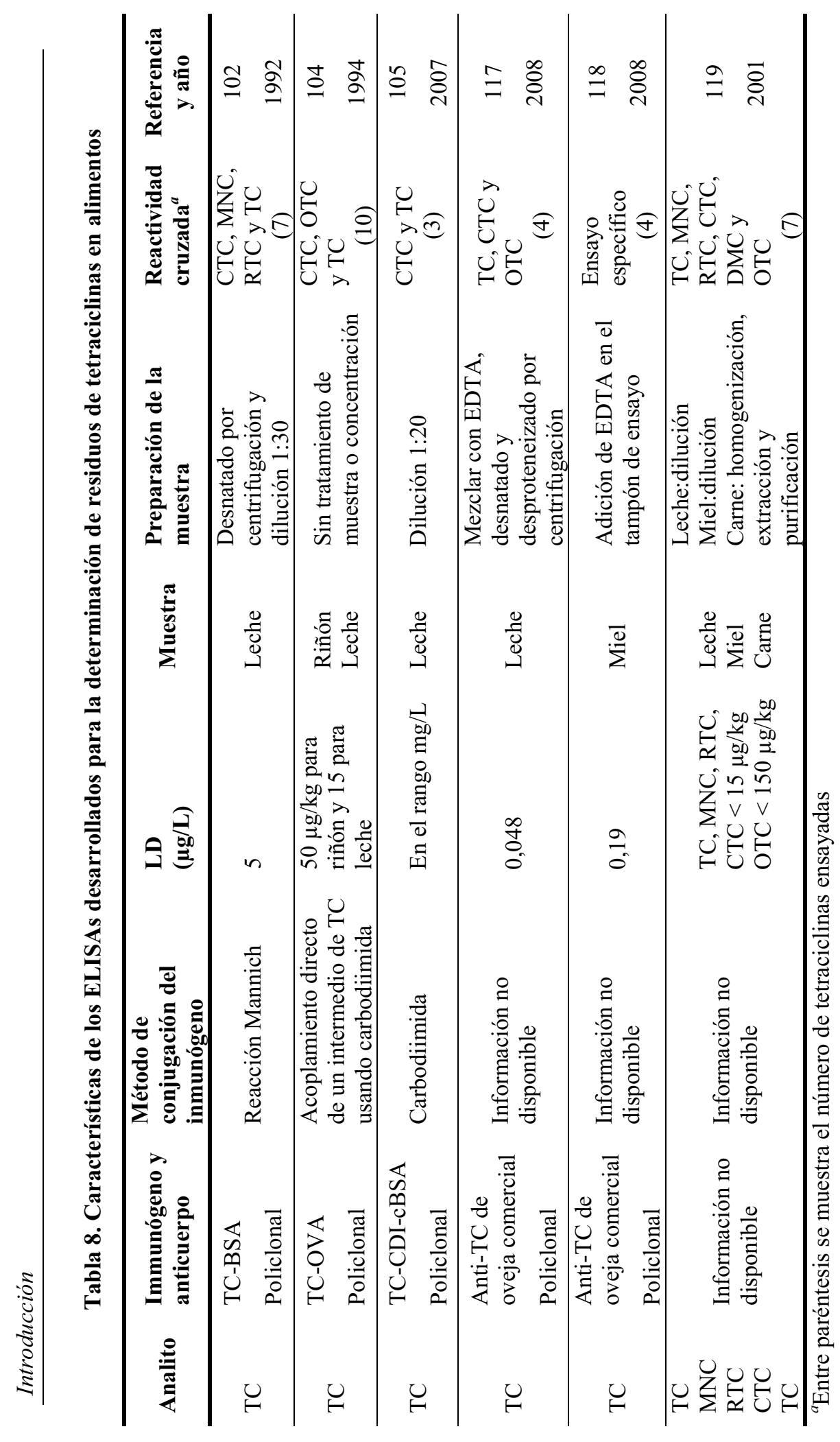


Durante el transcurso de esta tesis doctoral, Zhang et al. ${ }^{105}$ desarrollaron un inmunoensayo indirecto para TC utilizando antisuero policlonal. Los resultados mostraron que el antisuero obtenido del inmunógeno TC-CDI-cBSA, utilizando TC-ABA-cOVA como conjugado de tapizado, proporcionó los mejores resultados tanto en términos de afinidad como de especificidad, obteniendo un inmunoensayo con poca sensibilidad $(\mathrm{mg} / \mathrm{L})$ hacia la TC. La especificidad del ensayo se evaluó determinando la $\mathrm{RC}$ del suero con tres compuestos estructuralmente relacionados (TC, CTC, y OTC), mostrando una elevada reactividad cruzada con la TC y la CTC. El ELISA desarrollado se utilizó para analizar muestras de leche dopadas, obteniendo valores de recuperación aceptables (entre 74 y 116\%), mientras que los coeficientes de variación intra e interensayo fueron inferiores al $14,5 \%$ y $25,0 \%$, respectivamente.

En esta línea, también se desarrolló un ELISA competitivo basado en el sistema de reconocimiento avidina-biotina ${ }^{117}$ para la determinación de residuos de TC en leche, utilizando un anticuerpo policlonal comercial (ab30591, Abcam, Cambridge, MA, EE.UU.) y TC-OVA como conjugado de tapizado. Previo al análisis de la muestra, la leche se mezcló con ácido etilendiaminotetracético (EDTA) -para evitar la formación de complejos-, y se desnató y desproteinizó por centrifugación. Tras la optimización del ensayo, el LD fue de $0,048 \mu \mathrm{g} / \mathrm{L}$ para TC. El estudio de RC (competidores DXC, OTC y CTC) demostró que el ensayo reconoce CTC $(13,7 \%)$ y OTC $(10 \%)$. Las recuperaciones obtenidas fueron bastante satisfactorias (aproximadamente 90\%). Estos resultados indican que el ELISA desarrollado permite la determinación de bajos niveles de TC en leche con tan solo un simple pre-tratamiento de muestra.

Más recientemente, utilizando el mismo inmunógeno comercial, se desarrolló un ELISA competitivo, para determinar residuos de TC en miel. Para ello, se preparó un patrón de TC en una disolución de miel utilizando tampón PBS-EDTA a $\mathrm{pH} 7,2$, sin que fuese necesario ningún tratamiento de muestra o concentración. El ELISA optimizado para la TC presentó un LD de $0,19 \mu \mathrm{g} / \mathrm{L}$ y un rango dinámico entre 1,52 y $152 \mu \mathrm{g} / \mathrm{L}$. La media de las recuperaciones de las muestras de miel dopadas con TC osciló entre 95 y 101\%. No se observó reactividad cruzada con compuestos de estructura similar (DXC, OTC y CTC), demostrando que el ensayo era específico para la determinación de $\mathrm{TC}^{118}$. 
Además, una serie de kits comerciales basados en formato ELISA y detección colorimétrica están disponibles en el mercado para la determinación de TCs en huevos, leche, pescado, carne y miel. Uno de los más utilizados es el kit Ridascreen TC (r-Biopharm GmbH, Darmstadt, Alemania). Este test se utiliza para determinar TC, MNC, RTC y CTC por debajo de $15 \mu \mathrm{g} / \mathrm{kg}$. Al aplicar el kit a la cuantificación de residuos de TC, CTC y OTC en miel se observó una elevada reactividad cruzada con la $\mathrm{CTC}^{119}$. El ensayo presentó un LD de $15 \mu \mathrm{g} / \mathrm{L}$ tanto para la TC como para la CTC, mientras que para la OTC fue de $250 \mu \mathrm{g} / \mathrm{L}$. Los estudios realizados utilizando miel exenta de TCs demostraron que una dilución muestra/tampón (1:50) era suficiente para eliminar las interferencias de la matriz. Aplicando este kit, Aga et al. ${ }^{120}$ determinaron la persistencia de las TCs y sus productos de degradación en enmiendas orgánicas, expresando los resultados como "TCs totales".

El mismo kit se ha aplicado también para detectar algunas TCs en extracto de riñón y de músculo ${ }^{121}$, aunque la reactividad cruzada varió entre el $4-5 \%$ para OTC y DXC, hasta el 100\% para TC y CTC. En este caso, se requirió una extracción en fase sólida de la muestra antes de la realización del inmunoensayo.

Recientemente se ha incorporado un nuevo dispositivo comercial basado en un inmunoensayo fluorescente en fase sólida (SPFIA) y formato competitivo, denominado Parallux (IDEXX Laboratories, Inc., Maine). El sistema ha sido aplicado satisfactoriamente a la determinación de residuos de antibióticos $\beta$ lactámicos, TCs y cefalosporinas en leche. Okerman et al. ${ }^{122}$ han aplicado este test para la determinación de residuos de antibióticos en muestras de riñón, detectando TC, OTC, CTC y DXC a niveles de $300 \mu \mathrm{g} / \mathrm{kg}$.

La aceptación de los kits comerciales desarrollados va en aumento a pesar de su elevado precio y, en ocasiones, poca versatilidad, la caducidad de los reactivos y su falta de reproducibilidad, especialmente cuando se usan por personal no entrenado. A pesar de ello, ha de reconocerse su gran potencial.

Finalmente, el Tetrasensor es un test receptor en formato de tira (dipstick) para el cribado de TCs (CTC, DXC, MC, OTC y TC) en tejidos de animales, huevos, leche y miel. La empresa que comercializa dicho test dispone de kits específicos para cada tipo de muestra, con una sensibilidad que varia entre $5-85 \mu \mathrm{g} / \mathrm{kg}$ en función de la matriz y TC analizada. Alfredsson et al. ${ }^{123}$ han aplicado el test para la 
determinación de residuos de TCs (TC, OTC, CTC y DXC) en miel y huevos a niveles de $100 \mu \mathrm{g} / \mathrm{kg}$, lo que lo hace útil para planes de vigilancia.

Durante el transcurso de esta tesis doctoral, otros grupos de investigación han publicado trabajos que describen ensayos basados en anticuerpos específicos y genéricos para sulfonamidas y tetraciclinas. Considerando que el número de sulfonamidas y tetraciclinas utilizadas en producción animal está aumentando, es muy interesante desarrollar ELISAs específicos y genéricos para los nuevos antibióticos. Sin lugar a duda, el factor limitante es el desarrollo de anticuerpos adecuados, lo que básicamente implica diseñar nuevas rutas sintéticas de haptenos. De los trabajos publicados hasta el momento se puede deducir que las sulfonamidas son una familia de antibióticos con los que no se han producido anticuerpos de amplia capacidad de reconocimiento.

Con respecto a las tetraciclinas, la mayoría de los artículos determinan TC, estudiando otros compuestos relacionados con menor frecuencia. Además, los métodos descritos generan anticuerpos que no son específicos y, por lo general, presentan reactividad cruzada contra varios analitos. Esto hace que el diseño de nuevos haptenos y desarrollo de nuevos ELISAs para ambas familias sea de gran interés para la comunidad científica. 

2. OBJETIVOS 

Dada la problemática que presenta el desarrollo de inmunoensayos y la determinación de sulfonamidas y tetraciclinas con elevada sensibilidad, se han planteado diferentes objetivos.

El objetivo general de las investigaciones ha sido el desarrollo de inmunorreactivos y sistemas analíticos de barrido (screening) basados en métodos inmunoquímicos, que permitan la detección de residuos de antibióticos en alimentos, concretamente sulfonamidas y tetraciclinas. Estos desarrollos se dirigen a conocer los niveles de tetraciclinas y sulfonamidas en alimentos de una forma rápida, sensible, económica y fiable, con un tratamiento de muestra mínimo y por personal no cualificado.

Para ello se plantearon los siguientes objetivos particulares:

- Diseño y síntesis de haptenos, inmunógenos, trazadores y reactivos auxiliares para los antibióticos objeto de estudio

- Obtención de anticuerpos policlonales

- Desarrollo y puesta a punto de métodos inmunoquímicos tipo ELISA

- Aplicación a muestras reales. Estudio de la determinación de los antibióticos en mieles de distinta procedencia

- Validación de la metodología desarrollada. Estudio comparativo entre la información obtenida mediante la metodología desarrollada y los métodos de referencia

Dado que esta Tesis Doctoral se ha realizado en el marco de dos proyectos de investigación cuya área de aplicación ha sido la detección de residuos de antibióticos en mieles (AGL-2000-0522-P4-03 y CIT-060000-2005-86), la aplicación de las tecnologías desarrolladas se orientó a muestras de miel. 

3. PARTE EXPERIMENTAL 



\subsection{SÍNTESIS ORGÁNICA}

\subsubsection{Técnicas generales}

\subsubsection{Técnicas cromatográficas}

\section{Cromatografía en capa fina}

Para la cromatografía analítica en capa fina se utilizaron cromatofolios de gel de sílice $60 \mathrm{~F}_{254}$ (Fluka, Madrid, España) con un espesor de $0,2 \mathrm{~mm}$.

Los cromatofolios, una vez desarrollados, se observaron a la luz ultravioleta o se revelaron utilizando los siguientes reactivos:

-Anisaldehído: Disolución recién preparada de $0,5 \mathrm{~mL}$ de anisaldehído y $1 \mathrm{~mL}$ de ácido sulfúrico (conc) en $50 \mathrm{~mL}$ de ácido acético glacial. Las placas se sumergieron en la disolución y posteriormente se calentaron a $100-105{ }^{\circ} \mathrm{C}$ hasta obtener la máxima intensidad de color en las manchas.

-Verde de bromocresol: 0,04 $\mathrm{g}$ de verde de bromocresol disueltos en $100 \mathrm{~mL}$ de EtOH, adicionando $\mathrm{NaOH} 0,1 \mathrm{M}$ hasta viraje al azul. Los cromatofolios se sumergieron en la disolución y posteriormente se calentaron a $100-105^{\circ} \mathrm{C}$.

\section{Cromatografía en columna}

Para la cromatografía preparativa en columna se utilizó gel de sílice 60 de 0,063-0,200 mm de tamaño de partícula (J. T. Baker, Deventer, Holanda).

La muestra se depositó adsorbida sobre gel de sílice de las mismas características o disuelta en el disolvente adecuado. La elución se llevó a cabo a una velocidad de flujo de aproximadamente $5 \mathrm{~cm} / \mathrm{min}$.

Para la cromatografía preparativa HPLC se utilizó un equipo Waters $600 \mathrm{E}$ con una columna RP-18 (Lichrosorb $20 \times 250 \mathrm{~mm}$, tamaño de partícula de 7,0 $\mu \mathrm{m}$, Teknokroma, Barcelona, España). 


\subsubsection{Técnicas espectroscópicas}

\section{Espectroscopia infrarroja (IR)}

Los espectros de IR se realizaron utilizando pastillas de $\mathrm{KBr}$ y un espectrofotómetro Jasco FT/IR-460 Plus, con un intervalo de trabajo entre $4.000 \mathrm{y}$ $600 \mathrm{~cm}^{-1}$

\section{Resonancia magnética nuclear (RMN)}

Los espectros de RMN fueron obtenidos en un espectrómetro Varian Gemini $300\left(300,08 \mathrm{MHz}\right.$ para RMN ${ }^{1} \mathrm{H}$ y $75,45 \mathrm{MHz}$ para $\left.{ }^{13} \mathrm{C}\right)$.

El disolvente utilizado, excepto cuando se indique lo contrario, fue DMSO sin referencia interna, tomando la señal de este disolvente como referencia $(2,49 \mathrm{ppm}$ para ${ }^{1} \mathrm{H}$ y 39,5 ppm para ${ }^{13} \mathrm{C}$ ).

Los valores de desplazamiento se indican en unidades $\delta(\mathrm{ppm})$ y las constantes de acoplamiento $(\mathrm{J})$ en hertzios $(\mathrm{Hz})$. Las abreviaturas $\mathrm{s}, \mathrm{d}, \mathrm{t}, \mathrm{q}$, quint, $\mathrm{m}$ y ar representan singlete, doblete, triplete, cuadruplete, quintuplete, multiplete $\mathrm{y}$ aromático, respectivamente.

\section{Espectrometría de masas (MS)}

Todos los espectros de masas se obtuvieron previa separación de los compuestos por HPLC utilizando un equipo Waters 2690 con detector de masas, en modo IE-MS (Thermabeam Mass detector; Waters). Se empleó una columna de HPLC C18 (Symmetry 2,1 x $150 \mathrm{~mm}$, tamaño de partícula de $5 \mu \mathrm{m}$, Waters), metanol como eluyente a $0,25 \mathrm{~mL} / \mathrm{min}$ y $210{ }^{\circ} \mathrm{C}$ como temperatura del ionizador. Los datos representan la abundancia relativa de los fragmentos cargados positivamente frente a la relación masa/carga $(\mathrm{m} / \mathrm{z})$.

\subsubsection{Reactivos}

Para la síntesis de haptenos se utilizaron reactivos comerciales grado síntesis, suministrados por Fluka-Sigma-Aldrich Química (Madrid, España) y Acros 
Organics (Geel, Bélgica), excepto la 2- $N$-lisinometiltetraciclina que fue adquirida a Laboratoires Sophartex (Vernouillet, Francia). Los disolventes empleados fueron suministrados por Aldrich Química (Madrid, España) y Scharlab (Barcelona, España), en diferentes calidades (grado síntesis, pureza para análisis o calidad HPLC).

\subsubsection{Síntesis de haptenos para sulfonamidas}

Los compuestos de la familia de las sulfonamidas muestran una gran variabilidad, pero poseen una estructura general en la que se pueden diferenciar dos regiones: una constante (c) y otra variable (v), que constituye la mayor diferencia estructural (Figura 8).

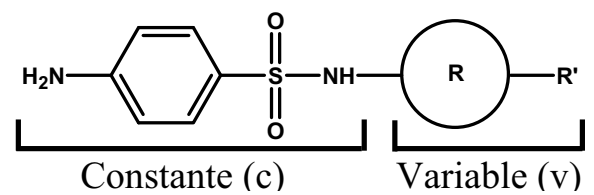

Figura 8. Estructura general de las sulfonamidas

Por este motivo, para la determinación de sulfonamidas se sintetizó una colección de 13 haptenos, con diferentes grados de heterología, que difieren tanto en la longitud como en el tipo del brazo espaciador, clasificándolos en tres tipos según la posición en que se introdujo dicho brazo.

Los haptenos se han agrupado en función de la aproximación sintética seguida, de ahí que la nomenclatura no sea correlativa.

\subsubsection{Haptenos tipo I}

La obtención de este tipo de haptenos se llevó a cabo manteniendo la región constante y efectuando la funcionalización a través de la región variable (Figura 9).

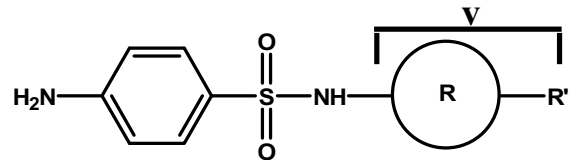

Figura 9. Estructura genérica de los haptenos tipo I para sulfonamidas 


\section{Síntesis del hapteno S2: Ácido 4-(4-amino-bencenosulfonilamino)benzoico}

La obtención del ácido 4-(4-acetilamino-bencenosulfonilamino)benzoico se llevó a cabo siguiendo el procedimiento descrito por Muldoon et al. ${ }^{88}$. Para ello, se agitó una mezcla de 6,11 g (44,6 mmoles) de ácido 4-aminobenzoico y 10,48 g (44,9 mmoles) de cloruro de $N$-acetilsulfanililo en $42 \mathrm{~mL}$ de acetona anhidra conteniendo un $8 \%(\mathrm{v} / \mathrm{v})$ de piridina seca, durante $21 \mathrm{~h}$ bajo atmósfera de $\mathrm{Ar}$ a temperatura ambiente. A continuación, se evaporó la acetona en corriente de aire obteniendo un semisólido anaranjado. Tras la adición de $120 \mathrm{~mL}$ de agua destilada, el precipitado se filtró, se lavó con EtOH frío $(10 \mathrm{~mL})$ y se secó a vacío. Se obtuvieron 9,34 g (63\%) de un sólido blanco que no necesitó purificación posterior y que fue identificado como "producto I".

Producto I

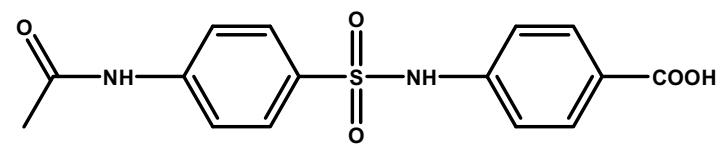

${ }^{1} \mathrm{H}-\mathrm{RMN}\left(300 \mathrm{MHz}, \mathrm{DMSO}-\mathrm{d}_{6}\right) \delta(\mathrm{ppm}): 10,73\left(1 \mathrm{H}, \mathrm{s}, \mathrm{SO}_{2} \mathrm{NH}\right), 10,34(1 \mathrm{H}, \mathrm{s}$, $\mathrm{CON} \underline{\mathrm{H}}), 7,81-7,75\left(6 \mathrm{H}, \underline{\mathrm{C}}_{\mathrm{ar}}\right), 7,19\left(2 \mathrm{H}, \mathrm{d}, J=6,9 \mathrm{~Hz}, \mathrm{C}_{\mathrm{H}}\right), 2,05\left(3 \mathrm{H}, \mathrm{s}, \mathrm{C}_{3} \mathrm{CO}\right)$.

${ }^{13} \mathrm{C}-\mathrm{RMN}\left(75,4 \mathrm{MHz}, \mathrm{DMSO}-\mathrm{d}_{6}\right) \delta(\mathrm{ppm}): 169,0(\underline{\mathrm{COOH}}), 166,7(\underline{\mathrm{CO}}), 143,4$, 142,1 y $132,6\left(3 \underline{\mathrm{C}}_{\mathrm{ar}}\right), 130,7\left(2 \underline{\mathrm{CH}}_{\mathrm{ar}}\right), 128,0\left(2 \underline{\mathrm{CH}}_{\mathrm{ar}}\right), 125,4\left(\underline{\mathrm{C}}_{\mathrm{ar}}\right), 118,6\left(2 \underline{\mathrm{CH}}_{\mathrm{ar}}\right)$, $118,0\left(2 \underline{\mathrm{CH}}_{\mathrm{ar}}\right), 24,1\left(\mathrm{CH}_{3}\right)$.

A $1,72 \mathrm{~g}(5,1$ mmoles $)$ del producto I se añadieron $54 \mathrm{~mL}$ de agua destilada y $12 \mathrm{~mL}$ de $\mathrm{HCl}$ conc. La mezcla se calentó a reflujo durante $40 \mathrm{~min}$ y se ajustó el $\mathrm{pH}$ de la disolución hasta 4,0 con $\mathrm{NH}_{4} \mathrm{OH}$ 6,5 M. El precipitado, una vez filtrado usando una placa de vidrio, se lavó con agua fría y se secó a vacío. Se obtuvieron 1,41 g de un sólido blanco (rendimiento 94\%) que correspondía al producto deseado, "hapteno S2".

S2

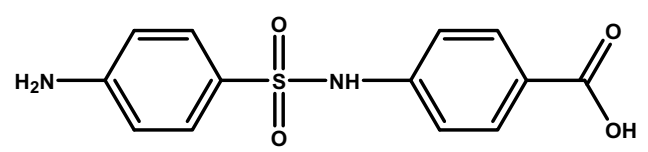


${ }^{1} \mathrm{H}-\mathrm{RMN}\left(300 \mathrm{MHz}, \mathrm{DMSO}-\mathrm{d}_{6}\right) \delta(\mathrm{ppm}): 12,66(1 \mathrm{H}, \mathrm{br} \mathrm{s}, \mathrm{COOH}), 10,41(1 \mathrm{H}, \mathrm{s}$, $\left.\mathrm{SO}_{2} \mathrm{~N} \underline{\mathrm{H}}\right), 7,77\left(2 \mathrm{H}, \mathrm{d}, J=7,2 \mathrm{~Hz}, \underline{\mathrm{H}}_{\mathrm{ar}}\right), 7,44\left(2 \mathrm{H}, \mathrm{d}, J=7,2 \mathrm{~Hz}, \underline{\mathrm{C}}_{\mathrm{ar}}\right), 7,14(2 \mathrm{H}, \mathrm{d}$, $\left.J=7,2 \mathrm{~Hz}, \underline{\mathrm{CH}}_{\mathrm{ar}}\right), 6,53\left(2 \mathrm{H}, \mathrm{d}, J=7,2 \mathrm{~Hz}, \underline{\mathrm{C}}_{\mathrm{ar}}\right), 6,04\left(2 \mathrm{H}, \mathrm{s}, \mathrm{NH}_{2}\right)$.

${ }^{13} \mathrm{C}-\mathrm{RMN}\left(75,4 \mathrm{MHz}, \mathrm{DMSO}-\mathrm{d}_{6}\right) \delta(\mathrm{ppm}): 166,8(\underline{\mathrm{COOH}}), 153,1$ y $142,7\left(2 \underline{\mathrm{C}}_{\mathrm{ar}}\right)$, $130,6\left(2 \underline{\mathrm{CH}}_{\mathrm{ar}}\right), 128,8\left(2 \underline{\mathrm{C}} \mathrm{H}_{\mathrm{ar}}\right), 124,8$ y $123,9\left(2 \underline{\mathrm{C}}_{\mathrm{ar}}\right), 117,5\left(2 \underline{\mathrm{CH}}_{\mathrm{ar}}\right), 112,6\left(2 \underline{\mathrm{C}} \mathrm{H}_{\mathrm{ar}}\right)$.

IR $(\mathrm{KBr}) v_{\max }\left(\mathrm{cm}^{-1}\right): 3411\left(\mathrm{NH}_{2}\right.$, as), $3332\left(\mathrm{NH}_{2}, \operatorname{sim}\right), 3217(\mathrm{NH}), 1697(\mathrm{C}=\mathrm{O})$, $1608\left(\mathrm{C}_{\mathrm{ar}}=\mathrm{C}_{\mathrm{ar}}\right), 1516\left(\mathrm{C}_{\mathrm{ar}}=\mathrm{C}_{\mathrm{ar}}\right), 1327\left(\mathrm{SO}_{2}\right.$, as $)$ y $1157\left(\mathrm{SO}_{2}, \operatorname{sim}\right)$.

MS $m / z$ (fragmento, intensidad relativa): $292\left(\mathrm{M}^{+}, 20\right), 156\left(\mathrm{C}_{6} \mathrm{H}_{6} \mathrm{NO}_{2} \mathrm{~S}, 100\right), 108$ $\left(\mathrm{C}_{6} \mathrm{H}_{6} \mathrm{NO}, 74\right), 92\left(\mathrm{C}_{6} \mathrm{H}_{6} \mathrm{~N}, 93\right), 65\left(\mathrm{C}_{5} \mathrm{H}_{5}, 73\right)$.

\section{Síntesis del hapteno S9: Ácido [4-(4-amino-bencenosulfonilamino)fenil]acético}

Para la síntesis de este compuesto se agitó una mezcla de 3,22 g (21,3 mmoles) de ácido (4-aminofenil)acético y $5 \mathrm{~g}(21,4$ mmoles) de cloruro de $\mathrm{N}$ acetilsulfanililo, en $17 \mathrm{~mL}$ de acetona anhidra conteniendo un $18 \%(\mathrm{v} / \mathrm{v})$ de piridina seca, durante $21 \mathrm{~h}$ bajo atmósfera de $\mathrm{Ar}$ a temperatura ambiente. A continuación, se eliminó el disolvente a presión reducida, obteniéndose un sólido rojizo como producto de condensación. Su purificación, mediante cromatografía en columna sobre gel de sílice con hexano/AcOEt (90:10), permitió obtener el ácido [4-(4-acetilamino-benceno sulfonilamino)fenil]acético -producto I- (4,37 g, 59\%) como un sólido naranja.

Producto I

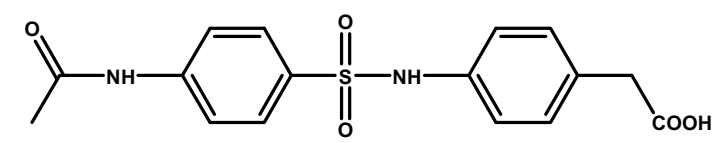

${ }^{1} \mathrm{H}-\mathrm{RMN}\left(300 \mathrm{MHz}, \mathrm{DMSO}-\mathrm{d}_{6}\right) \delta(\mathrm{ppm}): 12,25(1 \mathrm{H}, \mathrm{br} \mathrm{s}, \mathrm{COO} \underline{\mathrm{H}} 10,30(1 \mathrm{H}, \mathrm{s}$, $\left.\mathrm{SO}_{2} \mathrm{~N} \underline{\mathrm{H}}\right), 10,13(1 \mathrm{H}, \mathrm{s}, \mathrm{CON} \underline{\mathrm{H}}), 7,68\left(4 \mathrm{H}, \mathrm{s}, \underline{\mathrm{C}}_{\mathrm{ar}}\right), 7,10\left(2 \mathrm{H}, \mathrm{d}, J=8,5 \mathrm{~Hz}, \mathrm{C}_{\mathrm{H}_{\mathrm{ar}}}\right)$, $6,99\left(2 \mathrm{H}, \mathrm{d}, J=8,5 \mathrm{~Hz}, \mathrm{C}_{\mathrm{ar}}\right), 3,43\left(2 \mathrm{H}, \mathrm{s}, \mathrm{C}_{2} \mathrm{COOH}\right), 2,04\left(3 \mathrm{H}, \mathrm{s}, \underline{\mathrm{C}}_{3} \mathrm{CO}\right)$. 


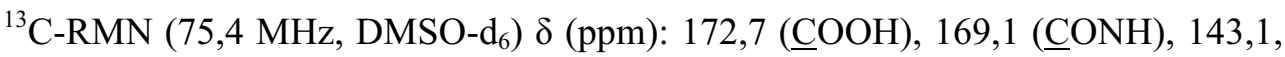
$136,3,133,1$ y $130,7\left(4 \underline{\mathrm{C}}_{\mathrm{ar}}\right), 130,1\left(2 \underline{\mathrm{CH}}_{\mathrm{ar}}\right), 128,0\left(2 \underline{\mathrm{CH}}_{\mathrm{ar}}\right), 120,0\left(2 \underline{\mathrm{C}} \mathrm{H}_{\mathrm{ar}}\right), 118,6$ $\left(2 \underline{\mathrm{CH}}_{\mathrm{ar}}\right), 39,9\left(\mathrm{CH}_{2} \mathrm{COOH}\right), 24,2\left(\underline{\mathrm{CH}}_{3} \mathrm{CO}\right)$.

A $0,92 \mathrm{~g}$ (2,6 mmoles) del producto I se añadieron $30 \mathrm{~mL}$ de agua destilada y 6 $\mathrm{mL}$ de $\mathrm{HCl}$ conc, manteniendo la mezcla a reflujo durante $35 \mathrm{~min}$. Tras ajustar el $\mathrm{pH}$ de la disolución a 4,0 con $\mathrm{NH}_{4} \mathrm{OH}$ 6,5 $\mathrm{M}$, el precipitado formado se filtró en placa de vidrio, se lavó con agua fría y se secó a vacío. Como resultado se obtuvo un sólido puro de color marrón $(0,498 \mathrm{~g}, 62 \%)$, que fue identificado como "hapteno S9”.

S9

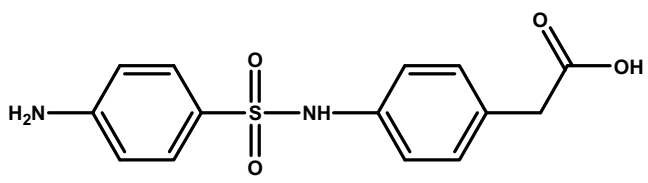

${ }^{1} \mathrm{H}-\mathrm{RMN}\left(300 \mathrm{MHz}, \mathrm{DMSO}-\mathrm{d}_{6}\right) \delta(\mathrm{ppm}): 12,22(1 \mathrm{H}, \mathrm{br} \mathrm{s}, \mathrm{COO} \underline{\mathrm{H}}), 9,81(1 \mathrm{H}, \mathrm{s}$, $\left.\mathrm{SO}_{2} \mathrm{~N} \underline{\mathrm{H}}\right), 7,37\left(2 \mathrm{H}, \mathrm{d}, J=8,73 \mathrm{~Hz}, \mathrm{C}_{\mathrm{Har}}\right), 7,06\left(2 \mathrm{H}, \mathrm{d}, J=8,5 \mathrm{~Hz}, \mathrm{C}_{\mathrm{H}}\right), 6,97(2 \mathrm{H}$, $\left.\mathrm{d}, J=8,5 \mathrm{~Hz}, \underline{\mathrm{H}}_{\mathrm{ar}}\right), 6,51\left(2 \mathrm{H}, \mathrm{d}, J=8,73 \mathrm{~Hz}, \underline{\mathrm{C}}_{\mathrm{ar}}\right), 5,95\left(2 \mathrm{H}, \mathrm{s}, \mathrm{N}_{2}\right), 3,43(2 \mathrm{H}, \mathrm{s}$, $\left.\mathrm{C}_{2} \mathrm{COOH}\right)$.

${ }^{13} \mathrm{C}-\mathrm{RMN}\left(75,4 \mathrm{MHz}, \mathrm{DMSO}-\mathrm{d}_{6}\right) \delta(\mathrm{ppm}): 172,7(\underline{\mathrm{COOH}}), 152,8\left(2 \underline{\mathrm{C}}_{\mathrm{ar}}\right), 137,0$ $\left(\underline{\mathrm{C}}_{\mathrm{ar}}\right), 130,0\left(2 \underline{\mathrm{CH}}_{\mathrm{ar}}\right), 128,7\left(2 \underline{\mathrm{C}} \mathrm{H}_{\mathrm{ar}}\right), 124,5\left(\underline{\mathrm{C}}_{\mathrm{ar}}\right), 119,4\left(2 \underline{\mathrm{CH}}_{\mathrm{ar}}\right), 112,6\left(2 \underline{\mathrm{C}} \mathrm{H}_{\mathrm{ar}}\right), 39,9$ $\left(\mathrm{CH}_{2} \mathrm{COOH}\right)$.

IR $(\mathrm{KBr}) v_{\max }\left(\mathrm{cm}^{-1}\right): 3493\left(\mathrm{NH}_{2}\right.$, as $), 3391\left(\mathrm{NH}_{2}, \operatorname{sim}\right), 3239(\mathrm{NH}), 1705(\mathrm{C}=\mathrm{O})$, $1628\left(\mathrm{C}_{\mathrm{ar}}=\mathrm{C}_{\mathrm{ar}}\right), 1505\left(\mathrm{C}_{\mathrm{ar}}=\mathrm{C}_{\mathrm{ar}}\right), 1321\left(\mathrm{SO}_{2}\right.$, as $)$ y $1148\left(\mathrm{SO}_{2}, \operatorname{sim}\right)$.

MS $m / z$ (fragmento, intensidad relativa): $306\left(\mathrm{M}^{+}, 19\right), 156\left(\mathrm{C}_{6} \mathrm{H}_{6} \mathrm{NO}_{2} \mathrm{~S}, 64\right), 151$ $\left(\mathrm{C}_{8} \mathrm{H}_{9} \mathrm{NO}_{2}, 32\right), 108\left(\mathrm{C}_{6} \mathrm{H}_{6} \mathrm{NO}, 45\right), 106\left(\mathrm{C}_{7} \mathrm{H}_{8} \mathrm{~N}, 100\right), 92\left(\mathrm{C}_{6} \mathrm{H}_{6} \mathrm{~N}, 55\right), 65\left(\mathrm{C}_{5} \mathrm{H}_{5}\right.$, $40)$. 


\section{Síntesis del hapteno S3: Ácido [2-(4-amino-bencenosulfonilamino)-1,3-tiazol-4- il]acético}

Este derivado de STZ fue preparado utilizando una modificación del procedimiento descrito por Haasnoot et al. ${ }^{91}$.

A 5,00 g (31,6 mmoles) del ácido 2-amino-4-tiazolacético se añadieron $92 \mathrm{~mL}$ de $\mathrm{EtOH}$ y $18,4 \mathrm{~mL}$ de $\mathrm{HCl}$ conc, calentando la mezcla a reflujo durante $30 \mathrm{~min}$. Tras eliminar el disolvente a presión reducida, el residuo se disolvió en $95 \mathrm{~mL}$ de agua destilada y se alcalinizó hasta $\mathrm{pH} 8,0$ con $\mathrm{NH}_{4} \mathrm{OH} 6,5 \mathrm{M}$. La mezcla obtenida se extrajo con acetato de etilo $(3 \times 100 \mathrm{~mL})$ y tras unir las fases orgánicas, éstas se secaron sobre $\mathrm{Na}_{2} \mathrm{SO}_{4}$ anhidro. El extracto se concentró a presión reducida y el sólido obtenido se recristalizó con acetato de etilo, obteniendo 4,45 g (76\%) de un sólido amarillo que fue identificado como (2-amino-1,3-tiazol-4-il)acetato de etilo -producto I-.

Producto I

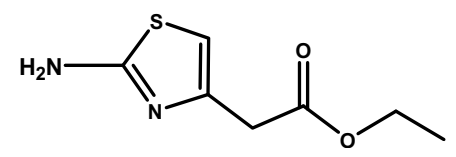

${ }^{1} \mathrm{H}-\mathrm{RMN}\left(300 \mathrm{MHz}, \mathrm{CDCl}_{3}\right) \delta$ (ppm): 6,33 (1H, s, $\left.\mathrm{C}_{\mathrm{rr}-\mathrm{S}}\right), 5,20\left(2 \mathrm{H}, \mathrm{br} \mathrm{s}, \mathrm{N}_{2}\right)$, $4,17\left(2 \mathrm{H}, \mathrm{q}, J=7,1 \mathrm{~Hz}, \mathrm{CH}_{3} \underline{\mathrm{CH}}_{2} \mathrm{O}\right), 3,55\left(2 \mathrm{H}, \mathrm{s}, \mathrm{COCH}_{2}\right), 1,26(3 \mathrm{H}, \mathrm{t}, J=7,1 \mathrm{~Hz}$, $\left.\mathrm{CH}_{3} \mathrm{CH}_{2} \mathrm{O}\right)$.

${ }^{13} \mathrm{C}-\mathrm{RMN}\left(75,4 \mathrm{MHz}, \mathrm{CDCl}_{3}\right) \delta(\mathrm{ppm}): 170,5$ (므), 167,8 y 144,5 (2 $\left.\underline{\mathrm{C}}_{\mathrm{ar}}\right), 105,3$ $\left(\underline{\mathrm{CH}}_{\mathrm{ar}-\mathrm{S}}\right), 61,0\left(\mathrm{CH}_{3} \underline{\mathrm{CH}}_{2} \mathrm{O}\right), 37,2\left(\mathrm{COC} \mathrm{H}_{2}\right), 14,2\left(\mathrm{CH}_{3} \mathrm{CH}_{2} \mathrm{O}\right)$.

A una disolución de 1,98 g (10,6 mmoles) del producto I en 7,3 $\mathrm{mL}$ de piridina anhidra, se adicionaron lentamente -a $0{ }^{\circ} \mathrm{C}$ y bajo atmósfera de Ar- 2,67 g (11,4 mmoles) de cloruro de $\mathrm{N}$-acetilsulfanililo. Tras agitar la mezcla durante $38 \mathrm{~h}$ a temperatura ambiente y bajo atmósfera de Ar, se adicionaron $2 \mathrm{~mL}$ de EtOH y se ajustó el pH de la disolución a 3,0 con $\mathrm{HCl} 4 \mathrm{M}$. El precipitado formado se filtró en una placa de vidrio, se lavó con agua destilada y se secó a presión reducida. El producto obtenido se recristalizó en acetona, obteniendo 2,04 g (50\%) de un sólido 
ligeramente amarillo que fue identificado como [2-(4-acetilamino-benceno sulfonilamino)-1,3-tiazol-4-il]acetato de etilo -producto II-.

Producto II

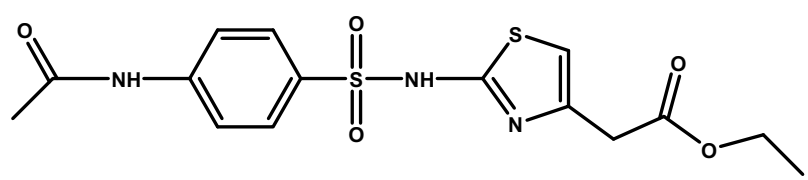

${ }^{1} \mathrm{H}-\mathrm{RMN}\left(300 \mathrm{MHz}, \mathrm{DMSO}-\mathrm{d}_{6}\right) \delta(\mathrm{ppm}): 12,63\left(1 \mathrm{H}, \mathrm{s}, \mathrm{SO}_{2} \mathrm{NH}\right), 10,27(1 \mathrm{H}, \mathrm{s}$, $\mathrm{CON} \underline{\mathrm{H}}), 7,70\left(4 \mathrm{H}, \mathrm{s}, \mathrm{C}_{\mathrm{H}}\right), 6,59\left(1 \mathrm{H}, \mathrm{s}, \mathrm{C} \underline{H}_{\mathrm{ar}-\mathrm{s}}\right), 4,07(2 \mathrm{H}, \mathrm{q}, J=7,1 \mathrm{~Hz}$, $\left.\mathrm{CH}_{3} \underline{\mathrm{C}}_{2} \mathrm{O}\right), 3,61\left(2 \mathrm{H}, \mathrm{s}, \mathrm{COC}_{2}\right), 2,05\left(3 \mathrm{H}, \mathrm{s}, \underline{\mathrm{CH}}_{3} \mathrm{CO}\right), 1,17(3 \mathrm{H}, \mathrm{t}, J=7,1 \mathrm{~Hz}$, $\left.\mathrm{C}_{3} \mathrm{CH}_{2} \mathrm{O}\right)$.

${ }^{13} \mathrm{C}-\mathrm{RMN}\left(75,4 \mathrm{MHz}, \mathrm{DMSO}-\mathrm{d}_{6}\right) \delta(\mathrm{ppm}): 168,9,168,6$ y $168,3\left(2 \mathrm{CO}\right.$ у $\left.\underline{\mathrm{C}}_{\mathrm{ar}}\right)$, $142,5,136,1$ y $130,7\left(3 \underline{\mathrm{C}}_{\mathrm{ar}}\right), 127,0\left(2 \underline{\mathrm{CH}}_{\mathrm{ar}}\right), 118,4\left(2 \underline{\mathrm{CH}}_{\mathrm{ar}}\right), 105,5(\underline{\mathrm{CH}} \mathrm{ar}-\mathrm{s}), 60,8$ $\left(\mathrm{CH}_{3} \underline{\mathrm{CH}}_{2} \mathrm{O}\right), 32,9\left(\mathrm{CO}^{\mathrm{C}} \mathrm{H}_{2}\right), 24,1\left(\underline{\mathrm{CH}}_{3} \mathrm{CO}\right), 14,0\left(\underline{\mathrm{CH}}_{3} \mathrm{CH}_{2} \mathrm{O}\right)$.

Finalmente, a 1,00 g (2,6 mmoles) del producto II se añadieron $24,1 \mathrm{~mL}$ de $\mathrm{NaOH}$ 2,0 M, calentando la mezcla resultante durante $5 \mathrm{~h}$ a reflujo. Tras ajustar el pH de la disolución a 3,0 con $\mathrm{HCl} 4 \mathrm{M}$, se filtró el precipitado formado en placa de vidrio, se lavó con agua destilada y se secó a vacío. Se obtuvieron $689 \mathrm{mg}(84 \%)$ de un sólido ligeramente amarillo que no necesitó purificación posterior, y que fue identificado como "hapteno S3".

S3

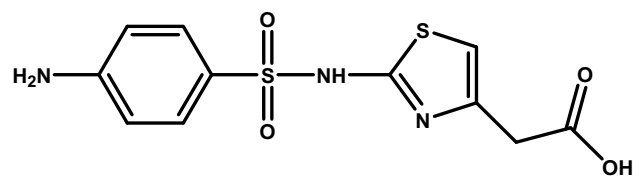

${ }^{1} \mathrm{H}-\mathrm{RMN}\left(300 \mathrm{MHz}, \mathrm{DMSO}-\mathrm{d}_{6}\right) \delta$ (ppm): 12,44 (1H, br s, COOH), 7,42 (2H, d, $J=$ $\left.8,5 \mathrm{~Hz}, \underline{\mathrm{C}}_{\mathrm{ar}}\right), 6,54\left(2 \mathrm{H}, \mathrm{d}, J=8,5 \mathrm{~Hz}, \mathrm{C}_{\mathrm{ar}}\right), 6,49\left(1 \mathrm{H}, \mathrm{s}, \mathrm{C}_{\mathrm{H}} \mathrm{r}-\mathrm{S}\right), 5,82(2 \mathrm{H}, \mathrm{br} \mathrm{s}$, $\left.\mathrm{NH}_{2}\right), 3,49\left(2 \mathrm{H}, \mathrm{s}, \mathrm{CH}_{2} \mathrm{COOH}\right)$.

${ }^{13} \mathrm{C}-\mathrm{RMN}\left(75,4 \mathrm{MHz}, \mathrm{DMSO}-\mathrm{d}_{6}\right) \delta(\mathrm{ppm}): 170,2(\underline{\mathrm{COOH}}), 167,7\left(\underline{\mathrm{C}}_{\mathrm{ar}-\mathrm{NH}}\right), 152,3$ $\left(2 \underline{\mathrm{C}}_{\mathrm{ar}}\right), 131,2\left(\underline{\mathrm{C}}_{\mathrm{ar}}\right), 127,8\left(2 \underline{\mathrm{CH}}_{\mathrm{ar}}\right), 112,5\left(2 \underline{\mathrm{CH}}_{\mathrm{ar}}\right), 104,6\left(\underline{\mathrm{CH}}_{\mathrm{ar}-\mathrm{S}}\right), 33,2\left(\underline{\mathrm{C}}_{2} \mathrm{COOH}\right)$. 
IR (KBr) $v_{\max }\left(\mathrm{cm}^{-1}\right): 3444\left(\mathrm{NH}_{2}\right.$, as), $3357\left(\mathrm{NH}_{2}, \operatorname{sim}\right), 3109(\mathrm{NH}), 1703(\mathrm{C}=\mathrm{O})$, $1597\left(\mathrm{C}_{\mathrm{ar}}=\mathrm{C}_{\mathrm{ar}}\right), 1529$ (anillo tiazol), $1300\left(\mathrm{SO}_{2}\right.$, as) y $1122\left(\mathrm{SO}_{2}, \mathrm{sim}\right)$.

MS $m / z$ (fragmento, intensidad relativa): 269 ([M-CO $\left.]^{+}, 18\right), 205\left(\mathrm{C}_{10} \mathrm{H}_{11} \mathrm{~N}_{3} \mathrm{~S}, 77\right.$ ), $156\left(\mathrm{C}_{6} \mathrm{H}_{6} \mathrm{NO}_{2} \mathrm{~S}, 74\right), 108\left(\mathrm{C}_{6} \mathrm{H}_{6} \mathrm{NO}, 78\right), 93\left(\mathrm{C}_{6} \mathrm{H}_{7} \mathrm{~N}, 100\right), 92\left(\mathrm{C}_{6} \mathrm{H}_{6} \mathrm{~N}, 96\right), 65$ $\left(\mathrm{C}_{5} \mathrm{H}_{5}, 57\right)$.

\section{Síntesis del hapteno S4: Ácido 6-(4-amino-bencenosulfonilamino)nicotínico}

A 2,00 g (14,5 mmoles) de ácido 6-amino-nicotínico se añadieron $42 \mathrm{~mL}$ de EtOH y $8,42 \mathrm{~mL}$ de $\mathrm{HCl}$ conc. La mezcla de reacción se calentó a reflujo durante 90 min, eliminando el disolvente a presión reducida. El residuo se disolvió en 43 $\mathrm{mL}$ de agua destilada y tras ajustar el $\mathrm{pH}$ de la disolución a 8,0 con $\mathrm{NH}_{4} \mathrm{OH}$ 6,5 M, se extrajo la mezcla con diclorometano $(3 \times 40 \mathrm{~mL})$; las fases orgánicas se secaron sobre $\mathrm{Na}_{2} \mathrm{SO}_{4}$ anhidro y el extracto se concentró a presión reducida. Se obtuvieron $848 \mathrm{mg}$ de un sólido blanco puro que correspondía a 6-aminonicotinato de etilo -producto I-, con un rendimiento del $35 \%$.

Producto I

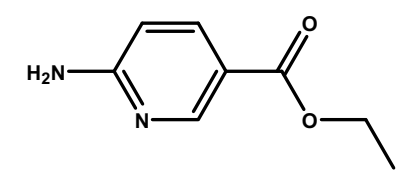

${ }^{1} \mathrm{H}-\mathrm{RMN}\left(300 \mathrm{MHz}, \mathrm{CDCl}_{3}\right) \delta(\mathrm{ppm}): 8,73\left(1 \mathrm{H}, \mathrm{d}, J=2,2 \mathrm{~Hz}, \mathrm{CH}_{\mathrm{ar}-\mathrm{N}}\right), 8,01(1 \mathrm{H}$, dd, $\left.J=2,2,8,7 \mathrm{~Hz}, \underline{\mathrm{C}}_{\mathrm{ar}-\mathrm{CCO}}\right), 6,47\left(1 \mathrm{H}, \mathrm{d}, J=8,7 \mathrm{~Hz}, \mathrm{C}_{\mathrm{Hr}-\mathrm{CNH}}\right), 4,98(2 \mathrm{H}, \mathrm{br} \mathrm{s}$, $\left.\mathrm{N}_{2}\right), 4,33\left(2 \mathrm{H}, \mathrm{q}, J=7,1 \mathrm{~Hz}, \mathrm{CH}_{3} \underline{\mathrm{C}}_{2} \mathrm{O}\right), 1,36\left(3 \mathrm{H}, \mathrm{t}, J=7,1 \mathrm{~Hz}, \mathrm{C}_{3} \mathrm{CH}_{2} \mathrm{O}\right)$.

${ }^{13} \mathrm{C}-\mathrm{RMN}\left(75,4 \mathrm{MHz}, \mathrm{CDCl}_{3}\right) \delta(\mathrm{ppm}): 165,6(\underline{\mathrm{CO}}), 161,0\left(\underline{\mathrm{C}}_{\mathrm{ar}-\mathrm{NH} 2}\right), 151,3\left(\underline{\mathrm{C}}_{\mathrm{ar}-\mathrm{N}}\right)$, $138,9\left(\underline{\mathrm{CH}}_{\mathrm{ar}-\mathrm{CCO}}\right), \quad 116,6 \quad\left(\underline{\mathrm{C}}_{\mathrm{ar}-\mathrm{CO}}\right), \quad 107,3 \quad\left(\underline{\mathrm{CH}}_{\mathrm{ar}-\mathrm{CCNH}}\right), \quad 60,6 \quad\left(\mathrm{CH}_{3} \underline{\mathrm{CH}}_{2} \mathrm{O}\right), 14,4$ $\left(\mathrm{C}_{3} \mathrm{CH}_{2} \mathrm{O}\right)$.

A una disolución de $0,8 \mathrm{~g}(4,8$ mmoles) del producto I en $3,3 \mathrm{~mL}$ de piridina anhidra, se adicionaron lentamente -a $0{ }^{\circ} \mathrm{C}$ y bajo atmósfera de Ar- 1,18 g (5,1 mmoles) de cloruro de $N$-acetilsulfanililo. Tras $27 \mathrm{~h}$ de agitación a temperatura ambiente y bajo atmósfera de Ar, se adicionaron $2 \mathrm{~mL}$ de EtOH y $10 \mathrm{~mL}$ de agua 
destilada, ajustando el $\mathrm{pH}$ a 3,0 con $\mathrm{HCl} 6 \mathrm{M}$. El precipitado, recogido por filtración en una placa de vidrio, se lavó con EtOH frío y se secó a vacío, obteniéndose un sólido blanco puro (859 mg, 49\%) que fue identificado como 6-(4acetilamino-bencenosulfonilamino)nicotinato de etilo -producto II-.

Producto II

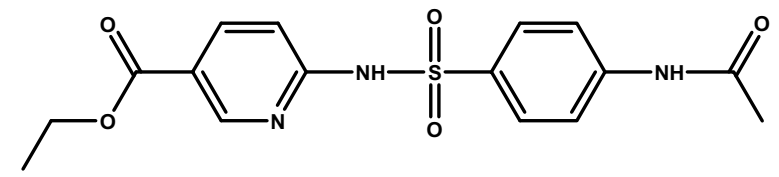

${ }^{1} \mathrm{H}-\mathrm{RMN}\left(300 \mathrm{MHz}, \mathrm{DMSO}-\mathrm{d}_{6}\right) \delta(\mathrm{ppm}): 11,94\left(1 \mathrm{H}, \mathrm{br} \mathrm{s}, \mathrm{SO}_{2} \mathrm{~N} \underline{\mathrm{H}}\right), 10,31(1 \mathrm{H}, \mathrm{s}$, $\mathrm{CON} \underline{\mathrm{H}}), 8,57\left(1 \mathrm{H}, \mathrm{s}, \underline{\mathrm{C}}_{\mathrm{ar}-\mathrm{N}}\right), 8,11\left(1 \mathrm{H}, \mathrm{d}, J=8,7 \mathrm{~Hz}, \underline{\mathrm{C}}_{\mathrm{ar}-\mathrm{CCO}}\right), 7,86(2 \mathrm{H}, \mathrm{d}, J=8,3$ $\left.\mathrm{Hz}, \underline{\mathrm{C}}_{\mathrm{ar}}\right), 7,72\left(2 \mathrm{H}, \mathrm{d}, J=8,3 \mathrm{~Hz}, \mathrm{CH}_{\mathrm{ar}}\right), 7,14\left(1 \mathrm{H}, \mathrm{d}, J=8,7 \mathrm{~Hz}, \underline{\mathrm{C}}_{\mathrm{ar}-\mathrm{CNH}}\right), 4,25$ $\left(2 \mathrm{H}, \mathrm{q}, J=7,1 \mathrm{~Hz}, \mathrm{CH}_{3} \mathrm{CH}_{2} \mathrm{O}\right), 2,05\left(3 \mathrm{H}, \mathrm{s}, \underline{\mathrm{CH}}_{3} \mathrm{CO}\right), 1,26(3 \mathrm{H}, \mathrm{t}, J=7,1 \mathrm{~Hz}$, $\left.\mathrm{C}_{3} \mathrm{CH}_{2} \mathrm{O}\right)$.

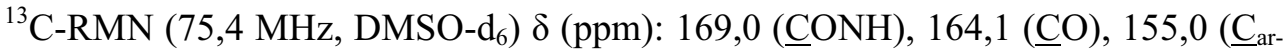
NHSO2$), 147,6$ y 143,2 (DEPT $\left.\underline{\mathrm{C}}_{\mathrm{ar}-\mathrm{NHCOCH} 3}, \underline{\mathrm{CH}}_{\mathrm{ar}-\mathrm{N}}\right), 139,5\left(\underline{\mathrm{CH}}_{\mathrm{ar}-\mathrm{CCO}}\right), 134,0\left(\underline{\mathrm{C}}_{\mathrm{ar}-}\right.$ SO2NH $), 128,3\left(2 \underline{\mathrm{CH}}_{\mathrm{ar}}\right), 111,9\left(\underline{\mathrm{CH}}_{\mathrm{ar}-\mathrm{CNH}}\right), 60,8\left(\mathrm{CH}_{3} \underline{\mathrm{CH}}_{2} \mathrm{O}\right), 24,1\left(\underline{\mathrm{CH}}_{3} \mathrm{CO}\right), 14,1$ $\left(\underline{\mathrm{CH}_{3}} \mathrm{CH}_{2} \mathrm{O}\right)$.

Posteriormente, a $0,8 \mathrm{~g}(2,2$ mmoles $)$ del producto II se añadieron $4 \mathrm{~mL}$ de $\mathrm{NaOH} 2,5 \mathrm{M}$ y $8 \mathrm{~mL}$ de agua destilada. Tras calentar la mezcla a reflujo durante 2 h, se ajustó el pH de la disolución a 4,0 con $\mathrm{HCl}$ conc. El precipitado, recogido por filtración en una placa de vidrio, se lavó con agua destilada y se secó a presión reducida. Se obtuvieron $587 \mathrm{mg}$ de un sólido ligeramente amarillo que correspondía al ácido 6-(4-amino-bencenosulfonilamino)nicotínico -hapteno S4-, con un rendimiento del $91 \%$.

S4

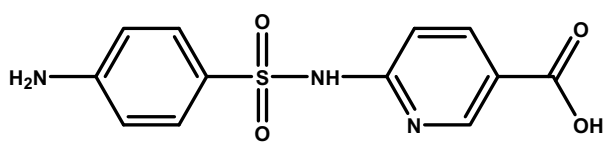

${ }^{1} \mathrm{H}-\mathrm{RMN}\left(300 \mathrm{MHz}, \mathrm{DMSO}-\mathrm{d}_{6}\right) \delta(\mathrm{ppm}): 12,19(1 \mathrm{H}, \mathrm{br} \mathrm{s}, \mathrm{COOH}), 10,37(1 \mathrm{H}, \mathrm{br} \mathrm{s}$, $\left.\mathrm{SO}_{2} \mathrm{NH}\right), 8,6\left(1 \mathrm{H}, \mathrm{s}, \mathrm{CH}_{\mathrm{ar}-\mathrm{N}}\right), 8,08\left(1 \mathrm{H}, \mathrm{d}, J=8,7 \mathrm{~Hz}, \mathrm{C}_{\underline{\mathrm{H}}-\mathrm{CCO}}\right), 7,56(2 \mathrm{H}, \mathrm{d}, J=7,9$ 
$\left.\mathrm{Hz}, \underline{\mathrm{H}}_{\mathrm{ar}}\right), 7,09\left(1 \mathrm{H}, \mathrm{d}, J=8,7 \mathrm{~Hz}, \underline{\mathrm{C}}_{\mathrm{ar}-\mathrm{CNH}}\right), 6,55\left(2 \mathrm{H}, \mathrm{d}, J=7,9 \mathrm{~Hz}, \mathrm{C}_{\mathrm{H}}\right), 6,04$ $\left(2 \mathrm{H}, \mathrm{s}, \mathrm{N}_{2}\right)$.

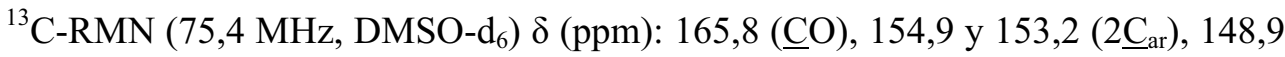
$\left(\underline{\mathrm{CH}}_{\mathrm{ar}-\mathrm{N}}\right), 139,3\left(\underline{\mathrm{CH}}_{\mathrm{ar}-\mathrm{CCO}}\right), 129,3\left(2 \underline{\mathrm{CH}}_{\mathrm{ar}}\right), 124,7$ y $120,0\left(2 \underline{\mathrm{C}}_{\mathrm{ar}}\right), 112,4\left(2 \underline{\mathrm{C}} \mathrm{H}_{\mathrm{ar}}\right)$, $110,8\left(\underline{\mathrm{C}}_{\mathrm{ar}}\right)$.

IR (KBr) $v_{\max }\left(\mathrm{cm}^{-1}\right): 3485\left(\mathrm{NH}_{2}\right.$, as), $3383\left(\mathrm{NH}_{2}, \operatorname{sim}\right), 2854(\mathrm{NH}), 1697(\mathrm{C}=\mathrm{O})$, $1593\left(\mathrm{C}_{\mathrm{ar}}=\mathrm{C}_{\mathrm{ar}}\right), 1502\left(\mathrm{C}_{\mathrm{ar}}=\mathrm{C}_{\mathrm{ar}}\right), 1306\left(\mathrm{SO}_{2}\right.$, as $)$ y $1147\left(\mathrm{SO}_{2}, \operatorname{sim}\right)$.

MS $m / z$ (fragmento, intensidad relativa): 229 ([M-SO $\left.]^{+}, 74\right), 228\left(\mathrm{C}_{12} \mathrm{H}_{10} \mathrm{~N}_{3} \mathrm{O}_{2}\right.$, 72), $138\left(\mathrm{C}_{6} \mathrm{H}_{6} \mathrm{~N}_{2} \mathrm{O}_{2}, 34\right), 93\left(\mathrm{C}_{6} \mathrm{H}_{7} \mathrm{~N}, 100\right), 92\left(\mathrm{C}_{6} \mathrm{H}_{6} \mathrm{~N}, 58\right), 63$ (HNOS, 65).

\section{Síntesis del hapteno S14: Ácido 4-[4-(4-amino-bencenosulfonilamino)benceno} sulfonilamino]benzoico

El último hapteno de este grupo, denominado S14, posee la región variable idéntica a la región constante.

A una disolución de $2,92 \mathrm{~g} \quad(10 \mathrm{mmol})$ de ácido 4-(4-aminobencenosulfonilamino)benzoico (S2) en $10 \mathrm{~mL}$ de agua destilada, conteniendo 800 mg de $\mathrm{NaOH}(20 \mathrm{mmol})$, se adicionaron lentamente -a $0{ }^{\circ} \mathrm{C}$ y bajo atmósfera de Ar- 2,34 g (10 mmoles) de cloruro de $N$-acetilsulfanililo. Tras $2 \mathrm{~h}$ y $30 \mathrm{~min}$ de agitación a temperatura ambiente, se adicionaron $25 \mathrm{~mL}$ de agua destilada, acidificando la disolución con $\mathrm{HCl}$ conc hasta precipitación, apareciendo un sólido rosa de aspecto ceroso. El producto obtenido se recristalizó en una mezcla de EtOH/agua, obteniendo 3,03g (62 \%) de un sólido que fue identificado como ácido 4-[ 4 -( 4 - acetilamino - bencenosulfonilamino ) bencenosulfonilamino ] benzoico -producto I-.

Producto I

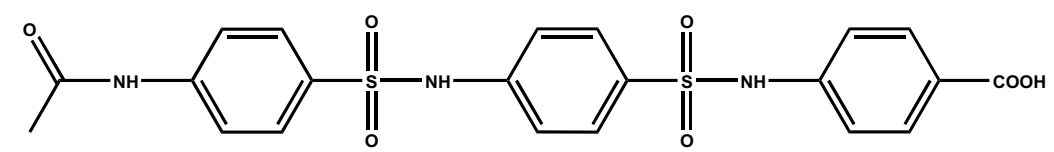




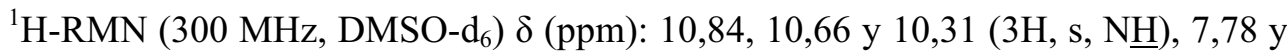
7,12 (4H, d, AA'BB', $\left.J=8,7 \mathrm{~Hz}, \underline{C}_{\text {ar }}\right), 7,76-7,68\left(4 \mathrm{H}, \underline{C}_{\mathrm{H}}\right), 7,67$ y 7,20 $(4 \mathrm{H}, \mathrm{d}$, $\left.\mathrm{AA}^{\prime} \mathrm{BB}^{\prime}, J=8,7 \mathrm{~Hz}, \underline{\mathrm{C}}_{\mathrm{ar}}\right), 2,09\left(3 \mathrm{H}, \mathrm{s}, \mathrm{CH}_{3}\right)$.

${ }^{13} \mathrm{C}-\mathrm{RMN}\left(75,4 \mathrm{MHz}, \mathrm{DMSO}-\mathrm{d}_{6}\right) \delta(\mathrm{ppm}): 169,1$ y 166,7 (2ㅇ) $), 143,5,142,3$, $141,9,133,3$ y $132,4\left(5 \underline{\mathrm{C}}_{\mathrm{ar}}\right), 130,7\left(2 \underline{\mathrm{CH}}_{\mathrm{ar}}\right), 128,3\left(2 \underline{\mathrm{CH}}_{\mathrm{ar}}\right), 128,0\left(2 \underline{\mathrm{CH}}_{\mathrm{ar}}\right), 125,6$ $\left(\underline{\mathrm{C}}_{\mathrm{ar}}\right), 118,7\left(2 \underline{\mathrm{CH}}_{\mathrm{ar}}\right), 118,3\left(2 \underline{\mathrm{CH}}_{\mathrm{ar}}\right), 118,1\left(2 \underline{\mathrm{CH}}_{\mathrm{ar}}\right), 24,1\left(\underline{\mathrm{CH}}_{3}\right)$.

A $1 \mathrm{~g}$ (2 mmoles) del producto I se añadieron $31 \mathrm{~mL}$ de agua destilada y $7 \mathrm{~mL}$ de $\mathrm{HCl}$ conc, calentando la mezcla a reflujo durante $3 \mathrm{~h}$. Tras ajustar el $\mathrm{pH}$ de la disolución a 5,0 con $\mathrm{NH}_{4} \mathrm{OH}$ 6,5 M, el precipitado obtenido se aisló por filtración y se secó a presión reducida. Se obtuvieron $406 \mathrm{mg}$ de un sólido puro de color crema que correspondía al aminoácido deseado, "hapteno S14", con un rendimiento del $44 \%$.

S14

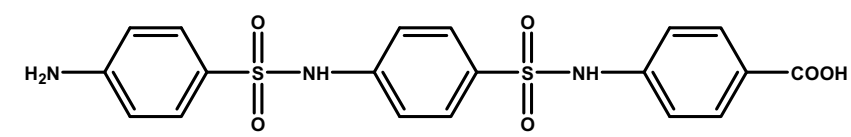

${ }^{1} \mathrm{H}-\mathrm{RMN}\left(300 \mathrm{MHz}, \mathrm{DMSO}-\mathrm{d}_{6}\right) \delta(\mathrm{ppm}): 10,67$ y 10,55 (2H, s, $\left.2 \mathrm{SO}_{2} \mathrm{~N} \underline{\mathrm{H}}\right), 7,78$ y $7,14\left(4 \mathrm{H}, \mathrm{d}, \mathrm{AA}^{\prime} \mathrm{BB}^{\prime}, J=9,0 \mathrm{~Hz}, \mathrm{C}_{\mathrm{Hr}}\right), 7,66$ y $7,17\left(4 \mathrm{H}, \mathrm{d}, \mathrm{AA}^{\prime} \mathrm{BB}^{\prime}, J=8,7 \mathrm{~Hz}\right.$, $\mathrm{C}_{\mathrm{H}}$ ) $), 7,42$ y $6,53\left(4 \mathrm{H}, \mathrm{d}, \mathrm{AA}^{\prime} \mathrm{BB}^{\prime}, J=8,7 \mathrm{~Hz}, \underline{\mathrm{C}}_{\mathrm{ar}}\right), 6,04\left(2 \mathrm{H}, \mathrm{br} \mathrm{s}, \mathrm{N}_{2}\right)$.

${ }^{13} \mathrm{C}-\mathrm{RMN}\left(75,4 \mathrm{MHz}, \mathrm{DMSO}-\mathrm{d}_{6}\right) \delta(\mathrm{ppm}): 166,7(\underline{\mathrm{COOH}}), 153,2,142,9,142,0 \mathrm{y}$ $132,7\left(4 \underline{\mathrm{C}}_{\mathrm{ar}}\right), 130,7\left(2 \underline{\mathrm{CH}}_{\mathrm{ar}-\mathrm{C}-\mathrm{COOH}}\right), 128,8\left(2 \underline{\mathrm{CH}}_{\mathrm{ar}-\mathrm{CSO} 2}\right), 128,2\left(2 \underline{\mathrm{CH}}_{\mathrm{ar}-\mathrm{CSO} 2}\right), 125,5$ (C$\left.\underline{\mathrm{C}}_{\mathrm{ar}}\right), 123,7\left(\mathrm{C}-\underline{\mathrm{C}}_{\mathrm{ar}}\right), 118,1\left(2 \underline{\mathrm{CH}}_{\mathrm{ar}-\mathrm{CNH}}\right), 117,8\left(2 \underline{\mathrm{CH}}_{\mathrm{ar}-\mathrm{CNH}}\right), 112,7\left(2 \underline{\mathrm{CH}}_{\mathrm{ar}-\mathrm{CNH} 2}\right)$.

IR (KBr) $v_{\text {max. }}\left(\mathrm{cm}^{-1}\right): 3258(\mathrm{NH}), 1678(\mathrm{C}=\mathrm{O}), 1607\left(\mathrm{C}_{\mathrm{ar}}=\mathrm{C}_{\mathrm{ar}}\right), 1497\left(\mathrm{C}_{\mathrm{ar}}=\mathrm{C}_{\mathrm{ar}}\right)$, $1321\left(\mathrm{SO}_{2}\right.$, as $)$ y $1153\left(\mathrm{SO}_{2}, \mathrm{sim}\right)$.

MS $m / z$ (fragmento, intensidad relativa): $156\left(\mathrm{C}_{6} \mathrm{H}_{6} \mathrm{NO}_{2} \mathrm{~S}, 17\right), 125\left(\mathrm{C}_{6} \mathrm{H}_{5} \mathrm{OS}, 53\right)$, $93\left(\mathrm{C}_{6} \mathrm{H}_{7} \mathrm{~N}, 100\right), 63$ (HNOS, 63). 


\subsubsection{Haptenos tipo II}

Este tipo de haptenos fueron funcionalizados a través del grupo amino aromático de la región constante (Figura 10).

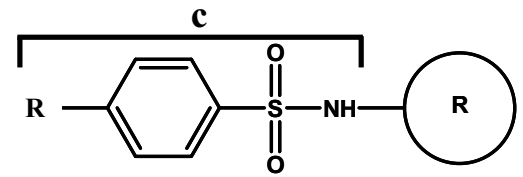

Figura 10. Estructura genérica de los haptenos tipo II para sulfonamidas

\section{Hapteno S5: Sulfasalazina}

La sulfasalazina es un producto comercial que posee un ácido carboxílico, lo que permite su conjugación directa a una proteína carrier, enzima, etc. Por ello, este compuesto se utilizó como hapteno, sin derivatización previa (hapteno S5).

S5

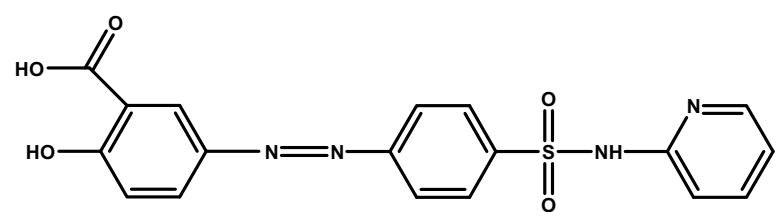

\section{Hapteno S6: $N^{4}$-ftalilsulfatiazol}

El $N^{4}$-ftalilsulfatiazol (PSTZ) es un producto comercial, seleccionado por su similitud con el STZ y por poseer un ácido carboxílico en su estructura, lo que hace posible su acoplamiento directo a proteínas carrier, enzimas, etc. (hapteno S6).

S6<smiles>O=C(O)c1ccccc1C=Cc1ccc(S(=O)(=O)Nc2nccs2)cc1</smiles> 


\section{Síntesis del hapteno S7: Ácido 3-\{4-hidroxi-3-[4-(tiazol-2-ilsulfamoil)fenilazo] fenil\}propanoico}

A una disolución de 5,00 g (19,6 mmoles) de $\mathrm{STZ}$ en $55 \mathrm{~mL}$ de $\mathrm{MeOH}$, se añadieron $70 \mathrm{~mL}$ de $\mathrm{HCl} 1,5 \mathrm{M}$ y se enfrió en baño de hielo. Posteriormente, se adicionó gota a gota una disolución de 1,49 $\mathrm{g}$ (21,6 mmoles) de nitrito sódico en 2 $\mathrm{mL}$ de agua. La temperatura se mantuvo entre 0 y $5{ }^{\circ} \mathrm{C}$, y la sal de diazonio resultante se agitó vigorosamente durante $30 \mathrm{~min}$. Transcurrido este tiempo, la mezcla de reacción fue adicionada lentamente a una disolución de 3,77 g (22,7 mmoles) de ácido 3-(4-hidroxifenil)propanoico en $110 \mathrm{~mL}$ de NaOH $1 \mathrm{M}$. El pH de la mezcla se mantuvo entre 12-13 adicionando $\mathrm{NaOH} 5 \mathrm{M}$. Tras agitar la mezcla durante $2 \mathrm{~h}$ a $10^{\circ} \mathrm{C}$ hasta completar la reacción, ésta se llevó a temperatura ambiente y se agitó de nuevo durante $1 \mathrm{~h}$. Finalmente, se ajustó el $\mathrm{pH}$ de la disolución a 3,0 con $\mathrm{HCl}$ conc, y el precipitado obtenido se aisló por filtración, se lavó con agua destilada fría, y se secó a presión reducida. El ácido 3-\{4-hidroxi-3[4-(thiazol-2-ilsulfamoil)fenilazo]fenil\} propanoico -hapteno S7-, se obtuvo como un sólido rojo que no requirió purificación $(8,25 \mathrm{~g}, 97 \%)$.

S7

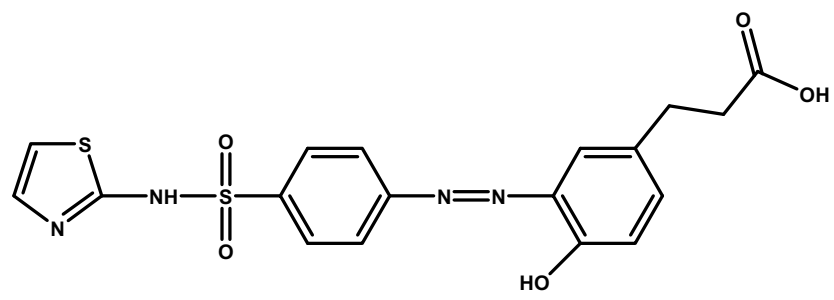

${ }^{1} \mathrm{H}-\mathrm{RMN}\left(300 \mathrm{MHz}, \mathrm{DMSO}-\mathrm{d}_{6}\right) \delta(\mathrm{ppm}): 12,85\left(1 \mathrm{H}\right.$, br s, COO$\underline{\mathrm{H}}$ o $\left.\mathrm{SO}_{2} \mathrm{~N} \underline{\mathrm{H}}\right), 12,12$ $\left(1 \mathrm{H}\right.$, br s, $\mathrm{COO} \underline{\mathrm{H}}$ or $\left.\mathrm{SO}_{2} \mathrm{~N} \underline{\mathrm{H}}\right), 10,87\left(1 \mathrm{H}, \mathrm{s}, \underline{\mathrm{O}}_{\mathrm{ar}}\right), 8,10\left(2 \mathrm{H}, \mathrm{d}, J=8,7 \mathrm{~Hz}, \mathrm{C}_{\mathrm{H}}\right)$, $7,99\left(2 \mathrm{H}, \mathrm{d}, J=8,7 \mathrm{~Hz}, \mathrm{C} \underline{H}_{\mathrm{ar}}\right), 7,60\left(1 \mathrm{H}, \mathrm{d}, J=2,1 \mathrm{~Hz}, \underline{\mathrm{H}}_{\mathrm{ar}}\right), 7,35(1 \mathrm{H}, \mathrm{dd}, J=6,3$ $\left.\mathrm{Hz}, J=2,1 \mathrm{~Hz}, \underline{\mathrm{C}}_{\mathrm{ar}}\right), 7,30\left(1 \mathrm{H}, \mathrm{d}, J=4,5 \mathrm{~Hz}, \underline{\mathrm{H}}_{\mathrm{ar}-\mathrm{N}}\right), 7,02(1 \mathrm{H}, \mathrm{d}, J=8,5 \mathrm{~Hz}$, $\left.\mathrm{C}_{\mathrm{ar}}\right), 6,88\left(1 \mathrm{H}, \mathrm{d}, J=4,5 \mathrm{~Hz}, \mathrm{C}_{\mathrm{ar}-\mathrm{s}}\right), 2,82\left(2 \mathrm{H}, \mathrm{t}, J=7,4 \mathrm{~Hz}, \mathrm{CH}_{2} \mathrm{CH}_{2} \mathrm{COOH}\right)$, $2,55\left(2 \mathrm{H}, \mathrm{t}, J=7,4 \mathrm{~Hz}, \mathrm{CH}_{2} \underline{\mathrm{C}}_{2} \mathrm{COOH}\right)$.

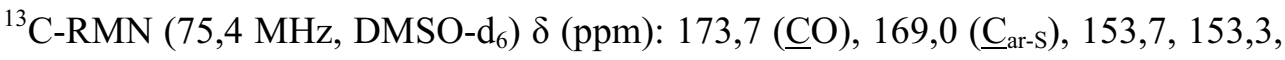
143,7 y $138,3\left(4 \underline{\mathrm{C}}_{\mathrm{ar}}\right), 134,8\left(\underline{\mathrm{CH}}_{\mathrm{ar}}\right), 132,3\left(\underline{\mathrm{C}}_{\mathrm{ar}}\right), 127,1\left(2 \underline{\mathrm{C}} \mathrm{H}_{\mathrm{ar}}\right), 124,6\left(\underline{\mathrm{C}} \mathrm{H}_{\mathrm{ar}-\mathrm{N}}\right), 123,0$ 
$\left(2 \underline{\mathrm{CH}}_{\mathrm{ar}}\right), 120,9$ y $118,3\left(2 \underline{\mathrm{C}} \mathrm{H}_{\mathrm{ar}}\right), 108,6\left(\underline{\mathrm{CH}}_{\mathrm{ar}-\mathrm{S}}\right), 35,2\left(\mathrm{CH}_{2} \underline{\mathrm{CH}}_{2} \mathrm{COOH}\right), 29,3$ $\left(\underline{\mathrm{CH}_{2}} \mathrm{CH}_{2} \mathrm{COOH}\right)$.

IR $(\mathrm{KBr}) v_{\max }\left(\mathrm{cm}^{-1}\right): 3416\left(\mathrm{OH}_{\mathrm{ar}}\right), 3120(\mathrm{NH}), 1687(\mathrm{C}=\mathrm{O}), 1572(\mathrm{~N}=\mathrm{N}), 1535$ (anillo tiazol), $1296\left(\mathrm{SO}_{2}\right.$, as) y $1142\left(\mathrm{SO}_{2}, \mathrm{sim}\right)$.

MS m/z (fragmento, intensidad relativa): $93\left(\mathrm{C}_{6} \mathrm{H}_{7} \mathrm{~N}, 36\right), 63$ (HNOS, 100).

\section{Síntesis del hapteno S8: Ácido 3-\{4-hidroxi-3-[4-(pirimidin-2-ilsulfamoil) fenilazo]fenil\}propanoico}

El hapteno S8 fue preparado siguiendo el procedimiento descrito para la obtención del compuesto $\mathrm{S} 7$. A partir de 2,00 g (8,0 mmoles) de sulfadiazina, 0,61 g (8,8 mmoles) de nitrito sódico y $1,54 \mathrm{~g}$ (9,5 mmoles) de ácido 3-(4hidroxifenil)propanoico, se obtuvieron 2,58 g (76\%) del "hapteno S8" como un sólido anaranjado.

S8

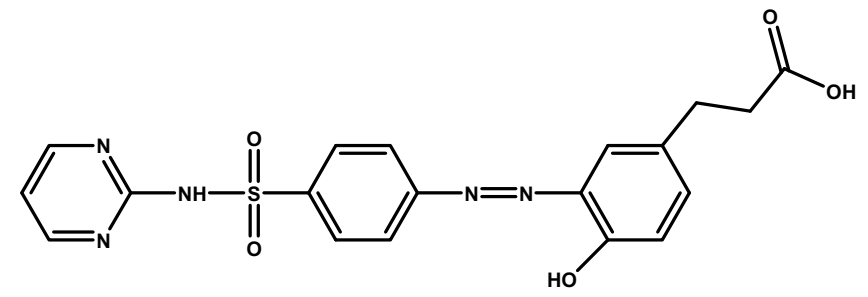

${ }^{1} \mathrm{H}-\mathrm{RMN}\left(300 \mathrm{MHz}, \mathrm{DMSO}-\mathrm{d}_{6}\right) \delta(\mathrm{ppm}): 12,06(1 \mathrm{H}, \mathrm{br}, \mathrm{COO} \underline{\mathrm{H}}), 10,84(1 \mathrm{H}, \mathrm{s}$, $\left.\mathrm{OH}_{\mathrm{ar}}\right), 8,54\left(2 \mathrm{H}, \mathrm{d}, J=4,8 \mathrm{~Hz}, \mathrm{C}_{\mathrm{H}} \mathrm{r}-\mathrm{N}\right), 8,19-8,11\left(4 \mathrm{H}, \mathrm{m}, \mathrm{C}_{\mathrm{Hr}}\right), 7,59(1 \mathrm{H}, \mathrm{d}, J=2,2$ $\left.\mathrm{Hz}, \mathrm{CH}_{\mathrm{ar}}\right), 7,37\left(1 \mathrm{H}, \mathrm{dd}, J=6,3 \mathrm{~Hz}, J=2,2 \mathrm{~Hz}, \mathrm{CH}_{\mathrm{ar}}\right), 7,08\left(1 \mathrm{H}, \mathrm{t}, J=4,8 \mathrm{~Hz}, \mathrm{CH}_{\mathrm{ar}}\right)$, $7,03\left(1 \mathrm{H}, \mathrm{d}, J=8,5 \mathrm{~Hz}, \underline{\mathrm{C}}_{\mathrm{ar}}\right), 2,82\left(2 \mathrm{H}, \mathrm{t}, J=7,4 \mathrm{~Hz}, \underline{\mathrm{C}}_{2} \mathrm{CH}_{2} \mathrm{COOH}\right), 2,56(2 \mathrm{H}, \mathrm{t}$, $\left.J=7,4 \mathrm{~Hz}, \mathrm{CH}_{2} \mathrm{CH}_{2} \mathrm{COOH}\right)$.

${ }^{13} \mathrm{C}-\mathrm{RMN}\left(75,4 \mathrm{MHz}, \mathrm{DMSO}-\mathrm{d}_{6}\right) \delta(\mathrm{ppm}): 173,7(\underline{\mathrm{CO}}), 158,4\left(2 \underline{\mathrm{CH}}_{\mathrm{ar}-\mathrm{N}}\right), 156,8\left(\underline{\mathrm{C}}_{\mathrm{ar}-}\right.$ N), 154,0, 153,8, 141,8 y 138,4 (4 $\left.\underline{\mathrm{C}}_{\mathrm{ar}}\right), 135,0\left(\underline{\mathrm{CH}}_{\mathrm{ar}}\right), 132,3\left(\underline{\mathrm{C}}_{\mathrm{ar}}\right), 128,9$ y 122,8 $\left(2 \underline{\mathrm{CH}}_{\mathrm{ar}}\right), 120,5\left(\underline{\mathrm{CH}}_{\mathrm{ar}}\right), 118,4\left(\underline{\mathrm{CH}}_{\mathrm{ar}}\right), 115,7\left(\underline{\mathrm{CH}}_{\mathrm{ar}}\right), 35,2\left(\mathrm{CH}_{2} \underline{\mathrm{CH}}_{2} \mathrm{COOH}\right), 29,3$ $\left(\mathrm{CH}_{2} \mathrm{CH}_{2} \mathrm{COOH}\right)$. 
IR $(\mathrm{KBr}) v_{\max }\left(\mathrm{cm}^{-1}\right): 3420\left(\mathrm{OH}_{\mathrm{ar}}\right), 3097(\mathrm{NH}), 1682(\mathrm{C}=\mathrm{O}), 1579(\mathrm{~N}=\mathrm{N}), 1340$ $\left(\mathrm{SO}_{2}\right.$, as) y $1169\left(\mathrm{SO}_{2}, \mathrm{sim}\right)$.

MS $m / z$ (fragmento, intensidad relativa): $185\left(\mathrm{C}_{10} \mathrm{H}_{9} \mathrm{~N}_{4}, 15\right), 170\left(\mathrm{C}_{10} \mathrm{H}_{8} \mathrm{~N}_{3}, 28\right), 95$ $\left(\mathrm{C}_{4} \mathrm{H}_{5} \mathrm{~N}_{3}, 53\right), 63$ (HNOS, 100).

\subsubsection{Haptenos tipo III}

Este conjunto de haptenos fueron obtenidos manteniendo invariable la región constante y efectuando la funcionalización a través del grupo sulfonamido (Figura 11).

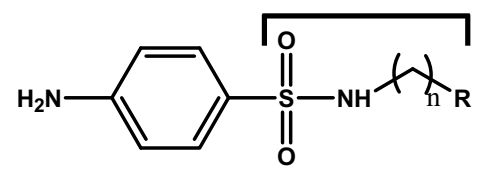

Figura 11. Estructura genérica de los haptenos tipo III para sulfonamidas

\section{Síntesis del hapteno S10: Ácido (4-amino-bencenosulfonilamino)acético}

La síntesis de este hapteno se llevó a cabo siguiendo el procedimiento descrito por Kolloff ${ }^{124}$.

A una disolución de 7,5 g (0,1 moles) de glicina en $50 \mathrm{~mL}$ de agua destilada conteniendo $8,0 \mathrm{~g}(0,2$ moles $)$ de $\mathrm{NaOH}$, se adicionaron lentamente -a $0{ }^{\circ} \mathrm{C}$ y bajo atmósfera de Ar- 23,4 g (0,1 moles) de cloruro de $N$-acetilsulfanililo. Tras $2 \mathrm{~h}$ de agitación a temperatura ambiente y bajo atmósfera de Ar, la disolución se acidificó con $\mathrm{HCl}$ conc y se enfrió a $5{ }^{\circ} \mathrm{C}$, agitándose hasta la aparición de precipitado. El sólido obtenido se recristalizó en una mezcla de EtOH/agua (60:40), obteniendo 19,2 g (71 \%) de un sólido blanco que fue identificado como ácido (4-acetilaminobencenosulfonilamino)acético -producto I-.

Producto I

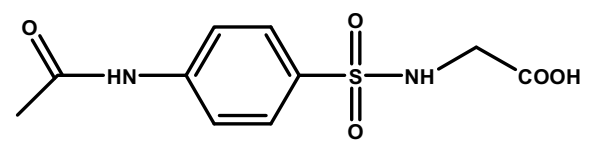


${ }^{1} \mathrm{H}-\mathrm{RMN}(300 \mathrm{MHz}$, DMSO-d 6 ) $\delta(\mathrm{ppm}): 10,31(1 \mathrm{H}, \mathrm{s}, \mathrm{CON} \underline{\mathrm{H}}), 7,90(1 \mathrm{H}, \mathrm{t}, J=6,0$ $\mathrm{Hz}, \mathrm{N} \underline{\mathrm{H}}), 7,80-7,70\left(4 \mathrm{H}, \mathrm{m}, \mathrm{C}_{\mathrm{Har}}\right), 3,56\left(2 \mathrm{H}, \mathrm{d}, J=6,0 \mathrm{~Hz}, \mathrm{C}_{2}\right), 2,09\left(3 \mathrm{H}, \mathrm{s}, \underline{\mathrm{C}}_{3}\right)$.

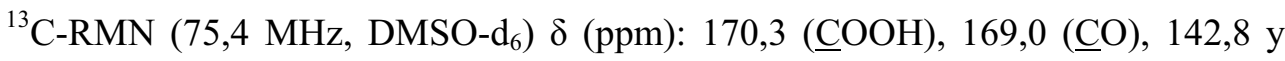
$134,3\left(2 \underline{\mathrm{C}}_{\mathrm{ar}}\right), 127,7\left(2 \underline{\mathrm{CH}}_{\mathrm{ar}}\right), 118,5\left(2 \underline{\mathrm{CH}}_{\mathrm{ar}}\right), 43,8\left(\underline{\mathrm{CH}}_{2}\right), 24,1\left(\underline{\mathrm{C}} \mathrm{H}_{3}\right)$.

A $12,5 \mathrm{~g}$ (45,96 mmoles) del producto I se añadieron $7 \mathrm{~mL}$ de $\mathrm{HCl}$ 4,9 $\mathrm{M}$ y la mezcla resultante se calentó a reflujo durante $35 \mathrm{~min}$. La disolución amarilla obtenida se enfrió a $5{ }^{\circ} \mathrm{C}$ en agitación hasta la aparición del hidrocloruro cristalino. El sólido obtenido se aisló por filtración y se disolvió en una pequeña cantidad de agua destilada. Posteriormente, el pH de la disolución se ajustó a 4,0 con $\mathrm{NaOH} 6$ $\mathrm{M}$ y se enfrió a $5{ }^{\circ} \mathrm{C}$ hasta la aparición de un precipitado que, tras ser filtrado en placa de vidrio, se secó a presión reducida. Como resultado se obtuvo un sólido puro de color blanco $(9,12 \mathrm{~g}, 86 \%)$, que fue identificado como "hapteno S10".

S10

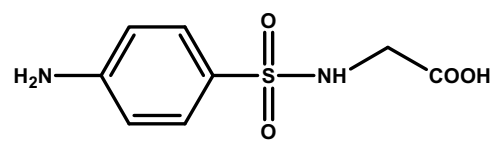

${ }^{1} \mathrm{H}-\mathrm{RMN}\left(300 \mathrm{MHz}\right.$, DMSO-d $\left.\mathrm{d}_{6}\right) \delta(\mathrm{ppm}): 7,38\left(2 \mathrm{H}, \mathrm{d}, J=8,7 \mathrm{~Hz}, 2 \mathrm{CH}_{\mathrm{ar}-\mathrm{CSO} 2}\right), 6,58$ $\left(2 \mathrm{H}, \mathrm{d}, J=8,7 \mathrm{~Hz}, 2 \underline{\mathrm{H}}_{\mathrm{ar}-\mathrm{CNH}}\right), 5,90\left(2 \mathrm{H}, \mathrm{br} \mathrm{s}, \underline{\mathrm{N}}_{2}\right), 2,94\left(2 \mathrm{H}, \mathrm{s}, \mathrm{C}_{2}\right)$.

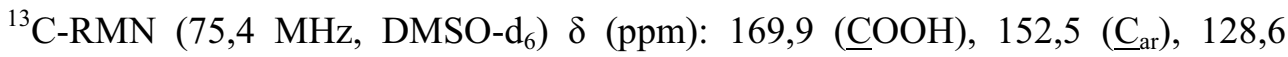
$\left(2 \underline{\mathrm{CH}}_{\mathrm{ar}-\mathrm{CSO} 2}\right), 124,5\left(\underline{\mathrm{C}}_{\mathrm{ar}}\right), 112,6\left(2 \underline{\mathrm{CH}}_{\mathrm{ar}-\mathrm{CNH} 2}\right), 46,1\left(\underline{\mathrm{CH}}_{2}\right)$.

IR (KBr) $v_{\max }\left(\mathrm{cm}^{-1}\right): 3416\left(\mathrm{NH}_{2}\right.$, as), $3331\left(\mathrm{NH}_{2}, \operatorname{sim}\right), 3252(\mathrm{NH}), 1643(\mathrm{C}=\mathrm{O})$, $1601\left(\mathrm{C}_{\mathrm{ar}}=\mathrm{C}_{\mathrm{ar}}\right), 1504\left(\mathrm{C}_{\mathrm{ar}}=\mathrm{C}_{\mathrm{ar}}\right), 1331\left(\mathrm{SO}_{2}\right.$, as $)$ y $1161\left(\mathrm{SO}_{2}, \mathrm{sim}\right)$.

MS $m / z$ (fragmento, intensidad relativa): $172\left(\mathrm{C}_{6} \mathrm{H}_{8} \mathrm{~N}_{2} \mathrm{O}_{2} \mathrm{~S}, 10\right), 156\left(\mathrm{C}_{6} \mathrm{H}_{6} \mathrm{NO}_{2} \mathrm{~S}\right.$, 11), $93\left(\mathrm{C}_{6} \mathrm{H}_{7} \mathrm{~N}, 100\right), 63$ (HNOS, 45). 


\section{Síntesis del hapteno S12: 4-amino- $N$-(3-hidroxipropil)bencenosulfonamida}

La síntesis de este hapteno se llevó a cabo siguiendo una estrategia similar a la descrita por Adams et al. ${ }^{125}$.

A una disolución de 7,5 g (0,1 moles) de 3-amino-1-propanol en $100 \mathrm{~mL}$ de agua destilada, se adicionaron lentamente -a $0{ }^{\circ} \mathrm{C}$ y bajo atmósfera de Ar- $11,7 \mathrm{~g}$ (50 mmoles) de cloruro de $N$-acetilsulfanililo. La mezcla de reacción se agitó durante $2 \mathrm{~h}$ a temperatura ambiente y se enfrió a $0{ }^{\circ} \mathrm{C}$ hasta la aparición de precipitado, el cual se aisló por filtración, se lavó con agua destilada fría, y se secó a presión reducida. La $N$-[4-(3-hidroxipropilsulfamoil)fenil]acetamida -producto Ise obtuvo como un sólido blanco que no requirió purificación $(12,05 \mathrm{~g}, 89 \%)$.

Producto I

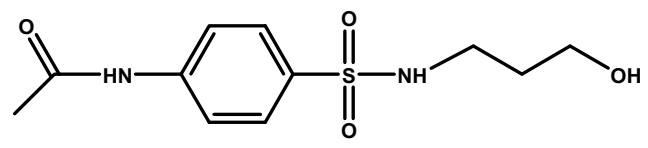

${ }^{1} \mathrm{H}-\mathrm{RMN}\left(300 \mathrm{MHz}, \mathrm{DMSO}-\mathrm{d}_{6}\right) \delta(\mathrm{ppm}): 10,31(1 \mathrm{H}, \mathrm{s}, \mathrm{N} \underline{\mathrm{H}}-\mathrm{CO}), 7,76(2 \mathrm{H}, \mathrm{d}, J=$ $\left.9,0 \mathrm{~Hz}, \mathrm{C}_{\mathrm{ar}}\right), 7,70\left(2 \mathrm{H}, \mathrm{d}, J=9,0 \mathrm{~Hz}, \mathrm{C}_{\mathrm{ar}}\right), 7,37(1 \mathrm{H}, \mathrm{t}, J=6,0 \mathrm{~Hz}, \mathrm{~N} \underline{\mathrm{H}}), 3,35$ $\left(2 \mathrm{H}, \mathrm{t}, J=6,3 \mathrm{~Hz}, \underline{\mathrm{C}}_{2} \mathrm{OH}\right), 2,75\left(2 \mathrm{H}, \mathrm{q}, J=6,6 \mathrm{~Hz}, \underline{\mathrm{CH}}_{2} \mathrm{NH}\right), 2,08\left(3 \mathrm{H}, \mathrm{s}, \underline{\mathrm{C}}_{3}\right)$, $1,49\left(2 \mathrm{H}\right.$, quint, $\left.J=6,9 \mathrm{~Hz}, \underline{\mathrm{C}}_{2}\right)$.

${ }^{13} \mathrm{C}-\mathrm{RMN}\left(75,4 \mathrm{MHz}, \mathrm{DMSO}-\mathrm{d}_{6}\right) \delta(\mathrm{ppm}): 169,0(\underline{\mathrm{COOH}}), 142,6$ y $134,1\left(2 \underline{\mathrm{C}}_{\mathrm{ar}}\right)$, $127,6\left(2 \underline{\mathrm{C}} \mathrm{H}_{\mathrm{ar}}\right), 118,6\left(2 \underline{\mathrm{CH}}_{\mathrm{ar}}\right), 58,0\left(\underline{\mathrm{CH}}_{2} \mathrm{OH}\right), 39,9\left(\underline{\mathrm{CH}}_{2} \mathrm{NH}\right), 32,3\left(\underline{\mathrm{CH}}_{2}\right), 24,1$ $\left(\mathrm{CH}_{3}\right)$.

A $1,5 \mathrm{~g}(5,5$ mmoles $)$ del producto I se añadieron $4 \mathrm{~mL}$ de $\mathrm{HCl} 4,9 \mathrm{M}$, calentando la mezcla resultante durante $35 \mathrm{~min}$ a reflujo. Tras neutralizar la mezcla adicionando carbonato sódico seco, se eliminó el disolvente a presión reducida. El crudo obtenido se recristalizó en una mezcla de EtOH/agua (85:15), obteniendo $691 \mathrm{mg}$ de un sólido blanco que correspondía al aminoalcohol deseado, "hapteno S12", con un rendimiento del 54\%.

S12

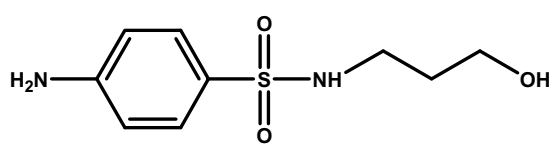


${ }^{1} \mathrm{H}-\mathrm{RMN}\left(300 \mathrm{MHz}, \mathrm{DMSO}-\mathrm{d}_{6}\right) \delta(\mathrm{ppm}): 7,40\left(2 \mathrm{H}, \mathrm{d}, J=8,7 \mathrm{~Hz}, 2 \mathrm{C}_{\mathrm{Har}-\mathrm{CSO}}\right), 6,99$ $(1 \mathrm{H}, \mathrm{t}, J=6,0 \mathrm{~Hz}, \mathrm{~N} \underline{\mathrm{H}}), 6,61\left(2 \mathrm{H}, \mathrm{d}, J=8,7 \mathrm{~Hz}, 2 \underline{\mathrm{H}}_{\mathrm{ar}-\mathrm{CNH}}\right), 5,89\left(2 \mathrm{H}, \mathrm{s}, \underline{\mathrm{N}}_{2}\right)$, $3,35\left(2 \mathrm{H}, \mathrm{t}, J=6,3 \mathrm{~Hz}, \mathrm{C}_{2} \mathrm{OH}\right), 2,69\left(2 \mathrm{H}, \mathrm{q}, J=6,6 \mathrm{~Hz}, \underline{\mathrm{C}}_{2} \mathrm{NH}\right), 1,49$ (2H, quint, $\left.J=6,9 \mathrm{~Hz}, \underline{\mathrm{CH}}_{2}\right)$.

${ }^{13} \mathrm{C}-\mathrm{RMN}\left(75,4 \mathrm{MHz}, \mathrm{DMSO}-\mathrm{d}_{6}\right) \delta(\mathrm{ppm}): 152,3\left(\underline{\mathrm{C}}_{\mathrm{ar}}\right), 128,4\left(2 \underline{\mathrm{CH}}_{\mathrm{ar}-\mathrm{CSO} 2}\right), 125,4$ $\left(\underline{\mathrm{C}}_{\mathrm{ar}}\right), 112,6\left(2 \underline{\mathrm{CH}}_{\mathrm{ar}-\mathrm{CNH} 2}\right), 58,2\left(\underline{\mathrm{CH}}_{2} \mathrm{OH}\right), 39,9\left(\underline{\mathrm{CH}}_{2} \mathrm{NH}\right), 32,2\left(\underline{\mathrm{CH}}_{2}\right)$.

IR (KBr) $v_{\max }\left(\mathrm{cm}^{-1}\right): 3385\left(\mathrm{NH}_{2}\right.$, as), $3300\left(\mathrm{NH}_{2}, \mathrm{sim}\right), 2940$ y $2882\left(\mathrm{CH}_{2}\right), 1601$ $\left(\mathrm{C}_{\mathrm{ar}}=\mathrm{C}_{\mathrm{ar}}\right), 1501\left(\mathrm{C}_{\mathrm{ar}}=\mathrm{C}_{\mathrm{ar}}\right), 1306\left(\mathrm{SO}_{2}\right.$, as $)$ y $1155\left(\mathrm{SO}_{2}, \operatorname{sim}\right)$.

MS $m / z$ (fragmento, intensidad relativa): $230\left(\mathrm{M}^{+}, 20\right), 185\left(\mathrm{C}_{7} \mathrm{H}_{9} \mathrm{~N}_{2} \mathrm{O}_{2} \mathrm{~S}, 27\right), 156$ $\left(\mathrm{C}_{6} \mathrm{H}_{6} \mathrm{NO}_{2} \mathrm{~S}, 100\right), 108\left(\mathrm{C}_{6} \mathrm{H}_{6} \mathrm{NO}, 36\right), 93\left(\mathrm{C}_{6} \mathrm{H}_{7} \mathrm{~N}, 69\right), 92\left(\mathrm{C}_{6} \mathrm{H}_{6} \mathrm{~N}, 56\right), 65\left(\mathrm{C}_{5} \mathrm{H}_{5}\right.$, $36)$.

\section{Síntesis del hapteno S13: Ácido 4-(4-amino-bencenosulfonilamino)butanoico}

El hapteno S13 fue preparado siguiendo el procedimiento descrito para la obtención del hapteno S10, a excepción del tiempo de agitación que, en este caso, fue de $3 \mathrm{~h}$.

A partir de 5,2 g (50 mmoles) de ácido 4-aminobutanoico y 11,7 g (50 mmoles) de cloruro de $\mathrm{N}$-acetilsulfanililo, se obtuvieron 10,4 g (69\%) de ácido 4-(4acetilamino-bencenosulfonilamino)butanoico -producto I- como un sólido blanco.

Producto I

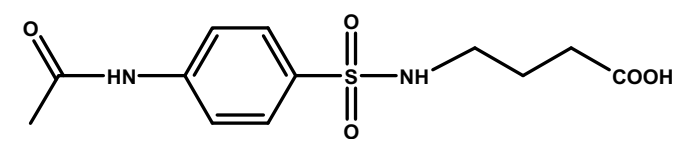

${ }^{1} \mathrm{H}-\mathrm{RMN}\left(300 \mathrm{MHz}, \mathrm{DMSO}-\mathrm{d}_{6}\right) \delta(\mathrm{ppm}): 12,03(\mathrm{COO} \underline{\mathrm{H}}), 10,30(1 \mathrm{H}, \mathrm{s}, \mathrm{N} \underline{\mathrm{HCO}})$, 7,76 (2H, d, $\left.J=9,0 \mathrm{~Hz}, \underline{\mathrm{C}}_{\mathrm{ar}}\right), 7,69\left(2 \mathrm{H}, \mathrm{d}, J=9,0 \mathrm{~Hz}, \mathrm{C}_{\mathrm{ar}}\right), 7,47(1 \mathrm{H}, \mathrm{t}, J=6,0$ $\mathrm{Hz}, \mathrm{N} \underline{\mathrm{H}}), 2,72\left(2 \mathrm{H}, \mathrm{q}, J=6,3 \mathrm{~Hz}, \underline{\mathrm{C}}_{2} \mathrm{NH}\right), 2,20\left(2 \mathrm{H}, \mathrm{t}, J=7,5 \mathrm{~Hz}, \underline{\mathrm{H}}_{2} \mathrm{CO}\right), 2,08$ $\left(3 \mathrm{H}, \mathrm{s}, \mathrm{C}_{3}\right), 1,57$ (2H, quint, $\left.J=7,2 \mathrm{~Hz}, \underline{\mathrm{C}}_{2}\right)$. 
${ }^{13} \mathrm{C}-\mathrm{RMN}\left(75,4 \mathrm{MHz}, \mathrm{DMSO}-\mathrm{d}_{6}\right) \delta(\mathrm{ppm}): 174,0(\underline{\mathrm{COOH}}), 169,0(\underline{\mathrm{CO}}), 142,7$ у $134,1\left(\underline{\mathrm{C}}_{\mathrm{ar}}\right), 127,6\left(2 \underline{\mathrm{CH}}_{\mathrm{ar}}\right), 118,6\left(2 \underline{\mathrm{CH}}_{\mathrm{ar}}\right), 41,9\left(\underline{\mathrm{CH}}_{2} \mathrm{NH}\right), 30,6\left(\underline{\mathrm{C}}_{2} \mathrm{CO}\right), 24,5$ $\left(\underline{\mathrm{CH}}_{2}\right), 24,1\left(\underline{\mathrm{CH}}_{3}\right)$.

La hidrólisis ácida de $2 \mathrm{~g}$ (6,7 mmoles) del producto I permitió obtener 1,0 g de un sólido puro de color blanco que correspondía al aminoácido deseado, "hapteno S13", con un rendimiento del 58\%.

S13

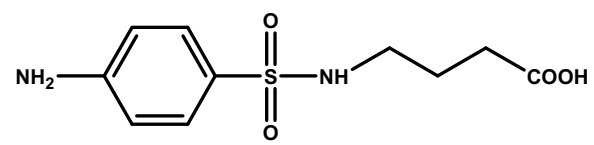

${ }^{1} \mathrm{H}-\mathrm{RMN}\left(300 \mathrm{MHz}, \mathrm{DMSO}-\mathrm{d}_{6}\right) \delta(\mathrm{ppm}): 12,02(1 \mathrm{H}, \mathrm{s}, \mathrm{COOH}), 7,39(2 \mathrm{H}, \mathrm{d}, J=$ $\left.8,7 \mathrm{~Hz}, 2 \underline{\mathrm{C}}_{\mathrm{ar}-\mathrm{CSO}}\right), 7,09(1 \mathrm{H}, \mathrm{t}, J=6,0 \mathrm{~Hz}, \mathrm{~N} \underline{\mathrm{H}}), 6,60\left(2 \mathrm{H}, \mathrm{d}, J=8,7 \mathrm{~Hz}, 2 \underline{\mathrm{H}}_{\mathrm{ar}-}\right.$ $\left.\mathrm{CNH}_{2}\right), 5,90\left(2 \mathrm{H}\right.$, br s, $\left.\underline{\mathrm{N}}_{2}\right), 2,66\left(2 \mathrm{H}, \mathrm{q}, J=6,6 \mathrm{~Hz}, \underline{\mathrm{C}}_{2} \mathrm{NH}\right), 2,19(2 \mathrm{H}, \mathrm{t}, J=7,2$ $\left.\mathrm{Hz}, \underline{\mathrm{C}}_{2} \mathrm{COOH}\right), 1,57$ (2H, quint, $\left.J=7,2 \mathrm{~Hz}, \mathrm{C}_{2}\right)$.

${ }^{13} \mathrm{C}-\mathrm{RMN}\left(75,4 \mathrm{MHz}, \mathrm{DMSO}-\mathrm{d}_{6}\right) \delta(\mathrm{ppm}): 174,0(\underline{\mathrm{COOH}}), 152 ; 3\left(\underline{\mathrm{C}}_{\mathrm{ar}}\right), 128,3$ $\left(2 \underline{\mathrm{CH}}_{\mathrm{ar}-\mathrm{CSO} 2}\right), 125,5\left(\underline{\mathrm{C}}_{\mathrm{ar}}\right), 112,9\left(2 \underline{\mathrm{CH}}_{\mathrm{ar}-\mathrm{CNH} 2}\right), 41,8\left(\underline{\mathrm{CH}}_{2} \mathrm{NH}\right), 30,7\left(\underline{\mathrm{CH}}_{2} \mathrm{CO}\right), 24,4$ $\left(\mathrm{CH}_{2}\right)$.

IR $(\mathrm{KBr}) v_{\max }\left(\mathrm{cm}^{-1}\right): 3414\left(\mathrm{NH}_{2}\right.$, as $), 3335\left(\mathrm{NH}_{2}, \operatorname{sim}\right), 3219(\mathrm{NH}), 2970$ y 2949 $\left(\mathrm{CH}_{2}\right), 1697(\mathrm{C}=\mathrm{O}), 1597\left(\mathrm{C}_{\mathrm{ar}}=\mathrm{C}_{\mathrm{ar}}\right), 1501\left(\mathrm{C}_{\mathrm{ar}}=\mathrm{C}_{\mathrm{ar}}\right), 1306\left(\mathrm{SO}_{2}\right.$, as $)$ y $1148\left(\mathrm{SO}_{2}\right.$, $\operatorname{sim})$.

MS $m / z$ (fragmento, intensidad relativa): $258\left(\mathrm{M}^{+}, 4\right), 156\left(\mathrm{C}_{6} \mathrm{H}_{6} \mathrm{NO}_{2} \mathrm{~S}, 30\right), 93$ $\left(\mathrm{C}_{6} \mathrm{H}_{7} \mathrm{~N}, 100\right), 63$ (HNOS, 59).

\section{Síntesis del hapteno S11: Ácido 6-(4-amino-bencenosulfonilamino)hexanoico}

A una disolución de 2,62 g (20 mmoles) de ácido 6-aminohexanoico en $20 \mathrm{~mL}$ de agua destilada conteniendo $1,6 \mathrm{~g}$ (40 mmoles) de $\mathrm{NaOH}$, se adicionaron lentamente -bajo atmósfera de $\mathrm{Ar}-4,4 \mathrm{~g}$ (20 mmoles) de cloruro de 4nitrobencenosulfonilo. Finalizada la adición, se elevó la temperatura a $65{ }^{\circ} \mathrm{C}$, 
agitando la mezcla de reacción durante 30 min. A continuación, se llevó a temperatura ambiente y se enfrió a $0{ }^{\circ} \mathrm{C}$, tras lo cual, se ajustó el $\mathrm{pH}$ de la disolución a 1,0 con $\mathrm{HCl}$ conc hasta precipitación, apareciendo un sólido de color amarillo. El producto se aisló por filtración y se recristalizó en una mezcla de EtOH/agua (50:50), obteniendo 3,8 g (60\%) de un sólido marrón claro que fue identificado como ácido 6-(4-nitro-bencenosulfonilamino)hexanoico -producto I-.

Producto I

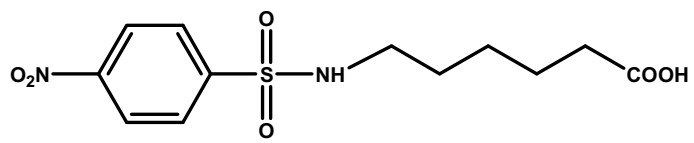

${ }^{1} \mathrm{H}-\mathrm{RMN}\left(300 \mathrm{MHz}, \mathrm{DMSO}-\mathrm{d}_{6}\right) \delta(\mathrm{ppm}): 8,42\left(2 \mathrm{H}, \mathrm{d}, J=9,0 \mathrm{~Hz}, 2 \mathrm{CH}_{\mathrm{ar}-\mathrm{CNO}}\right), 8,05$ $\left(2 \mathrm{H}, \mathrm{d}, J=9,0 \mathrm{~Hz}, 2 \mathrm{C}_{\mathrm{Har}-\mathrm{CSO}}\right), 7,98(1 \mathrm{H}, \mathrm{t}, J=5,7 \mathrm{~Hz}, \mathrm{~N} \underline{\mathrm{H}}), 2,79(2 \mathrm{H}, \mathrm{q}, J=6,9$ $\left.\mathrm{Hz}, \underline{\mathrm{C}}_{2} \mathrm{NH}\right), 2,14\left(2 \mathrm{H}, \mathrm{t}, J=7,2 \mathrm{~Hz}, \underline{\mathrm{C}}_{2} \mathrm{COOH}\right), 1,47-1,30\left(4 \mathrm{H}, \mathrm{m}, 2 \underline{\mathrm{C}}_{2}\right), 1,28-$ $1,15\left(2 \mathrm{H}, \mathrm{m}, \mathrm{C}_{2}\right)$.

${ }^{13} \mathrm{C}-\mathrm{RMN}\left(75,4 \mathrm{MHz}, \mathrm{DMSO}-\mathrm{d}_{6}\right) \delta(\mathrm{ppm}): 174,3(\underline{\mathrm{COOH}}), 149,5$ y $146,2\left({ }^{2} \underline{\mathrm{C}}_{\mathrm{ar}}\right)$, $128,0\left(2 \underline{\mathrm{CH}}_{\mathrm{ar}-\mathrm{CSO}}\right), 124,6\left(2 \underline{\mathrm{CH}}_{\mathrm{ar}-\mathrm{CNO} 2}\right), 42,4\left(\underline{\mathrm{CH}}_{2} \mathrm{NH}\right), 33,5\left(\underline{\mathrm{CH}_{2} \mathrm{CO}}\right), 28,7\left(\underline{\mathrm{CH}}_{2}\right)$, 25,5 y $24,0\left(2 \mathrm{CH}_{2}\right)$.

Una disolución de 1,4 g (4,43 mmoles) del producto I en $70 \mathrm{~mL}$ de EtOH, se agitó bajo atmósfera de $\mathrm{H}_{2}$ en presencia de $\mathrm{Pd} / \mathrm{C}$ al $5 \%(120 \mathrm{mg})$ durante $4 \mathrm{~h}$. A continuación, se eliminó el catalizador por filtración y el filtrado se concentró a presión reducida, obteniéndose un sólido blanquecino como producto de reducción. La purificación del sólido por cromatografía en columna sobre gel de sílice con hexano/AcOEt de polaridad creciente, permitió obtener el "hapteno S11" (900 mg, $71 \%$ ) como un sólido amarillento.

S11

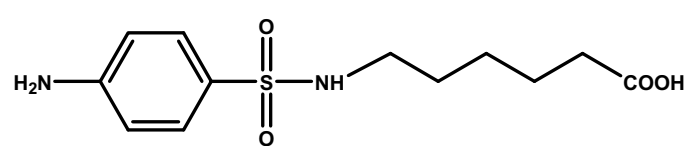

${ }^{1} \mathrm{H}-\mathrm{RMN}\left(300 \mathrm{MHz}, \mathrm{DMSO}_{\mathrm{d}}\right) \delta(\mathrm{ppm}): 11,95(1 \mathrm{H}, \mathrm{s}, \mathrm{COOH}), 7,40(2 \mathrm{H}, \mathrm{d}, J=$ $\left.8,7 \mathrm{~Hz}, 2 \underline{\mathrm{H}}_{\mathrm{ar}-\mathrm{CSO} 2}\right), 6,60\left(2 \mathrm{H}, \mathrm{d}, J=8,7 \mathrm{~Hz}, 2 \underline{\mathrm{H}}_{\mathrm{ar}-\mathrm{CNH} 2}\right), 7,04(1 \mathrm{H}, \mathrm{t}, J=6,0 \mathrm{~Hz}$, 
$\mathrm{N} \underline{\mathrm{H}}), 5,85\left(2 \mathrm{H}\right.$, br s, $\left.\underline{\mathrm{H}}_{2}\right), 2,62\left(2 \mathrm{H}, \mathrm{q}, J=6,6 \mathrm{~Hz}, \underline{\mathrm{C}}_{2} \mathrm{NH}\right), 2,15(2 \mathrm{H}, \mathrm{t}, J=7,2$ $\left.\mathrm{Hz}, \underline{\mathrm{C}}_{2} \mathrm{COOH}\right), 1,47-1,27$ (4H, m, 2C $\left.\underline{\mathrm{H}}_{2}\right), 1,27-1,19$ (2H, m, $\left.\underline{\mathrm{C}}_{2}\right)$.

${ }^{13} \mathrm{C}-\mathrm{RMN}\left(75,4 \mathrm{MHz}, \mathrm{DMSO}-\mathrm{d}_{6}\right) \delta(\mathrm{ppm}): 174,4(\underline{\mathrm{COOH}}), 152,3\left(\underline{\mathrm{C}}_{\mathrm{ar}}\right), 128,4$ $\left(2 \underline{\mathrm{CH}}_{\mathrm{ar}-\mathrm{CSO} 2}\right), 125,6\left(\underline{\mathrm{C}}_{\mathrm{ar}}\right), 112,6\left(2 \underline{\mathrm{CH}}_{\mathrm{ar}-\mathrm{CNH} 2}\right), 42,3\left(\underline{\mathrm{CH}}_{2} \mathrm{NH}\right), 33,5\left(\underline{\mathrm{CH}}_{2} \mathrm{CO}\right), 28,6$, 25,7 y $24,1\left(3 \underline{\mathrm{CH}}_{2}\right)$.

IR $(\mathrm{KBr}) v_{\max }\left(\mathrm{cm}^{-1}\right): 3414\left(\mathrm{NH}_{2}\right.$, as $), 3327\left(\mathrm{NH}_{2}, \operatorname{sim}\right), 3123(\mathrm{NH}), 2947$ y 2859 $\left(\mathrm{CH}_{2}\right), 1697(\mathrm{C}=\mathrm{O}), 1597\left(\mathrm{C}_{\mathrm{ar}}=\mathrm{C}_{\mathrm{ar}}\right), 1501\left(\mathrm{C}_{\mathrm{ar}}=\mathrm{C}_{\mathrm{ar}}\right), 1304\left(\mathrm{SO}_{2}\right.$, as $)$ y $1144\left(\mathrm{SO}_{2}\right.$, $\operatorname{sim})$.

MS $m / z$ (fragmento, intensidad relativa): $286\left(\mathrm{M}^{+}, 5\right), 156\left(\mathrm{C}_{6} \mathrm{H}_{6} \mathrm{NO}_{2} \mathrm{~S}, 47\right), 93$ $\left(\mathrm{C}_{6} \mathrm{H}_{7} \mathrm{~N}, 100\right), 63$ (HNOS, 40). 


\subsubsection{Síntesis de haptenos para tetraciclinas}

Los compuestos pertenecientes a la familia de las tetraciclinas, muy similares entre si, se caracterizan por tener un esqueleto común de octahidronaftaceno formado por cuatro anillos ( $A, B, C$ y D), siendo $R_{1}, R_{2}, R_{3}, R_{4}$ y $R_{5}$ los radicales que dan lugar a los diferentes compuestos que constituyen dicha familia (Figura 12).

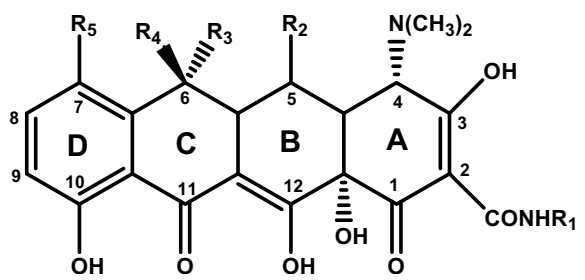

Figura 12. Estructura general de las tetraciclinas

Se han sintetizado dos tipos de haptenos que, manteniendo el esqueleto común característico de las tetraciclinas, presentan diferentes grupos y brazos espaciadores, tanto alifáticos como aromáticos. Asimismo, los haptenos se han agrupado en función de la aproximación sintética utilizada, de ahí que la nomenclatura no sea correlativa.

Los haptenos obtenidos para tetraciclinas (excepto OTC-3) no han podido caracterizarse inequívocamente; debido a su baja estabilidad, rápidamente se forman productos de degradación, isomerización y complejos, proporcionando espectros con señales difíciles de interpretar (ver sección 4.1.2, Resultados).

\subsubsection{Haptenos tipo I}

Este tipo de haptenos fueron obtenidos efectuando la funcionalización a través del radical $\mathrm{R}_{1}$ del anillo A de octahidronaftaceno (Figura 13).

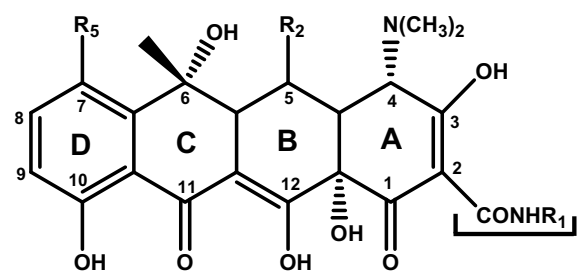

Figura 13. Estructura genérica de los haptenos tipo I para tetraciclinas 


\section{Síntesis del hapteno CTC-2: Glicinametilclortetraciclina}

Este hapteno, derivado de la clortetraciclina, fue obtenido siguiendo una estrategia similar a la patentada por Lazareva et al. ${ }^{126}$. La reacción se llevó a cabo bajo atmósfera inerte (Ar), protegida de la luz y con agitación magnética. En un matraz de fondo redondo de tres bocas provisto de un refrigerante y dos embudos de adición, se introdujeron $106 \mathrm{~mL}$ de $\mathrm{MeOH}$ que se calentaron a $50-55^{\circ} \mathrm{C}$ en un baño de agua. Tras adicionar 17,50 g (33,96 mmoles) de CTC, lentamente y con agitación vigorosa, se añadieron, gota a gota, $7,33 \mathrm{~mL}$ de una disolución acuosa de glicina 2,64 M, utilizando un embudo de adición compensada. Después de enfriar la mezcla a $40{ }^{\circ} \mathrm{C}$, se adicionaron simultáneamente y gota a gota, $2,17 \mathrm{~mL}$ de disolución acuosa de formaldehído al 37\% y 3,67 mL de una disolución acuosa de glicina $(2,64 \mathrm{M})$, se agitó durante 15 min y se filtró en caliente por gravedad para eliminar el producto sin reaccionar. El filtrado se enfrió a $5{ }^{\circ} \mathrm{C}$, protegido de la luz y con agitación magnética, hasta la aparición de precipitado $(5 \mathrm{~h})$. Finalmente, el sólido se aisló por filtración, se lavó con agua destilada fría, y se secó a presión reducida. El hapteno CTC-2 se obtuvo como un sólido ocre puro (0,213 g, 1\%).

CTC-2

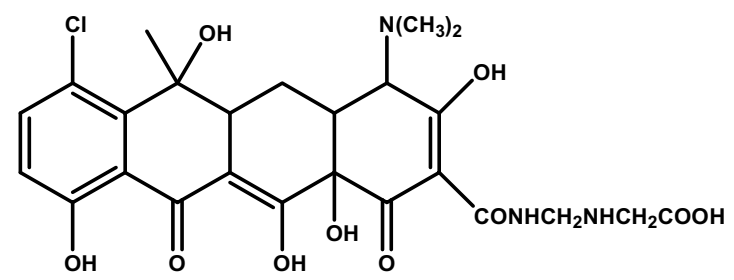

\section{Síntesis del hapteno OTC-2: Hidrocloruro de glicinametiloxitetraciclina}

El hapteno OTC-2 se obtuvo mezclando $225 \mathrm{~mL}$ de $\mathrm{MeOH}, 35,89 \mathrm{~g}(72,28$ mmoles) de oxitetraciclina, 4,62 $\mathrm{mL}$ de formaldehído aq al 37\% y $23,25 \mathrm{~mL}$ de una disolución acuosa de glicina $(2,66 \mathrm{M})$, siguiendo el procedimiento descrito para la obtención de CTC-2. En este caso, la OTC en exceso se eliminó tras acidificar ligeramente con $\mathrm{HCl} 6 \mathrm{M}$. Una segunda acidificación con $\mathrm{HCl} 6 \mathrm{M}$ proporcionó el hapteno deseado como un sólido amarillento (1,08 g, 3\%). 
OTC-2<smiles>CC1(O)c2cccc(O)c2C(=O)C2=C(O)C3(O)C(=O)C(OCCC(=O)O)=C(O)C([N+](C)(C)C)C3C(O)C21</smiles>

\section{Hapteno TC-3:Tetralisal (2- $N$-lisinometiltetraciclina)}

La tetraciclina comercial Tetralisal posee en su estructura un ácido carboxílico que permite su conjugación directa a proteínas, conservando su estructura específica en el conjugado. Por este motivo, se utilizó como hapteno TC-3 $\sin$ modificar.

TC-3

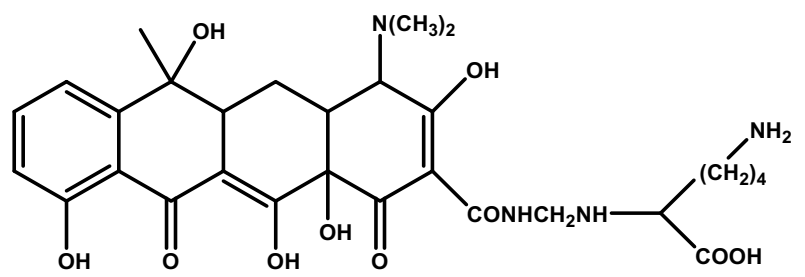

\subsubsection{Haptenos tipo II}

Este tipo de haptenos fueron obtenidos efectuando la funcionalización a través del anillo D del esqueleto común de octahidronaftaceno (Figura 14).

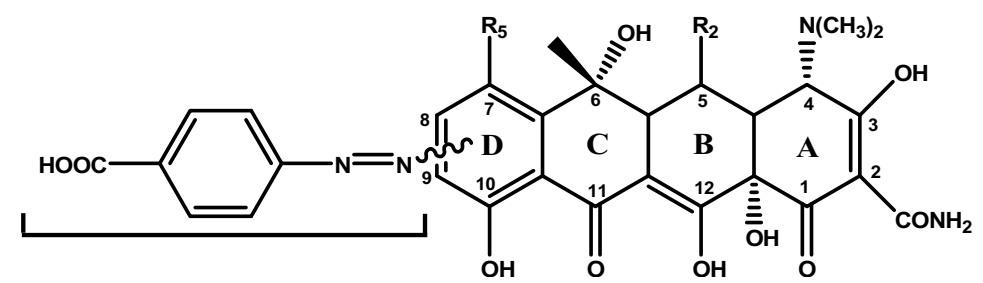

Figura 14. Estructura genérica de los haptenos tipo II para tetraciclinas 


\section{Síntesis del hapteno OTC-3: Hidrocloruro de 7 y 9-(4'-carboxifenilazo) oxitetraciclina}

Para la síntesis de este compuesto se disolvió 1,00 g (7,29 mmoles) de ácido 4aminobenzoico en $14 \mathrm{~mL}$ de $\mathrm{HCl} 2 \mathrm{M}$, enfriando la disolución resultante en baño de hielo. A continuación, se adicionaron gota a gota $0,62 \mathrm{~g}(9,01 \mathrm{mmoles})$ de nitrito sódico disueltos en $1 \mathrm{~mL}$ de agua, manteniendo la temperatura por debajo de $5{ }^{\circ} \mathrm{C}$, agitando durante $10 \mathrm{~min}$ la disolución de la sal de diazonio resultante. La mezcla de reacción se adicionó lentamente a una disolución de 3,61 g (7,27 mmoles) de OTC en $40 \mathrm{~mL} \mathrm{NaOH} \mathrm{0,2} \mathrm{M.} \mathrm{El} \mathrm{pH} \mathrm{de} \mathrm{la} \mathrm{mezcla} \mathrm{se} \mathrm{mantuvo} \mathrm{entre} \mathrm{8-9} \mathrm{mediante} \mathrm{la}$ adición de carbonato de sodio sólido. La mezcla se agitó durante $2 \mathrm{~h} \mathrm{a} 0{ }^{\circ} \mathrm{C}$, se llevó a temperatura ambiente, y se agitó de nuevo durante $1 \mathrm{~h}$. La OTC en exceso se eliminó de la mezcla después de una ligera acidificación con $\mathrm{HCl} 6 \mathrm{M}$. Finalmente, el pH del filtrado se ajustó a 3,0 con $\mathrm{HCl}$ conc y el precipitado se aisló por filtración, se lavó con agua destilada fría, y se secó a presión reducida. El hidrocloruro de 7 ó 9-(4'-carboxifenilazo)oxitetraciclina (hapteno OTC-3), se obtuvo como un sólido anaranjado $(3,18 \mathrm{~g}, 68 \%)$. Para caracterizar la zona aromática del "hapteno OTC-3", se purificó una pequeña porción del sólido por HPLC, en modo gradiente -ácido oxálico $0,01 \mathrm{M}(\mathrm{pH} 2)$ : metanol: acetonitrilo desde 50:25:25 hasta 50:0:50 en 27 min y desde 50:0:50 hasta 50:25:25 en 20 minmanteniendo un flujo de $6 \mathrm{~mL} / \mathrm{min}$, volumen inyección $200 \mu \mathrm{L}$ y detector UV-VIS operando a $265 \mathrm{~nm}$.

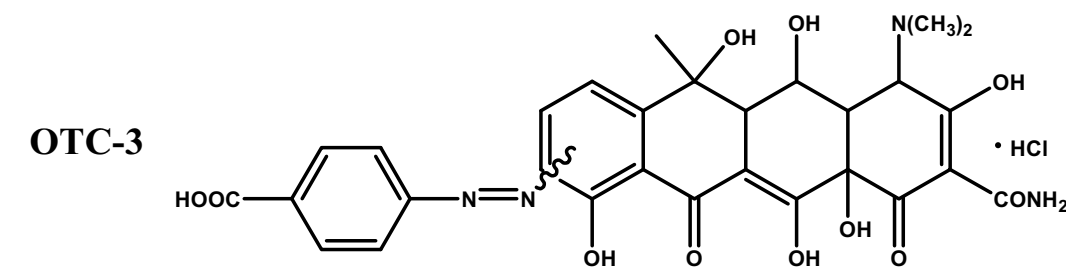

${ }^{1} \mathrm{H}-\mathrm{RMN}\left(300 \mathrm{MHz}, \mathrm{DMSO}-\mathrm{d}_{6}\right) \delta(\mathrm{ppm}): 7,83\left(2 \mathrm{H}, \mathrm{d}, J=8,7 \mathrm{~Hz}, \mathrm{C}_{\mathrm{ar}}\right), 7,61(1 \mathrm{H}$, $\left.\mathrm{d}, J=8,1 \mathrm{~Hz}, \underline{\mathrm{C}}_{\mathrm{ar}}\right), 7,58\left(1 \mathrm{H}, \mathrm{d}, J=8,4 \mathrm{~Hz}, \underline{\mathrm{H}}_{\mathrm{ar}}\right), 7,18\left(2 \mathrm{H}, \mathrm{d}, J=8,7 \mathrm{~Hz}, \mathrm{C}_{\mathrm{ar}}\right)$, $7,12\left(1 \mathrm{H}, \mathrm{d}, J=8,1 \mathrm{~Hz}, \mathrm{C} \underline{H}_{\mathrm{ar}}\right), 6,98\left(1 \mathrm{H}, \mathrm{d}, J=8,4 \mathrm{~Hz}, \underline{\mathrm{CH}}_{\mathrm{ar}}\right)$. 


\section{Síntesis del hapteno CTC-3: Hidrocloruro de 9-(4'-carboxifenilazo) clortetraciclina}

El compuesto CTC-3 se sintetizó siguiendo el procedimiento descrito para el hapteno OTC-3, utilizando $0,69 \mathrm{~g}$ (5,01 mmoles) de ácido 4-aminobenzoico, 0,48 g (7,00 mmoles) de nitrito sódico y 2,58 g (5,00 mmoles) de CTC. La mezcla de reacción se agitó durante $2 \mathrm{~h} 15 \mathrm{~min}$ a $0{ }^{\circ} \mathrm{C}$, y el pH se ajustó a 9 con carbonato de sodio sólido para completar la reacción. Tras la acidificación con $\mathrm{HCl}$, el producto deseado se obtuvo como un sólido naranja (0,73 g, 23\%).<smiles>CCCCN(C)C1C(O)=C(C(N)O)C(=O)C2(O)C(O)=C3C(=O)c4c(O)c(N=Nc5ccc(C(=O)O)cc5)cc(Cl)c4C(C)(O)C3CC12</smiles>

\section{Síntesis del hapteno TC-4: Hidrocloruro de 7 y 9-(4'-carboxifenilazo) tetraciclina}

El hapteno TC-4 fue preparado siguiendo el procedimiento descrito para la obtención del OTC-3. A partir de 1,12 g (8,14 mmoles) de ácido 4-aminobenzoico, $0,61 \mathrm{~g}(8,82$ mmoles $)$ de nitrito sódico y $3,47 \mathrm{~g}$ (7,80 mmoles) de tetraciclina, se obtuvieron 8,25 g (97\%) del hapteno TC-4 como un sólido rojizo. En este caso, la mezcla se agitó durante $2 \mathrm{~h}$ a $10{ }^{\circ} \mathrm{C}$, y el pH se mantuvo entre 9-10 para completar la reacción, eliminando la TC en exceso por filtración.

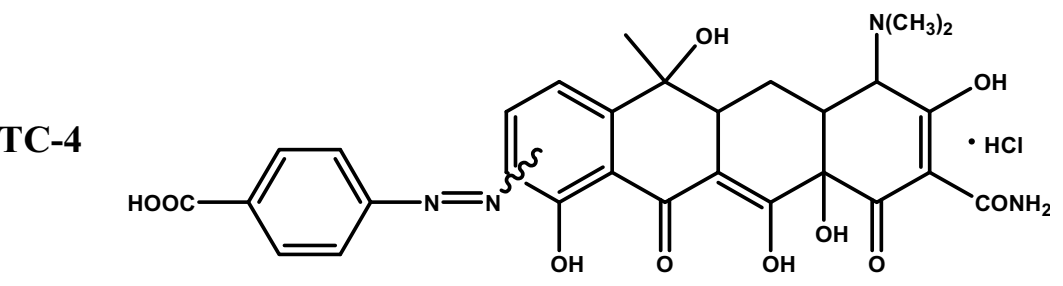




\subsection{DESARROLLO DE INMUNOENSAYOS}

\subsubsection{Instrumentación}

\section{Equipos instrumentales}

La densidad óptica fue medida a dos longitudes de onda -490 y $650 \mathrm{~nm}$-, utilizando un lector de placas marca Wallac (Turku, Finlandia), modelo Victor 1420 multilabel counter.

Las medidas de absorbancia para el control de la eficacia en la preparación de los conjugados hapténicos y trazadores enzimáticos, se realizaron utilizando un espectrofotómetro de fila de diodos Hewlett Packard 8452 (Palo Alto, CA, EE. UU.).

Para el lavado de las placas se utilizó un lavador de microplacas Nunc Inmuno Wash 12 (Nunc MaxiSarp, Roskilde, Dinamarca).

El procesamiento de los datos se llevó cabo utilizando el paquete informático Sigmaplot 9.0 (Jandel Scientific, Erkrath, Alemania).

\section{Otros materiales}

- Placas ELISA de poliestireno de 96 pocillos (Costar Corporation, Cambridge, MA, EE.UU.)

- Columnas de exclusión molecular D-Salt Dextran (Pierce, Rockford, IL, EE. UU.)

- Cartuchos de extracción en fase sólida (Phenomenex, Torrance, CA, EE.UU.): Strata C18-E (500 mg), con soporte de partículas de sílice funcionalizadas con C18; Strata-X (200 mg), basados en un polímero de estireno-divinilbenceno de superficie modificada; Strata X-C (500 mg), de intercambio catiónico 


\subsubsection{Reactivos y disoluciones}

\section{Reactivos químicos}

Los patrones de las sulfonamidas y tetraciclinas objeto de estudio, así como los compuestos de estructura similar utilizados para la determinación de la selectividad de los inmunoensayos, fueron adquiridos a las empresas Fluka-Sigma-Aldrich Química (Madrid, España) y Acros Organics (Geel, Bélgica).

Las disoluciones estándar se prepararon en hidróxido de sodio $0,5 \mathrm{M}$ y $N, N$ 'dimetilformamida, para la familia de las sulfonamidas, y en metanol para la familia de las tetraciclinas; en ambos casos se almacenaron a $-20{ }^{\circ} \mathrm{C}$ hasta su uso.

Las proteínas BSA y OVA, la enzima HRP, la inmunoglobulina G de cabra anti-conejo marcada con HRP (GAR-HRP), el adyuvante de Freund's completo e incompleto, y los reactivos $o$-fenilendiamina (OPD) y polioxietilensorbitan monolaurato (Tween 20), fueron suministrados por Fluka-Sigma-Aldrich Química (Madrid, España). La hemocianina del molusco Megathura crenulata (KLH) fue adquirida a Pierce (Rockford, IL, EE.UU.). Los reactivos $N$-hidroxisuccinimida (NHS), $N, N$ '-diciclohexilcarbodiimida (DCC), tributilamina (TBA), cloroformiato de isobutilo (CFI), $N, N^{\prime}$-dimetilformamida (DMF) y formaldehído aq al $37 \%$, utilizados para la conjugación de los haptenos a proteínas, fueron adquiridos a Fluka-Aldrich Química (Madrid) y Acros Organics (Geel, Bélgica).

El gel cromatográfico Sephadex G-25 utilizado para la purificación de los conjugados fue suministrado por Pharmacia (Lund, Suecia).

El reactivo de Bradford (Bio-Rad protein assay) utilizado para la determinación de proteína fue adquirido a Bio-Rad (Barcelona, España).

Los disolventes orgánicos y las sales utilizadas para la preparación de los tampones fueron suministrados por Scharlab (Barcelona, España).

\section{Disoluciones reguladoras}

- Tampón fosfato sódico salino (PBS): fosfato $10 \mathrm{mM}, \mathrm{NaCl} 137 \mathrm{mM}, \mathrm{KCl}$ 2,7 $\mathrm{mM}, \mathrm{pH} 7,5$

- Tampón PBS-T: PBS conteniendo Tween 20 al 0,05\% (v/v)

- Tampón carbonato sódico (CB): tampón carbonato-bicarbonato 50 mM, pH 9,6 
- Tampón acetato sódico $100 \mathrm{mM}, \mathrm{pH} 5$

- Tampón de revelado: citrato sódico $25 \mathrm{mM}$ y fosfato sódico $62 \mathrm{mM}, \mathrm{pH}$ 5,5

Todas las disoluciones fueron filtradas a través de una membrana de nitrocelulosa (Whatman Protran BA-83, 0,22 $\mu \mathrm{m}$ tamaño de poro) antes de su uso.

\subsubsection{Protocolos generales}

\subsubsection{Preparación de conjugados hapténicos, trazadores y reactivos auxiliares. Protocolos de conjugación}

Los haptenos seleccionados para cada familia -sulfonamidas y tetraciclinas- se conjugaron, a través de sus grupos ácidos, a una proteína carrier -BSA o KLHutilizando el método del éster activo. Los conjugados resultantes se emplearon como inmunógenos para la producción de anticuerpos.

El método del éster activo se desarrolla en dos etapas ${ }^{127}$. La primera consiste en la activación del hapteno mediante DCC y NHS. En la segunda etapa, preparación de los inmunógenos propiamente dicha (BSA-hapteno y/o KLH-hapteno), la reacción tiene lugar en medio alcalino entre el grupo carboxílico del hapteno activado y los grupos amino libres de los aminoácidos básicos (lisina y arginina) de la proteína.

La preparación de los diferentes conjugados se realizó del modo siguiente: se disolvieron, aproximadamente, $100 \mu$ moles de hapteno en $150 \mu \mathrm{L}$ de DMF anhidra, añadiendo gota a gota $150 \mu \mathrm{L}$ de una disolución de DCC $(105 \mu$ moles $)$ y $100 \mu \mathrm{L}$ de una disolución de NHS (105 $\mu$ moles), ambas en DMF. La mezcla se dejó reaccionar durante $5 \mathrm{~h}$ a temperatura ambiente, con agitación y protegida de la luz, hasta la formación de un precipitado de diciclohexilurea. En una segunda etapa y tras centrifugar durante $15 \mathrm{~min}$ a $7.500 \mathrm{rpm}$, el sobrenadante de la disolución de hapteno activo (200 $\mu \mathrm{L}$ para BSA y $100 \mu \mathrm{L}$ para $\mathrm{KLH})$ se mezcló con $800 \mu \mathrm{L}$ de una disolución que contenía $25 \mathrm{mg}$ de BSA en tampón $\mathrm{CB}$ o con $1 \mathrm{~mL}$ de una disolución que contenía $10 \mathrm{mg}$ de KLH en tampón PBS, dependiendo del conjugado hapténico deseado. La mezcla se incubó durante $4 \mathrm{~h}$ a temperatura ambiente, en constante agitación y protegida de la luz. Transcurrido este tiempo, el producto de la reacción (inmunógeno) se purificó mediante cromatografía de 
exclusión molecular utilizando una columna D-Salt Dextran, y las fracciones obtenidas se cuantificaron por el método de Bradford. En la Figura 15 se muestra el esquema del método de conjugación utilizado para la preparación de los inmunógenos.

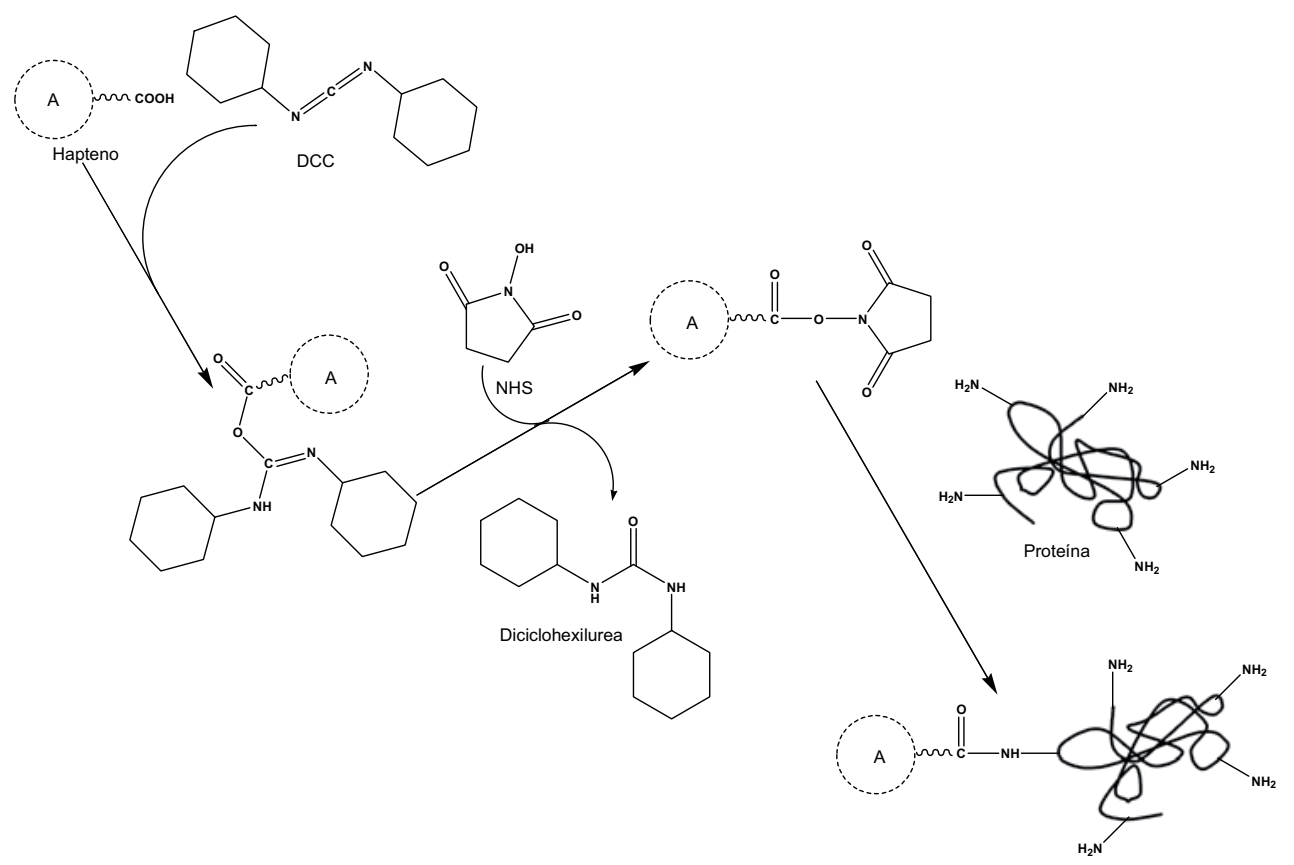

Figura 15. Esquema del método del éster activo para la conjugación de haptenos a proteínas

Por otro lado, los haptenos también se unieron a OVA para obtener los conjugados de tapizado, y a HRP para obtener los trazadores, utilizando en ambos casos el método del anhídrido mixto ${ }^{128}$. El procedimiento consiste, básicamente, en activar el hapteno mediante reacción con CFI y TBA en DMF, y una vez activado adicionarlo a la disolución de proteína en medio ligeramente alcalino. Para ello, 15 $\mu$ moles de hapteno se disolvieron en $200 \mu \mathrm{L}$ de DMF anhidra y se mezclaron con $15 \mu$ moles $(3,5 \mu \mathrm{L})$ de TBA y $15 \mu$ moles $(2 \mu \mathrm{L})$ de CFI. La mezcla se mantuvo durante $1 \mathrm{~h}$ a temperatura ambiente, en constante agitación y protegida de la luz. Transcurrido este tiempo, se mezclaron $150 \mu \mathrm{L}$ de disolución de hapteno activo y $1 \mathrm{~mL}$ de una disolución que contenía $12 \mathrm{mg}$ de OVA en tampón CB para la 
obtención del conjugado de tapizado. Para la preparación del trazador se mezclaron $15 \mu \mathrm{L}$ de disolución de hapteno activo y 4 mg de HRP en tampón CB.

La mezcla se incubó a temperatura ambiente durante $3 \mathrm{~h}$, con agitación y en oscuridad, y posteriormente toda la noche a $4{ }^{\circ} \mathrm{C}$.

Los conjugados obtenidos se purificaron en las condiciones anteriormente descritas para los inmunógenos, y las fracciones obtenidas se cuantificaron por el método de Bradford. La Figura 16 muestra un esquema del método utilizado para la preparación de los conjugados hapteno-proteína y de los trazadores.

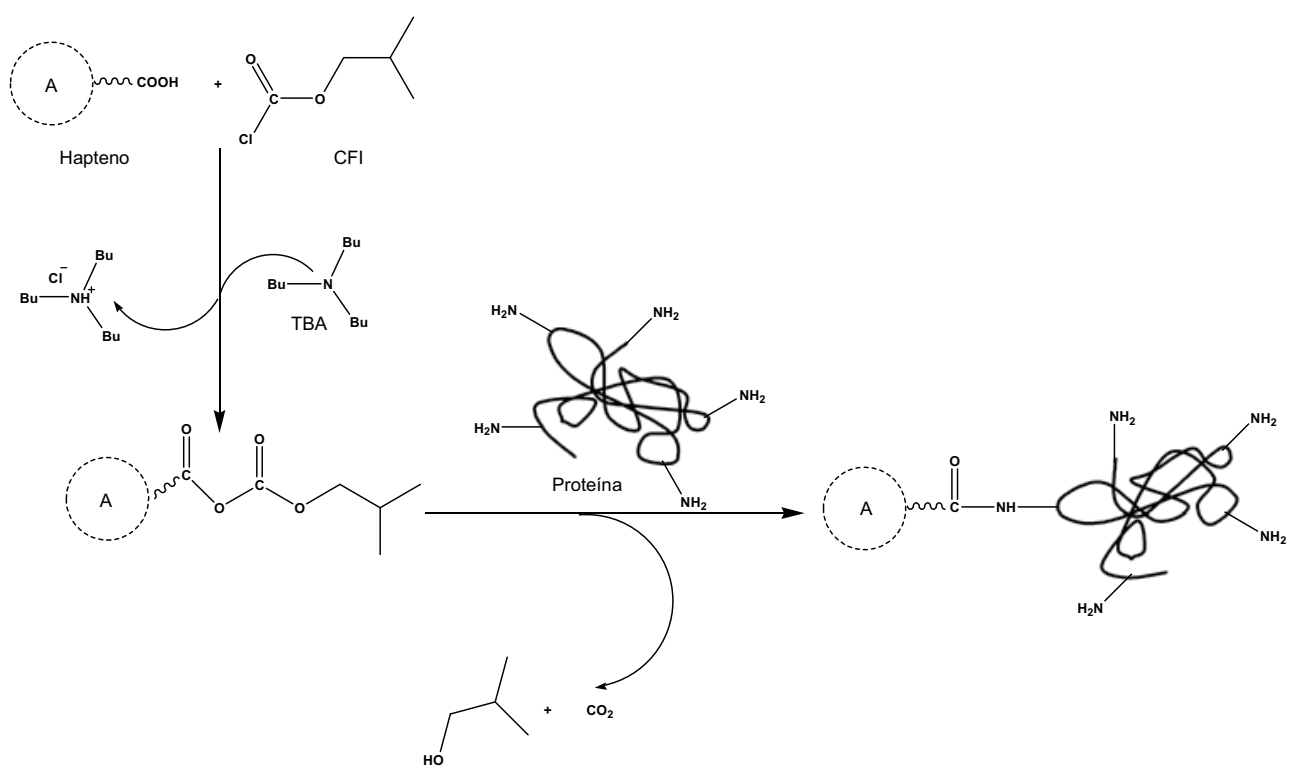

Figura 16. Esquema del método del anhídrido mixto para la conjugación de haptenos a proteínas

Los haptenos que presentaban grupos hidroxilo se conjugaron a las proteínas (BSA, OVA y HRP) utilizando un procedimiento descrito por Beasley et al. ${ }^{129}$ basado en el acoplamiento de alcoholes a proteínas. Para ello, a una disolución de 0,63 mmoles de hapteno en $6 \mathrm{~mL}$ de acetonitrilo anhidro -a $0{ }^{\circ} \mathrm{C}$ bajo atmósfera de Ar- se le adicionaron 0,75 mmoles de CDI. La reacción se mantuvo en agitación a $4{ }^{\circ} \mathrm{C}$ durante $48 \mathrm{~h}$ y bajo atmósfera de Ar. El crudo de reacción, obtenido tras la eliminación del disolvente a presión reducida, se disolvió en $6 \mathrm{~mL}$ de DMF anhidra. A continuación, una cantidad apropiada de la disolución de hapteno activo 
(3 $\mathrm{mL}$ para BSA, $1 \mathrm{~mL}$ para OVA y HRP) se mezcló con una disolución de proteína en tampón $\mathrm{CB}-30 \mathrm{mg} \mathrm{BSA} / 7,5 \mathrm{~mL}$ tampón $\mathrm{CB}, 20 \mathrm{mg} \mathrm{OVA} / 2 \mathrm{~mL}$ tampón $\mathrm{CB}, 3 \mathrm{mg} \mathrm{HRP} / 1,5 \mathrm{~mL}$ tampón $\mathrm{CB}$, en función del conjugado deseado-, dejando reaccionar la mezcla durante $48 \mathrm{~h} \mathrm{a} 4{ }^{\circ} \mathrm{C}$ y en agitación constante.

Los conjugados obtenidos se purificaron por cromatografía de exclusión molecular y las fracciones obtenidas se cuantificaron por el método de Bradford. En la Figura 17 se muestra el esquema del método de conjugación utilizado.

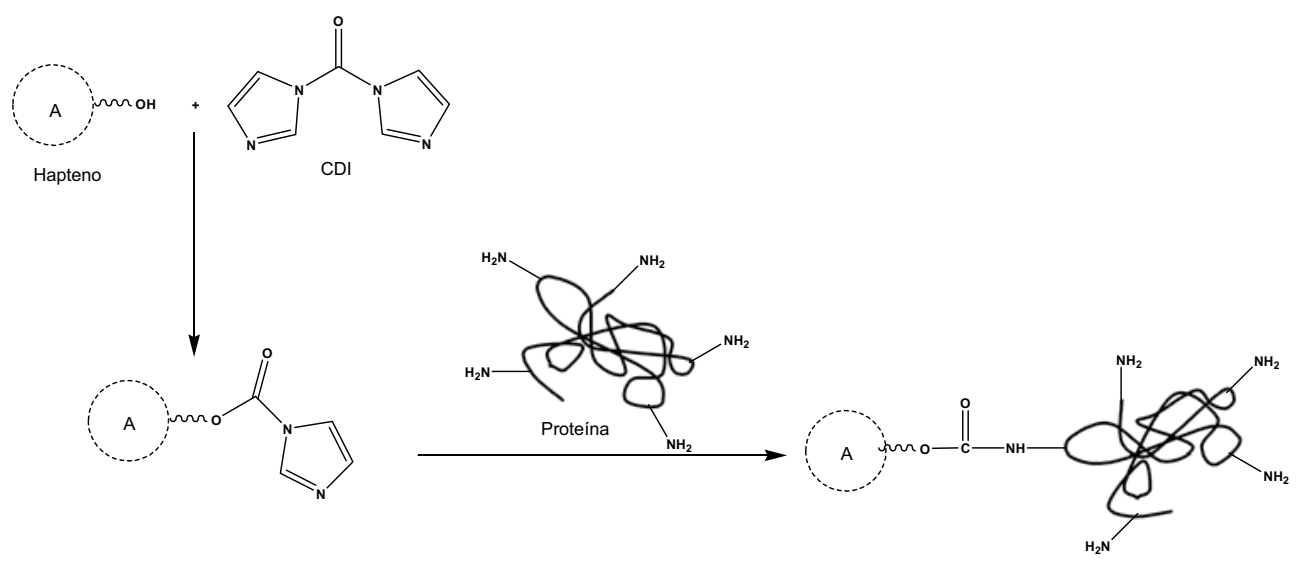

Figura 17. Esquema del método para el acoplamiento de alcoholes a proteínas

Finalmente, los compuestos de la familia de las tetraciclinas -TC, CTC y OTC-, se unieron directamente a proteínas para la preparación de inmunógenos $\boldsymbol{y}$ conjugados de tapizado mediante una reacción de condensación de Mannich, siguiendo el método descrito por Faraj et al.$^{101}$. Este método se basa en utilizar los hidrógenos activos de los haptenos, los cuales pueden condensarse a una amina primaria en presencia de formaldehído, resultando un enlace covalente estable. Para ello, 0,11 mmol de la tetraciclina correspondiente se disolvió en $2 \mathrm{~mL}$ de agua y se adicionó a una disolución que contenía $2,25 \mu \mathrm{mol}$ de proteína en $1,5 \mathrm{~mL}$ de agua. A continuación, se adicionó $1 \mathrm{~mL}$ de acetato sódico $3 \mathrm{M}, \mathrm{pH} 5,5$ y $0,4 \mathrm{~mL}$ de formaldehído al 37\%. La mezcla de reacción se mantuvo a pH 6-7 en constante agitación durante $2 \mathrm{~h}$, a temperatura ambiente, bajo atmósfera de Ar y protegida de la luz. Posteriormente, se centrifugó durante $12 \mathrm{~min}$ a $10.000 \mathrm{rpm}$. Los conjugados obtenidos se purificaron en las condiciones anteriormente descritas y las fracciones obtenidas se cuantificaron por el método de Bradford. La Figura 18 muestra un 
esquema de las reacciones que tienen lugar en la conjugación mediante condensación de Mannich.
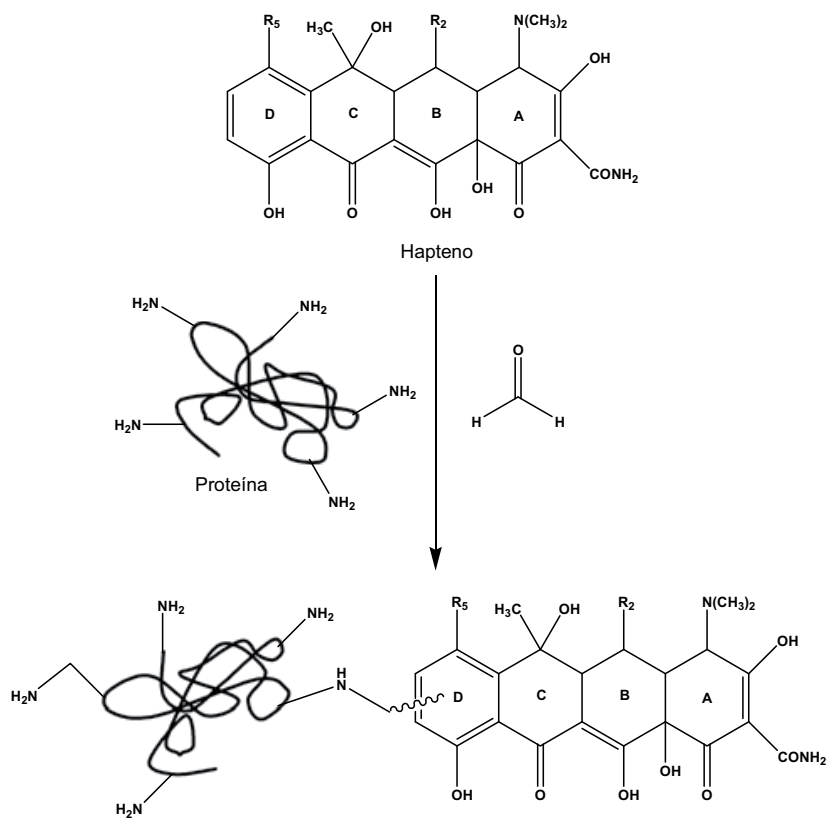

Figura 18. Esquema del método de condensación de Mannich para la conjugación de haptenos a proteínas

Todos los conjugados se purificaron mediante cromatografía de exclusión molecular utilizando columnas D-Salt Dextran, con un límite de exclusión de 5.000 Daltons, utilizando PBS como eluyente. Los conjugados purificados se recogieron -en alícuotas de $1 \mathrm{~mL}$ - en un total de diez fracciones, desechando las tres primeras por corresponder al volumen muerto de la columna.

Para la cuantificación espectrofotométrica de proteínas se utilizó el método descrito por Bradford ${ }^{130}$. Para cada una de las proteínas utilizadas (BSA, KLH y OVA) se prepararon patrones de calibración ( $25 \mathrm{mg} / \mathrm{L}$ a $200 \mathrm{mg} / \mathrm{L}$ ) en PBS y, junto con las muestras correspondientes a los conjugados proteicos (en diluciones seriadas en PBS), se añadieron a una microplaca de 96 pocillos ( $25 \mu \mathrm{L} /$ pocillo) por triplicado. A continuación se añadieron $200 \mu \mathrm{L}$ /pocillo del reactivo de Bradford -diluido 1:5 en agua destilada- y, tras 15 min en oscuridad, se midieron los valores de absorbancia a $590 \mathrm{~nm}$.

La concentración de enzima HRP de los trazadores se determinó espectrofotométricamente por medida directa de la absorbancia a $404 \mathrm{~nm}$. 


\subsubsection{Determinación de la relación hapteno/proteína}

La eficacia de la reacción de conjugación viene dada por la relación molar (RM) de marcaje o número de moléculas de hapteno que se han unido a una molécula de proteína. Su cuantificación se realizó espectrofotométricamente a la longitud de onda característica de cada una de las especies (hapteno y proteína), asumiendo la aditividad de las absorbancias de los conjugados, y que la absortividad molar de las formas libre y conjugada del hapteno es idéntica. La RM de los conjugados hapténicos se estimó midiendo la densidad óptica a $280 \mathrm{~nm}$ y a la longitud de onda específica de cada hapteno, obteniéndose valores comprendidos entre 20 y 30 para los inmunógenos, y entre 3 y 9 para los conjugados de tapizado. Para la estimación de la RM de los trazadores se midió la densidad óptica a $404 \mathrm{~nm}$ y a la longitud de onda característica de cada hapteno, obteniéndose valores comprendidos entre 2 y 3 .

Finalmente, todos los conjugados obtenidos se almacenaron a $-20{ }^{\circ} \mathrm{C}$ hasta su uso.

\subsubsection{Protocolo de inmunización y obtención de anticuerpos policlonales}

Los conjugados de inmunización (inmunógenos) se inocularon en conejas de la raza New Zealand ${ }^{*}$ California siguiendo la metodología habitual ${ }^{131}$. Para ello, cada inmunógeno se inyectó intramuscularmente en dos conejas (I y II). Para inmunizar, se inyectaron $0,5 \mathrm{~mL}$ de conjugado BSA-hapteno o KLH-hapteno a una concentración de $200 \mu \mathrm{g} / \mathrm{mL}$, mezclados con $0,5 \mathrm{~mL}$ de adyuvante de Freund completo, para la primera inmunización. Transcurridos 21 días se inyectaron a cada animal $0,5 \mathrm{~mL}$ del conjugado BSA-hapteno o KLH-hapteno de $200 \mu \mathrm{g} / \mathrm{mL}$, emulsionados con $0,5 \mathrm{~mL}$ de adyuvante de Freund incompleto. Diez días después de cada inmunización se realizaron sangrías con el fin de conocer el título del antisuero de cada animal. Estas sangrías permiten seguir el proceso de inmunización hasta alcanzar el nivel óptimo. Una vez alcanzado un título alto, se sangraron los animales y se dejó coagular la sangre a $4{ }^{\circ} \mathrm{C}$. Posteriormente, se separó el antisuero mediante centrifugación y, tras añadir azida sódica $(0,02 \%)$ como conservante, se almacenó a $-80{ }^{\circ} \mathrm{C}$. 


\subsubsection{Ensayos inmunoenzimáticos. ELISAs}

Básicamente, se utilizaron dos formatos ELISA. Uno consiste en la inmovilización del anticuerpo (Ab) y la detección directa de la interacción $\mathrm{Ab}-\mathrm{Ag}$ mediante un trazador enzimático (ELISA directo). El otro formato se basa en la inmovilización del conjugado hapténico, y detección indirecta de la interacción inmunológica mediante un anticuerpo secundario marcado con una enzima (ELISA indirecto).

Tanto los anticuerpos como los conjugados hapténicos se inmovilizaron sobre placas de poliestireno por adsorción pasiva. El procedimiento es simple, y consiste en disolver el receptor -a la concentración óptima- en tampón $\mathrm{CB}$, e incubar $16 \mathrm{~h}$ a $4{ }^{\circ} \mathrm{C}$.

\subsubsection{ELISAs no competitivos}

Una vez obtenidos los antisueros, se seleccionaron las condiciones óptimas de ensayo utilizando ELISAs no competitivos; para ello se examinaron diferentes concentraciones de anticuerpo, conjugado de tapizado y trazador mediante ensayos de titulación, tanto en formato directo como indirecto. El objetivo de esta experiencia era determinar el grado de reconocimiento de los anticuerpos frente a los conjugados hapténicos. Las concentraciones óptimas de los conjugados de tapizado o trazadores y la dilución de los antisueros, se seleccionaron teniendo en cuenta que las señales de absorbancia en ausencia de analito presentaran un valor próximo a la unidad. A continuación se detalla el protocolo general seguido para los dos formatos estudiados.

\section{ELISA directo}

1. Tapizar la placa con $100 \mu \mathrm{L} /$ pocillo de diferentes concentraciones de $\mathrm{Ab}$ específico disuelto en tampón CB e incubar durante $16 \mathrm{~h} \mathrm{a} 4^{\circ} \mathrm{C}$

2. Lavar la placa 6 veces con PBS-T

3. Añadir $100 \mu \mathrm{L}$ /pocillo de trazador (HRP-hapteno) disuelto en PBS-T a distintas concentraciones, e incubar durante $1 \mathrm{~h}$ a temperatura ambiente y protegido de la luz 
4. Lavar la placa 6 veces con PBS-T

5. Revelar con $100 \mu \mathrm{L} /$ pocillo de disolución de substrato $(2 \mathrm{mg} / \mathrm{mL}$ OPD y $0,012 \% \mathrm{H}_{2} \mathrm{O}_{2}$ en tampón revelado). Transcurridos diez minutos, detener la reacción enzimática añadiendo $50 \mu \mathrm{L} /$ pocillo de ácido sulfúrico 2,5 M. Medir la absorbancia a $490 \mathrm{~nm}$

6. Seleccionar las combinaciones Ab/trazador que proporcionen señales de absorbancia entre 1,0-1,5, para posteriores ensayos competitivos

\section{ELISA indirecto}

1. Tapizar la placa con $100 \mu \mathrm{L} /$ pocillo de diferentes concentraciones de conjugado de tapizado (OVA-hapteno) disuelto en tampón $\mathrm{CB}$ e incubar durante $16 \mathrm{~h}$ a $4{ }^{\circ} \mathrm{C}$

2. Lavar la placa 6 veces con PBS-T

3. Añadir $100 \mu \mathrm{L} /$ pocillo de distintas concentraciones de antisuero disuelto en PBS-T, e incubar durante $1 \mathrm{~h}$ a temperatura ambiente

4. Lavar la placa 6 veces con PBS-T

5. Añadir $100 \mu \mathrm{L} /$ pocillo de GAR-HRP (dilución 1:4.000 en PBS-T), e incubar durante $1 \mathrm{~h}$ a temperatura ambiente y protegido de la luz

6. Lavar la placa 6 veces con PBS-T

7. Revelar en las condiciones descritas en el punto 5 del formato directo

8. Seleccionar las combinaciones que proporcionen señales específicas en el intervalo 1,0-1,5, para su posterior evaluación mediante ensayos de competición

\subsubsection{ELISAs competitivos}

Con el fin de establecer la metodología para cada analito, se desarrollaron ELISAs competitivos partiendo de las combinaciones de inmunorreactivos seleccionadas en los ensayos de titulación. A continuación se detalla el protocolo general para cada formato de ensayo. 


\section{ELISA directo}

1. Tapizar la placa con $100 \mu \mathrm{L} /$ pocillo de disolución de $\mathrm{Ab}$ e incubar durante 16 h a $4{ }^{\circ} \mathrm{C}$

2. Lavar la placa 6 veces con PBS-T

3. Añadir $50 \mu \mathrm{L} /$ pocillo de analito y $50 \mu \mathrm{L} /$ pocillo de trazador (HRP-hapteno), disuelto en PBS-T, e incubar durante $1 \mathrm{~h}$ a temperatura ambiente y protegido de la luz

4. Lavar la placa 6 veces con PBS-T

5. Revelar en las condiciones descritas en el punto 5 del ELISA directo no competitivo

6. Seleccionar las combinaciones Ab/trazador que presentan las mejores prestaciones analíticas

\section{ELISA indirecto}

1. Tapizar la placa con $100 \mu \mathrm{L} /$ pocillo de conjugado de tapizado (OVA-hapteno) disuelto en tampón $\mathrm{CB}$ e incubar durante $16 \mathrm{~h}$ a $4{ }^{\circ} \mathrm{C}$

2. Lavar la placa 6 veces con PBS-T

3. Añadir $50 \mu \mathrm{L} /$ pocillo de analito y $50 \mu \mathrm{L}$ /pocillo de antisuero disuelto en PBS-T, e incubar durante $1 \mathrm{~h}$ a temperatura ambiente

4. Lavar la placa 6 veces con PBS-T

5. Añadir $100 \mu \mathrm{L}$ /pocillo de GAR-HRP (dilución 1:4.000 en PBS-T), e incubar durante $1 \mathrm{~h}$ a temperatura ambiente y protegido de la luz

6. Lavar la placa 6 veces con PBS-T

7. Revelar en las condiciones descritas en el punto 5 del ELISA directo no competitivo

8. Seleccionar las combinaciones que presentan las mejores prestaciones para su posterior optimización 


\subsubsection{Optimización de los ensayos ELISA}

A partir de los ensayos de competición se obtuvieron curvas dosis-respuesta que permitieron establecer las características analíticas de los ensayos: sensibilidad, estimada como valor de $\mathrm{IC}_{50}$ (concentración correspondiente a un $50 \%$ de la señal máxima), absorbancia máxima $\left(\mathrm{A}_{0}\right), \mathrm{LD}$ (concentración correspondiente a un $90 \%$ de la señal máxima), e intervalo de trabajo o rango dinámico ( $\mathrm{RD}$, concentraciones que producen entre un $20 \%$ y un $80 \%$ de inhibición de la señal), con el fin de seleccionar los ELISAs que presentaban las mejores prestaciones.

Para optimizar la sensibilidad de los ensayos seleccionados, se estudió -de modo secuencial- la influencia de distintas variables experimentales (fuerza iónica, $\mathrm{pH}$, concentración de tensioactivo -Tween 20- y tiempo de incubación en la etapa competitiva).

En primer lugar se evaluó el efecto de la fuerza iónica utilizando disoluciones de tampón PBS-T a diferentes concentraciones (5 a $100 \mathrm{mM}, \mathrm{pH}$ 7,5). A continuación, se estudió el efecto del pH entre 4 y 9,5, la concentración de Tween 20 en el intervalo de 0 a $0,5 \% \mathrm{v} / \mathrm{v} \mathrm{y}$, finalmente, el efecto del tiempo de competición $(15,30,45$ y $60 \mathrm{~min})$.

\subsubsection{Estudio de la selectividad de los ensayos}

La selectividad de los ELISAs optimizados se evaluó determinando la reactividad cruzada con un conjunto de compuestos relacionados química y estructuralmente con cada una de las familias objeto de estudio. Se seleccionaron un total de quince compuestos para la familia de las sulfonamidas (Figura 19) y once para la de tetraciclinas (Figura 20).

Para ello, se llevaron a cabo ensayos competitivos con cada uno de estos compuestos. Las curvas de inhibición resultantes, obtenidas $(n=3)$ para el mismo intervalo de concentraciones que la curva del analito objeto de estudio, se ajustaron a la ecuación sigmoide de cuatro parámetros, determinándose la $\mathrm{IC}_{50}$ de cada uno de los interferentes. El porcentaje de RC se calculó según la expresión:

$$
\% \mathrm{RC}=\frac{\mathrm{IC}_{50} \text { analito }}{\mathrm{IC}_{50} \text { interferente }} \times 100
$$




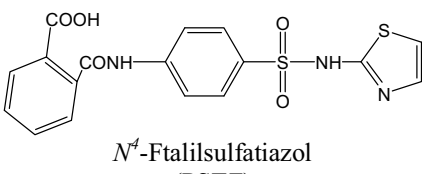

(PSTZ)

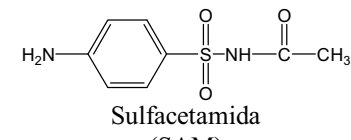

(SAM)

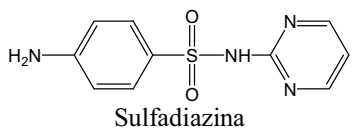

(SDZ)

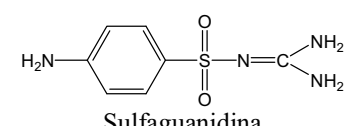

(SG)

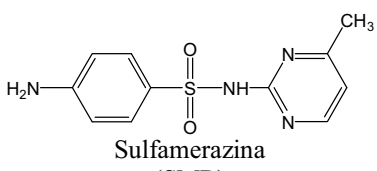

(SMR)

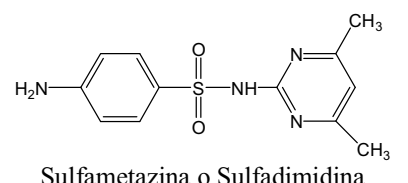

Sulfametazina o Sulfadimidina (SMZ)

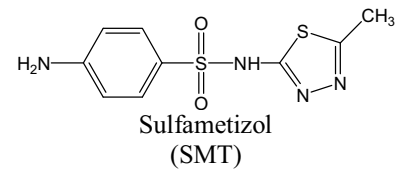

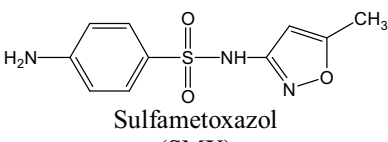

(SMX)

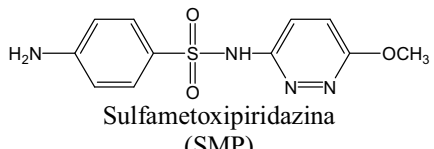

(SMP)

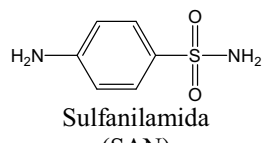

(SAN)

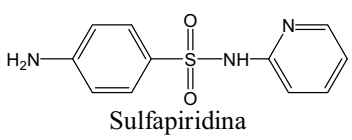

(SP)

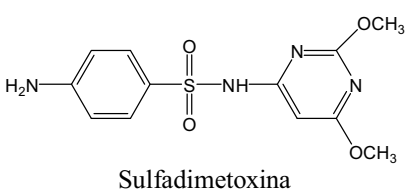
(SDM)

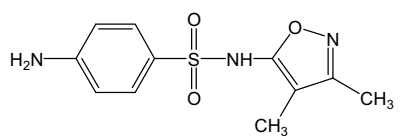

Sulfisoxazol

(SOX)

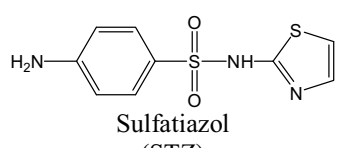

(STZ)

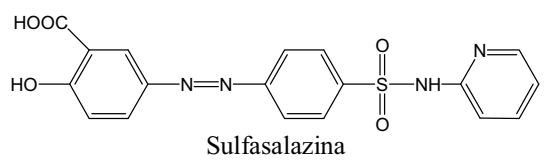

(SSZ)

Figura 19. Estructura de las sulfonamidas utilizadas en los estudios de selectividad 


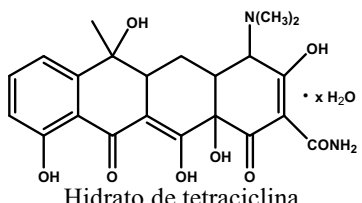

(TC)

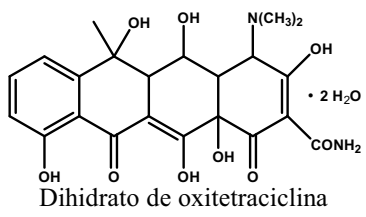
(OTC)

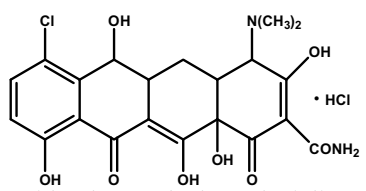

Hidrocloruro de demeclociclina (DMC)

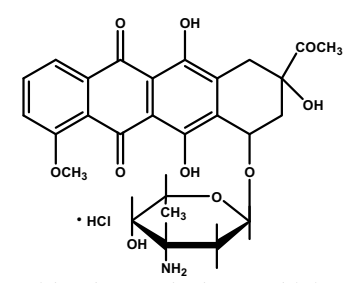

Hidrocloruro de daunorubicina (DR)

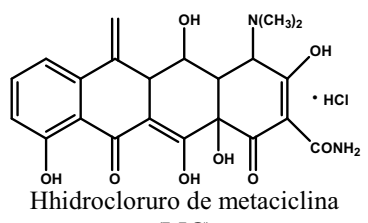

(MC)

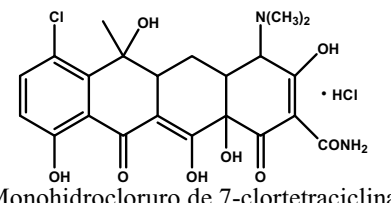

Monohidrocloruro de 7-clortetraciclina (CTC)

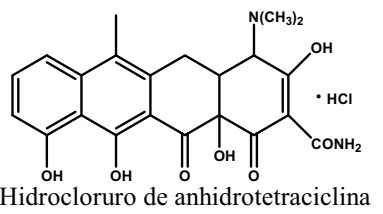
(ATC)

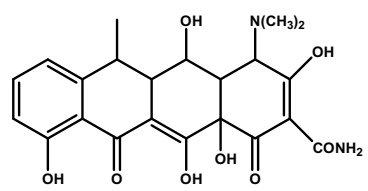

$\cdot \mathrm{HCl}$

- $1 / 2 \mathrm{H}_{2} \mathrm{O}$

. $1 / 2 \mathrm{CH}_{3} \mathrm{CH}_{2} \mathrm{OH}$

Hiclato de doxiciclina (DXC)

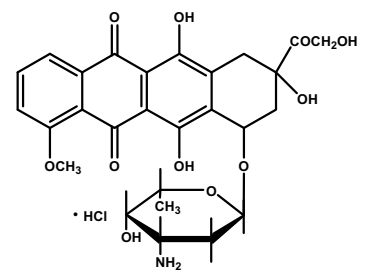

Hidrocloruro de doxorubicina (DXR)

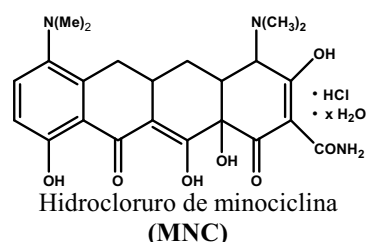
(MNC)<smiles>[R20]C1=C2C(=O)c3c(O)cccc3C(C)(O)C2CC2C([N+]([R])(C)Cl)C(O)=C(C(=O)O)C(=O)C12O</smiles>

Figura 20. Estructura de las tetraciclinas utilizadas en los estudios de selectividad 


\subsubsection{Efecto de los disolventes orgánicos}

Optimizadas las condiciones de ensayo y las prestaciones de los distintos sistemas, se determinó la tolerancia de los ELISAs desarrollados a diferentes disolventes orgánicos, con el fin de utilizarlos como extractantes de antibióticos. Para cada sistema se estudió la influencia de aquellos disolventes más frecuentemente empleados para la extracción de antibióticos en diferentes matrices ${ }^{132,133}$, llevando a cabo ensayos competitivos, utilizando disoluciones con diferentes proporciones ( $\mathrm{v} / \mathrm{v}$ ) analito/disolvente (de 0 a $40 \%$ ). El porcentaje óptimo de disolvente se estimó teniendo en cuenta que no se vieran afectadas negativamente las características propias del ensayo, especialmente señal máxima $\left(\mathrm{A}_{0}\right)$ y sensibilidad $\left(\mathrm{IC}_{50}\right)$.

\subsubsection{Análisis de muestras reales}

Dado que las investigaciones se realizaron en el marco de un proyecto de investigación cuyo objetivo era la determinación de residuos de antibióticos en miel, los primeros ensayos ELISA fueron aplicados a este tipo de muestras. Además, como se dispuso de un ELISA de elevada sensibilidad para SSZ, se consideró su aplicación a plasma humano y suero fisiológico, por ser una sulfonamida de escasa absorción y muy empleada en medicina humana.

\section{a) Miel}

Se utilizaron muestras comerciales de miel de diferente origen (azahar, milflores, etc.) y procedencia. Además, en todos los casos se dispuso de muestras control (exentas de antibióticos).

\section{a.1) Sulfonamidas}

Las muestras de miel fueron analizadas previamente por HPLC para verificar que no contenían STZ $(\mathrm{LD}<10 \mathrm{ng} / \mathrm{mL})$. Posteriormente, las muestras fueron diluidas 1:100 (p/v) con PBS-T y dopadas con STZ a diferentes concentraciones, dentro del intervalo de trabajo. Finalmente, se analizaron directamente mediante ELISA, sin tratamiento previo o limpieza. 
Por otro lado, dado que uno de los inmunoensayos desarrollados presentaba una elevada reactividad cruzada ( $\mathrm{RC}>10 \%$ ) hacia seis sulfonamidas (genérico I), este ensayo se aplicó también a la determinación de sulfonamidas en mieles. En este caso, dado que se trata de un ensayo multianalito y teniendo en cuenta que las sulfonamidas en mayor o menor extensión reaccionan con los azúcares reductores de la miel, se llevó a cabo su extracción previa mediante hidrólisis.

La hidrólisis se realizó siguiendo el procedimiento descrito por Posyniak et $a l .{ }^{132}$. Para ello, 2,5 g de miel -dopada con STZ-, se diluyeron con $12,5 \mathrm{~mL}$ de tampón acetato sódico $100 \mathrm{mM}, \mathrm{pH}$ 5. Tras agitar la disolución en vórtex, se introdujo en un baño de ultrasonidos durante $15 \mathrm{~min}$. Posteriormente, se hizo pasar la disolución a través de un cartucho Strata C18-E (500 mg) -previamente activado con $2 \mathrm{~mL}$ de metanol y equilibrado con $2 \mathrm{~mL}$ de tampón acetato sódico-, que se lavó con $2 \mathrm{~mL}$ de tampón acetato sódico para eliminar al máximo los componentes de la matriz de la muestra, y se dejó secar durante aproximadamente $1 \mathrm{~min}$. Finalmente, el cartucho se eluyó con $2 \mathrm{~mL}$ de metanol y el extracto metanólico se diluyó con PBS-T hasta que el porcentaje de metanol fue del 10\% (v/v) (Figura 21).

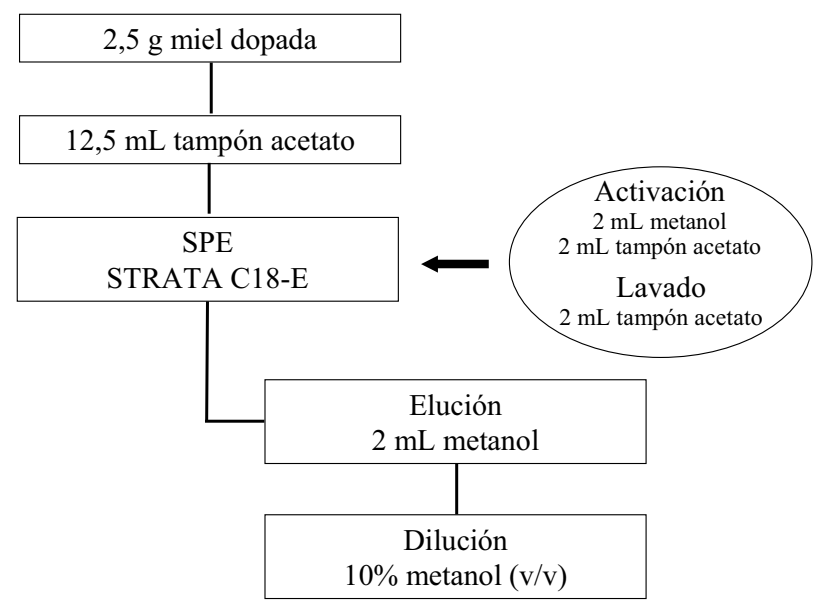

Figura 21. Esquema del proceso de extracción de sulfonamidas en miel

El procedimiento de extracción se evaluó utilizando diez submuestras de una misma miel (exenta de sulfonamidas), fortificadas con STZ a una concentración de 
$24 \mu \mathrm{g} / \mathrm{kg}$ de miel ( $3 \mu \mathrm{g} / \mathrm{L})$, las cuales una vez extraídas fueron analizadas mediante ELISA.

Finalmente, se evaluó la reproducibilidad del proceso según las recuperaciones (R) y coeficientes de variación (CV) obtenidos. Estos mismos parámetros se utilizaron como criterio de selección en posteriores experiencias.

\section{ELISA Genérico I}

Seis muestras comerciales de miel de diferente origen exentas de sulfonamidas, se enriquecieron con STZ, SMP, SP, SMT, SSZ y PSTZ a tres niveles (expresada la concentración como equivalentes de STZ). Tras ser extraídas, tal y como se ha descrito previamente, se analizaron por triplicado mediante el ELISA denominado genérico I.

\section{a.2) Tetraciclinas}

Dado que el ELISA optimizado para TC mostró una sensibilidad adecuada para determinar simultáneamente distintas tetraciclinas (TC, CTC, MN, OTC y RTC) dentro de los LMRs permitidos por la legislación, éste se utilizó para el análisis directo de mieles.

En una primera etapa se evaluó el efecto matriz con el fin de evitar interferencias potenciales. Para realizar estos ensayos, diferentes muestras comerciales de miel -libres de TCs, previo análisis por HPLC-, fueron dopadas con $\mathrm{TC}$, diluidas en PBS-T y filtradas a través de una membrana de nitrocelulosa (Whatman Protran BA-83, 0,22 $\mu \mathrm{m}$ ). Se prepararon cinco curvas patrón, cuatro de ellas con diferentes diluciones de miel en tampón PBS-T -1:10, 1:20, 1:25, y 1:50 (p/v)- y una quinta, en PBS-T. Todos los ensayos se efectuaron por triplicado. Los valores de sensibilidad y absorbancia máxima de las curvas realizadas con miel diluida se compararon con los obtenidos en la curva estándar (PBS-T).

Una vez evaluado el efecto matriz, se estimó la idoneidad de la metodología propuesta para el análisis de residuos de tetraciclinas en miel utilizando ocho muestras, libres de TCs. Para ello, las muestras se doparon con TC dentro del intervalo analítico de trabajo, se diluyeron 1:20 (p/v) en PBS-T y se filtraron, tal y como se ha descrito previamente. La curva de calibrado se preparó utilizando una matriz modelo, preparada como mezcla proporcional de diferentes muestras de miel comerciales, libres de TCs. Las muestras fueron directamente analizadas 
mediante el ELISA para TC, sin extracción previa. Tanto los patrones como las muestras se analizaron por triplicado.

\section{b) Suero fisiológico}

Con el fin de evaluar el potencial analítico del ELISA desarrollado para la determinación de SSZ, éste se ensayó con muestras de suero fisiológico.

Con el objetivo de estudiar el efecto matriz, se prepararon (por triplicado) seis curvas de competición conteniendo diferentes proporciones $(\mathrm{v} / \mathrm{v})$ de suero fisiológico en tampón PBS-T (de 0 a 100\%). El porcentaje óptimo de suero se estimó teniendo en cuenta que no influyera negativamente en las características propias de ensayo, $\mathrm{A}_{0}$ y $\mathrm{IC}_{50}$. Posteriormente se llevaron a cabo estudios de recuperación estimando la exactitud y reproducibilidad del método. Para ello se utilizaron diferentes muestras de suero fisiológico fortificadas con SSZ a cuatro niveles, entre 0,5 y $2 \mu \mathrm{g} / \mathrm{L}$. Una muestra sin fortificar se utilizó como control. Las muestras, previa dilución 1:5 (v/v) en el tampón de trabajo, se analizaron directamente mediante ELISA.

\section{c) Plasma humano}

Para evaluar la aplicación del inmunoensayo desarrollado para SSZ, se utilizó plasma humano comercial. Para ello, se realizaron diluciones del plasma entre 1:50 y 1:500, siguiendo la estrategia descrita previamente para el suero fisiológico.

Además, con el objetivo de conocer la interferencia matriz producida por las proteínas y demás sustancias presentes en el plasma, se estudiaron diversos tratamientos de muestra: extracción en fase sólida con cartuchos Strata X-C y precipitación con metanol.

\section{c.1) Extracción en fase sólida}

De acuerdo al procedimiento descrito por Huq et al. ${ }^{134}$, muestras dopadas de plasma humano comercial se diluyeron 1:1 (v/v) con agua destilada conteniendo un $2 \%$ de ácido ortofosfórico. Un $\mathrm{mL}$ de esta disolución se cargó en un cartucho Strata $\mathrm{X}-\mathrm{C}$-previamente activado con $1 \mathrm{~mL}$ de metanol y equilibrado con $1 \mathrm{~mL}$ de agua 
destilada-, se lavó con $1 \mathrm{~mL}$ de $\mathrm{HCl} 0,1 \mathrm{M}$ y $1 \mathrm{~mL}$ de metanol para eliminar al máximo los componentes de la matriz de la muestra, y se dejó secar 1 min, aproximadamente. Finalmente, la SSZ se eluyó con $1 \mathrm{~mL}$ de metanol conteniendo un $5 \%(\mathrm{v} / \mathrm{v})$ de amoniaco, y el extracto metanólico se diluyó con agua destilada hasta un $10 \%(\mathrm{v} / \mathrm{v})$ de metanol. En la Figura 22 se esquematiza el proceso de extracción utilizado.

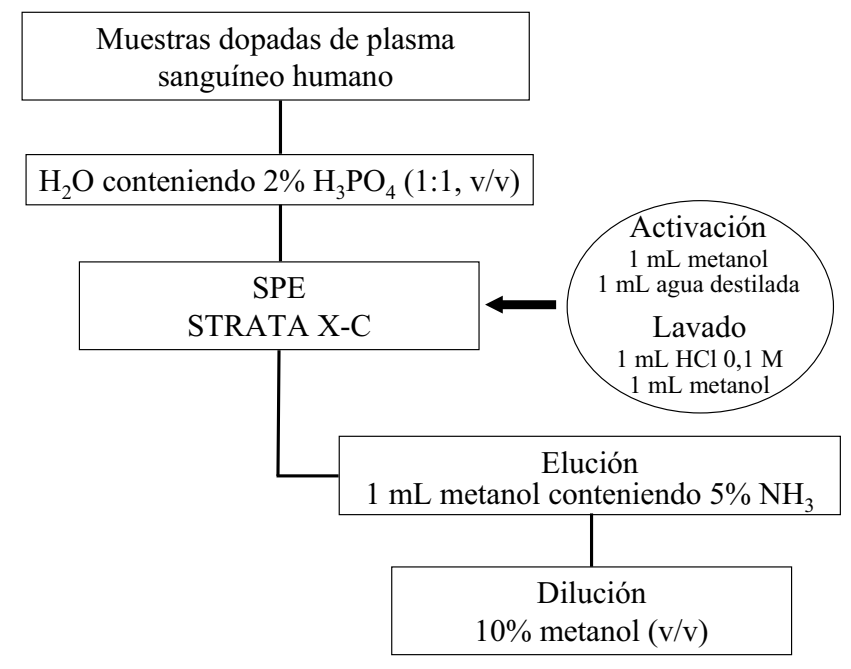

Figura 22. Esquema del proceso de extracción de SSZ en plasma humano

\section{c.2) Precipitación con metanol}

La precipitación de las proteínas con metanol se realizó utilizando una modificación del procedimiento descrito por Palumbo et al. ${ }^{133}$ y Hansen ${ }^{135}$. La Figura 23 muestra un esquema del proceso seguido.

Brevemente, las muestras de plasma dopadas con SSZ se diluyeron con metanol $(1: 2 \mathrm{v} / \mathrm{v})$ para provocar la precipitación de las proteínas, evitando así el posible efecto matriz debido a las mismas. Posteriormente, las muestras se agitaron en vortex y se centrifugaron a $10.000 \mathrm{rpm}$ durante $10 \mathrm{~min}$. Una alícuota del sobrenadante $(2 / 3$ del volumen total) se diluyó 1:10 (v/v) con PBS-T, de modo que el porcentaje de metanol fuera del $10 \%(\mathrm{v} / \mathrm{v})$. 


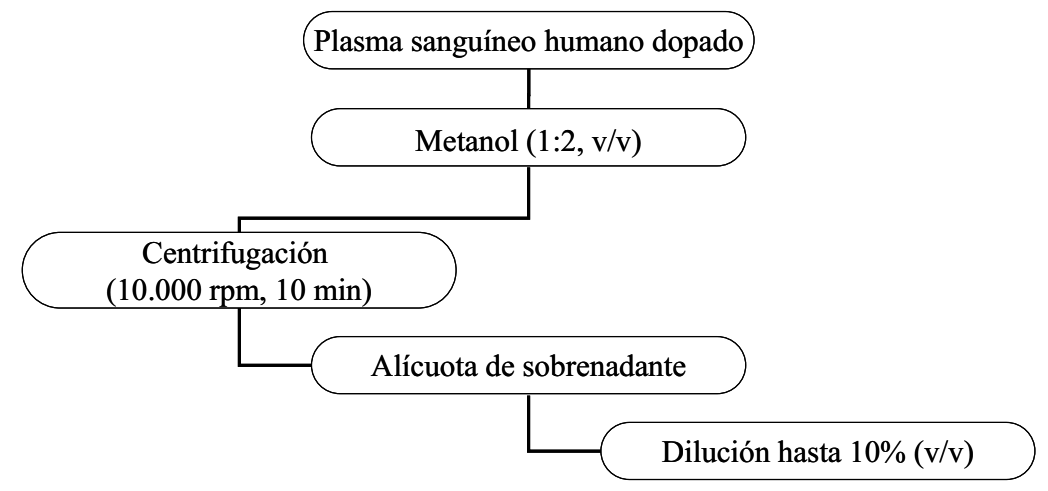

Figura 23. Esquema del proceso de precipitación de proteínas en plasma humano

El proceso de precipitación se evaluó utilizando veinte alícuotas de plasma humano, fortificadas con SSZ a dos niveles $(0,5 \mu \mathrm{g} / \mathrm{L}$ y $1 \mu \mathrm{g} / \mathrm{L})$, y procesadas tal y como se ha descrito previamente. Finalmente, los extractos se analizaron por triplicado mediante ELISA. 

4. RESULTADOS Y DISCUSIÓN 



\subsection{DISEÑO Y SÍNTESIS DE HAPTENOS}

La etapa inicial, y quizás la más critica en el desarrollo de inmunoensayos para moléculas de bajo peso molecular como sulfonamidas y tetraciclinas, consiste en el diseño y la síntesis de los haptenos a utilizar en la preparación de los inmunorreactivos.

Los haptenos son pequeñas moléculas que por si mismas no son capaces de inducir una respuesta inmune, pero que conjugadas a una macromolécula provocan y estimulan la producción de anticuerpos. La gran importancia que se le atribuye a esta etapa radica en el hecho de que la especificidad y la afinidad de los anticuerpos están fundamentalmente determinadas por la estructura de dicho hapteno $^{136,137}$.

En este sentido, un hapteno para inmunizar debería tener una estructura química lo más parecida posible a la del analito, así como conservar la conformación espacial, distribución electrónica y propiedades hidrofóbicas del mismo. Sin embargo, en ocasiones, partes o porciones características del analito son suficientes para generar buenos anticuerpos ${ }^{137,138}$. Además, para poder acoplar covalentemente un compuesto a una proteína, es necesario que el primero disponga de grupos funcionales tales como - $\mathrm{COOH},-\mathrm{NH}_{2},-\mathrm{OH},-\mathrm{CHO}$ y $-\mathrm{SH}$, susceptibles de reaccionar con los grupos funcionales de las proteínas. Asimismo, para favorecer la presentación del hapteno al sistema inmunológico, es necesario que en el conjugado hapteno-proteína el primero esté separado espacialmente de la segunda. Por ello, el hapteno debe funcionalizarse con un brazo espaciador que presente un grupo funcional en el extremo, de modo que permita su acoplamiento a la proteína y facilite su reconocimiento. A la hora de derivatizar el analito (o molécula similar) para introducir el brazo espaciador, hay que evitar, en lo posible, que sus grupos funcionales queden bloqueados por el brazo espaciador; por ello, es preferible llevar a cabo la derivatización a través de los átomos de carbono del analito, ya que su influencia en las propiedades electrónicas y estéricas es menor. Generalmente, si se utilizan grupos funcionales característicos del analito se reducen los sitios que podrían ayudar a estabilizar el inmunocomplejo Ab-analito, obteniendo anticuerpos con menor afinidad, lo que dirige a ensayos menos sensibles ${ }^{137,139}$. Otro aspecto importante a tener en cuenta es la longitud del brazo espaciador; estudios realizados por Marco et al. ${ }^{137}$ y Lee et al. ${ }^{140}$ llegaron a la conclusión que la longitud 
óptima está comprendida entre 3 y 6 átomos de carbono, aunque se han obtenido anticuerpos utilizando brazos espaciadores más cortos ${ }^{90,91}$.

Además del diseño de los haptenos inmunizantes, hay que tener en cuenta el diseño de los haptenos de tapizado y de los trazadores, ya que los inmunoensayos para la detección de moléculas de bajo peso molecular son, generalmente, competitivos, es decir, se establece una competencia entre el analito y un compuesto análogo marcado por unirse al $\mathrm{Ab}$. En el diseño de los haptenos de tapizado o de los trazadores, la similitud química, geométrica y electrónica con el analito no es tan determinante como en el caso de los haptenos inmunizantes. Así pues, la introducción de ciertas diferencias estructurales respecto al hapteno de inmunización resulta necesario debido al denominado "principio de heterología"137. En los sistemas que operan en condiciones heterólogas, la afinidad del Ab por el competidor es menor, de manera que en la competición el analito es capaz de desplazar el equilibrio de formación del complejo Ab-competidor hacia la formación del complejo Ab-analito. En este contexto, se pueden encontrar ejemplos en la bibliografía relacionados con la mejora de la detectabilidad en condiciones heterólogas ${ }^{141,142}$. La heterología puede introducirse de diversas maneras, ya sea empleando un brazo espaciador diferente al utilizado en la preparación del hapteno de inmunización, ubicándolo en una posición diferente de la molécula, cambiando la estructura química del hapteno, o empleando un fragmento característico de la estructura.

Por todo ello, es difícil predecir a priori la estructura del hapteno más apropiada para producir anticuerpos con las características deseadas, siendo recomendable la síntesis de una colección de haptenos con diferentes grados de heterología respecto al analito de interés.

\subsubsection{Diseño y síntesis de haptenos para sulfonamidas}

Las sulfonamidas son un grupo de compuestos sintéticos que tienen como núcleo básico el $p$-amino-bencenosulfonamida. Por sustitución de uno de los hidrógenos del grupo sulfonamida se pueden obtener un gran número de derivados. Por ello, los compuestos pertenecientes a la familia de las sulfonamidas muestran una gran variabilidad, pero poseen una estructura general con dos regiones claramente diferenciadas: una constante y otra variable, la cual constituye la mayor diferencia estructural (sección 3.1.3, Experimental). 
En principio, observando la estructura general, la estrategia más sencilla de síntesis de haptenos para sulfonamidas con determinantes para inmunización selectiva sería funcionalizarlos a través del grupo amino aromático de la región constante. De esta manera, una vez conjugado a la proteína, la presentación del hapteno sería tal, que los anticuerpos se desarrollarían principalmente contra la región variable, la cual está más alejada de la proteína, obteniendo así anticuerpos específicos. Por otro lado, para la obtención de anticuerpos genéricos, la región constante se debería mantener invariable, por lo que el hapteno inmunizante debería estar funcionalizado a través de la región variable, conservando así la estructura del analito. Otra alternativa, sería producir anticuerpos a partir de haptenos que posean únicamente una parte de la estructura completa de la sulfonamida.

No obstante, la incertidumbre sobre el diseño de haptenos es considerable, de modo que las hipótesis sobre diseño de antígenos para la obtención de anticuerpos específicos o genéricos presentan notables excepciones, especialmente para policlonales. Así, Haasnoot et al. ${ }^{91}$ han descrito la obtención de anticuerpos específicos a partir de haptenos inmunizantes diseñados a priori para la obtención de anticuerpos genéricos.

Teniendo en cuenta los precedentes bibliográficos sobre el desarrollo de inmunoensayos para sulfonamidas, se propusieron tres tipos de haptenos, que corresponden a las tres posiciones donde es posible introducir el brazo espaciador (Figura 24).

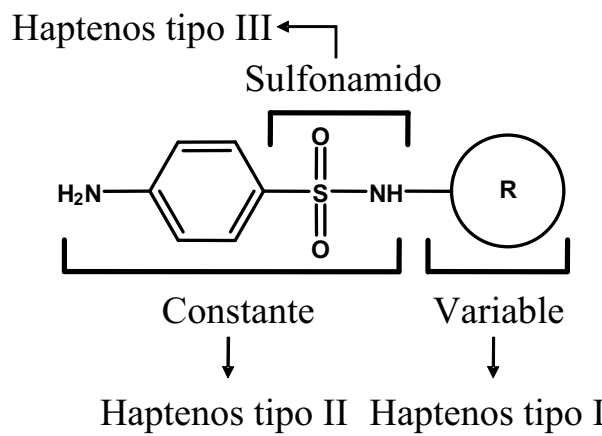

Figura 24. Clasificación de los haptenos para sulfonamidas según la ubicación del brazo espaciador 
- Haptenos tipo I: funcionalizados a través de la región variable

- Haptenos tipo II: funcionalizados a través del grupo amino aromático de la región constante

- Haptenos tipo III: funcionalizados a través del grupo sulfonamido

En total, se sintetizaron trece haptenos con diferentes grados de heterología, que difieren tanto en la estructura, como en la longitud y el tipo de brazo espaciador utilizado. En todos los casos, los productos obtenidos se caracterizaron e identificaron mediante IR, RMN y MS (Apéndice I).

Por otro lado, se realizó una búsqueda de productos comerciales de características similares que pudiesen ser utilizados como haptenos.

\subsubsection{Haptenos tipo I}

Este tipo de haptenos fué sintetizado modificando la región variable de las sulfonamidas. De esta manera, se obtuvieron cinco haptenos funcionalizados como ácidos carboxílicos cuya estructura se muestra en la Figura 25. E1 hapteno S2 se caracteriza por poseer un anillo bencénico como región variable; el hapteno S9 posee la misma región variable y un brazo espaciador de mayor longitud.

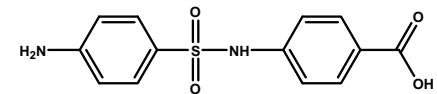

S2

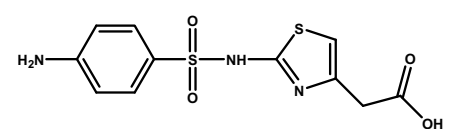

S3

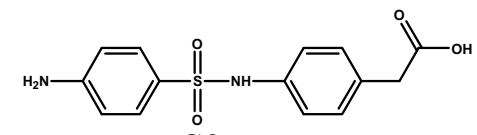

S9

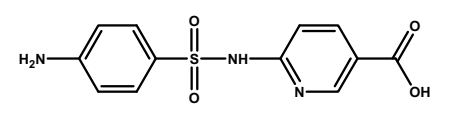

S4

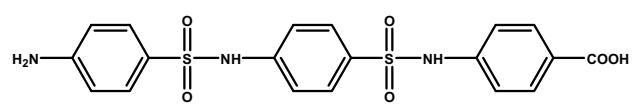

S14

Figura 25. Estructura química de los haptenos tipo I para sulfonamidas 
Además, se sintetizó una sulfonamida (hapteno S3) con un anillo de tiazol como región variable y un derivado de la sulfapiridina (hapteno $\mathbf{S 4}$ ), que posee un anillo de piridina. Finalmente, se sintetizó el hapteno S14, el cual posee una estructura diferenciada, de modo que la región variable es idéntica a la región constante $y$, además, es el único que posee un brazo espaciador aromático.

La ruta sintética planteada para la preparación de los haptenos S2 y S9 comprende dos etapas, tal y como se muestra en la Figura 26: condensación del cloruro de $\mathrm{N}$-acetilsulfanililo con una amina primaria, en presencia de piridina como aceptor del ácido clorhídrico generado, seguida de una desacetilación por hidrólisis ácida.

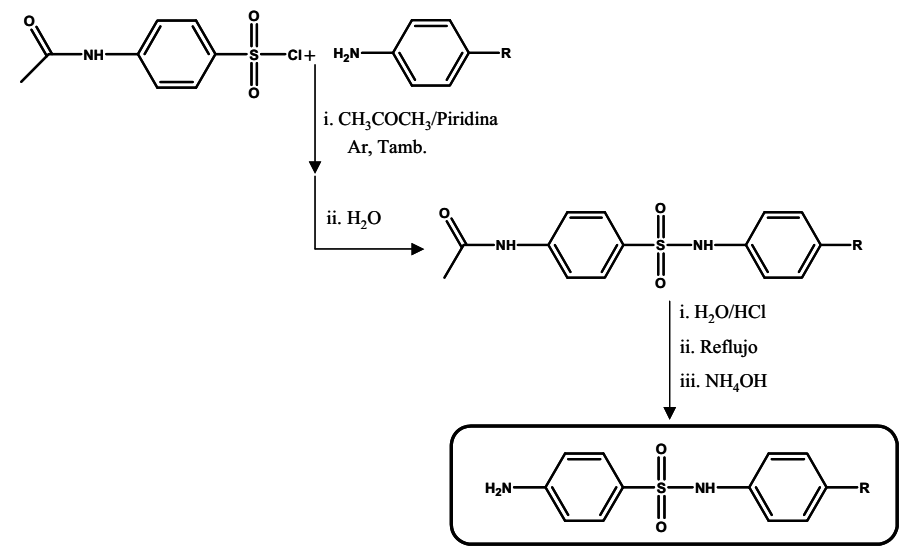

Figura 26. Esquema sintético seguido para la obtención de los haptenos S2 y S9

La primera etapa de la síntesis del hapteno $\mathbf{S 2}$ fue la preparación del ácido 4-(4acetilamino-bencenosulfonilamino)benzoico. Este intermedio fue sintetizado por sustitución nucleofílica del cloruro de $\mathrm{N}$-acetilsulfanililo con el ácido 4aminobenzoico, en acetona seca conteniendo un $8 \%$ de piridina anhidra. La identificación del producto I fue posible gracias al espectro de ${ }^{1} \mathrm{H}-\mathrm{RMN}$. La aparición de un singlete a 10,73 ppm correspondiente al hidrógeno del grupo $\mathrm{NH}$ de la sulfonamida, indicaba que la reacción de condensación se había llevado a buen término. En la segunda etapa, la desacetilación por hidrólisis ácida proporcionó el hapteno deseado con un rendimiento global del 59\%.

La caracterización de S2 se realizó mediante ${ }^{1} \mathrm{H}-\mathrm{RMN},{ }^{13} \mathrm{C}-\mathrm{RMN}$, espectroscopía de IR y MS (Espectros 1-4, Apéndice I). El espectro de ${ }^{1} \mathrm{H}-\mathrm{RMN}$ presentaba un singlete ancho a 12,66 ppm correspondiente al grupo ácido, y un 
singlete a 10,41 ppm debido al grupo sulfonamida. En el espectro de ${ }^{13} \mathrm{C}-\mathrm{RMN}$ se observó una señal a 166,8 ppm que correspondía al grupo ácido. El espectro IR del producto obtenido presentaba, entre otras, bandas a $3411 \mathrm{~cm}^{-1}$ y $3332 \mathrm{~cm}^{-1}$, correspondientes a la tensión nitrógeno-hidrógeno de la amina aromática, una banda a $3217 \mathrm{~cm}^{-1}$ característica de la tensión del enlace nitrógeno-hidrógeno del grupo sulfonamida, otra a $1697 \mathrm{~cm}^{-1}$ debida a la tensión del doble enlace carbonooxígeno del grupo ácido, y dos bandas a 1327 y $1157 \mathrm{~cm}^{-1}$ correspondientes a la tensión del doble enlace azufre-oxígeno, asimétrica y simétrica, respectivamente. Finalmente, el espectro de masas presentaba el pico molecular a un valor de relación $\mathrm{m} / \mathrm{z}$ de 292, además de los fragmentos típicos de la familia de las sulfonamidas: 156, 108, 92, 65 (Figura 27).

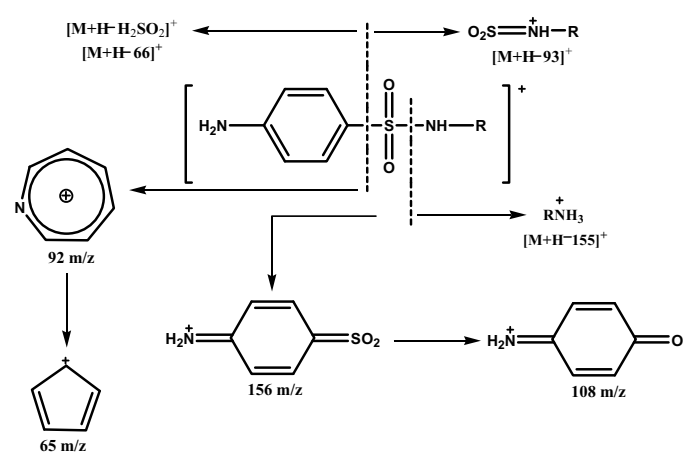

Figura 27. Esquema general de fragmentación de las sulfonamidas

La síntesis de este compuesto había sido descrita con anterioridad por Muldoon et al. $^{88}$ y Sheth y Sporns ${ }^{86}$, eliminando el grupo acetil por hidrólisis básica, con un rendimiento global del $29 \%$ y $20 \%$, respectivamente. Sin embargo, el intento inicial de llevar a cabo la hidrólisis básica en las condiciones descritas por ambos autores fue infructuoso, obteniendo un producto que correspondía, principalmente, al de partida. Por ello, se optó por realizar una hidrólisis ácida, conociendo $a$ priori $^{143}$ que este tratamiento causa, generalmente, la ruptura de la unión sulfonamida. Sin embargo, en este caso, dicha unión permaneció intacta, obteniendo un rendimiento global del 59\%, mucho más elevado que el alcanzado por los citados autores. 
La síntesis del hapteno S9 se llevó a cabo siguiendo un procedimiento análogo al descrito para S2. El reactivo de partida fue el ácido (4-aminofenil)acético, obteniéndose un hapteno con la misma estructura pero con un mayor brazo espaciador. La síntesis de este producto no había sido descrita previamente, por lo que tuvieron que optimizarse todas las condiciones de trabajo. La preparación del ácido [4-(4-amino-bencenosulfonilamino)fenil]acético se abordó haciendo reaccionar el ácido (4-aminofenil)acético con cloruro de $N$-acetilsulfanililo, en acetona seca conteniendo un $18 \%$ de piridina anhidra, y posterior desacetilación por hidrólisis ácida. En este caso, el contenido en piridina fue muy superior al utilizado para la obtención del hapteno $\mathbf{S 2}$ con el fin de lograr la total disolución del ácido (4-aminofenil)acético. Tras mantener $21 \mathrm{~h}$ en agitación y eliminar el disolvente a baja presión, el producto de condensación se separó del crudo de reacción por cromatografía en columna sobre sílica gel, con hexano/AcOEt (90:10) como eluyente. La posterior desacetilación del producto obtenido por hidrólisis ácida proporcionó el hapteno $\mathbf{S 9}$.

Uno de los principales problemas a solucionar fue aislar el producto de condensación. En general, en este tipo de reacciones, el producto se aísla por precipitación. Sin embargo, en este caso y debido al mayor contenido en piridina, se formaba un semisólido de aspecto gelatinoso, lo que obligó a ensayar otros métodos. El procedimiento más adecuado fue la purificación por cromatografía preparativa en columna, alcanzando un rendimiento total del $37 \%$.

El hapteno S9 se caracterizó por ${ }^{1} \mathrm{H}-\mathrm{RMN},{ }^{13} \mathrm{C}-\mathrm{RMN}$, espectroscopía de IR y MS (Espectros 13-16, Apéndice I). El espectro de ${ }^{1} \mathrm{H}-\mathrm{RMN}$ presentaba, entre otras señales, un singlete amplio a 12,22 ppm característico del sustituyente ácido, y un singlete a 3,43 ppm, que integraba dos hidrógenos correspondientes al grupo metileno del brazo espaciador. Mediante el ${ }^{13} \mathrm{C}-\mathrm{RMN}$ se pudo corroborar la señal a $172,7 \mathrm{ppm}$ correspondiente al carbono cuaternario del grupo ácido, y la señal a 39,9 ppm que identifica al carbono del grupo metileno. El espectro de IR presentó características espectroscópicas acordes con su estructura. El espectro de masas del producto obtenido presentaba, entre otras señales, el pico molecular a 306 unidades de $\mathrm{m} / \mathrm{z}$ y los fragmentos típicos de la familia de las sulfonamidas.

Para la síntesis de los haptenos $\mathbf{S 3}$ y $\mathbf{S 4}$ se siguió el esquema que se muestra en la Figura 28. 

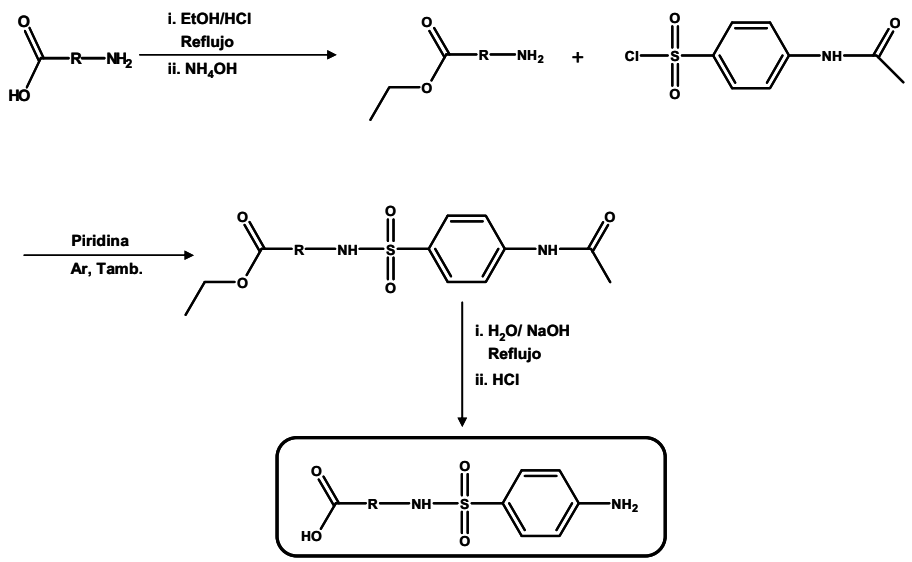

Figura 28. Esquema sintético seguido para la obtención de los haptenos S3 y S4

En la bibliografía se ha descrito que, en función de la posición del grupo carboxilo, la descarboxilación se favorece a temperaturas por debajo de $80{ }^{\circ} \mathrm{C}^{144}$. Por ello, para la síntesis de estos haptenos, se llevó a cabo una primera etapa de esterificación con el fin de proteger el grupo ácido y evitar su descarboxilación (Figura 28). Posteriormente, se llevó a cabo la condensación del cloruro de $\mathrm{N}$ acetilsulfanililo con el grupo amino para dar lugar al grupo sulfonamida, seguida de una hidrólisis básica.

La síntesis del hapteno $\mathbf{S 3}$ se concluyó con éxito partiendo del ácido 2-amino-4tiazolacético. Para ello, se utilizó una reacción de esterificación del ácido 2-amino4-tiazolacético con etanol, en presencia de un catalizador ácido (ácido clorhídrico), obteniéndose el producto I, (2-amino-1,3-tiazol-4-il)acetato de etilo, con un rendimiento del $76 \%$. La identificación del producto se realizó por ${ }^{1} \mathrm{H}-\mathrm{RMN}$; la aparición de un cuadruplete a 4,17 ppm -identificado como el metileno unido al oxígeno- y un triplete a 1,26 ppm -identificado como el metilo unido al metileno-, confirmaron la formación de éste. Además, las señales obtenidas por ${ }^{13} \mathrm{C}-\mathrm{RMN}$ a 61,0 y 14,2 ppm corroboraron la identificación del producto, indicando la presencia del carbono del metileno y del carbono del metilo, respectivamente.

La etapa siguiente se basó en el acoplamiento del producto I con cloruro de $\mathrm{N}$ acetilsulfanililo en piridina anhidra. Por resonancia de hidrógeno se comprobó la formación del denominado "producto II", observando dos singletes a 12,63 ppm (correspondiente al hidrógeno del nitrógeno de la sulfonamida) y 10,27 ppm 
(identificado como el hidrógeno unido al nitrógeno del grupo acetil del cloruro de $N$ - acetilsulfanililo). Finalmente, el producto de condensación fue hidrolizado en medio básico. El producto deseado se separó del crudo de reacción por precipitación, obteniendo un rendimiento del 84\%. Mediante ${ }^{1} \mathrm{H}-\mathrm{RMN}$ (Espectro 5, Apéndice I) se comprobó la existencia del hapteno $\mathbf{S 3}$ por la aparición de dos singletes a 12,44 y $5,82 \mathrm{ppm}$, correspondientes al hidrógeno del grupo ácido y a los hidrógenos de la amina libre, respectivamente. El espectro de ${ }^{13} \mathrm{C}-\mathrm{RMN}$ (Espectro 6, Apéndice I) presentó características espectroscópicas acordes con su estructura. Además, se identificó el producto mediante IR (Espectro 7, Apéndice I), obteniendo, entre otras bandas, la característica del anillo de tiazol a $1529 \mathrm{~cm}^{-1}$. En este caso, el masas no proporcionó el pico del ión molecular, siendo el correspondiente a la descarboxilación del ácido carboxílico el que apareció en primer lugar (Espectro 8, Apéndice I).

La síntesis de este hapteno había sido descrita con anterioridad por Sheth y Sporns ${ }^{86}$ y Haasnoot et al. ${ }^{91}$, utilizando tres etapas: formación del éster metílico, condensación con cloruro de $N$-acetilsulfanililo y por último, hidrólisis básica, con un rendimiento global del $5 \%$ en el primer caso y del 13\% en el segundo. En este trabajo se optó por utilizar una ruta de síntesis ligeramente diferente, aunque con el mismo número de etapas. Por un lado, se utilizaron reactivos con menores problemas de manipulación en la primera etapa $\left(\mathrm{EtOH} / \mathrm{HCl}_{(\mathrm{aq})}\right.$ en lugar de $\mathrm{CH}_{3} \mathrm{OH} /\left(\mathrm{CH}_{3}\right)_{3} \mathrm{SiCl}$ o $\left.\mathrm{CH}_{3} \mathrm{OH} / \mathrm{HCl}_{(\mathrm{g})}\right)$ y, por otro, se incrementó el rendimiento global del proceso al $32 \%$.

Uno de los haptenos más interesantes para sintetizar -a priori- era el ácido 6-(4amino-bencenosulfonilamino)nicotínico, hapteno $\mathbf{S 4}$, ya que este compuesto presenta un anillo de piridina en la región variable, pudiendo generar anticuerpos con respuesta específica para la sulfapiridina y sus derivados, e incluso para las dos posibles diazinas incluidas en la familia de las sulfonamidas (piridazinas y pirimidinas). Para la síntesis del hapteno $\mathbf{S 4}$ se siguió un procedimiento análogo al descrito para S3. En este caso, la esterificación se realizó partiendo del ácido 6amino-nicotínico. Este producto, insoluble en medio etanólico a temperatura ambiente, se disolvió por calentamiento a reflujo, observando mediante TLC que la reacción tenía lugar, aunque tendía a bloquearse. Los mejores resultados se obtuvieron calentando a reflujo durante $90 \mathrm{~min}$. Tras el proceso de extracción, se aisló el producto I con un rendimiento del $35 \%$, porcentaje inferior al esperado 
debido a que parte del producto de partida no había reaccionado a causa del bloqueo. El producto I presentó características espectroscópicas acordes con su estructura, destacando la aparición de un cuadruplete a 4,33 ppm correspondiente al metileno unido al oxígeno, y de un triplete a $1,36 \mathrm{ppm}$ identificado como el metilo unido al metileno, confirmando que la esterificación había tenido lugar.

A continuación, tal como se indica en la Figura 28, se llevó a cabo la condensación del grupo amino con cloruro de $\mathrm{N}$-acetilsulfanililo, seguida de una hidrólisis básica, lo que permitió obtener el ácido 6-(4-aminobencenosulfonilamino)nicotínico, hapteno $\mathbf{S 4}$, que fue caracterizado mediante los datos espectroscópicos (Espectros 9-12, Apéndice I). En el espectro de RMN, la ausencia de señales debidas a los protones de los grupos éster, así como la aparición de señales debidas a dos nuevos protones a 12,19 y 6,04 ppm, asignables respectivamente al grupo ácido y al grupo amino libre, confirmaron que la hidrólisis había tenido lugar. El espectro de IR presentó características espectroscópicas acordes con su estructura, al igual que el espectro de MS, del cual cabe destacar el fragmento de 138 unidades $\mathrm{m} / \mathrm{z}$, identificado como ácido 6-aminonicotínico.

El último hapteno de este grupo, denominado S14, presenta dos características: la región variable es idéntica a la región constante y posee un brazo espaciador aromático. La síntesis de este hapteno a partir de S2 había sido descrita anteriormente por $\mathrm{Li}$ et al. ${ }^{145}$, mediante un acoplamiento del grupo amino aromático con cloruro de $\mathrm{N}$-acetilsulfanililo en piridina anhidra, seguido de una hidrólisis ácida.

En este caso, se decidió utilizar una ruta sintética alternativa debido a los problemas inherentes al uso de elevados contenidos en piridina durante la etapa de aislamiento del producto. En un primer momento, se intentó acoplar la segunda molécula de cloruro de $N$-acetilsulfanililo siguiendo un procedimiento análogo al descrito en S2, en el que sólo se utilizaba un $8 \%$ de piridina en acetona anhidra. El primer problema se planteó al obtener una masa de aspecto pegajoso imposible de filtrar, de modo que el producto acetilado no podía ser aislado. Se procedió a realizar la hidrólisis sin aislar dicho producto, pero la reacción no llegó a buen término. Finalmente, la síntesis se abordó haciendo reaccionar el hapteno $\mathbf{S 2}$ con cloruro de $N$-acetilsulfanililo en agua destilada conteniendo hidróxido de sodio, y 
posterior desacetilación por hidrólisis ácida, alcanzando un rendimiento global del $27 \%$.

Del análisis espectroscópico del hapteno S14 (Espectros 17-20, Apéndice I) cabe destacar que el espectro de ${ }^{1} \mathrm{H}-\mathrm{RMN}$ presenta dos singletes, a 10,67 y 10,55 ppm, correspondientes al hidrógeno de los dos grupos sulfonamida, así como seis dobletes aromáticos, confirmando la estructura del hapteno. Mediante el ${ }^{13} \mathrm{C}-\mathrm{RMN}$ se pudo observar la señal a $166,7 \mathrm{ppm}$ correspondiente al carbono cuaternario del grupo ácido. El espectro IR del producto obtenido presentaba, entre otras, una banda a $1678 \mathrm{~cm}^{-1}$ característica de la tensión del doble enlace carbono-oxígeno del grupo ácido, y dos bandas (1321 y $1153 \mathrm{~cm}^{-1}$ ) correspondientes a la tensión del doble enlace azufre-oxígeno, asimétrica y simétrica, respectivamente.

\subsubsection{Haptenos tipo II}

Este tipo de haptenos se obtuvieron por funcionalización del grupo amino aromático de la región constante. Los cuatro haptenos de este grupo presentan como característica común la presencia de un brazo espaciador aromático, tal como muestra la Figura 29. Mediante diazotación se sintetizaron dos haptenos, denominados $\mathbf{S 7}$ y $\mathbf{S 8}$, los cuales se diferencian en la región variable.

En este tipo de haptenos se han incluido, además, dos sulfonamidas comerciales -sulfasalazina (S5) y $N^{4}$-ftalilsulfatiazol (S6)-, las cuales presentan un sustituyente ácido que permite su conjugación directa a proteínas.

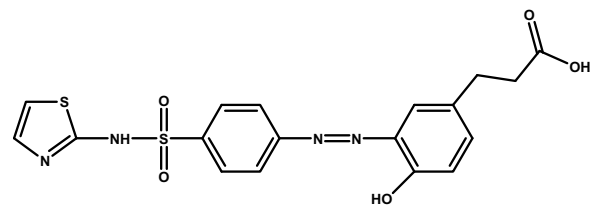

S7

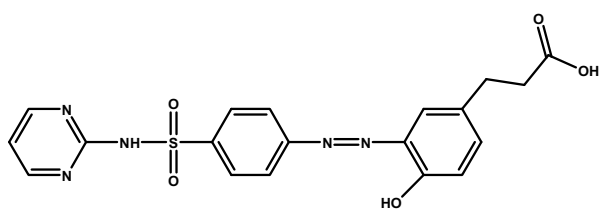

S8

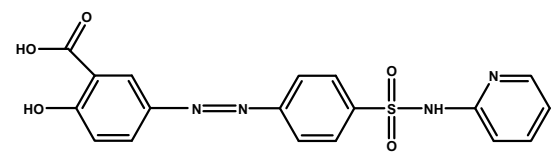

S5

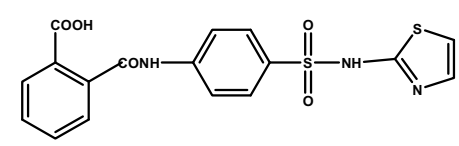

S6

Figura 29. Estructura química de los haptenos tipo II para sulfonamidas 
La estrategia sintética planteada para la obtención de los haptenos $\mathbf{S 7}$ y $\mathbf{S 8}$ se basó, en primer lugar, en la formación de la sal de diazonio de la sulfonamida correspondiente, seguida de un acoplamiento diazo con el ácido 3-(4hidroxifenil)propanoico, lo que da lugar al azocompuesto correspondiente, tal y como se muestra en la Figura 30.
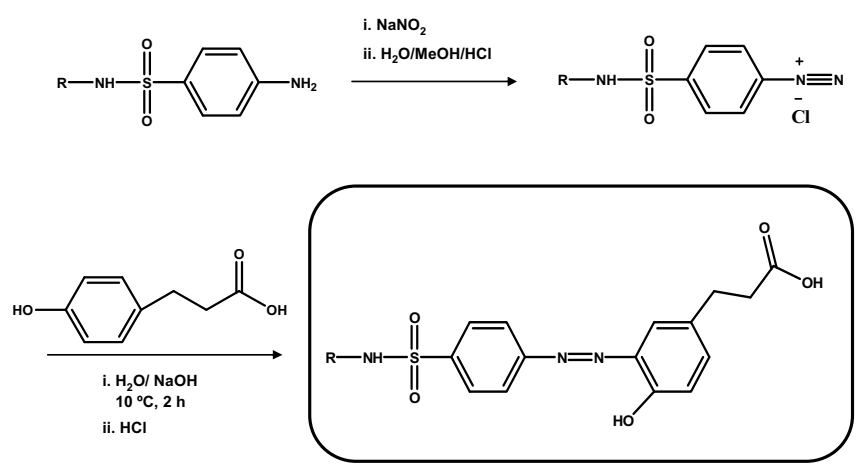

Figura 30. Esquema sintético seguido para la obtención de los haptenos S7 y S8

Para la obtención del hapteno $\mathbf{S 7}$ se abordó, en primer lugar, la formación de la sal de diazonio de STZ. Para ello, el grupo amino del STZ se sometió a diazotación con nitrito sódico en medio metanólico acidificado, de modo que la concentración de la sal de diazonio fuese máxima. Paralelamente, se preparó una disolución del ácido 3-(4-hidroxifenil)propanoico en hidróxido de sodio $1 \mathrm{M}$ y, rápidamente, se mezclaron las dos disoluciones, produciéndose el acoplamiento diazo que permitió obtener el azocompuesto correspondiente. Tras ajustar el $\mathrm{pH}$ con ácido clorhídrico concentrado, el producto deseado se aisló por filtración obteniendo un rendimiento del 97\%.

En el espectro de IR realizado al producto no se observó la banda de tensión característica del grupo amino libre de la sulfonamida; sin embargo, aparecía una banda de tensión a $1572 \mathrm{~cm}^{-1}$ característica del grupo azo, lo que confirmaba que la reacción había tenido lugar. Por otra parte, los espectros de ${ }^{1} \mathrm{H}-\mathrm{RMN}$ y de ${ }^{13} \mathrm{C}$ RMN presentaron características acordes con su estructura, mientras que su espectro de MS no proporcionó gran información (Espectros 21-24, Apéndice I).

Hasta la fecha no se ha encontrado documentación sobre la síntesis de este compuesto, aunque las reacciones de acoplamiento diazo son reacciones 
frecuentemente descritas en la bibliografía. El principal problema de esta ruta sintética fue debido a la baja solubilidad del producto de partida (STZ) en las condiciones descritas en la bibliografía para las reacciones de diazotación, las cuales generalmente se llevan a cabo en disolución acuosa. Por ello, se realizaron una serie de ensayos utilizando diferentes disolventes orgánicos (metanol, etanol, propanol y acetona) en disolución acuosa, resultando el metanol el más adecuado.

La síntesis del ácido 3-\{4-hidroxi-3-[4-(pirimidin-2-ilsulfamoil)fenilazo]fenil\} propanoico (hapteno S8) se abordó siguiendo un procedimiento análogo al descrito para S7. En este caso, el reactivo diazotizado fue la SDZ, obteniendo un rendimiento final del $76 \%$.

Este hapteno se caracterizó por sus datos espectroscópicos (Espectros 25-28, Apéndice I). El espectro de ${ }^{1} \mathrm{H}-\mathrm{RMN}$ presentaba, entre otras señales, un singlete amplio a 12,06 ppm correspondiente al grupo ácido del ácido 3-(4hidroxifenil)propanoico, así como un doblete aromático a 8,54 ppm que fue asignado a los dos hidrógenos aromáticos unidos a los nitrógenos del anillo aromático de la SDZ, lo que confirmó que la reacción había llegado a buen término. La principal característica del espectro de IR fue la presencia de una banda de tensión a $1579 \mathrm{~cm}^{-1}$ que correspondía al grupo azo. El espectro de MS no proporcionó el pico del ión molecular, apareciendo, en primer lugar, el pico correspondiente a un fragmento de la $\mathrm{SDZ}\left(\mathrm{C}_{10} \mathrm{H}_{9} \mathrm{~N}_{4}\right)$.

\subsubsection{Haptenos tipo III}

Finalmente, la tercera estrategia utilizada permitió obtener cuatro haptenos con el brazo espaciador unido por el grupo sulfonamido, de modo que se dispone de haptenos fragmentarios que contienen la región constante de la estructura general de las sulfonamidas. Como muestra la Figura 31, los haptenos S10, S11 y S13 difieren únicamente en la longitud del brazo espaciador. Así, el hapteno S10 presenta un brazo espaciador derivado de la glicina, el S11 del ácido 6aminohexanoico y el S13 del ácido 4-aminobutanoico. Por otro lado, el hapteno S12 difiere de los anteriores en el tipo de grupo funcional, presentando un brazo espaciador derivado del 3-amino-1-propanol. 


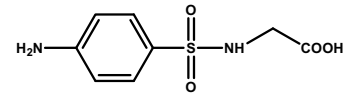

S10

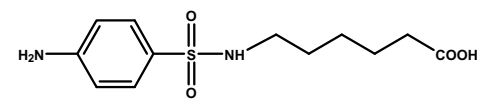

S11

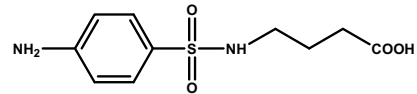

S13

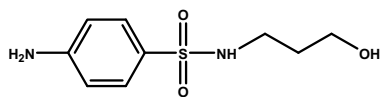

S12

Figura 31. Estructura química de los haptenos tipo III para sulfonamidas

La Figura 32 muestra la ruta sintética seguida para la obtención de los haptenos S10, S12 y S13. Como se observa, el método general llevado a cabo para la preparación de estos compuestos fue la condensación del cloruro de $\mathrm{N}$ acetilsulfanililo con una amina primaria, en presencia de hidróxido de sodio o de exceso de amina, seguida de la hidrólisis del grupo acetil mediante reflujo con ácido clorhídrico. La etapa de condensación no requirió el uso de piridina o acetona/piridina, ya que los derivados de la $p$-amino-bencenosulfonamida son más solubles en agua.

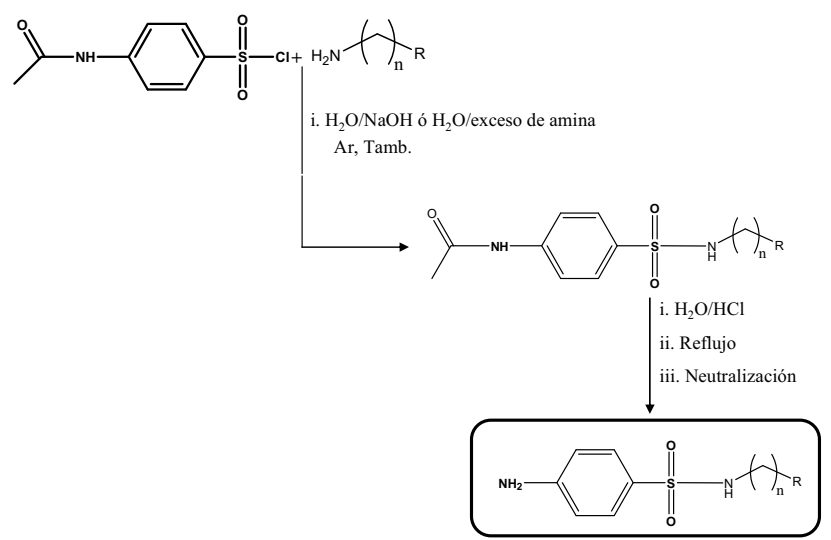

Figura 32. Esquema sintético seguido para la obtención de los haptenos S10, S12 y S13

La síntesis del ácido (4-amino-bencenosulfonilamino)acético (S10) se llevó a cabo siguiendo el procedimiento descrito por Kolloff ${ }^{124}$. La condensación del cloruro de $\mathrm{N}$-acetilsulfanililo con glicina se efectuó en presencia de hidróxido de 
sodio, seguida de hidrólisis ácida, dando lugar al hapteno $\mathbf{S 1 0}$ con un rendimiento global del 61\%.

Al caracterizar este compuesto (Espectros 29-32, Apéndice I) se observó que el espectro de ${ }^{1} \mathrm{H}-\mathrm{RMN}$ presentaba, entre otras señales, un singlete amplio a 5,90 ppm característico del grupo amino aromático, y un singlete a 2,94 ppm que integraba los dos hidrógenos correspondientes al grupo metileno del brazo espaciador. En el espectro de ${ }^{13} \mathrm{C}$-RMN se observó una señal a 169,9 ppm correspondiente al carbono cuaternario del grupo ácido, y otra a 46,1 ppm que identifica al carbono del grupo metileno. El espectro de IR presentó características espectroscópicas acordes con su estructura, obteniendo, entre otras bandas, la característica del grupo carbonilo a $1643 \mathrm{~cm}^{-1}$. En este caso, el espectro de masas no proporcionó el pico del ión molecular, apareciendo, en primer lugar, el pico correspondiente a la descarboxilación del ácido carboxílico.

El hapteno 4-amino- $N$-(3-hidroxipropil)bencenosulfonamida (S12) fue sintetizado siguiendo un procedimiento análogo al utilizado por Adams et al. ${ }^{125}$. Se preparó por condensación del cloruro de $\mathrm{N}$-acetilsulfanililo con una alcanolamina, la 3-amino-1-propanol, en agua destilada. En este caso, la reacción se llevó a cabo en presencia de un exceso de amina, con el fin de neutralizar el ácido clorhídrico generado que no es eliminado en el proceso de lavado. El producto de condensación se separó del crudo de reacción por precipitación, alcanzando un rendimiento del $89 \%$. La obtención del producto I se comprobó mediante ${ }^{1} \mathrm{H}-\mathrm{RMN}$, observando un triplete a 7,37 ppm, identificado como el hidrógeno del nitrógeno de la sulfonamida unido al grupo metileno del brazo espaciador. Finalmente, el producto I fue hidrolizado en medio ácido y, tras neutralizar con carbonato sódico y recristalizar en EtOH/agua, se obtuvo el aminoalcohol deseado (hapteno S12), con un rendimiento global del $48 \%$.

Del análisis espectroscópico del hapteno S12 (Espectros 37-40, Apéndice I) cabe destacar la ausencia de las señales debidas a los protones y carbonos que constituyen el grupo acetil en los espectros de RMN, y la presencia del pico molecular a un valor de la relación $\mathrm{m} / \mathrm{z}$ de 230 , además de los fragmentos típicos de la familia de las sulfonamidas, en el espectro de masas.

A continuación, tal como se indica en la Figura 32, se llevó a cabo la síntesis del hapteno S13, siguiendo un procedimiento análogo al descrito para S10. El reactivo de partida fue el ácido 4-aminobutanoico. El crudo de reacción se agitó 
durante $3 \mathrm{~h}$ a temperatura ambiente, se acidificó con ácido clorhídrico concentrado y el sólido obtenido se recristalizó en etanol al 60\% (Producto I). Posteriormente, se efectuó una hidrólisis ácida del producto I que dio lugar al aminoácido deseado, con un rendimiento global del 40\%. Mediante resonancia magnética de protón se comprobó que el producto obtenido correspondía al hapteno S13 (presencia de dos singletes a 12,02 y 5,90 ppm, correspondientes al hidrógeno del grupo ácido y a los hidrógenos de la amina libre, respectivamente). La identificación del producto se completó mediante IR y MS. En este caso, el espectro de masas proporcionó el pico del ión molecular a un valor de 258 unidades de m/z (Espectros 41-44, Apéndice I).

Recientemente, la síntesis de este hapteno ha sido descrita también por Zhang et al. ${ }^{96}$, alcanzando un rendimiento global del 28\%. Estos autores realizan la condensación con cloruro de $N$-acetilsulfanililo en piridina anhidra, seguida de una hidrólisis básica sin aislamiento del producto intermedio. Sin embargo, en estas condiciones, la bis-sulfonilación de la amina primaria tiene lugar como reacción secundaria, lo que provoca una disminución del rendimiento de la reacción. Por otro lado, la ruta sintética planteada en esta tesis elimina el uso de piridina, ya que como compuesto de partida se utiliza el ácido 4-aminobutanoico, soluble en agua, permitiendo aislar fácilmente el producto obtenido con rendimientos excelentes.

El último hapteno de este grupo es el denominado ácido 6-(4-aminobencenosulfonilamino)hexanoico (S11), cuyo esquema sintético sigue las pautas planteadas para la preparación de derivados de glicina descritas por Mayfield et al. ${ }^{146}$. Como se muestra en la Figura 33, para la obtención de este hapteno se realizó el acoplamiento entre el cloruro de 4-nitrobencenosulfonilo y el ácido 6aminohexanoico, seguido de la reducción del grupo nitro a amino con hidrógeno en presencia de paladio sobre carbono. El producto deseado se separó del crudo de reacción por cromatografía en columna sobre sílica gel, utilizando hexano/AcOEt de polaridad creciente. El rendimiento total obtenido fue del $43 \%$.

El hapteno S11 se caracterizó por sus datos espectroscópicos (Espectros 33-36, Apéndice I). Los espectros de ${ }^{1} \mathrm{H}-\mathrm{RMN}$ y de ${ }^{13} \mathrm{C}-\mathrm{RMN}$ presentaron características acordes con su estructura. En el espectro de IR destacó, principalmente, la ausencia de la banda de tensión característica del grupo nitro, y la presencia de las bandas de tensión a 3414 y $3327 \mathrm{~cm}^{-1}$ características del grupo amino aromático de la sulfonamida, confirmando que la reacción de reducción había tenido lugar. 


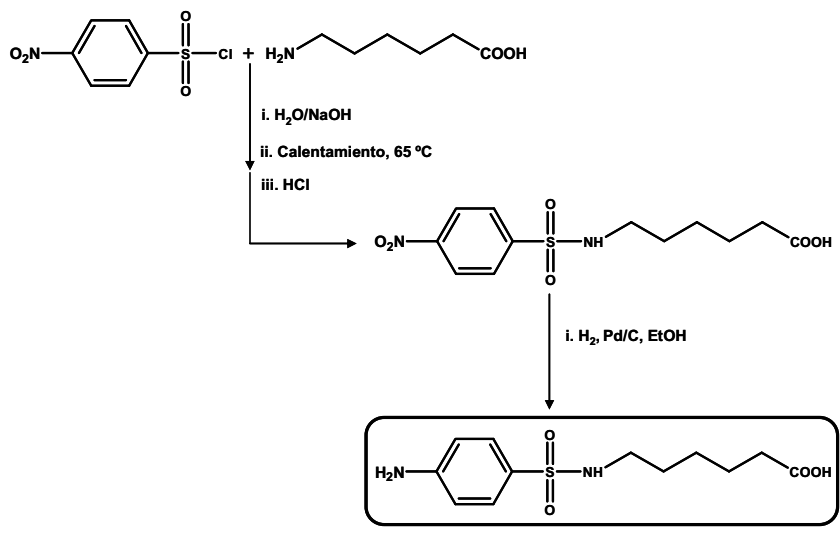

Figura 33. Esquema sintético seguido para la obtención del hapteno S11

La síntesis de este hapteno había sido descrita con anterioridad por Li et al. ${ }^{145} \mathrm{y}$ más recientemente, por Zhang et al. ${ }^{96}$. En ambos casos, la ruta sintética utilizada implica la condensación del ácido 6-aminohexanoico con cloruro de $\mathrm{N}$ acetilsulfanililo en piridina seca, seguida de una hidrólisis básica y posterior purificación mediante cromatografía en columna, con un rendimiento global del $21 \%$ en el primer caso y $35 \%$ en el segundo. La ruta de síntesis utilizada en esta tesis es totalmente diferente; aunque el número de etapas es similar, la toxicidad de los reactivos utilizados y el tiempo de reacción son inferiores, consiguiendo, además, un rendimiento global más elevado.

Teniendo en cuenta las distintas estrategias sintéticas utilizadas para la preparación de los haptenos, así como los resultados obtenidos, puede observarse que, en general, la etapa clave en el rendimiento global de la reacción es la condensación, y su factor limitante, la solubilidad del compuesto de partida. Cuando dicha etapa se lleva a cabo con disolventes orgánicos -debido a la insolubilidad del compuesto de partida en disolución acuosa- y piridina como aceptor del ácido clorhídrico generado, los rendimientos alcanzados son inferiores a los obtenidos al realizar la condensación en medio acuoso, debido a que se favorece la bis-sulfonilación de la amina primaria (Figura 34) ${ }^{147}$. 


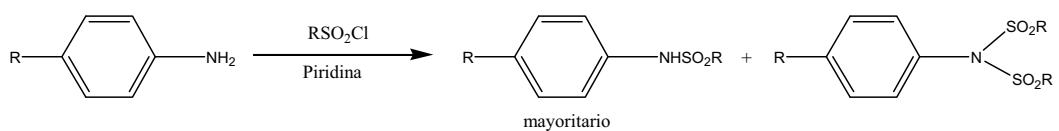

Figura 34. Reacción secundaria descrita por Deng et al.

Por último, cabe destacar que la estrategia de diazotación, estudiada por primera vez en el contexto de esta tesis doctoral, ha dado resultados prometedores, ya que el producto puede ser aislado con facilidad y con rendimientos excelentes, superiores al $76 \%$.

\subsubsection{Diseño y síntesis de haptenos para tetraciclinas}

Las tetraciclinas constituyen una familia de productos naturales y semisintéticos que se caracterizan por tener una estructura tetracíclica lineal compuesta de cuatro anillos fusionados (designados A, B, C y D), siendo $\mathrm{R}_{1}, \mathrm{R}_{2}, \mathrm{R}_{3}, \mathrm{R}_{4}$ y $\mathrm{R}_{5}$ los radicales que dan lugar a los diferentes compuestos que constituyen dicha familia (sección 3.1.4, Experimental).

Las tetraciclinas son sustancias muy reactivas debido a su compleja funcionalidad y a la sensibilidad de las moléculas en condiciones de reacción suaves ( $\mathrm{pH}$ y temperatura) ${ }^{148}$. Además, son inestables bajo condiciones básicas y ácidas fuertes, y forman epímeros reversibles. Muchos de estos antibióticos se fotodescomponen, dando lugar a varios subproductos ${ }^{149}$. Asimismo, debido a la presencia de grupos que pueden formar puentes de hidrógeno intramoleculares, las tetraciclinas forman complejos con un gran número de especies químicas. Estas son algunas de las razones por las que la síntesis y purificación de haptenos para tetraciclinas es complicada, y las referencias bibliográficas sobre la determinación de tetraciclinas mediante inmunoensayos escasas.

En la bibliografía se observan dos tipos de estrategias para la obtención de anticuerpos. La primera está basada en el acoplamiento directo de una TC comercial a la proteína carrier y, la segunda, en la síntesis de un hapteno por derivatización de la tetraciclina ${ }^{104}$.

Inicialmente, teniendo en cuenta los precedentes bibliográficos y partiendo de la tetraciclina hidratada, se ensayaron cuatro rutas sintéticas diferentes (Figura 35). 


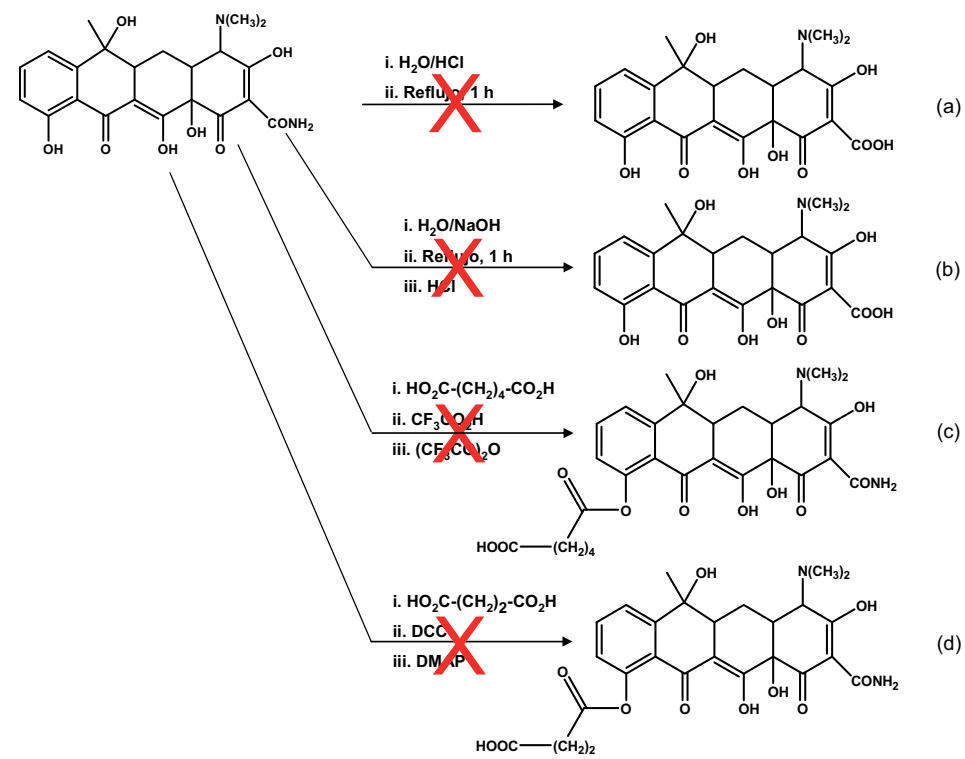

Figura 35. Esquemas sintéticos ensayados en la obtención de haptenos para tetraciclinas

En primer lugar se intentó llevar a cabo la hidrólisis ácida del grupo amida (a). Para ello, a 1,00 g (2,25 mmoles) de TC se añadieron $31 \mathrm{~mL}$ de $\mathrm{HCl} 2 \mathrm{M}$, calentando la mezcla resultante durante $1 \mathrm{~h}$ a reflujo. Inicialmente, la reacción era una suspensión amarillenta, observándose la disolución de todos los reactivos a medida que evolucionaba. El seguimiento de la reacción se hizo por TLC (AcOEt/EtOH, 95:5 v/v), comprobando la desaparición del producto de partida y la formación de un nuevo producto con un $\mathrm{R}_{\mathrm{f}}$ mayor. Tras enfriar a temperatura ambiente apareció un sólido anaranjado que se aisló por filtración. El espectro de masas del producto obtenido presentaba, entre otras señales, el pico molecular a un valor de 426 unidades de $\mathrm{m} / \mathrm{z}$, lo que indicaba que no se había obtenido el producto deseado, sino la anhidrotetraciclina (aromatización del anillo C).

La segunda ruta sintética ensayada se basó en la hidrólisis básica del grupo amida (b). Para ello, a 1,00 g (2,25 mmoles) de TC se adicionaron $10 \mathrm{~mL}$ de $\mathrm{NaOH}$ $1 \mathrm{M}$, calentando la mezcla resultante durante $1 \mathrm{~h}$ a reflujo. El seguimiento de la reacción se realizó mediante TLC (AcOEt/EtOH, 90:10), observando la presencia de un gran número de productos. Para comprobar si alguno de ellos pudiera ser el 
ácido, el $\mathrm{pH}$ de la disolución se ajustó a 5 con $\mathrm{HCl} 6 \mathrm{M}$ y se enfrió a $5{ }^{\circ} \mathrm{C}$, no apareciendo ningún precipitado, por lo que esta ruta sintética fue desechada.

Finalmente, se ensayó la esterificación del único fenol presente en la TC utilizando dos vías sintéticas. En la primera (c), se partió de 1,06 g (7,25 mmoles) de ácido adípico, 3,19 g (7,18 mmoles) de TC, 5,5 $\mathrm{mL}$ de ácido trifluoroacético (TFA) y 4,2 $\mathrm{mL}$ de anhídrido trifluoroacético (TFAA). Tras $1 \mathrm{~h}$ en agitación, bajo atmósfera de $\operatorname{Ar}$ a $0{ }^{\circ} \mathrm{C}$, se obtuvo una disolución anaranjada. El crudo de reacción se rotavaporó para eliminar el exceso de TFA y TFAA, y se secó a vacío. El sólido anaranjado obtenido se disolvió en $30 \mathrm{~mL}$ de $\mathrm{CH}_{2} \mathrm{Cl}_{2}$, se lavó con una disolución de bicarbonato de sodio $1 \mathrm{M}(3 \times 10 \mathrm{~mL})$, se secó con $\mathrm{Na}_{2} \mathrm{SO}_{4}$ anhidro y el extracto se concentró a presión reducida. Mediante el análisis por espectroscopía de masas se comprobó que el producto obtenido no era el deseado, se trataba de la anhidrotetraciclina.

Para la segunda vía (d), se partió de $0,57 \mathrm{~g}$ (1,28 mmoles) de TC disueltos en $12,6 \mathrm{~mL}$ de $\mathrm{CH}_{2} \mathrm{Cl}_{2}$ anhidro y $3 \mathrm{~mL}$ de $\mathrm{CH}_{3} \mathrm{CN}$ anhidro. Tras obtener una mezcla homogénea, se adicionaron $0,16 \mathrm{~g}$ (1,32 mmoles) de ácido succínico y se mantuvo en agitación durante $30 \mathrm{~min}$. Posteriormente, se adicionaron lentamente -a $0{ }^{\circ} \mathrm{C}$ y bajo atmósfera de Ar- $17 \mathrm{mg}$ de DMAP y 0,27 g (1,33 mmoles) de DCC, y se agitó la mezcla durante $3 \mathrm{~h}$. La reacción se siguió mediante TLC (AcOEt/EtOH, 85:15), no observando ningún producto de la misma, por lo que se agitó durante toda la noche. La TLC indicó que la reacción no se había llevado a cabo y que los productos de partida permanecían sin reaccionar, por lo que se desechó esta vía sintética.

Dado que todas las vías sintéticas propuestas dieron resultados negativos, se intentó llevar a cabo la síntesis descrita por Everest et al. ${ }^{104}$, basada en la obtención de un derivado de la TC, el 4-hidrazono-4-dedimetilamino tetraciclina. Como muestra la Figura 36, la tetraciclina fue derivatizada por tratamiento con $\mathrm{N}$ clorosuccinimida (NCS) 0,1 M en medio acuoso, formándose la 4-oxotetraciclina. Dicho intermedio fue tratado con hidrato de hidrazina $\left(\mathrm{H}_{2} \mathrm{~N}-\mathrm{NH}_{2}\right)$ en etanol durante toda una noche para obtener el 4-hidrazono-4-dedimetilamino tetraciclina. Aunque el procedimiento está descrito en la bibliografía, los resultados no pudieron reproducirse, probablemente por la inestabilidad del compuesto intermedio, 4oxotetraciclina. Se llevaron a cabo varios intentos obteniendo siempre mezclas de productos muy difíciles de separar. 


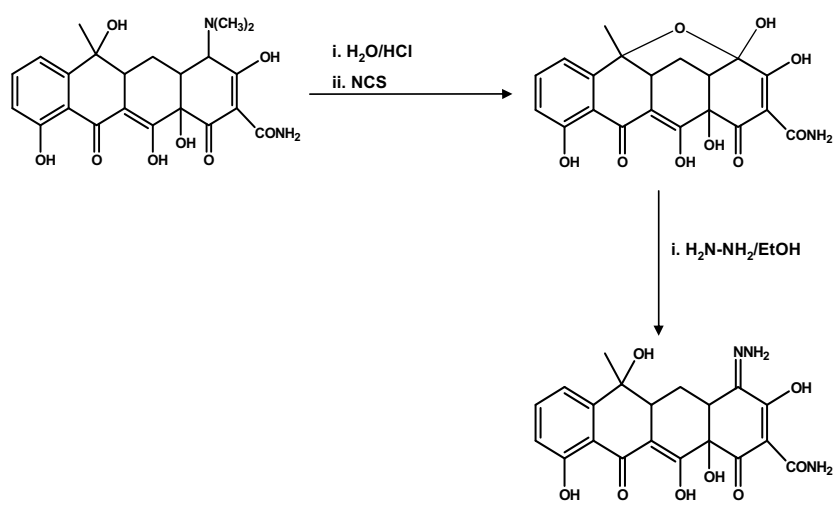

Figura 36. Esquema sintético seguido para la obtención de 4-hidrazono-4dedimetilaminotetraciclina

Dado que ninguna de las rutas ensayadas condujo a la obtención de un hapteno, se plantearon nuevas estrategias. Teniendo en cuenta los buenos resultados obtenidos mediante la estrategia de diazotación para las sulfonamidas, se pensó que podría ser una buena vía para la síntesis de azoderivados de tetraciclinas. Otra alternativa era sintetizar derivados de carboxamida mediante una condensación de Mannich. Por ello, se propusieron dos tipos de haptenos, en función del lugar en que es posible introducir el brazo espaciador (Figura 37):

- Haptenos tipo I: derivados de carboxamida, funcionalizados a través del anillo A del esqueleto común

- Haptenos tipo II: azoderivados, funcionalizados a través del anillo D del esqueleto común

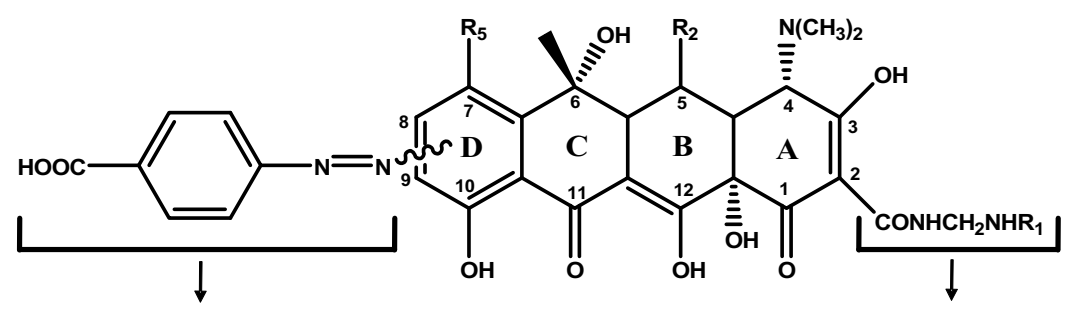

Haptenos tipo II

Haptenos tipo I

Figura 37. Clasificación de los haptenos para tetraciclinas según la ubicación del brazo espaciador 
Además, se llevó a cabo una búsqueda de productos comerciales de características similares que pudiesen ser utilizados como haptenos.

En total, para la determinación de tetraciclinas se sintetizaron seis haptenos que, manteniendo el núcleo básico de la familia de las tetraciclinas, poseen un brazo espaciador aromático o alifático, de modo que se genera cierto grado de heterología en la estructura química.

\subsubsection{Haptenos tipo I}

Este tipo de haptenos fueron obtenidos efectuando la funcionalización a través del anillo A del esqueleto común de octahidronaftaleno. Los tres haptenos de este grupo son derivados carboxamida y presentan un brazo espaciador alifático, tal como muestra la Figura 38.

Mediante condensación se sintetizaron los haptenos denominados CTC-2 y OTC-2, con un brazo espaciador derivado de la glicina y que difieren entre sí en la tetraciclina base.

En este grupo se incluye también el hapteno TC-3, una tetraciclina comercial (2-N-lisinometiltetraciclina) que presenta un sustituyente ácido que permite su conjugación directa a proteínas.

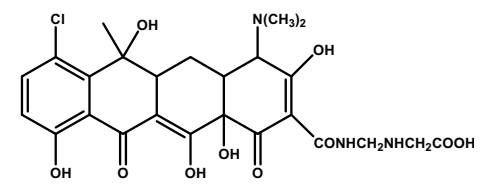

CTC-2

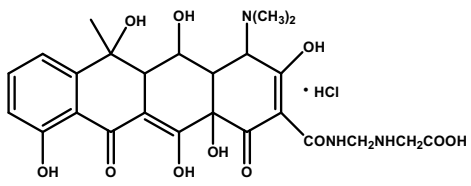

OTC-2

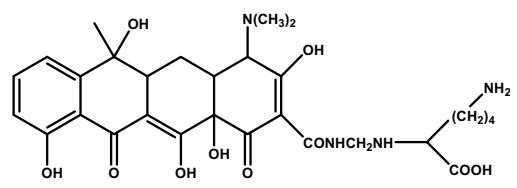

TC-3

Figura 38. Estructura química de los haptenos tipo I para tetraciclinas

La ruta sintética planteada para la preparación de los haptenos CTC-2 (glicinametilclortetracilina) y OTC-2 (hidrocloruro de glicinametiloxitetraciclina), 
se muestra en la Figura 39. El método general seguido para la preparación de estos compuestos fue la formación de derivados carboxamida de tetraciclinas con glicina, mediante una reacción de condensación de Mannich, donde la función carboxamida primaria del anillo A sufre una $N$-alquilación, siguiendo una estrategia similar a la patentada por Lazareva et al. ${ }^{126}$ para la TC.

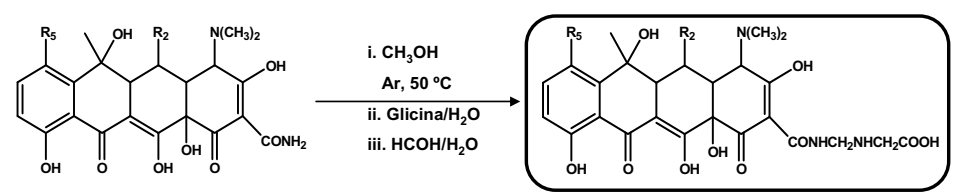

Figura 39. Esquema sintético seguido para la obtención de los haptenos CTC-2 y

OTC-2

Para la síntesis de estos haptenos, se mezclaron cantidades adecuadas de la correspondiente TC (CTC y OTC, respectivamente) y glicina, en presencia de formaldehído diluido en metanol caliente. Tras agitar durante $15 \mathrm{~min}$, la mezcla de reacción se filtró con el fin de eliminar el producto de partida que no había reaccionado.

El hapteno correspondiente se obtuvo por enfriamiento de la mezcla de reacción (CTC-2), o por acidificación con $\mathrm{HCl} 6 \mathrm{M}$ (OTC-2). Los rendimientos fueron bajos en ambos casos debido a la reducida solubilidad del compuesto de partida en metanol.

La caracterización de CTC-2 se realizó por comparación de los espectros de resonancia magnética nuclear con los del producto de partida -CTC- (Espectros 4548, Apéndice I). La mayor información la proporcionó el ${ }^{13} \mathrm{C}-\mathrm{RMN}$, al observar tres nuevas señales a 171,4, 72,1 y 53,2 ppm, asignables al carbono cuaternario del grupo ácido y a los dos carbonos de los grupos metilenos del brazo espaciador, respectivamente.

La caracterización del hapteno OTC-2 se llevó a cabo utilizando el mismo procedimiento y OTC como producto de partida (Espectros 49-52, Apéndice I). El ${ }^{13} \mathrm{C}$-RMN mostró tres nuevas señales a 171,5, 72,2 y 53,3 ppm, asignables -como en el caso anterior- a los tres carbonos que aporta el brazo espaciador de glicina. 


\subsubsection{Haptenos tipo II}

La segunda estrategia utilizada permitió obtener tres haptenos azoderivados con el brazo espaciador unido por el anillo D del octahidronaftaleno. Como muestra la Figura 40, OTC-3, CTC-3 y TC-4 presentan como característica común un brazo espaciador aromático derivado del ácido 4-aminobenzoico, y difieren entre sí en la tetraciclina base.

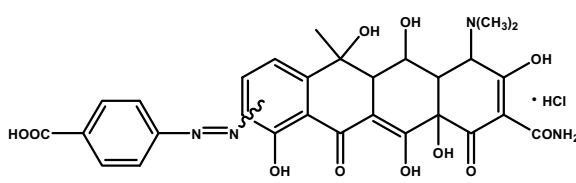

OTC-3

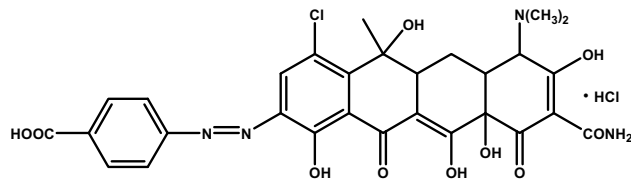

CTC-3

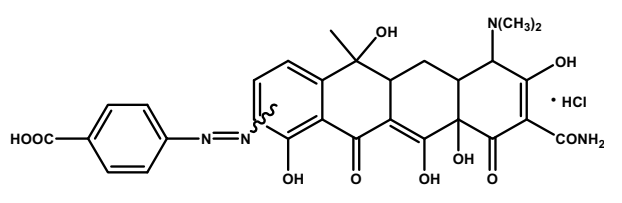

TC-4

Figura 40. Estructura química de los haptenos tipo II para tetraciclinas

La estrategia sintética planteada para la obtención de los haptenos OTC-3, CTC-3 y TC-4 se basó en la reacción de diazotación utilizada para las sulfonamidas, como se ha comentado anteriormente. En el caso de las sulfonamidas, la sal de diazonio se forma a partir de la sulfonamida correspondiente; sin embargo, debido a la inestabilidad de las tetraciclinas en medio ácido, la sal de diazonio se formó a partir del ácido 4-aminobenzoico, seguida de un acoplamiento diazo con la tetraciclina base, lo que dio lugar al azocompuesto correspondiente (Figura 41).

Para la obtención del hapteno OTC-3 se abordó, en primer lugar, la formación de la sal de diazonio del ácido 4-aminobenzoico, sometiéndolo a diazotación con nitrito sódico en medio acuoso acidificado (1). En esta etapa sintética la temperatura de reacción se mantuvo entre 0 y $10{ }^{\circ} \mathrm{C}$, de modo que la sal de diazonio fuese estable y se alcanzara la máxima concentración. Paralelamente, se preparó una disolución de OTC en hidróxido de sodio 0,2 M (2) y se mezclaron 
rápidamente las dos disoluciones ( 1 y 2), produciéndose el acoplamiento diazo. $\mathrm{La}$ mezcla de reacción se acidificó ligeramente con $\mathrm{HCl} 6 \mathrm{M}$ hasta la aparición de un precipitado amarillo, que se aisló por filtración. Mediante ${ }^{1} \mathrm{H}-\mathrm{RMN}$ se comprobó que el sólido obtenido correspondía a OTC en exceso. Finalmente, el $\mathrm{pH}$ del filtrado se ajustó a 3 con $\mathrm{HCl}$ concentrado, obteniéndose el azocompuesto correspondiente como un sólido anaranjado. El espectro de ${ }^{1} \mathrm{H}-\mathrm{RMN}$ (Espectro 53, Apéndice I) permitió comprobar que el sólido obtenido correspondía a una mezcla de productos.

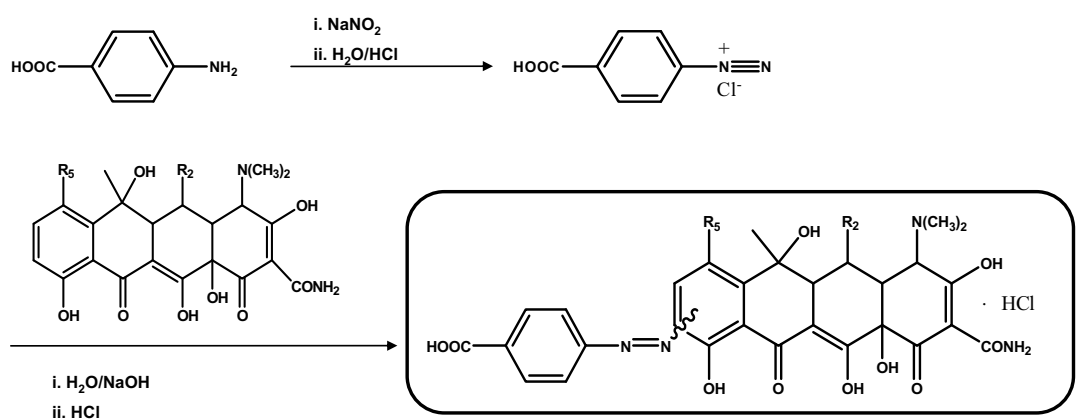

Figura 41. Esquema sintético seguido para la obtención de los haptenos OTC-3, CTC-3 y TC-4

Con el fin de poder caracterizar el sólido obtenido y verificar que la estrategia sintética planteada era adecuada, una pequeña porción de dicho sólido se purificó por HPLC.

El análisis de TCs por HPLC es complicado debido a que los compuestos de esta familia tienen propiedades químicas y fisicoquímicas muy similares. Uno de los principales problemas que presentan estos compuestos es que forman complejos quelatos con iones metálicos e interaccionan fuertemente con los grupos silanoles libres presentes en la fase estacionaria, causando picos anchos y con colas $50,150,151$. Para evitar este inconveniente, se han desarrollado métodos cromatográficos que utilizan columnas en fase reversa $\left(\mathrm{C}_{18}-\mathrm{C}_{8}\right)$ y fases móviles con bajo $\mathrm{pH}^{50}$.

La separación en fase reversa exige el empleo de una fase móvil de alta polaridad, lo que se consigue utilizando agua bidestilada y desionizada como disolvente base. A éste se incorpora un modificador orgánico y, en general, un modificador ácido que mejora la separación y evita la formación de colas en los 
picos del cromatograma. El modificador orgánico más utilizado para la purificación de TCs es el metanol ${ }^{152,153}$, aunque también se ha empleado acetonitrilo $^{154,155}$. Para disminuir el $\mathrm{pH}$ del eluyente se utiliza generalmente ácido oxálico $^{156,157}$, empleándose también ácido ortofosfórico ${ }^{155,158} \mathrm{o}$ ácido fórmico ${ }^{152,154}$. La mayoría de los métodos desarrollados llevan a cabo la separación de TCs en modo isocrático.

\section{Puesta a punto y optimización del procedimiento de purificación}

La purificación del producto sólido sintetizado se efectuó mediante cromatografía líquida preparativa. Para ello, se seleccionó una columna Lichrosorb RP-18 ( $20 \times 250 \mathrm{~mm}$, tamaño de partícula de 7,0 $\mu \mathrm{m})$ instalada en un cromatógrafo HPLC con detector de fila de diodos.

La Figura 42 muestra los espectros de absorción de la OTC pura y del sólido a purificar.

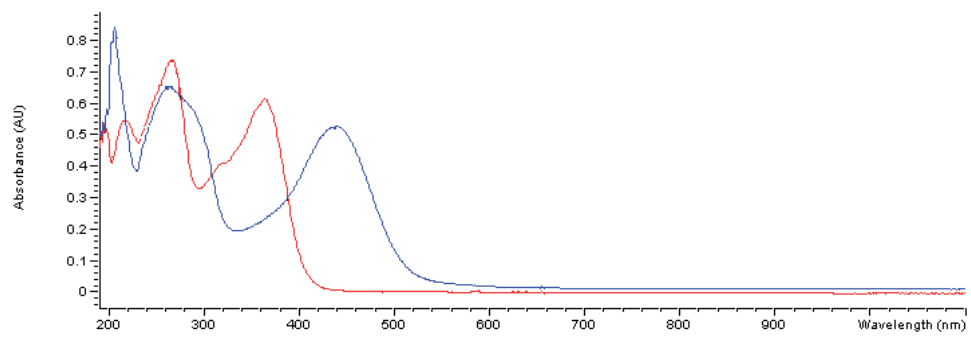

Figura 42. Espectros de absorción UV-VIS del patrón de OTC (línea roja) y del sólido a purificar (línea azul)

Ambos compuestos presentan un máximo de absorción alrededor de $265 \mathrm{~nm}$, seleccionando esta longitud de onda para la detección.

Para optimizar la fase móvil, se realizaron una serie de ensayos con diferentes eluyentes y condiciones de trabajo. Utilizando régimen isocrático, una mezcla eluyente A:B:C en proporción 50:25:25 durante $40 \mathrm{~min}$, y las siguientes condiciones cromatográficas:

- Eluyente A: ácido oxálico 0,01 M (pH 2)

- Eluyente B: metanol

- Eluyente C: acetonitrilo 
- Flujo $6 \mathrm{~mL} / \mathrm{min}$

- Detección a $265 \mathrm{~nm}$
- Presión 1.000 psi

- Vol. inyección $200 \mu \mathrm{L}$

no se consiguió la elución del hapteno OTC-3, aunque la resolución resultó satisfactoria para el patrón de OTC. Un aumento en la proporción de acetonitrilo (eluyente C) hasta un 50\% permitió eluir el hapteno OTC-3 en un tiempo superior a $50 \mathrm{~min}$. En consecuencia, se procedió a trabajar en modo gradiente, utilizando la misma mezcla ternaria de ácido oxálico-metanol-acetonitrilo, a fin de obtener un método que permitiera la separación de todos los compuestos en un tiempo inferior.

Los mejores resultados se obtuvieron con una elución en gradiente de A:B:C desde 50:25:25 hasta 50:0:50 en 27 min y desde 50:0:50 hasta 50:25:25 en $20 \mathrm{~min}$, empleando las condiciones cromatográficas siguientes:

- Eluyente A: ácido oxálico 0,01 M (pH 2)

- Eluyente B: metanol

- Eluyente C: acetonitrilo

- Flujo $6 \mathrm{~mL} / \mathrm{min}$

- Presión 1.020 psi

- Detección a $265 \mathrm{~nm}$

- Vol. inyección $200 \mu \mathrm{L}$

Operando de este modo se consiguió una buena separación de los compuestos en un tiempo apropiado ( $<25 \mathrm{~min}$ ). Después de repetidos análisis se comprobó que los cromatogramas presentaban una línea base irregular debida al excesivo ruido de fondo, lo que podía ser debido al ácido oxálico utilizado como modificador de la fase móvil, que absorbe en el ultravioleta. Por ello, se decidió sustituir el ácido oxálico por otros modificadores empleados en la bibliografía, manteniendo el resto de condiciones cromatográficas. Así pues, se ensayó con ácido fórmico a distintas proporciones. Los cromatogramas registrados mostraron una línea base estable; sin embargo, los picos obtenidos presentaban bastante cola. Posteriormente, se realizaron ensayos con ácido ortofosfórico, obteniendo resultados similares. Por ello, y teniendo en cuenta que el ácido oxálico no interfería en el proceso de purificación, se eligieron como óptimas las condiciones anteriormente descritas.

Los cromatogramas obtenidos para OTC patrón (a) y OTC-3 (b) se muestran en la Figura 43. Como puede observarse, los tiempos de retención $\left(t_{R}\right)$ para el patrón de OTC de $10 \mathrm{mg} / \mathrm{L}$ y OTC-3 fueron de 15,11 y 23,19 min, respectivamente. En el cromatograma b se observa que la mezcla purificada por HPLC contiene la 
fracción con el hapteno OTC-3 $\left(\mathrm{t}_{\mathrm{R}}=23,19 \mathrm{~min}\right)$. El método de purificación permitió la separación adecuada del exceso de reactivo de partida (OTC) y del hapteno deseado, OTC-3.

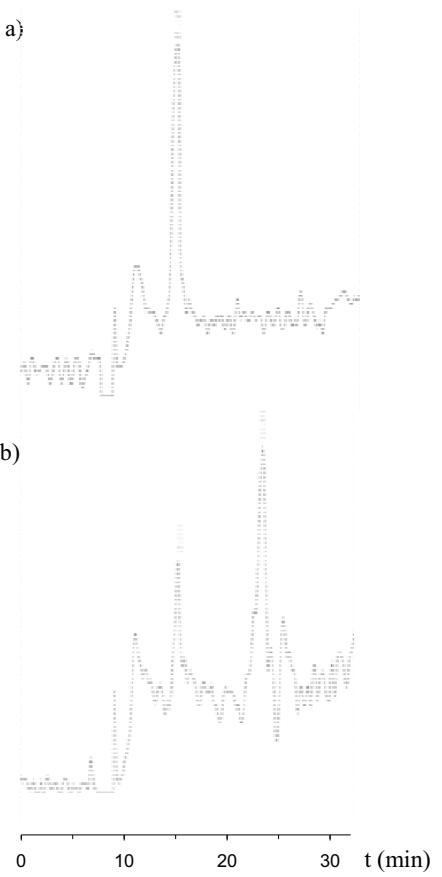

Figura 43. Cromatogramas obtenidos para (a) Patrón de OTC de $10 \mathrm{mg} / \mathrm{L}$, (b) Hapteno OTC-3 purificado

La caracterización de OTC-3 se realizó mediante ${ }^{1} \mathrm{H}-\mathrm{RMN}$ (Espectro 54, Apéndice I). La ampliación de la zona aromática confirmó que el sólido purificado se trataba de una mezcla de los hidrocloruros de 7 y 9-(4'carboxifenilazo)oxitetraciclina, por la aparición de seis dobletes (uno de ellos solapado). Los dobletes a 7,83 y 7,18 ppm pertenecen a los protones aromáticos que aporta el brazo espaciador (ácido 4-aminobenzoico), con una $J=8,7 \mathrm{~Hz}$. Los dobletes a 7,61 (solapado) y 7,12 ppm son asignables a los protones aromáticos de OTC cuando el brazo espaciador se introduce en el $\mathrm{C}_{9}$, con una $J=8,1 \mathrm{~Hz}$. Finalmente, los dobletes a 7,58 y $6,98 \mathrm{ppm}$ son asignables a los protones aromáticos de la OTC cuando el brazo espaciador se introduce en el $\mathrm{C}_{7}$, con una $J=$ 8,4 Hz. La inserción del Espectro 54 (Apéndice I), muestra el espectro completo, 
con una línea base ascendente como consecuencia del ácido oxálico de la fase móvil que acompaña al compuesto aislado por HPLC.

La síntesis del hidrocloruro de 9-(4'-carboxifenilazo)clortetraciclina (CTC-3) se abordó siguiendo un procedimiento análogo al descrito para OTC-3. En este caso, el acoplamiento diazo se llevó a cabo con la CTC, dando lugar a un único producto de reacción, ya que el hapteno CTC-3 tiene un sustituyente en posición para del anillo D. A través del ${ }^{1} \mathrm{H}-\mathrm{RMN}$ (Espectro 55, Apéndice I) se observó que el sólido obtenido correspondía al hapteno deseado junto al exceso de reactivo de partida (CTC). En este caso, no se llevó a cabo la purificación mediante HPLC debido a que la CTC no posee un grupo ácido y por tanto su interferencia en el proceso de conjugación del hapteno a las proteínas carrier es nulo; además, la estrategia planteada para la obtención de estos haptenos ya había sido verificada con la caracterización del hapteno OTC-3.

Finalmente, se llevó a cabo la síntesis del hapteno TC-4 (hidrocloruro de 7 y 9(4'-carboxifenilazo)tetraciclina), utilizando la TC para el acoplamiento diazo. A través del ${ }^{1} \mathrm{H}-\mathrm{RMN}$ (Espectro 56, Apéndice I) se observó que el sólido obtenido correspondía al hapteno deseado, junto al exceso de reactivo de partida (TC). El hapteno no fue purificado mediante HPLC por los motivos anteriormente descritos.

Hasta la fecha no se ha encontrado documentación sobre la síntesis de OTC-3, CTC-3 y TC-4, aunque las reacciones de acoplamiento diazo son reacciones frecuentemente descritas en la bibliografía. El principal problema de la ruta sintética planteada para la obtención de estos haptenos fue el aislamiento del producto obtenido del exceso de reactivo de partida. En general, en este tipo de reacciones, el producto se aísla por precipitación. Sin embargo, en este caso -debido a la funcionalidad compleja de ambos compuestos- la purificación del crudo de reacción se ha de realizar mediante HPLC, resultando un proceso muy laborioso. 


\subsection{DESARROLLO DE INMUNOENSAYOS}

\subsubsection{Caracterización y selección de los antisueros}

Por inmunización de conjugados de BSA o KLH (sección 3.2.3.3, Experimental), se obtuvieron un total de 46 antisueros, 26 para sulfonamidas y 20 para tetraciclinas. Los antisueros se nombraron en función de la proteína utilizada como inmunógeno y la abreviatura del hapteno. Los números romanos (I y II) hacen referencia a los dos animales inmunizados (sólo para el hapteno OTC-3 se inocularon 4 conejas, I a IV).

La caracterización de los antisueros se realizó en microplacas de 96 pocillos, operando en formato 2D mediante ensayos de titulación, basados en determinar la capacidad de reconocimiento específico antisuero/trazador y antisuero/conjugado de tapizado para el formato directo e indirecto, respectivamente.

En formato directo se ensayaron diluciones de antisuero entre 1:1.0001:128.000 (sentido vertical de la microplaca), y concentraciones de trazador entre $3,9 \mu \mathrm{g} / \mathrm{L}$ y $4,0 \mathrm{mg} / \mathrm{L}$ (sentido horizontal).

En formato indirecto se ensayaron diluciones seriadas del conjugado de tapizado entre $2 \mu \mathrm{g} / \mathrm{L}-1 \mathrm{mg} / \mathrm{L}$ (sentido horizontal), y diluciones del antisuero entre 1:1.000-1:128.000 (sentido vertical de la microplaca). Representando las absorbancias medidas en función de la concentración de antisuero, se obtuvieron las curvas de titulación para cada combinación y formato de ensayo. Así, se seleccionaron como concentraciones óptimas antisuero/trazador o antisuero/conjugado de tapizado aquellas que, sin llegar al punto de saturación de la curva, dieron absorbancias comprendidas entre 1,0 y 1,5 unidades.

\subsubsection{Selección de antisueros para sulfonamidas}

En formato directo, de los 26 antisueros obtenidos para sulfonamidas sólo mostraron cierto grado de reconocimiento BSA-S2-I, BSA-S3 (I y II), BSA-S4 (I y II), cuando se utilizaron los haptenos $\mathbf{S 2}, \mathbf{S 3}$ y $\mathbf{S 4}$ como trazadores.

Los haptenos tipo I se caracterizan por mantener intacta la región constante y poseer la región variable funcionalizada (Figura 25), mientras que los haptenos tipo II están funcionalizados a través de la región constante (Figura 29) y los tipo III 
son haptenos fragmentarios que carecen de la región variable (Figura 31). Los resultados muestran que los anticuerpos obtenidos a partir de haptenos tipo I fueron los únicos que presentaron un título medio o alto cuando se utilizó ese mismo tipo de hapteno para la preparación del trazador y que, en todos los casos, fue mayor en condiciones de homología.

En formato indirecto, todos los conjugados de tapizado fueron reconocidos por los antisueros en mayor o menor extensión, obteniéndose una señal de absorbancia máxima en ausencia de analito entre 1,0-1,5, dependiendo de las concentraciones de cada combinación antisuero/conjugado ensayadas.

En general, los antisueros obtenidos contra los haptenos tipo I (S2, S3, S4 y S14) dieron títulos altos frente a todos los conjugados, a excepción de BSA-S9 (I y II) que no presentaron reconocimiento alguno. Como hipótesis, se consideró que los antisueros obtenidos con el hapteno $\mathbf{S 9}$ deberían presentar títulos elevados, dado que su estructura es muy similar a otros haptenos que habían dado buenos $\operatorname{resultados}^{88,112,97}$, difiriendo únicamente en la longitud del brazo espaciador. Probablemente, al funcionalizar el hapteno con un brazo espaciador más largo, los grupos característicos del hapteno podrían haberse enmascarado debido a un plegamiento en la molécula.

Asimismo, el conjugado de tapizado preparado con el hapteno S4, que presenta un anillo de piridina como región variable, fue reconocido por la mayoría de los antisueros, quizás debido a la mayor densidad electrónica que introduce el átomo de nitrógeno del anillo de piridina.

Los antisueros obtenidos contra los haptenos tipo II (S5, S7 y S8) presentaron un título medio o alto únicamente cuando se utilizó ese mismo tipo de hapteno en el conjugado de tapizado, exceptuando los antisueros obtenidos contra el hapteno S6, que no presentaron reconocimiento probablemente por motivos de fotodegradación del hapteno. El hecho de que los antisueros obtenidos contra los haptenos tipo II solamente presentaron título cuando se utilizó ese mismo tipo de haptenos, evidencia la importancia de mantener intacta la región constante (c) en el reconocimiento de los haptenos heterólogos por parte de los anticuerpos.

Los antisueros obtenidos contra los haptenos tipo III (S10, S11, S12 y S13) dieron títulos medios o altos frente a los conjugados que conservan la región constante intacta (haptenos tipo I y III). Además, los conjugados de tapizado de este tipo de haptenos con un brazo espaciador de tres átomos de carbono (OVA- 
S12) y 6 (OVA-S11), fueron muy bien reconocidos por casi todos los antisueros, indicando que la región constante es clave en el grado de reconocimiento analito/anticuerpo.

\subsubsection{Selección de antisueros para tetraciclinas}

La selección de los pares antisuero/trazador y antisuero/conjugado de tapizado para TCs se llevó a cabo del modo descrito para los ensayos de sulfonamidas. En formato directo, no se observó reconocimiento específico de los antisueros por los trazadores, obteniendo señales de absorbancia inferiores a 0,4 en todos los casos.

Sin embargo, en formato indirecto los conjugados de tapizado fueron reconocidos por todos los antisueros en mayor o menor extensión. En general, los antisueros obtenidos por acoplamiento directo de las tetraciclinas -TC, CTC y OTC- a proteínas mediante una reacción de condensación de Mannich presentaron menor título que los antisueros obtenidos con los haptenos conjugados a través de su grupo ácido utilizando el método del éster activo. La causa más probable de este hecho es el tamaño del brazo espaciador, que en este caso era más corto. Sin embargo, los conjugados de tapizado preparados por acoplamiento directo de las tetraciclinas (TC-1, CTC-1 y OTC-1) fueron reconocidos por la mayoría de los antisueros, indicando que esta sencilla estrategia es adecuada para la obtención de conjugados.

Los antisueros obtenidos contra los haptenos tipo II, azoderivados (OTC-3, CTC-3 y TC-4), dieron títulos más altos que los obtenidos con los haptenos tipo I, derivados carboxamida (CTC-2, OTC-2 y TC-3), probablemente debido a la mayor densidad electrónica de su brazo espaciador aromático. Así, los títulos más altos correspondieron al antisuero OTC-3-III, conjugado tanto a KLH como a BSA.

En conclusión, hay que indicar que los inmunógenos preparados con KLH dieron antisueros con mayor título que los obtenidos con BSA, y que los títulos más altos se obtuvieron cuando la inmunización fue llevada a cabo usando haptenos de OTC. Sin embargo, en este tipo de ensayos es difícil establecer conclusiones definitivas, debido a la gran variabilidad de la respuesta inmunitaria. 


\subsubsection{ELISAs competitivos para sulfonamidas}

Los ensayos de competición, en formato directo e indirecto, se desarrollaron a partir de las combinaciones de inmunorreactivos que dieron mayores titulos.

Estos ensayos determinan la capacidad de competición del analito libre y el trazador, o conjugado de tapizado, por los sitios de unión del anticuerpo. Para seleccionar el par antisuero/conjugado más sensible se calcula el parámetro $\mathrm{IC}_{50}$, definido como la concentración de analito que inhibe el 50\% de la unión entre el anticuerpo y el conjugado. Así, un valor bajo de $\mathrm{IC}_{50}$ indica que el ensayo presenta mayor sensibilidad para detectar al analito.

Las Tablas 9 y 10 muestran los resultados obtenidos en los ensayos de competición utilizando $\mathrm{STZ}$ como analito competidor, expresados como $\mathrm{IC}_{50}$, para los formatos directo e indirecto, respectivamente.

Tabla 9. Valores de $\mathrm{IC}_{50}$ de los ensayos competitivos directos para sulfonamidas

\begin{tabular}{lcc}
\hline Antisuero & Trazador & IC $_{\mathbf{5 0}}(\boldsymbol{\mu} \mathbf{g} / \mathbf{L})$ \\
\hline BSA-S2-I & HRP-S2 & 100 \\
BSA-S2-I & HRP-S4 & 100 \\
BSA-S3-I & HRP-S3 & 24 \\
BSA-S3-I & HRP-S4 & 5 \\
BSA-S3-II & HRP-S3 & 100 \\
BSA-S3-II & HRP-S4 & 100 \\
BSA-S4-I & HRP-S4 & 100 \\
BSA-S4-II & HRP-S2 & 34 \\
BSA-S4-II & HRP-S3 & 30 \\
BSA-S4-II & HRP-S4 & 46 \\
BSA-S5-I & HRP-S6 & 62 \\
\hline
\end{tabular}




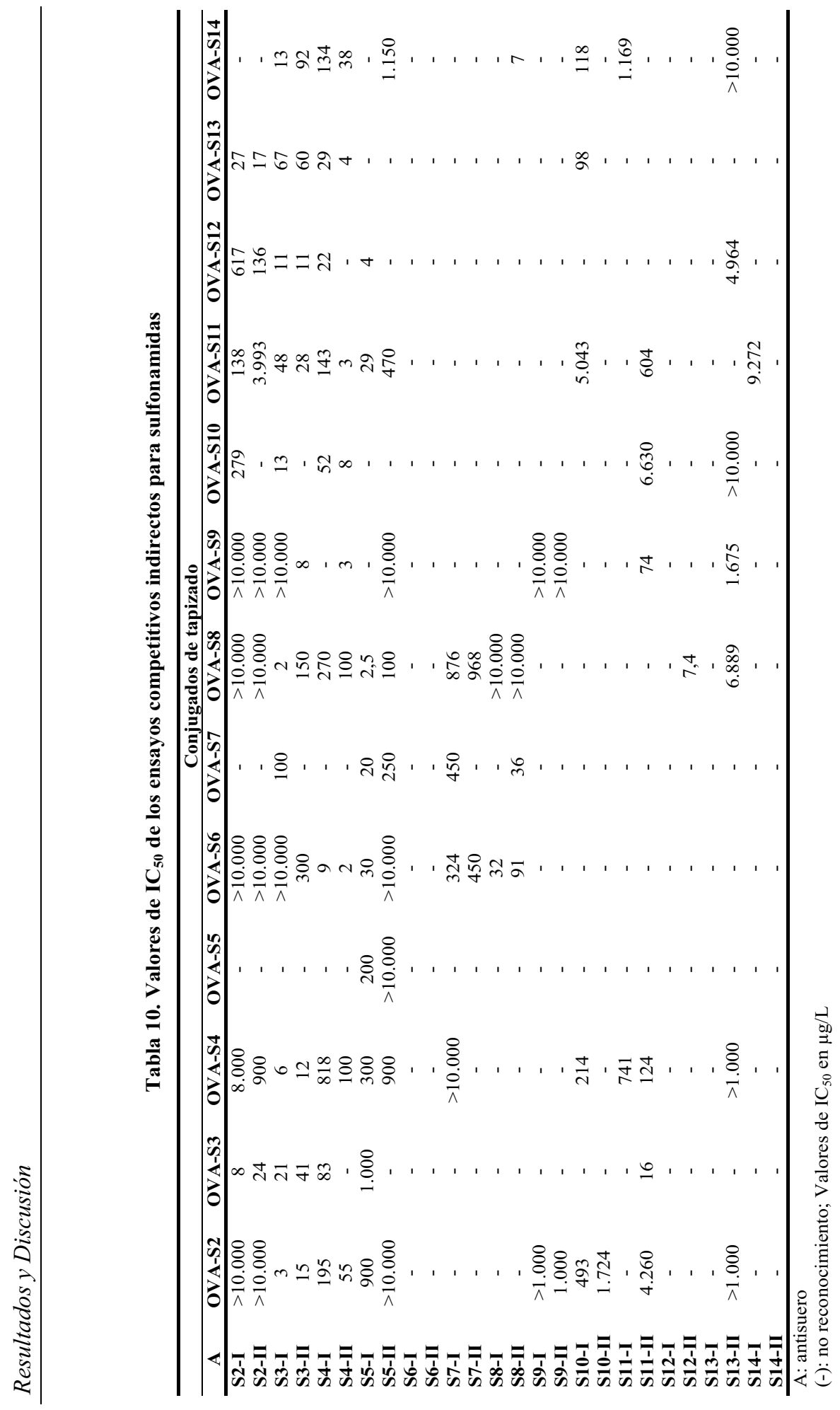


Dado el elevado número de combinaciones para ambos formatos, sólo aquellas con valores de $\mathrm{IC}_{50}$ inferiores a $100 \mu \mathrm{g} / \mathrm{L}$ fueron seleccionadas para llevar a cabo un estudio preliminar de especificidad, con el fin de clasificar los ensayos como selectivos o genéricos.

Los resultados obtenidos en estos ensayos para los quince compuestos seleccionados, con todos los antisueros y en todos los formatos, indicaron que se disponía de antisueros muy específicos, por ejemplo para sulfatiazol, y otros genéricos que reconocían a una parte de la familia de sulfonamidas.

A continuación se presentan los ensayos seleccionados para llevar a cabo los estudios de optimización.

\section{a) Ensayos para STZ}

Formato directo: BSA-S3-I/HRP-S3 (1:10.000/400 $\mu \mathrm{g} / \mathrm{L}$, ensayo A) BSA-S3-I/HRP-S4 (1:10.000/200 $\mu \mathrm{g} / \mathrm{L}$, ensayo B)

Formato indirecto: BSA-S3-I/OVA-S2 (1:10.000/25 $\mu \mathrm{g} / \mathrm{L}$, ensayo C) BSA-S3-I/OVA-S4 (1:20.000/0,625 $\mu \mathrm{g} / \mathrm{L}$, ensayo D)

Como se puede observar en las Tablas 9 y 10, los antisueros obtenidos mediante inmunización con el hapteno S3 (un derivado de STZ) fueron los más adecuados para la determinación de sulfatiazol, probablemente porque dicho hapteno contiene en mayor extensión la estructura de esta sulfonamida. La sensibilidad $\left(\mathrm{IC}_{50}\right)$ alcanzada con estas combinaciones fue de 24, 5, 3 y $6 \mu \mathrm{g} / \mathrm{L}$ para los ensayos A, B, C y D, respectivamente.

\section{b) Ensayo para SSZ}

Formato indirecto: BSA-S5-I/OVA-S8 (1:32.000/0,063 mg/L)

Para la determinación de SSZ, el par BSA-S5-I/OVA-S8 fue la combinación que proporcionó el ensayo más sensible y selectivo. De los resultados obtenidos en los ensayos de competición (Tabla 10) se concluye que los haptenos con una estructura similar a la SSZ proporcionaron los antisueros más sensibles y los conjugados de tapizado más adecuados. Así, el mejor inmunógeno fue el conjugado BSA-S5, posiblemente porque analito y hapteno son el mismo 
compuesto, y el mejor conjugado de tapizado OVA-S8, siendo el hapteno S8 un derivado de la SSZ.

\section{c) Ensayo para SMX}

Formato indirecto: BSA-S12-II/OVA-S8 (1:1.000/1,0 mg/L)

A la vista de los resultados, el antisuero obtenido mediante inmunización con el hapteno S12 fue el más adecuado para la determinación de sulfametoxazol. Este resultado es muy interesante, ya que S12 es un hapteno fragmentario que contiene la región constante de la estructura general de las sulfonamidas y fue diseñado con la intención de producir anticuerpos genéricos.

Por otro lado, se obtuvieron inmunorreactivos que presentaron una elevada reactividad cruzada con algunas de las sulfonamidas más ampliamente utilizadas, lo que permitió desarrollar ensayos genéricos. Los mejores ensayos se obtuvieron con los pares que se describen a continuación:

\section{d) ELISAs Genérico I}

Formato indirecto: BSA-S3-I/OVA-S8 (1:8.000/0,063 mg/L, ensayo A) BSA-S4-II/OVA-S6 (1:32.000/0,33 mg/L, ensayo B)

Estas combinaciones fueron capaces de reconocer 6 sulfonamidas con una sensibilidad de 2,0 $\mu \mathrm{g} / \mathrm{L}$. De acuerdo a los resultados obtenidos, el antisuero BSAS3-I presenta un grado de selectividad variable. Así, utilizando como tapizado OVA-S8 el ensayo presenta un carácter genérico, mientras que empleando OVAS2 como conjugado de tapizado se obtiene un ensayo específico para STZ.

\section{e) ELISA Genérico II}

Formato indirecto: BSA-S10-I/OVA-S2 (1:2.000/0,125 mg/L)

Esta combinación seleccionada fue capaz de reconocer 9 sulfonamidas distintas con una sensibilidad de $500 \mu \mathrm{g} / \mathrm{L}$. Como se puede observar en la Tabla 10, los antisueros obtenidos mediante inmunización con el hapteno S10 (un hapteno fragmentario) fueron los más adecuados para la obtención de anticuerpos 
genéricos, probablemente porque dicho hapteno únicamente contiene la región constante de la estructura general de las sulfonamidas.

\subsubsection{Optimización y estudio de la selectividad de los ensayos}

Una vez seleccionadas las combinaciones antisuero/conjugado con mejor sensibilidad y selectividad, se estudió, de modo secuencial, la influencia de la fuerza iónica, $\mathrm{pH}$, concentración de tensioactivo -Tween 20- contenido en el tampón de competición y tiempo de incubación de la etapa competitiva en los ELISAs. El criterio utilizado para evaluar el efecto de estos parámetros fisicoquímicos fue la sensibilidad, expresada como $\mathrm{IC}_{50}$, y la absorbancia máxima, como grado de reconocimiento anticuerpo/analito.

Después de optimizados los ensayos para cada analito, se estudió su selectividad evaluando la reactividad cruzada frente a quince compuestos relacionados química y estructuralmente con cada uno de los analitos objeto de estudio (Figuras 19, Experimental).

\subsubsection{Ensayos para $S T Z$}

Los ensayos de optimización para sulfatiazol se llevaron a cabo a temperatura ambiente. La duración de cada una de las etapas -competición y detección- fue de $60 \mathrm{~min}$, dado que las señales obtenidas en otras condiciones de ensayo eran poco reproducibles. La absorbancia máxima $\left(\mathrm{A}_{0}\right)$, que representa la unión del anticuerpo al trazador enzimático (formato directo) o al conjugado de tapizado (formato indirecto) en ausencia de analito, y la $\mathrm{IC}_{50}$, que representa la afinidad del anticuerpo hacia STZ, se determinaron en función de la fuerza iónica, $\mathrm{pH}$ y concentración de surfactante.

En la Tabla 11 se muestran los resultados obtenidos para el formato directo (ensayos A y B). Al evaluar el efecto de la fuerza iónica del medio se observó que para el ensayo $\mathrm{A}$, los valores de $\mathrm{IC}_{50}$ y $\mathrm{A}_{0}$ aumentaron hasta una concentración de PBS-T $20 \mathrm{mM}$ y posteriormente decrecieron de manera gradual. Mientras que en el ensayo $\mathrm{B}, \mathrm{IC}_{50} \mathrm{y} \mathrm{A}_{0}$ disminuyeron a medida que aumentaba la concentración salina, lo que indica que las interacciones que tienen lugar entre el analito y el anticuerpo deben ser principalmente hidrofóbicas. En ambos ensayos se seleccionó PBS-T 10 mM como concentración de compromiso entre señal y sensibilidad. 
Tabla 11. Resultados de la optimización de los ELISAs para STZ en formato directo

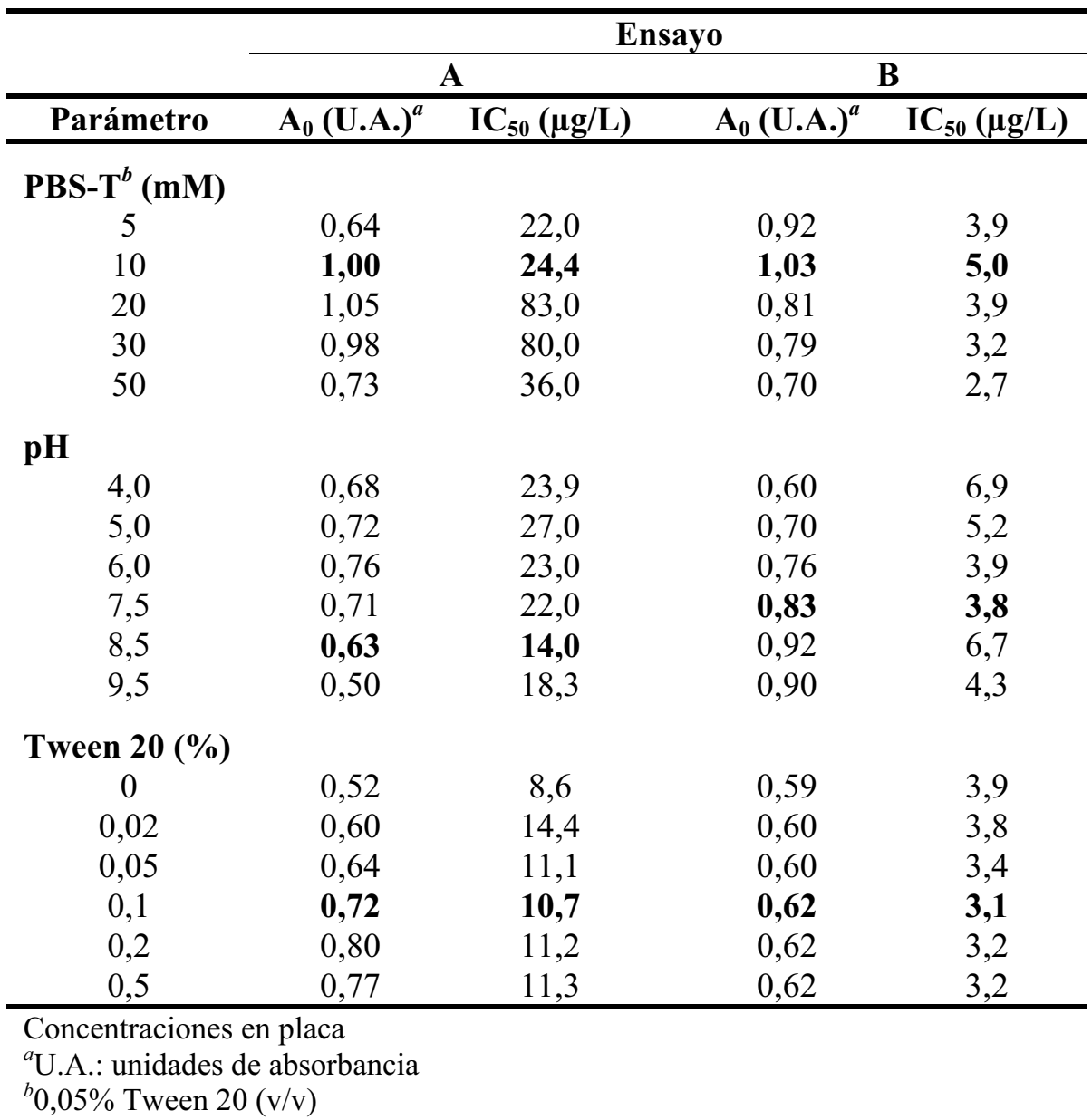

Posteriormente se estudió la influencia del $\mathrm{pH}$ utilizando disoluciones tamponadas entre 4,0 y 9,5. Se observó (Tabla 11) que los ensayos A y B eran ligeramente más sensibles ( $\mathrm{IC}_{50}$ inferior) a $\mathrm{pH} 8,5$ y 7,5, respectivamente, por lo que se seleccionaron estos valores como óptimos con el fin de mantener una relación aceptable entre señal y sensibilidad.

Utilizando la concentración de tampón y pH optimizado se estudió el efecto de la cantidad de surfactante en la señal y la sensibilidad, observando (Tabla 11) que la concentración de Tween 20 no tiene un efecto marcado en el valor de $\mathrm{A}_{0}$. Así pues, para ambos ensayos se seleccionó $0,1 \%$ de Tween 20 (en placa) con el fin de obtener señales aceptables y bajos valores de $\mathrm{IC}_{50}$. 
Los resultados de optimización obtenidos en formato indirecto (ensayos C y D) muestran (Tabla 12) que los valores de $\mathrm{IC}_{50}$ y $\mathrm{A}_{0}$ disminuyen gradualmente a medida que aumenta la concentración salina para ambos ensayos.

Tabla 12. Resultados de la optimización de los ELISAs para STZ en formato indirecto

\begin{tabular}{|c|c|c|c|c|}
\hline \multirow[b]{3}{*}{ Parámetro } & \multicolumn{4}{|c|}{ Ensayo } \\
\hline & \multicolumn{2}{|c|}{ C } & \multicolumn{2}{|c|}{ D } \\
\hline & $\mathrm{A}_{0}\left(\right.$ U.A.) ${ }^{a}$ & $\mathrm{IC}_{50}(\mu \mathrm{g} / \mathrm{L})$ & $\mathrm{A}_{0}$ (U.A.) $^{a}$ & $\mathrm{IC}_{50}(\mu \mathrm{g} / \mathrm{L})$ \\
\hline \multicolumn{5}{|l|}{ PBS-T $^{b}(\mathrm{mM})$} \\
\hline 5 & 1,79 & 14,1 & 0,95 & 5,2 \\
\hline 10 & 1,41 & 3,0 & 0,73 & 5,3 \\
\hline 20 & 1,11 & 2,5 & 0,53 & 1,5 \\
\hline 30 & 0,92 & 1,6 & $\mathbf{0 , 5 0}$ & 0,9 \\
\hline 50 & 0,71 & 1,4 & 0,52 & 0,5 \\
\hline \multicolumn{5}{|l|}{ pH } \\
\hline 4,0 & 0,43 & - & 0,22 & - \\
\hline 5,0 & 0,73 & 1,7 & 0,27 & - \\
\hline 6,0 & 0,83 & 1,6 & 0,51 & 1,6 \\
\hline 7,5 & 0,94 & 1,7 & 0,38 & - \\
\hline 8,5 & 1,11 & 1,7 & 0,57 & 6,0 \\
\hline 9,5 & 1,22 & 1,8 & 0,62 & 4,0 \\
\hline \multicolumn{5}{|l|}{ Tween 20 (\%) } \\
\hline 0 & 1,40 & 3,4 & 0,92 & 2,5 \\
\hline 0,02 & 1,21 & 1,6 & 0,87 & 2,4 \\
\hline 0,05 & 1,10 & 2,2 & 0,85 & 1,9 \\
\hline 0,1 & 0,98 & 1,5 & 0,92 & 1,6 \\
\hline 0,2 & 0,96 & 2,7 & $\mathbf{0 , 8 5}$ & 1,4 \\
\hline 0,5 & 0,94 & 3,1 & 0,85 & 1,5 \\
\hline
\end{tabular}

De acuerdo a estos resultados, el efecto de la concentración del tampón en la sensibilidad y señal máxima se debe, principalmente, a las interacciones hidrofóbicas entre el analito y el anticuerpo. Estas interacciones son generalmente favorecidas por el aumento de la fuerza iónica del medio de reacción, mientras que en las interacciones principalmente iónicas se produce el efecto contrario ${ }^{159}$. Algunos estudios han sugerido que la afinidad de los anticuerpos para analitos polares se incrementa al aumentar la fuerza iónica ${ }^{160}$. En este formato, se 
seleccionó una concentración $30 \mathrm{mM}$ de PBS-T, a pesar del bajo valor de $\mathrm{A}_{0}$ para el ensayo D.

Posteriormente se estudió la influencia de la acidez, observando (Tabla 12) que los valores de $\mathrm{IC}_{50} \mathrm{y} \mathrm{A}_{0}$ aumentan gradualmente a medida que lo hace el $\mathrm{pH}$ de la disolución tamponada, seleccionando pH 6 como óptimo para alcanzar la máxima señal y sensibilidad.

Finalmente, se procedió a estudiar el efecto de la concentración de Tween 20. Como se muestra en la Tabla 12, la señal del ensayo C disminuye con la concentración de Tween, siendo $0,02 \%$ la que proporcionó mejores resultados en términos de relación señal/sensibilidad; similar comportamiento se observa para el ensayo D en lo que respecta a la señal, si bien en este caso el ensayo de mayor sensibilidad se obtiene para una concentración de Tween del 0,2\%. La elevada concentración de Tween 20 para esta combinación anticuerpo/analito puede interpretarse como un parámetro critico para obtener un ensayo de mayor sensibilidad.

En resumen, la optimización de los ensayos puestos a punto para el STZ mejora la sensibilidad en un factor de 2,2, 1,5, 1,9 y 4,3, para los ensayos A, B, C y D, respectivamente.

Tras optimizar las variables experimentales, se llevaron a cabo ELISAs competitivos utilizando disoluciones patrón de STZ. Las curvas de calibrado normalizadas se muestran en la Figura 44.
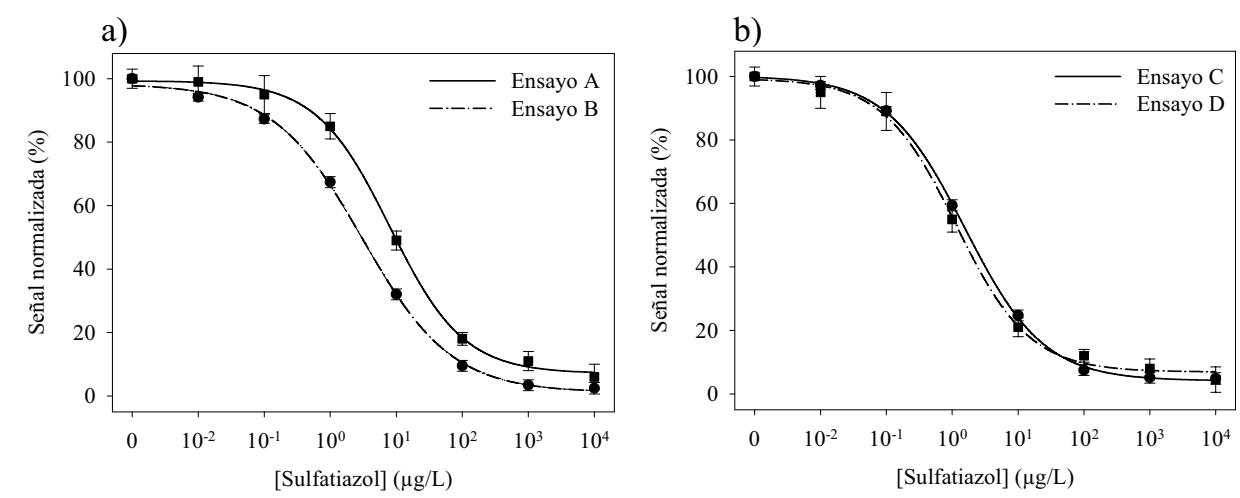

Figura 44. Curvas de competición para STZ (a) formato directo y (b) formato indirecto (media y desviación de tres réplicas) 
La Tabla 13 muestra los parámetros analíticos (definidos en la sección 3.2.4.3, Experimental) de los ELISAs desarrollados para los cuatro pares seleccionados.

Tabla 13. Parámetros analíticos de los ELISAs para STZ

\begin{tabular}{|c|c|c|c|c|c|}
\hline & Ensayo & $\begin{array}{c}\mathrm{IC}_{50}{ }^{a} \\
(\mu \mathrm{g} / \mathrm{L})\end{array}$ & $\begin{array}{c}\mathbf{A}_{0}{ }^{b} \\
\text { (U.A.) }\end{array}$ & $\begin{array}{c}\mathbf{R D}^{c} \\
(\mu \mathrm{g} / \mathbf{L})\end{array}$ & $\begin{array}{c}\mathbf{L D}^{d} \\
(\mu \mathrm{g} / \mathrm{L})\end{array}$ \\
\hline BSA-S3-I/HRP-S3 & A & 10,70 & 0,72 & $0,94-201,34$ & 0,25 \\
\hline BSA-S3-I/HRP-S4 & B & 3,11 & 0,62 & $0,25-14,49$ & 0,08 \\
\hline BSA-S3-I/OVA-S2 & $\mathrm{C}$ & 1,60 & 1,21 & $0,12-6,71$ & 0,03 \\
\hline BSA-S3-I/OVA-S4 & $\mathrm{D}$ & 1,40 & 0,85 & $0,16-17,71$ & 0,04 \\
\hline
\end{tabular}

${ }^{a} \mathrm{IC}_{50}$ : sensibilidad

${ }^{b} \mathrm{~A}_{0}$ : absorbancia máxima; U.A.: unidades de absorbancia

${ }^{c} \mathrm{RD}$ : intervalo de trabajo o rango dinámico

${ }^{d} \mathrm{LD}$ : límite de detección

Como se observa, los intervalos de trabajo (RD) de los ensayos directos (A y B) fueron mejores que los de formato indirecto ( $\mathrm{C}$ y D). Además, los límites de detección fueron también mayores en formato directo. Por ello, podemos concluir que los inmunoensayos en formato indirecto presentaron mayor sensibilidad y señal, siendo el ensayo D el más sensible, con un valor de $\mathrm{IC}_{50}$ de $1,4 \mu \mathrm{g} / \mathrm{L}$. No obstante, todos los inmunoensayos desarrollados pueden considerarse suficientemente sensibles para determinar residuos de STZ dentro de los LMRs permitidos por la legislación europea en alimentos de origen animal.

Tras la optimización, se estudió la selectividad de los cuatro ELISAs puestos a punto. Para ello, a partir de las curvas de inhibición obtenidas $(\mathrm{n}=3)$, se determinó la $\mathrm{IC}_{50}$ de cada uno de los interferentes y se calculó la reactividad cruzada (RC, \%). Los resultados obtenidos se recogen en las Tablas 14 y 15, para formato directo e indirecto, respectivamente.

Como puede observarse, en general, todos los inmunoensayos desarrollados para STZ son selectivos. Los valores de reactividad cruzada son bajos $(\mathrm{RC}<10 \%)$, excepto para SMP (ensayo B) y SMT (en ensayo B y D). Esto indica que, las sulfonamidas de bajo peso molecular, SAN, SAM y SG no han sido detectadas por ninguno de los inmunoensayos optimizados, debido a que presentan una región variable alifática, a diferencia del resto de sulfonamidas que es aromática. 
Tabla 14. Selectividad de los ELISAs para STZ en formato directo

\begin{tabular}{|c|c|c|c|c|c|}
\hline & & \multicolumn{4}{|c|}{ Ensayo } \\
\hline & & A & & $\mathbf{B}$ & \\
\hline \multicolumn{2}{|l|}{ Compuesto } & $\mathrm{IC}_{50}$ & $\mathbf{R C}$ & $\mathrm{IC}_{50}$ & $\mathbf{R C}$ \\
\hline Sulfatiazol & STZ & 10,7 & 100 & 3,1 & 100 \\
\hline Sulfadiazina & SDZ & $>10.000$ & $<0,11$ & 184,3 & 1,70 \\
\hline Sulfasalazina & SSZ & $>10.000$ & $<0,11$ & $>10.000$ & $<0,03$ \\
\hline$N^{4}$-ftalilsulfatiazol & PSTZ & $>1.000$ & $<1,07$ & $>10.000$ & $<0,03$ \\
\hline Sulfanilamida & SAN & $>10.000$ & $<0,11$ & $>10.000$ & $<0,03$ \\
\hline Sulfacetamida & SAM & $>10.000$ & $<0,11$ & $>10.000$ & $<0,03$ \\
\hline Sulfametazina & SMZ & $>1.000$ & $<1,07$ & $>10.000$ & $<0,03$ \\
\hline Sulfisoxazol & $\mathrm{SOX}$ & $>10.000$ & $<0,11$ & $>10.000$ & $<0,03$ \\
\hline Sulfametoxipiridazina & SMP & 107,9 & 9,90 & 16,6 & 19,20 \\
\hline Sulfapiridina & SP & 163,0 & 6,60 & 41,6 & 7,70 \\
\hline Sulfametizol & SMT & 128,4 & 8,30 & 22,4 & 14,30 \\
\hline Sulfametoxazol & SMX & $>10.000$ & $<1,07$ & $>10.000$ & $<0,03$ \\
\hline Sulfaguanidina & $\mathrm{SG}$ & $>10.000$ & $<0,11$ & $>10.000$ & $<0,03$ \\
\hline Sulfamerazina & SMR & 315,0 & 3,40 & 104,3 & 3,10 \\
\hline
\end{tabular}

Concentraciones en $\mu \mathrm{g} / \mathrm{L}$

$\mathrm{RC}(\%)=\left[\mathrm{IC}_{50}(\mathrm{STZ}) / \mathrm{IC}_{50}\right.$ (interferente) $] \times 100$

Tabla 15. Selectividad de los ELISAs para STZ en formato indirecto

\begin{tabular}{llrrrr}
\hline & & \multicolumn{4}{c}{ Ensayo } \\
\cline { 3 - 6 } \multicolumn{1}{c}{ Compuesto } & & \multicolumn{1}{c}{ C } & \multicolumn{1}{c}{ D } \\
\hline Sulfatiazol & STZ & $\mathbf{1 , 6}$ & $\mathbf{1 0 0}$ & $\mathbf{1 , 4}$ & $\mathbf{1 0 0}$ \\
Sulfadiazina & SDZ & 174,4 & 0,90 & 123,6 & 1,10 \\
Sulfasalazina & SSZ & 550,0 & 0,30 & $>1.000$ & $<0,14$ \\
$N^{4}$-ftalilsulfatiazol & PSTZ & 54,0 & 3,00 & 37,3 & 3,75 \\
Sulfanilamida & SAN & $>10.000$ & $<0,02$ & $>10.000$ & $<0,01$ \\
Sulfacetamida & SAM & $>10.000$ & $<0,02$ & $>10.000$ & $<0,01$ \\
Sulfametazina & SMZ & 550,0 & 0,30 & $>1.000$ & $<0,14$ \\
Sulfisoxazol & SOX & 450,0 & 0,40 & $>1.000$ & $<0,14$ \\
Sulfametoxipiridazina & SMP & 20,3 & 7,90 & 23,3 & 6,00 \\
Sulfapiridina & SP & 20,0 & 8,00 & 24,1 & 5,80 \\
Sulfametizol & SMT & 23,5 & 6,80 & 12,1 & 11,60 \\
Sulfametoxazol & SMX & 480,0 & 0,30 & 233,3 & 0,60 \\
Sulfaguanidina & SG & $>10.000$ & $<0,02$ & 10.000 & 0,01 \\
Sulfamerazina & SMR & 50,0 & 3,20 & 115,0 & 1,20 \\
\hline
\end{tabular}

Concentraciones en $\mu \mathrm{g} / \mathrm{L}$

$\mathrm{RC}(\%)=\left[\mathrm{IC}_{50}(\mathrm{STZ}) / \mathrm{IC}_{50}\right.$ (interferente) $] \times 100$ 
Recapitulando, de los cuatro inmunoensayos optimizados (A, B, C y D) el ensayo C (BSA-S3-I/OVA-S2, formato indirecto, $30 \mathrm{mM}$ PBS-T, pH 6 y 0,01\% Tween 20) presentó el límite de detección más bajo y mejor selectividad, siendo seleccionado para determinar residuos de STZ en muestras de miel. La curva de calibrado para STZ (ensayo C) presentó un intervalo de trabajo entre 0,12 y 6,71 $\mu \mathrm{g} / \mathrm{L}$. La sensibilidad fue $1,6 \mu \mathrm{g} / \mathrm{L}\left(\mathrm{IC}_{50}\right)$, permitiendo detectar concentraciones de STZ por encima de $0,03 \mu \mathrm{g} / \mathrm{L}$ (LD).

El ELISA desarrollado para la determinación de residuos de sulfatiazol presenta mayor sensibilidad que los inmunoensayos descritos en la bibliografía ${ }^{74,78,107}$. Una de las razones podría ser el inmunógeno utilizado, ya que los inmunoensayos descritos utilizaron el mismo hapteno de inmunización (STZ unido directamente a una proteína mediante diazotación). Asimismo, la heterología introducida con el hapteno de tapizado también influye en la sensibilidad, ya que todos los autores llevaron a cabo los ensayos en condiciones de homología. El ensayo $\mathrm{C}$ es el inmunoensayo más sensible para la determinación de STZ descrito hasta este momento.

\subsubsection{Ensayo para SSZ}

Los ensayos de competición se llevaron a cabo siguiendo el mismo protocolo de optimización secuencial descrito previamente para el ensayo de STZ, utilizando SSZ como analito competidor.

En primer lugar se optimizó la fuerza iónica del medio, variando la concentración de fosfato (PBS-T) entre 5-50 mM. Como puede observarse en la Tabla 16, la fuerza iónica tiene poca influencia en la sensibilidad del ensayo a partir de $5 \mathrm{mM}$, sin embargo la señal disminuye a medida que la concentración de PBS aumenta, hasta alcanzar una señal de absorbancia de 0,66 U.A. para una concentración $30 \mathrm{mM}$. Así, atendiendo a una buena sensibilidad y señal se seleccionó $10 \mathrm{mM}$ como concentración de PBS-T óptima.

Respecto al pH del medio (Tabla 16), se observa que la sensibilidad y la señal mejoran al incrementar el $\mathrm{pH}$, especialmente a partir de 7,5, siendo $\mathrm{pH} 8,5$ el que presenta una mayor relación $\mathrm{A}_{0} / \mathrm{IC}_{50}$.

En cuanto al efecto del Tween 20, se observa (Tabla 16) que la sensibilidad es mayor a medida que aumenta la concentración de tensioactivo hasta porcentajes de 
$0,1 \%$. A partir de esta concentración la sensibilidad no mejora. Por otro lado, la señal prácticamente se mantiene constante en todo el intervalo de trabajo. Así, se seleccionó como óptima una concentración de $0,1 \%$ de Tween 20 , ya que presentaba la mejor sensibilidad con un valor de señal aceptable.

Tabla 16. Resultados de la optimización del ELISA para SSZ en formato indirecto

\begin{tabular}{|c|c|c|}
\hline Parámetro & $\mathrm{A}_{0}$ (U.A.) $^{a}$ & $\mathrm{IC}_{50}(\mu \mathrm{g} / \mathrm{L})$ \\
\hline \multicolumn{3}{|l|}{ PBS-T $^{b}(\mathrm{mM})$} \\
\hline 5 & 2,42 & 0,7 \\
\hline 10 & 1,74 & 0,6 \\
\hline 20 & 1,10 & 1,5 \\
\hline 30 & 0,66 & 1,9 \\
\hline 50 & 0,30 & - \\
\hline \multicolumn{3}{|l|}{ pH } \\
\hline 4,5 & 0,89 & 2,1 \\
\hline 5,5 & 1,19 & 1,3 \\
\hline 6,5 & 1,31 & 0,8 \\
\hline 7,5 & 1,53 & 0,8 \\
\hline 8,5 & 1,34 & 0,7 \\
\hline 9,5 & 1,30 & 0,6 \\
\hline
\end{tabular}

\section{Tween $20(\%)$}

$\begin{array}{ccc}0 & 1,21 & 1,4 \\ 0,010 & 1,28 & 1,1 \\ 0,025 & 1,10 & 0,7 \\ 0,050 & 1,25 & 0,7 \\ 0,100 & \mathbf{1 , 2 0} & \mathbf{0 , 5} \\ 0,250 & 1,23 & 0,8\end{array}$

Tiempo (min)

\begin{tabular}{lll}
15 & 0,51 & 0,4 \\
30 & 0,83 & 0,5 \\
45 & $\mathbf{1 , 0 2}$ & $\mathbf{0 , 5}$ \\
60 & 1,12 & 0,6 \\
\hline
\end{tabular}

Concentraciones en placa

${ }^{a}$ U.A.: unidades de absorbancia

${ }^{b} 0,05 \%$ Tween $20(\mathrm{v} / \mathrm{v})$

En las condiciones previamente seleccionadas, se procedió a realizar la optimización del tiempo de competición con el objetivo de acortar la duración del ensayo. Para ello, se compararon tiempos de incubación de 15, 30, 45 y $60 \mathrm{~min}$ 
observando que la señal y la sensibilidad aumentan con el tiempo. Por ello, se seleccionó un tiempo de competición de $45 \mathrm{~min}$ como compromiso entre sensibilidad, señal máxima y duración del ensayo.

En conclusión, se puede afirmar que para este analito el proceso de optimización de los parámetros fisicoquímicos no mejoró significativamente la sensibilidad y señal máxima del ensayo.

En las condiciones optimizadas, la curva de calibrado para SSZ (Figura 45) presentó un intervalo de trabajo entre 0,06 y $3,75 \mu \mathrm{g} / \mathrm{L}$. La sensibilidad y el límite de detección del ensayo fueron 0,51 y $0,02 \mu \mathrm{g} / \mathrm{L}$, respectivamente (Tabla 17).

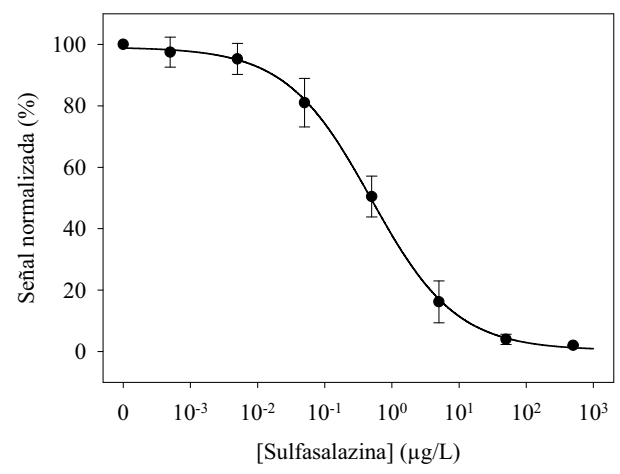

Figura 45. Curva de competición para SSZ (media y desviación de tres réplicas)

Tabla 17. Parámetros analíticos del ELISA desarrollado para SSZ

\begin{tabular}{cccccc}
\hline & Ensayo & $\begin{array}{c}\mathbf{I C}_{50}{ }^{a} \\
(\mu \mathbf{g} / \mathbf{L})\end{array}$ & $\begin{array}{c}\mathbf{A}_{\mathbf{0}}{ }^{b} \\
(\mathbf{U . A .})\end{array}$ & $\begin{array}{c}\mathbf{R D}^{c} \\
(\mu \mathrm{gg} / \mathbf{L})\end{array}$ & $\begin{array}{c}\mathbf{L D}^{d} \\
(\boldsymbol{\mu g} / \mathbf{L})\end{array}$ \\
\hline BSA-S5-I/OVA-S8 & $\mathrm{SSZ}$ & 0,51 & 1,02 & $0,06-3,75$ & 0,02 \\
\hline
\end{tabular}

${ }^{a} \mathrm{IC}_{50}:$ sensibilidad

${ }^{b} \mathrm{~A}_{0}$ : absorbancia máxima; U.A.: unidades de absorbancia

${ }^{c} \mathrm{RD}$ : intervalo de trabajo o rango dinámico

${ }^{d}$ LD: límite de detección

La sensibilidad del ensayo para SSZ es elevada en comparación con la obtenida mediante técnicas de referencia como HPLC. Así, Rona et al. ${ }^{161}$ determinaron SSZ en suero humano con un LD de $0,1 \mathrm{mg} / \mathrm{L}$. Gu et al. ${ }^{162}$ determinaron SSZ y sus principales metabolitos en plasma con un LD de $1 \mu \mathrm{g} / \mathrm{L}$. Recientemente, Elmasry 
et al. ${ }^{163}$ han descrito la determinación cuantitativa de SSZ en formulaciones farmacéuticas mediante HPLC/UV-VIS, alcanzando un límite de detección de 0,1 $\mu \mathrm{g} / \mathrm{L}$ y recuperaciones alrededor del $100 \%$.

Con respecto a la selectividad, el ensayo para SSZ resultó ser altamente específico, tal y como se muestra en la Tabla 18, con valores de reactividad cruzada inferiores al $2 \%$ para todos los interferentes ensayados. Estos resultados indican que el hapteno S5 utilizado para preparar el inmunógeno, es adecuado para la obtención de anticuerpos de elevada afinidad para la determinación de SSZ a nivel de $\mu \mathrm{g} / \mathrm{L}$. Este es el primer inmunoensayo específico descrito para la determinación de esta sulfonamida.

Tabla 18. Selectividad del ELISA para SSZ

\begin{tabular}{llrr}
\hline \multicolumn{1}{c}{ Compuesto } & & IC $_{\mathbf{5 0}}$ & \multicolumn{1}{c}{ RC } \\
\hline Sulfasalazina & SSZ & $\mathbf{0 , 5}$ & $\mathbf{1 0 0 , 0 0}$ \\
Sulfatiazol & STZ & 33,2 & 1,48 \\
$N^{4}$-ftalilsulfatiazol & PSTZ & 40,4 & 1,21 \\
Sulfapiridina & SP & 110,9 & 0,44 \\
Sulfametoxazol & SMX & 1,3 & 0,04 \\
Sulfadiazina & SDZ & 2,3 & 0,02 \\
Sulfametoxipiridazina & SMP & 3,7 & 0,01 \\
Sulfanilamida & SAN & $>10.000$ & $<0,01$ \\
Sulfadimetoxina & SDM & $>10.000$ & $<0,01$ \\
Sulfacetamida & SAM & $>10.000$ & $<0,01$ \\
Sulfametazina & SMZ & $>10.000$ & $<0,01$ \\
Sulfisoxazol & SOX & $>10.000$ & $<0,01$ \\
Sulfametizol & SMT & $>10.000$ & $<0,01$ \\
Sulfaguanidina & SG & $>10.000$ & $<0,01$ \\
Sulfamerazina & SMR & $>10.000$ & $<0,01$ \\
\hline
\end{tabular}

Concentraciones en $\mu \mathrm{g} / \mathrm{L}$

$\mathrm{RC}(\%)=\left[\mathrm{IC}_{50}(\mathrm{SSZ}) / \mathrm{IC}_{50}\right.$ (interferente) $] \times 100$

\subsubsection{ELISAs Genérico I}

La optimación de las variables que influyen en la sensibilidad del ensayo se llevó a cabo utilizando STZ como analito competidor, siguiendo el protocolo descrito previamente para el ensayo específico de STZ. Los parámetros fisicoquímicos como tiempo y temperatura se fijaron en $60 \min$ y $25{ }^{\circ} \mathrm{C}$, 
respectivamente, dado que las señales de absorbancia obtenidas en estas condiciones fueron más reproducibles.

Como se muestra en la Tabla 19, al evaluar el efecto de la fuerza iónica del medio se observa que tanto la señal máxima como la sensibilidad disminuyen gradualmente a medida que aumenta la concentración salina del tampón. Este hecho indica que las interacciones que tienen lugar entre el analito y el anticuerpo deben ser principalmente hidrofóbicas, al igual que ocurre para el ensayo específico de STZ. Para ambos ensayos (A y B) se seleccionó 30 mM PBS-T como concentración de compromiso entre señal y sensibilidad.

Tabla 19. Resultados de la optimización de los ELISAs Genérico I para STZ

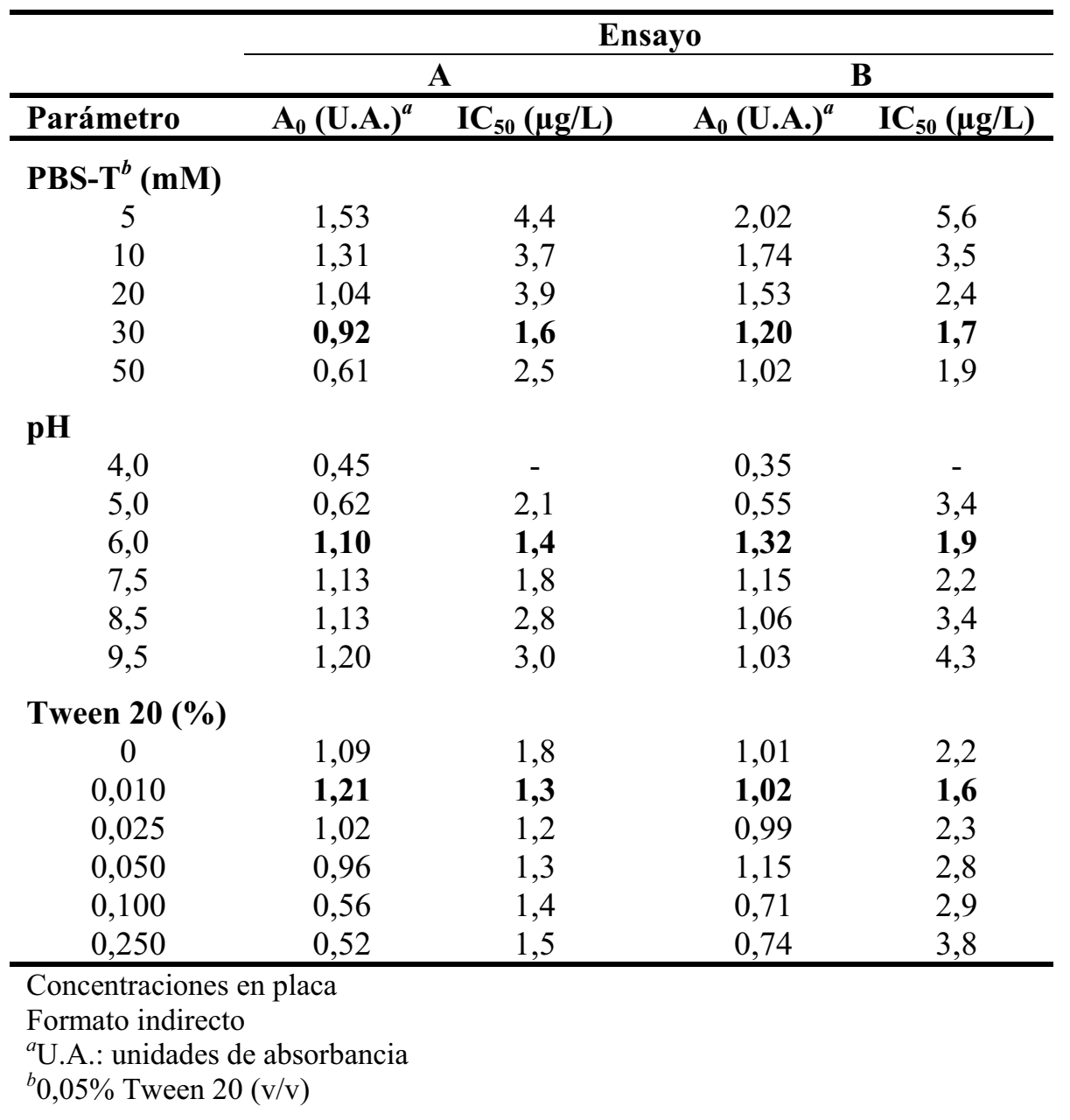


Por otro lado, al estudiar el efecto del pH se observa (Tabla 19) que la sensibilidad aumenta significativamente a $\mathrm{pH}>5$. Así, se seleccionó $\mathrm{pH} 6$ como óptimo para ambos ensayos, con el fin de mantener una relación aceptable entre señal y sensibilidad.

Finalmente, se estudió el efecto de la concentración de Tween 20, observando (Tabla 19) que tanto la señal como la sensibilidad disminuyen a medida que ésta aumenta. Se piensa que este efecto podría estar relacionado con una inmunorreacción inespecífica debido a interacciones hidrofóbicas, por lo que se seleccionó una concentración del $0,01 \%$ de Tween 20 para ambos ensayos, como compromiso entre sensibilidad y señal.

Del proceso de optimización se deduce que la fuerza iónica y el $\mathrm{pH}$ del medio son los parámetros más influyentes en la sensibilidad de los dos ELISAs.

En la Figura 46, se muestran las curvas de calibrado para STZ de los ensayos A y B.

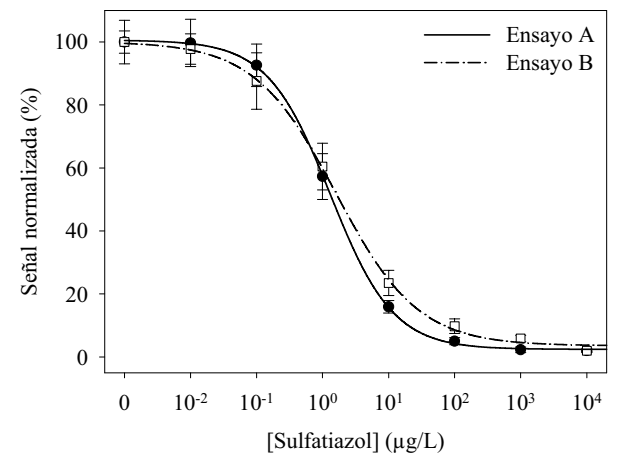

Figura 46. Curvas de competición para STZ (media y desviación de tres réplicas)

Los parámetros analíticos de los ELISAs desarrollados se muestran en la Tabla 20. La sensibilidad y la señal máxima fueron muy parejas en ambos ensayos, como se observa claramente en la Figura 46, donde las curvas de inhibición son muy similares. El intervalo de trabajo del ensayo B fue ligeramente mayor que el del ensayo A, presentando éste último un mayor LD. El ensayo más sensible lo proporcionó el inmunoensayo A (BSA-S3-I/OVA-S8), presentando un grado de reconocimiento analito/antígeno similar al obtenido en el ensayo específico. 
Resultados y Discusión

Tabla 20. Parámetros analíticos de los ELISAs Genérico I desarrollados para STZ

\begin{tabular}{lccccc}
\hline & Ensayo & $\begin{array}{c}\mathbf{I C}_{\mathbf{5 0}}{ }^{a} \\
(\boldsymbol{\mu g} / \mathbf{L})\end{array}$ & $\begin{array}{c}\mathbf{A}_{\mathbf{0}}{ }^{b} \\
(\mathbf{U . A .})\end{array}$ & $\begin{array}{c}\mathbf{R D}^{c} \\
(\boldsymbol{\mu g} / \mathbf{L})\end{array}$ & $\begin{array}{c}\mathbf{L D}^{d} \\
(\boldsymbol{\mu g} / \mathbf{L})\end{array}$ \\
\hline BSA-S3-I/OVA-S8 & $\mathrm{A}$ & 1,32 & 1,21 & $0,29-7,00$ & 0,13 \\
BSA-S4-II/OVA-S6 & $\mathrm{B}$ & 1,61 & 1,02 & $0,24-15,00$ & 0,07 \\
\hline
\end{tabular}

\footnotetext{
${ }^{a} \mathrm{IC}_{50}:$ sensibilidad

${ }^{b} \mathrm{~A}_{0}$ : absorbancia máxima; U.A.: unidades de absorbancia

${ }^{c} \mathrm{RD}$ : intervalo de trabajo o rango dinámico

${ }^{d}$ LD: límite de detección
}

En la Tabla 21 se muestran los resultados de selectividad para ambos ensayos, calculados a partir de la $\mathrm{IC}_{50}$ del $\mathrm{STZ}$, observando una alta reactividad cruzada $(>10 \%)$ frente a seis sulfonamidas. Así, el ensayo A es capaz de determinar STZ, PSTZ, SMP, SP y SMT, pudiendo detectar también SSZ, ya que preserva en mayor grado la estructura del conjugado de tapizado utilizado en dicho ensayo. Sin embargo el ensayo B permite determinar STZ, PSTZ, SMP, SP, SMT y SMX. Además, utilizando este ensayo pueden también cuantificarse a bajas concentraciones otras sulfonamidas como SDM y SMZ.

Tabla 21. Selectividad de los ELISAs Genérico I para sulfonamidas

\begin{tabular}{|c|c|c|c|c|c|}
\hline & & \multicolumn{4}{|c|}{ Ensayo } \\
\hline & & \multicolumn{2}{|c|}{ A } & \multicolumn{2}{|c|}{ B } \\
\hline \multicolumn{2}{|l|}{ Compuesto } & $\mathrm{IC}_{\mathbf{5 0}}$ & RC & $\mathrm{IC}_{50}$ & $\mathbf{R C}$ \\
\hline Sulfatiazol & STZ & 1,3 & 100 & 1,6 & 100 \\
\hline Sulfadiazina & SDZ & 57,6 & 2,08 & 774,5 & 0,22 \\
\hline Sulfasalazina & SSZ & 2,8 & 42,18 & 113,6 & 1,53 \\
\hline$N^{4}$-ftalilsulfatiazol & PSTZ & 8,5 & 14,13 & 6,9 & 25,26 \\
\hline Sulfanilamida & SAN & $>10.000$ & $<0,01$ & $>10.000$ & $<0,01$ \\
\hline Sulfadimetoxina & SDM & $>10.000$ & $<0,01$ & 25,4 & 6,86 \\
\hline Sulfacetamida & SAM & $>10.000$ & $<0,01$ & $>10.000$ & $<0,01$ \\
\hline Sulfametazina & SMZ & $>10.000$ & $<0,01$ & 23,1 & 7,55 \\
\hline Sulfisoxazol & SOX & $>10.000$ & $<0,01$ & 79,5 & 2,19 \\
\hline Sulfametoxipiridazina & SMP & 11,7 & 10,27 & $\mathbf{0 , 7}$ & 255,84 \\
\hline Sulfapiridina & SP & 7,5 & 15,90 & 2,9 & 61,09 \\
\hline Sulfametizol & SMT & 6,4 & 18,73 & $\mathbf{0 , 9}$ & 201,62 \\
\hline Sulfametoxazol & SMX & 236,8 & 0,51 & 12,8 & 13,58 \\
\hline Sulfaguanidina & SG & $>10.000$ & $<0,01$ & 149,3 & 1,17 \\
\hline Sulfamerazina & SMR & 64,1 & 1,87 & 39,3 & 4,43 \\
\hline
\end{tabular}

Concentraciones en $\mu \mathrm{g} / \mathrm{L}$

$\mathrm{RC}(\%)=\left[\mathrm{IC}_{50}(\mathrm{STZ}) / \mathrm{IC}_{50}(\right.$ interferente $\left.)\right] \times 100$ 
En estos inmunoensayos se confirma de nuevo que no es posible detectar sulfonamidas con grupos alifáticos (SAN, SAM y SG), indicando que la aromaticidad de la región variable es clave a la hora de producir anticuerpos con elevada especificidad.

Los ELISAs desarrollados utilizando anticuerpos policlonales permiten el reconocimiento de seis sulfonamidas a bajas concentraciones $\left(\mathrm{IC}_{50}<13 \mu \mathrm{g} / \mathrm{L}\right)$, mostrando valores de LD entre 0,13 y 1,28 $\mu \mathrm{g} / \mathrm{L}$ para el ensayo A, y de 0,07 a 1,21 $\mu \mathrm{g} / \mathrm{L}$ para el ensayo B. En comparación con otros ensayos descritos previamente en la bibliografía (Tabla 7, Introducción), los inmunoensayos desarrollados presentan buena sensibilidad, a niveles de $\mu \mathrm{g} / \mathrm{L}$, para los interferentes detectados, pero reconocen un menor número de éstos. Por ello, se deberían diseñar nuevas rutas sintéticas con el fin de obtener haptenos que produzcan anticuerpos con una mayor respuesta genérica, con el fin de poder desarrollar un ELISA multianalito para la familia de las sulfonamidas.

Con los inmunorreactivos desarrollados en esta tesis doctoral, el grupo de investigación ha puesto a punto dos inmunosensores sensibles y específicos para la determinación de STZ en agua mineral y miel ${ }^{164}$.

Utilizando el ensayo para STZ (BSA-S3-I/OVA-S2), otros investigadores del grupo han desarrollado tiras reactivas para la determinación de dicho analito en miel $^{165}$.

Utilizando el ensayo para SMX, otro miembro del grupo de investigación pudo desarrollar un inmunoensayo tipo ELISA y un microarray sobre disco compacto para la determinación de residuos de SMX en agua de depuradora con una sensibilidad aceptable ${ }^{166}$.

Recientemente, miembros del grupo de investigación han llevado a cabo la aplicación del inmunoensayo Genérico I (ensayo B, BSA-S4-II/OVA-S6) para la determinación de residuos de sulfonamidas en pescado ${ }^{167}$ y piensos ${ }^{168}$, alcanzando resultados muy satisfactorios en términos de sensibilidad y reproducibilidad.

Finalmente, utilizando el inmunoensayo Genérico II, otros investigadores del grupo han desarrollado un ELISA para la determinación de residuos de sulfatiazol, sulfadiazina, $N^{4}$-ftalilsulfatiazol, sulfadimetoxina, sulfacetamida, sulfametizol, sulfapiridina, sulfametoxipiridazina y sulfametoxazol en mieles ${ }^{169}$. 


\subsubsection{ELISAs competitivos para tetraciclinas}

Los ensayos de competición se llevaron a cabo con todas las combinaciones antisuero/conjugado de tapizado seleccionadas en los ensayos de titulación. La Tabla 22 muestra los resultados obtenidos en los ensayos de competición en formato indirecto, utilizando TC, CTC o OTC como analito competidor.

Tabla 22. Valores de $\mathrm{IC}_{50}$ de los ensayos competitivos indirectos para tetraciclinas

\begin{tabular}{llrrr}
\hline \multirow{2}{*}{ Antisuero } & \multirow{2}{*}{$\begin{array}{c}\text { Conjugado de } \\
\text { tapizado }\end{array}$} & \multicolumn{3}{c}{ IC $_{\mathbf{5 0}}(\boldsymbol{\mu} \mathbf{g} / \mathbf{L})$} \\
& & CTC & OTC \\
\hline BSA-OTC-1-I & OVA-CTC-1 & - & 110 & - \\
BSA-OTC-3-IV & OVA-CTC-1 & 20 & 30 & 93 \\
BSA-OTC-3-IV & OVA-CTC-2 & 16 & 55 & 184 \\
BSA-OTC-3-IV & OVA-TC-1 & 16 & 83 & 93 \\
KLH-OTC-3-III & OVA-TC-1 & 11 & 166 & 36 \\
KLH-OTC-3-III & OVA-OTC-1 & 15 & 178 & 77 \\
KLH-OTC-3-III & OVA-OTC-2 & 14 & 645 & 151 \\
KLH-OTC-3-IV & OVA-TC-1 & 40 & 13 & 41 \\
KLH-OTC-3-IV & OVA-TC-3 & 22 & 102 & 113 \\
\hline
\end{tabular}

(-): no reconocimiento

Se observa que los antisueros obtenidos a partir de haptenos de OTC proporcionaron los antisueros más sensibles, destacando el azoderivado OTC-3 (hapteno tipo II) conjugado tanto a KLH como a BSA. No obstante, el resto de haptenos resultaron adecuados como conjugados de tapizado.

De acuerdo a los resultados obtenidos, se seleccionó el par BSA-OTC-1I/OVA-CTC-1 (1:500/125 $\mu \mathrm{g} / \mathrm{L})$ como ensayo específico para CTC.

Por otra parte, la combinación KLH-OTC-3-III/OVA-TC-1 (1:1.000/250 $\mu \mathrm{g} / \mathrm{L})$ se seleccionó como ensayo genérico para la determinación simultánea de distintas tetraciclinas.

\subsubsection{Optimización y estudio de la selectividad de los ensayos}

Al igual que en el caso de las sulfonamidas, una vez establecidas las concentraciones de los inmunorreactivos, se procedió a optimizar las condiciones fisico-químicas del medio, así como otras características experimentales. Por tanto, 
utilizando las combinaciones seleccionadas en los ensayos competitivos, se llevaron a cabo ensayos de optimización con el fin de mejorar las prestaciones analíticas de los mismos.

Después de optimizar los ensayos, se estudió su selectividad evaluando la reactividad cruzada frente a once compuestos relacionados química $\mathrm{y}$ estructuralmente (Figuras 20, Experimental) con las tetraciclinas.

\subsubsection{Ensayo para TCs}

En primer lugar se procedió a optimizar las condiciones del ensayo en formato indirecto para TC. Al evaluar el efecto de la fuerza iónica del medio (Tabla 23) se observó que, en líneas generales, a medida que aumenta la concentración salina, tanto la sensibilidad como la señal máxima disminuyen, lo que indica que las interacciones que tienen lugar entre el analito y el anticuerpo deben ser principalmente hidrofóbicas, seleccionando PBS-T $10 \mathrm{mM}$ como concentración de compromiso entre señal y sensibilidad.

Por otro lado, se estudió la influencia del pH del medio en el intervalo 4,5-9,5, alcanzándose mayor sensibilidad a pH 7,5.

En las condiciones previamente establecidas, se evaluó el efecto de la concentración de tensioactivo en las prestaciones analíticas. A la vista de los resultados (Tabla 23), se concluye que la concentración de surfactante influye negativamente en la sensibilidad, ya que la $\mathrm{IC}_{50}$ aumenta a medida que lo hace la concentración de Tween 20, aunque no tiene un efecto marcado en la señal máxima obtenida, que se mantiene constante en todo el intervalo de trabajo. Así pues, se seleccionó como óptima una concentración de $0,01 \%$ de Tween 20 , al presentar la mejor sensibilidad con un valor de señal aceptable.

A continuación, se estudió la influencia del tiempo de incubación de la etapa competitiva (15, 30, 45 y 60 min). Como se muestra en la Tabla 23, los valores de $\mathrm{IC}_{50} \mathrm{y}$ la señal aumentan gradualmente con el tiempo de incubación, seleccionando 45 min como óptimo para obtener ensayos sensibles $\left(\mathrm{IC}_{50}=6,5\right)$ con una señal adecuada $\left(\mathrm{A}_{0}=1,02\right)$. 
Tabla 23. Resultados de la optimización del ELISA para TCs en formato indirecto

\begin{tabular}{|c|c|c|}
\hline Parámetro & $\mathbf{A}_{0}$ (U.A.) $^{a}$ & $\mathrm{IC}_{50}(\mu \mathrm{g} / \mathrm{L})$ \\
\hline \multicolumn{3}{|l|}{ 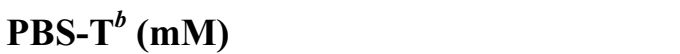 } \\
\hline 2,5 & 1,66 & 40,2 \\
\hline 5,0 & 1,58 & 25,0 \\
\hline 10 & 1,38 & 11,2 \\
\hline 20 & 1,07 & 13,2 \\
\hline 50 & 0,83 & 14,3 \\
\hline 100 & 0,45 & - \\
\hline \multicolumn{3}{|l|}{ pH } \\
\hline 4,5 & 0,89 & 22,8 \\
\hline 5,5 & 1,19 & 30,5 \\
\hline 6,5 & 1,31 & 21,3 \\
\hline 7,5 & 1,53 & 12,4 \\
\hline 8,5 & 1,34 & 12,7 \\
\hline 9,5 & 1,30 & 18,1 \\
\hline \multicolumn{3}{|l|}{ Tween 20 (\%) } \\
\hline 0,010 & 1,28 & 6,9 \\
\hline 0,025 & 1,10 & 10,2 \\
\hline 0,050 & 1,25 & 12,3 \\
\hline 0,100 & 1,20 & 10,4 \\
\hline 0,250 & 1,23 & 9,3 \\
\hline \multicolumn{3}{|l|}{ Tiempo (min) } \\
\hline 15 & 0,51 & 3,5 \\
\hline 30 & 0,83 & 6,5 \\
\hline 45 & 1,02 & 6,5 \\
\hline 60 & 1,12 & 6,9 \\
\hline
\end{tabular}

Del ensayo de optimización de este analito se deduce que la fuerza iónica y el $\mathrm{pH}$ del medio son los parámetros que más influyen en la mejora de la sensibilidad del ELISA desarrollado. La Figura 47 muestra la curva de calibrado para TC. 


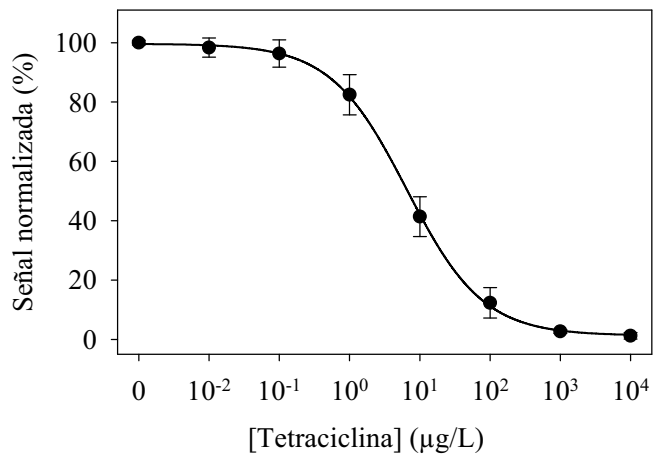

Figura 47. Curva de competición para TC (media y desviación de tres réplicas)

En las condiciones optimizadas, el ELISA desarrollado para TC (Tabla 24) presentó una sensibilidad y límite de detección de 6,52 y $0,40 \mu \mathrm{g} / \mathrm{L}$, respectivamente, y un intervalo de trabajo comprendido entre 1,15 y $38,89 \mu \mathrm{g} / \mathrm{L}$.

Tabla 24. Parámetros analíticos del ELISA desarrollado para TCs

\begin{tabular}{cccccc}
\hline & Ensayo & $\begin{array}{c}\mathbf{I C}_{\mathbf{5 0}}{ }^{a} \\
(\boldsymbol{\mu g} / \mathbf{L})\end{array}$ & $\begin{array}{c}\mathbf{A}_{\mathbf{0}}{ }^{b} \\
(\mathbf{U . A .})\end{array}$ & $\begin{array}{c}\mathbf{R D}^{c} \\
(\boldsymbol{\mu g} / \mathbf{L})\end{array}$ & $\begin{array}{c}\mathbf{L D}^{d} \\
(\boldsymbol{\mu g} / \mathbf{L})\end{array}$ \\
\hline KLH-OTC-3-III/OVA-TC-1 & TCs & 6,52 & 1,02 & $1,15-38,89$ & 0,40 \\
\hline
\end{tabular}

${ }^{a} \mathrm{IC}_{50}$ : sensibilidad

${ }^{b} \mathrm{~A}_{0}$ : absorbancia máxima; U.A.: unidades de absorbancia

${ }^{c} \mathrm{RD}$ : intervalo de trabajo o rango dinámico

${ }^{d}$ LD: límite de detección

La selectividad del ensayo se determinó mediante el estudio de reactividad cruzada, utilizando una serie de compuestos de estructura similar. La TC fue el analito que mostró el mejor reconocimiento, por lo que se utilizó como referencia. Los resultados obtenidos se recogen en la Tabla 25, en la que se observa que los principales interferentes para el ensayo de tetraciclina fueron RTC (91\%), OTC (30\%), MC (14\%) y CTC (10\%). La elevada RC exhibida por RTC puede ser debida a la hidrólisis espontánea a TC en medio acuoso. Por lo tanto, el inmunoensayo desarrollado podría ser considerado como un ensayo genérico para las tetraciclinas más utilizadas. 
Tabla 25. Selectividad del ELISA para TCs

\begin{tabular}{llrr}
\hline \multicolumn{1}{c}{ Compuesto } & \multicolumn{1}{c}{ IC $_{\mathbf{5 0}}$} & \multicolumn{1}{c}{ RC } \\
\hline Tetraciclina & TC & $\mathbf{6 , 5}$ & $\mathbf{1 0 0 , 0 0}$ \\
Anhidrotetraciclina & ATC & 453,8 & 1,44 \\
Clortetraciclina & CTC & $\mathbf{6 3 , 8}$ & $\mathbf{1 0 , 2 2}$ \\
Daunorubicina & DR & $>10.000$ & $<0,01$ \\
Demeclociclina & DMC & 972,4 & 0,67 \\
Doxiciclina & DXC & 139,2 & 4,68 \\
Doxorubicina & DXR & $>10.000$ & $<0,01$ \\
Metaciclina & MC & $\mathbf{4 5 , 7}$ & $\mathbf{1 4 , 2 8}$ \\
Minociclina & MNC & $>10.000$ & $<0,01$ \\
Oxitetraciclina & OTC & $\mathbf{2 1 , 7}$ & $\mathbf{3 0 , 0 3}$ \\
Rolitetraciclina & RTC & $\mathbf{7 , 2}$ & $\mathbf{9 0 , 9 3}$ \\
\hline
\end{tabular}

Concentraciones en $\mu \mathrm{g} / \mathrm{L}$

$\mathrm{RC}(\%)=\left[\mathrm{IC}_{50}(\mathrm{TC}) / \mathrm{IC}_{50}\right.$ (interferente) $] \times 100$

Teniendo en cuenta todos los resultados obtenidos, el ensayo genérico desarrollado (KLH-OTC-3-III/OVA-TC-1) permite la determinación simultánea de cinco tetraciclinas (TC, CTC, MC, OTC y RTC), con una sensibilidad $\left(\mathrm{IC}_{50}\right)$ de 6,5 $\mu \mathrm{g} / \mathrm{L}(\mathrm{LD} 0,4 \mu \mathrm{g} / \mathrm{L})$ expresada como TC. Comparando estos resultados con los obtenidos por otros autores, el ELISA desarrollado para TC muestra una buena sensibilidad (Tabla 8, Introducción). Con posterioridad a la obtención de estos resultados, Jeon et al. ${ }^{117}$ publicaron el desarrollo de un ELISA competitivo basado en el sistema de reconocimiento avidina-biotina para la determinación de residuos de TC, utilizando un anticuerpo policlonal comercial, con un LD de 0,05 $\mu \mathrm{g} / \mathrm{L}$, reconociendo únicamente tres tetraciclinas (TC, CTC, OTC). Así, la ventaja más significativa del ELISA desarrollado en esta Tesis es su bajo LD, así como la posibilidad de detectar las TCs más utilizadas en el campo agroalimentario dentro de los LMRs permitidos por la legislación, ya que se trata del inmunoensayo con mayor carácter genérico recogido en la bibliografía hasta la fecha.

En comparación con los kits comerciales, el inmunoensayo desarrollado para TCs presenta mejor sensibilidad y carácter genérico (mayor reactividad cruzada). Únicamente, el kit Ridascreen TC (r-Biopharm GmbH, Darmstadt, Alemania) presenta una respuesta genérica similar, permitiendo también la detección de cinco tetraciclinas (TC, OTC, MNC, RTC y CTC), aunque con menor sensibilidad. 


\subsubsection{Ensayo para CTC}

Con el fin de mejorar la sensibilidad del inmunoensayo para CTC, se estudió la influencia de distintas variables experimentales $(\mathrm{pH}$, fuerza iónica, concentración de surfactante y tiempo de competición) en las características del mismo. Los resultados se muestran en la Tabla 26. En este caso, la primera variable experimental estudiada fue el tiempo de competición.

Tabla 26. Resultados de la optimización del ELISA para CTC en formato indirecto

\begin{tabular}{ccc}
\hline Parámetro & $\mathbf{A}_{\mathbf{0}}$ (U.A.) $^{\boldsymbol{a}}$ & $\mathbf{I C}_{\mathbf{5 0}}(\boldsymbol{\mu g} / \mathbf{L})$ \\
\hline Tiempo (min) & & \\
15 & $\mathbf{1 , 2 1}$ & $\mathbf{5 3}$ \\
30 & 1,42 & 110 \\
60 & 1,65 & 235 \\
PBS-T $^{\boldsymbol{b}}$ (mM) & & \\
5 & 1,54 & 76 \\
10 & $\mathbf{1 , 2 4}$ & $\mathbf{4 9}$ \\
25 & 0,83 & 45 \\
50 & 0,68 & 51 \\
& & \\
pH & 1,43 & 99 \\
6,5 & 1,29 & 51 \\
7,5 & $\mathbf{1 , 2 3}$ & $\mathbf{4 1}$ \\
8,5 & & \\
Tween 20 (\%) & & 111 \\
0,010 & 1,64 & 95 \\
0,025 & 1,57 & 46 \\
0,050 & 1,32 & \\
0,100 & 1,23 & \\
0,250 & $\mathbf{1 , 1 8}$ & $\mathbf{3 6}$ \\
\hline Concentraciones en placa \\
${ }^{a}$ U.A.: unidades de absorbancia \\
${ }^{b} 0,05 \%$ Tween 20 (v/v)
\end{tabular}

Al evaluar el tiempo de incubación en la etapa competitiva se observa que tanto la señal máxima como la sensibilidad aumentan gradualmente a medida que lo hace el tiempo de competición. Con el fin de obtener ensayos sensibles, con una señal 
adecuada y en un tiempo reducido, se seleccionó 15 min como tiempo de incubación óptimo.

Para estudiar el efecto de la fuerza iónica se varió la concentración de PBS-T entre 5-50 mM (Tabla 26). Se observa que la fuerza iónica tiene poca influencia en la sensibilidad del ensayo a partir de $10 \mathrm{mM}$, aunque la señal disminuye a medida que la concentración salina aumenta, hasta alcanzar valores de 0,68 U.A. con 50 $\mathrm{mM}$. Así, se seleccionó $10 \mathrm{mM}$ de PBS-T como medio de competición óptimo atendiendo a una buena sensibilidad y señal.

A continuación se evaluó la influencia del pH del medio en las características del inmunoensayo, observando que tanto la señal como la sensibilidad disminuyen gradualmente a medida que aumenta el $\mathrm{pH}$, seleccionando $\mathrm{pH} 8,5$ por presentar una mayor relación $\mathrm{A}_{0} / \mathrm{IC}_{50}$.

Con las condiciones seleccionadas previamente, se procedió a estudiar el efecto de la concentración de tensioactivo, observando (Tabla 26) que tanto la señal como la $\mathrm{IC}_{50}$ disminuyen al aumentar la concentración de surfactante. La mayor sensibilidad se alcanza utilizando una concentración de Tween $0,25 \%$, indicando que para esta combinación anticuerpo/analito la concentración de Tween 20 es critica para obtener un ensayo sensible.

En resumen, la optimización del ELISA para CTC mejora la sensibilidad y reduce el tiempo de ensayo considerablemente.

Las características analíticas del inmunoensayo se resumen en la Tabla 27. El ELISA desarrollado permite la determinación de CTC con una sensibilidad $\left(\mathrm{IC}_{50}\right)$ de 36,4 $\mu \mathrm{g} / \mathrm{L}$, y un límite de detección de 2,3 $\mu \mathrm{g} / \mathrm{L}$ (Figura 48).

Tabla 27. Parámetros analíticos del ELISA desarrollado para CTC

\begin{tabular}{cccccc}
\hline & Ensayo & $\begin{array}{c}\mathbf{I C}_{50}{ }^{a} \\
(\mu \mathbf{g} / \mathbf{L})\end{array}$ & $\begin{array}{c}\mathbf{A}_{0}{ }^{b} \\
(\mathbf{U . A .})\end{array}$ & $\begin{array}{c}\mathbf{R D}^{c} \\
(\boldsymbol{\mu g} / \mathbf{L})\end{array}$ & $\begin{array}{c}\mathbf{L D}^{d} \\
(\boldsymbol{\mu g} / \mathbf{L})\end{array}$ \\
\hline BSA-OTC-1-I/OVA-CTC-1 & CTC & 36,40 & 1,18 & $5,9-240$ & 2,3 \\
\hline
\end{tabular}

${ }^{a} \mathrm{IC}_{50}$ : sensibilidad

${ }^{b} \mathrm{~A}_{0}$ : absorbancia máxima; U.A.: unidades de absorbancia

${ }^{c} \mathrm{RD}$ : intervalo de trabajo o rango dinámico

${ }^{d}$ LD: límite de detección 


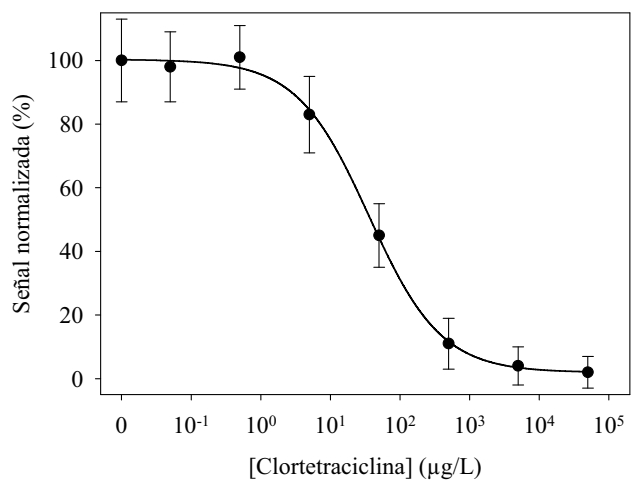

Figura 48. Curva de competición para CTC (media y desviación de tres réplicas)

La selectividad del ensayo se determinó utilizando una serie de interferentes de estructura similar. Los resultados (Tabla 28) indican que el ELISA desarrollado es altamente selectivo para CTC, con valores de RC (\%) inferiores al 3\% respecto a todas las tetraciclinas ensayadas.

Tabla 28. Selectividad del ELISA para CTC

\begin{tabular}{llrr}
\hline \multicolumn{1}{c}{ Compuesto } & \multicolumn{1}{c}{ IC $_{\mathbf{5 0}}$} & \multicolumn{1}{c}{ RC } \\
\hline Clortetraciclina & CTC & $\mathbf{3 6 , 4}$ & $\mathbf{1 0 0 , 0 0}$ \\
Anhidrotetraciclina & ATC & $>50.000$ & $<0,07$ \\
Doxiciclina & DXC & 50.000 & 0,07 \\
Metaciclina & MC & $>50.000$ & $<0,07$ \\
Minociclina & MNC & $>50.000$ & $<0,07$ \\
Oxitetraciclina & OTC & $>50.000$ & $<0,07$ \\
Rolitetraciclina & RTC & 12.750 & 0,28 \\
Tetraciclina & TC & 1500 & 2,39 \\
\hline
\end{tabular}

Concentraciones en $\mu \mathrm{g} / \mathrm{L}$

$\mathrm{RC}(\%)=\left[\mathrm{IC}_{50}(\mathrm{CTC}) / \mathrm{IC}_{50}\right.$ (interferente) $] \times 100$

En resumen, se ha puesto a punto un inmunoensayo (BSA-OTC-1-I/OVA-CTC1) sensible y específico, en formato indirecto, para la determinación de clortetraciclina. La ventaja más significativa del ensayo es su especificidad y bajo LD, lo que hace posible la determinación de CTC dentro de los LMRs permitidos por la legislación europea en alimentos de origen animal. Hay que destacar que es la primera vez que se describe un inmunoensayo específico para la determinación 
de esta tetraciclina. Como se ha comentado previamente (sección 1.6.3.4., Introducción), hasta la fecha la determinación de CTC se ha llevado a cabo mediante inmunoensayos genéricos, los cuales mostraron una elevada reactividad cruzada hacia otras tetraciclinas (Tabla 8, Introducción). Así, por ejemplo, Zhang et al. ${ }^{105}$ desarrollaron un inmunoensayo indirecto para CTC con elevada reactividad cruzada hacia TC y con baja sensibilidad, del orden de $(\mathrm{mg} / \mathrm{L})$.

Si comparamos los resultados obtenidos con los kits comerciales basados en formato ELISA se observa que éstos presentan una sensibilidad similar, pero no son específicos, reconociendo las tetraciclinas más utilizadas (TC, OTC, RTC).

Con el ensayo para TCs (KLH-OTC-3-III/OVA-TC-1) desarrollado en esta tesis doctoral, otros investigadores del grupo han determinado mediante ELISA dichos antibióticos en piensos ${ }^{168}$ y pescado ${ }^{170}$.

\subsubsection{Análisis de muestras}

Dado que las investigaciones se realizaron en el marco de un proyecto de investigación cuyo objetivo era la determinación de residuos de antibióticos en miel, algunos de los ensayos ELISA desarrollados fueron aplicados a este tipo de muestra. Además, al disponer de un ELISA de elevada sensibilidad para SSZ, se consideró su aplicación a plasma y suero fisiológico, por su utilización en medicina humana.

\subsubsection{Ensayo para $S T Z$}

La presencia de residuos de sulfonamidas en miel, especialmente sulfatiazol, representa un grave problema tanto desde el punto de vista toxicológico, puesto que pueden desencadenar reacciones tóxicas o alérgicas, como por la aparición de resistencias en humanos. Por ello, se justifica el desarrollo de metodologías alternativas a la cromatografía (método de referencia) que permitan llevar a cabo programas de vigilancia y control que aseguren la inocuidad de la miel.

El análisis de muestras de miel se llevó a cabo utilizando el inmunoensayo $\mathrm{C}$ (BSA-S3-I/OVA-S2), por presentar el límite de detección más bajo y mejor selectividad. Previamente, se consideró oportuno realizar un estudio del efecto 
matriz debido a la composición heterogénea y compleja de la miel. Para ello, se prepararon distintas diluciones de miel en PBS-T (1:5, 1:10, 1:20, 1:50, 1:100 y $1: 200, \mathrm{p} / \mathrm{v})$, se realizaron las curvas patrón y se compararon con la curva de calibrado obtenida en tampón PBS-T. Las diluciones 1:5, 1:10, 1:20 y 1:50 provocaban un descenso de la señal máxima muy significativo, disminuyendo paulatinamente a medida que aumentaba el porcentaje de miel en la disolución de trabajo, afectando por tanto la sensibilidad del ensayo. Por ello, se seleccionó 1:100 $(\mathrm{p} / \mathrm{v})$ como dilución de trabajo óptima, puesto que la $\mathrm{IC}_{50}$ era buena y la señal aceptable, alcanzando una sensibilidad similar a la obtenida en PBS-T (Figura 49).

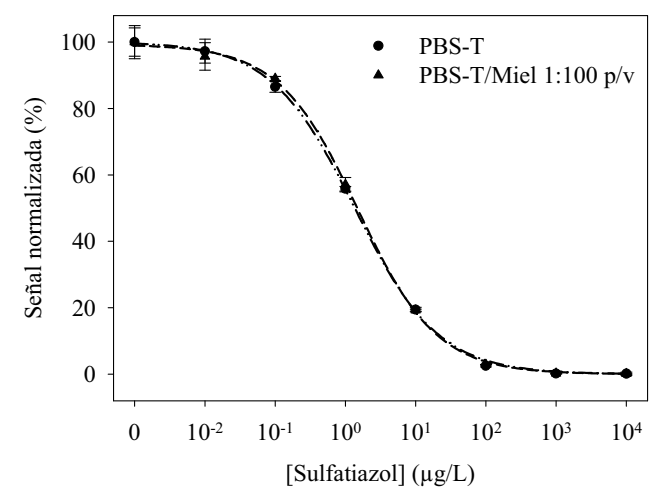

Figura 49. Curvas de calibrado de STZ en PBS-T y en miel diluida 1:100 (p/v) (media y desviación de tres réplicas)

Los estudios de recuperación en muestras de miel se llevaron a cabo utilizando cinco muestras comerciales exentas de sulfatiazol, como indicaron los análisis mediante HPLC. Para ello, se diluyeron en PBS-T $(1: 100, \mathrm{p} / \mathrm{v})$ con el fin de evitar el efecto matriz y se doparon con STZ a dos niveles dentro del intervalo de trabajo del método, 1,6 y 2,4 $\mu \mathrm{g} / \mathrm{L}$. La Tabla 29 muestra las recuperaciones obtenidas en la cuantificación de residuos de sulfatiazol mediante ELISA, en las diferentes muestras de miel. Los valores de recuperación oscilaron entre 80 y $116 \%$, excepto para la muestra 5, que fue alrededor del 70\%. Este efecto puede ser probablemente atribuido al diferente contenido de azúcar (glucosa y fructosa), color, y enzimas presentes en la miel ${ }^{171}$. 
Tabla 29. Determinación de STZ mediante ELISA en miel

\begin{tabular}{|c|c|c|c|}
\hline Muestra $^{a}$ & [STZ]añadida & $\begin{array}{c}{[S T Z] \text { determinada }} \\
(\text { media } \pm \text { SD })\end{array}$ & $\begin{array}{c}\text { Recuperación } \\
(\%)\end{array}$ \\
\hline \multirow[t]{3}{*}{1} & 0,0 & - & \\
\hline & 1,6 & $1,58 \pm 0,20$ & 99 \\
\hline & 2,4 & $2,42 \pm 0,27$ & 101 \\
\hline \multirow[t]{3}{*}{2} & 0,0 & - & \\
\hline & 1,6 & $1,55 \pm 0,12$ & 97 \\
\hline & 2,4 & $1,97 \pm 0,21$ & 82 \\
\hline \multirow[t]{3}{*}{3} & 0,0 & - & \\
\hline & 1,6 & $1,86 \pm 0,19$ & 116 \\
\hline & 2,4 & $1,92 \pm 0,25$ & 80 \\
\hline \multirow[t]{3}{*}{4} & 0,0 & - & \\
\hline & 1,6 & $1,31 \pm 0,14$ & 82 \\
\hline & 2,4 & $2,06 \pm 0,23$ & 86 \\
\hline \multirow[t]{3}{*}{5} & 0,0 & - & \\
\hline & 1,6 & $1,07 \pm 0,16$ & 67 \\
\hline & 2,4 & $1,73 \pm 0,15$ & 72 \\
\hline \multicolumn{4}{|c|}{$\begin{array}{l}\text { Concentraciones en } \mu \mathrm{g} / \mathrm{L} \\
\text { SD desviación estándar par }\end{array}$} \\
\hline
\end{tabular}

\subsubsection{Ensayo para $S S Z$}

La sulfasalazina es una sulfonamida empleada en el tratamiento de enfermedades inflamatorias del intestino, como por ejemplo la artritis reumatoide, la enfermedad de Crohn o la colitis ulcerosa. La concentración máxima de SSZ encontrada en plasma de voluntarios sanos se obtiene a las 11,5-14,5 h de su administración, y varía entre 6 y $32 \mathrm{mg} / \mathrm{L}^{172}$. La frecuencia de efectos adversos en los tratamientos con SSZ es elevada, alrededor del $86 \%{ }^{173}$. Por ello, se consideró de interés estudiar la aplicación del inmunoensayo desarrollado para SSZ (BSAS5-I/OVA-S8) a la determinación de residuos de este analito en plasma humano.

En primer lugar, se analizaron muestras de suero fisiológico dopadas a distintos niveles con SSZ, como un primer estudio para la determinación de este analito en plasma humano. Con el objetivo de estudiar el efecto matriz, se prepararon (por triplicado) seis curvas de competición conteniendo diferentes proporciones $(\mathrm{v} / \mathrm{v}) \mathrm{de}$ 
suero fisiológico en tampón PBS-T (de 0 a 100\%). El porcentaje óptimo de suero se estimó teniendo en cuenta que no influyera negativamente en las características propias de ensayo, $\mathrm{A}_{0}$ y $\mathrm{IC}_{50}$. Los resultados mostraron que la señal del inmunoensayo depende en gran medida de la fuerza iónica del medio ( $\mathrm{A}_{0}$ disminuye al aumentar el porcentaje de suero), tal y como se observó previamente en los estudios de optimización. Por tanto, se seleccionó un porcentaje del $20 \%$ de suero fisiológico, al conseguir así una buena sensibilidad y señal, además de un menor efecto matriz. En la Figura 50, se observa que la curva de calibrado es comparable en términos de sensibilidad (similar valor de $\mathrm{IC}_{50}$ ) a la obtenida en PBS-T. En estas condiciones, el ensayo alcanzó un LD de 0,01 $\mu \mathrm{g} / \mathrm{L}$, una $\mathrm{IC}_{50}$ de $0,49 \mu \mathrm{g} / \mathrm{L}$, y un intervalo de trabajo entre 0,06 y $3,59 \mu \mathrm{g} / \mathrm{L}$, siendo la sensibilidad del método para determinar SSZ en suero de $2,45 \mu \mathrm{g} / \mathrm{L}$.

Posteriormente se llevaron a cabo estudios de recuperación estimando la exactitud y reproducibilidad del método. Para ello se utilizaron diferentes muestras de suero fisiológico fortificadas con SSZ a cuatro niveles $(0,5,1,01,5$ y $2 \mu \mathrm{g} / \mathrm{L})$. Una muestra sin fortificar se utilizó como control. Las muestras, previa dilución en el tampón de trabajo al 20\%, se analizaron directamente mediante ELISA.

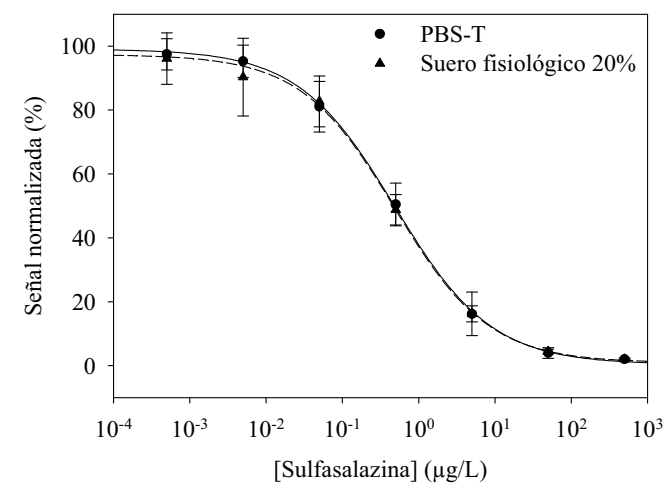

Figura 50. Curvas de calibrado de SSZ en PBS-T y suero fisiológico al $20 \% \mathrm{v} / \mathrm{v}$ (media y desviación de tres réplicas)

Como puede observarse en la Tabla 30, el valor de la recuperación osciló entre 97 y $112 \%$, obteniendo una recuperación media del 104\% con un coeficiente de variación del $6 \%$. Estos resultados indican que se pueden determinar residuos de 
SSZ en suero fisiológico directamente con solo diluir la muestra 1:5 (v/v) en el tampón de trabajo.

Tabla 30. Determinación de SSZ mediante ELISA en suero fisiológico

\begin{tabular}{ccc}
\hline [SSZ] $^{\text {nñadida }}{ }^{a}$ & $\begin{array}{c}\left.\text { [SSZ]determinada }_{(\mathbf{m e d i a}} \pm \mathbf{S D}\right) \\
0,5\end{array}$ & $\begin{array}{c}\text { Recuperación } \\
\mathbf{( \% )}\end{array}$ \\
\hline $0,56 \pm 0,04$ & 112 \\
1,0 & $1,06 \pm 0,07$ & 106 \\
1,5 & $1,45 \pm 0,11$ & 97 \\
2,0 & $2,05 \pm 0,14$ & 103 \\
\hline
\end{tabular}

Concentraciones en $\mu \mathrm{g} / \mathrm{L}$

SD desviación estándar para $\mathrm{n}=3$

${ }^{a}$ Diluida $20 \%$ en $10 \mathrm{mM}$ PBS, $0,1 \%$ Tween $\mathrm{pH} 8,5$

Antes de analizar las muestras de plasma, se estudió el efecto del metanol sobre las prestaciones analíticas del ensayo desarrollado para SSZ, ya que dicho disolvente se utiliza para extraer residuos de sulfonamidas de muestras biológicas mediante diferentes metodologías. El intervalo de concentraciones de $\mathrm{MeOH}$ estudiadas fue de $0-40 \%(\mathrm{v} / \mathrm{v})$. En la Figura 51 se muestra el efecto de la adición de $\mathrm{MeOH}$-al tampón en la etapa de competición- sobre la sensibilidad $\left(\mathrm{IC}_{50}\right)$ y el valor de la señal en ausencia de analito $\left(\mathrm{A}_{0}\right)$.

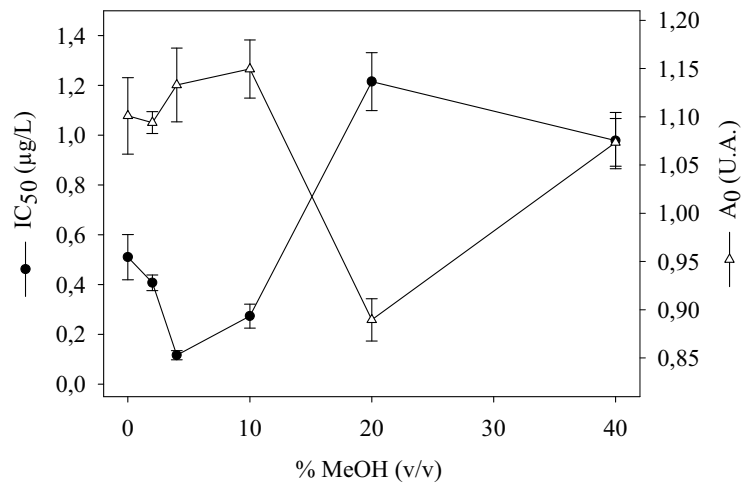

Figura 51. Tolerancia al metanol del inmunoensayo para SSZ

Los resultados indicaron que porcentajes inferiores el 10\% eran bien tolerados, manteniendo buenas propiedades analíticas, incluso mejoraron la sensibilidad alcanzada por el inmunoensayo en medio acuoso. Sin embargo, concentraciones 
superiores al 10\% disminuían la sensibilidad respecto a los ensayos efectuados en medio acuoso. Así pues, se puede utilizar hasta un 10\% de disolvente metanólico, manteniendo buenos valores de $\mathrm{IC}_{50}$ y señal. En la Figura 52 se muestran las curvas de calibrado para SSZ en PBS-T y PBS-T/MeOH 10\%. Se observa que los parámetros de la curva de calibrado en PBS-T son significativamente diferentes de los obtenidos en PBS-T con un $10 \%$ de $\mathrm{MeOH}$. Por ello, la concentración de sulfasalazina de los extractos metanólicos de muestras biológicas se determinará por interpolación de la señal en la curva de calibrado preparada en dicho medio.

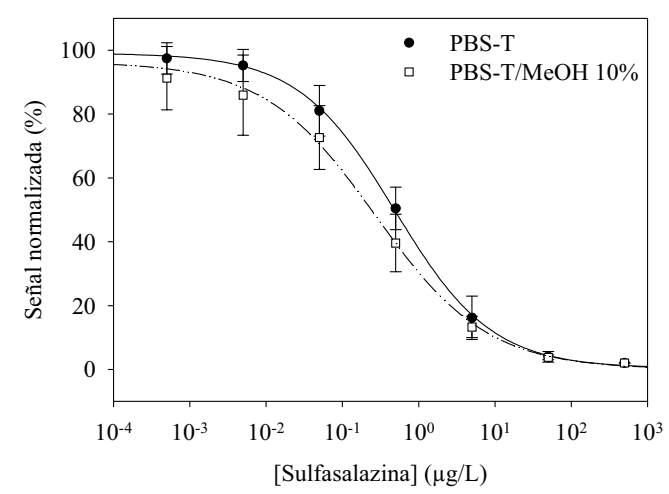

Figura 52. Curvas de calibrado de SSZ en PBS-T y PBS-T/MeOH al $10 \%$ v/v (media y desviación de tres réplicas)

Al comparar las características del inmunoensayo en ambos medios podemos concluir que, a pesar de que el intervalo de trabajo fue más limitado en el medio metanólico $(\mathrm{RD}=0,02-2,60 \mu \mathrm{g} / \mathrm{L})$, la sensibilidad $\left(\mathrm{IC}_{50}=0,27 \mu \mathrm{g} / \mathrm{L}\right)$ y el $\mathrm{LD}(0,003$ $\mu \mathrm{g} / \mathrm{L})$ fueron mejores que en medio acuoso, tal y como se muestra en la Tabla 31.

Tabla 31. Parámetros analíticos para el ELISA de SSZ

\begin{tabular}{ccccc}
\hline Medio & $\begin{array}{c}\mathbf{I C}_{\mathbf{5 0}}{ }^{a} \\
(\boldsymbol{\mu g} / \mathbf{L})\end{array}$ & $\begin{array}{c}\mathbf{A}_{\mathbf{0}}{ }^{b} \\
(\mathbf{U} . \mathbf{A} .)\end{array}$ & $\begin{array}{c}\mathbf{R D}^{c} \\
(\boldsymbol{\mu g} / \mathbf{L})\end{array}$ & $\begin{array}{c}\mathbf{L D}^{d} \\
(\boldsymbol{\mu g} / \mathbf{L})\end{array}$ \\
\hline Tampón & 0,51 & 1,02 & $0,06-3,75$ & 0,020 \\
$10 \%$ metanol & 0,27 & 1,15 & $0,02-2,60$ & 0,003 \\
\hline${ }^{a} \mathrm{I} \mathrm{C}_{50}$ : sensibilidad \\
${ }^{b} \mathrm{~A}_{0}$ : absorbancia máxima; U.A.: unidades de absorbancia \\
${ }^{c} \mathrm{RD}$ : intervalo de trabajo o rango dinámico \\
${ }^{d}$ LD: límite de detección
\end{tabular}


Para evaluar el potencial analítico del método, éste se aplicó a muestras de plasma humano adquiridas a Sigma (Madrid, España).

En primer lugar, se obtuvieron curvas de calibrado con diluciones de plasma entre $1 / 50$ y $1 / 500$, siguiendo la estrategia descrita previamente para el suero fisiológico. Para ello, el plasma fue dopado con SSZ a distintas concentraciones $\left(10^{-1}-10^{5} \mu \mathrm{g} / \mathrm{L}\right)$. Como puede observarse en la Figura 53, las curvas de calibrado en plasma presentan una sensibilidad considerablemente inferior a la obtenida en PBS-T. Por ello, se concluye que una dilución del plasma con el tampón de trabajo no resultó ser adecuado como acondicionamiento de las muestras para su análisis mediante ELISA.

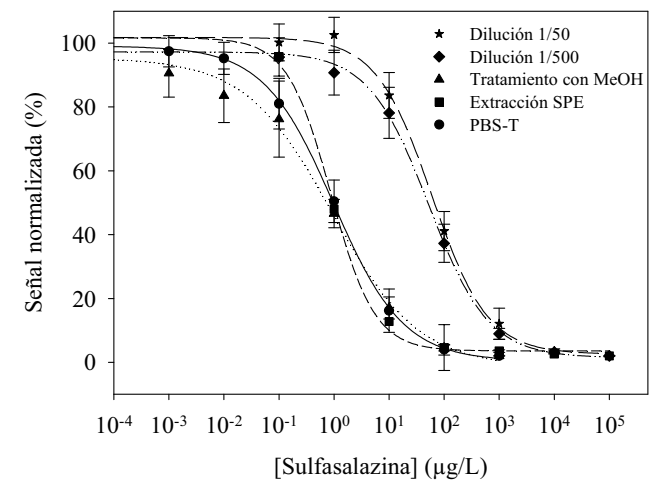

Figura 53. Curvas de calibrado de SSZ en plasma humano utilizando diferentes tratamientos de muestra (media y desviación de tres réplicas)

Para evitar el efecto matriz debido a proteínas y demás sustancias presentes en el plasma humano, se ensayó la extracción en fase sólida con cartuchos Strata X-C (polímero de estireno-divinilbenceno químicamente modificado con grupos sulfónicos) y la precipitación con metanol. Ambos tratamientos de muestra se llevaron a cabo según se describe en la sección 3.2.4.6. (Parte Experimental).

Las curvas de calibrado obtenidas utilizando ambos procedimientos presentaron una sensibilidad similar: $\mathrm{IC}_{50}=0,44 \mu \mathrm{g} / \mathrm{L}$ en el caso del tratamiento con metanol, $\mathrm{y}$ $\mathrm{IC}_{50}=0,43 \mu \mathrm{g} / \mathrm{L}$ en la extracción SPE, como puede observarse en la Figura 53. No obstante, el tratamiento con metanol permite llevar a cabo la extracción simultánea de un mayor número de muestras. Además, reduce el coste y el tiempo de análisis en comparación con la extracción en fase sólida, por lo que fue seleccionado como tratamiento de muestra más adecuado. 
Para evaluar la reproducibilidad del tratamiento de muestra, se fortificaron 20 alícuotas de plasma humano con SSZ, a distintos niveles: 10 alícuotas a $10 \mu \mathrm{g} / \mathrm{L}$ y otras 10 alícuotas a $20 \mu \mathrm{g} / \mathrm{L}$. Todas las alícuotas fueron tratadas con metanol y analizadas por triplicado mediante ELISA. Los resultados se obtuvieron utilizando la curva de calibrado en PBS-T con un $10 \%$ de $\mathrm{MeOH}$. Como puede observarse en la Tabla 32, los resultados demuestran la efectividad del tratamiento seleccionado, alcanzándose valores de recuperación entre el 83 y 119\%, con un valor medio de recuperación del 99\% (CV=13\%). Se observa que los resultados se correlacionan aceptablemente con los valores teóricos de concentración de sulfasalazina, ya que la recuperación obtenida (cociente porcentual entre el valor medido y el valor de referencia) se sitúa, en la mayoría de los casos, entre el 80 y el $120 \%$. Por tanto, se puede concluir que el tratamiento de muestra empleado es eficaz y la reproducibilidad alcanzada es buena a las concentraciones estudiadas.

Teniendo en cuenta que la concentración máxima de SSZ encontrada en plasma de voluntarios sanos varía entre 6 y $32 \mathrm{mg} / \mathrm{L}$, el ELISA desarrollado para SSZ permitiría llevar a cabo programas de control de este tipo de residuos y decidir si un tratamiento debe ser prolongado o interrumpido para evitar los efectos secundarios en los pacientes, dado que el inmunoensayo puesto a punto tiene una sensibilidad del orden de $\mu \mathrm{g} / \mathrm{L}$.

Tabla 32. Determinación de SSZ mediante ELISA en plasma humano

\begin{tabular}{cccccc}
\hline $\mathbf{A}^{a}$ & $\begin{array}{c}{[\mathbf{S S Z}] \mathbf{d e t e r m i n a d a}} \\
(\mathbf{m e d i a} \pm \mathbf{S D})\end{array}$ & $\begin{array}{c}\text { Recuperación } \\
\mathbf{( \% )}\end{array}$ & $\mathbf{B}^{b}$ & $\begin{array}{c}{[\mathbf{S S Z}] \text { determinada }} \\
(\mathbf{m e d i a} \pm \mathbf{S D})\end{array}$ & $\begin{array}{c}\text { Recuperación } \\
(\mathbf{\%})\end{array}$ \\
\hline 1 & $0,45 \pm 0,01$ & 90 & 1 & $0,97 \pm 0,02$ & 97 \\
2 & $0,42 \pm 0,04$ & 83 & 2 & $1,15 \pm 0,03$ & 115 \\
3 & $0,42 \pm 0,02$ & 84 & 3 & $1,17 \pm 0,05$ & 117 \\
4 & $0,44 \pm 0,05$ & 87 & 4 & $0,88 \pm 0,05$ & 88 \\
5 & $0,44 \pm 0,03$ & 88 & 5 & $1,15 \pm 0,09$ & 115 \\
6 & $0,44 \pm 0,02$ & 87 & 6 & $0,91 \pm 0,03$ & 91 \\
7 & $0,53 \pm 0,05$ & 105 & 7 & $1,11 \pm 0,02$ & 111 \\
8 & $0,49 \pm 0,03$ & 98 & 8 & $1,09 \pm 0,02$ & 109 \\
9 & $0,42 \pm 0,02$ & 83 & 9 & $1,19 \pm 0,08$ & 119 \\
10 & $0,57 \pm 0,03$ & 113 & 10 & $0,96 \pm 0,05$ & 96 \\
\hline
\end{tabular}

${ }^{a} \mathrm{~A}$ : muestras de plasma humano dopadas con SSZ a $10 \mu \mathrm{g} / \mathrm{L}$

${ }^{b} \mathrm{~B}$ : muestras de plasma humano dopadas con SSZ a $20 \mu \mathrm{g} / \mathrm{L}$

Concentraciones en $\mu \mathrm{g} / \mathrm{L}$

SD desviación estándar para $n=3$ 


\subsubsection{ELISA Genérico I}

Para evaluar la utilidad del inmunoensayo genérico desarrollado para la determinación de sulfonamidas en muestras reales, se utilizó el inmunoensayo A (BSA-S3-I/OVA-S8) por presentar mejor sensibilidad y señal máxima, utilizando inicialmente STZ como analito en los estudios preliminares. Posteriormente, se llevó a cabo la determinación de STZ, PSTZ, SMP, SSZ, SP y SMT, en mieles enriquecidas con dichos antibióticos a distintos niveles.

Debido a la experiencia previa con el ensayo de STZ se decidió probar distintos tratamientos de muestra para evitar el efecto matriz, puesto que la miel es una matriz compleja. Por ello, en primer lugar se estudió cómo afectaban distintos disolventes en las características del inmunoensayo, ya que para la extracción de residuos de sulfonamidas en miel $^{132,174}$ generalmente se utilizan disolventes orgánicos.

Los disolventes ensayados fueron: metanol, acetonitrilo, acetona, dimetilsulfóxido e isopropanol, llevando a cabo ensayos competitivos, utilizando disoluciones de STZ en diferentes porcentajes de disolvente hasta un máximo del 40\%. La influencia de los disolventes estudiados se muestra en la Figura 54. En general, se observa una disminución de la sensibilidad y de la señal máxima según aumenta el porcentaje del disolvente utilizado, siendo bien tolerados hasta un $10 \%$. Se observa que el acetonitrilo es el disolvente peor tolerado, por producir una mayor disminución de la sensibilidad para un mismo porcentaje de disolvente $(10 \%)$.

De todos los disolventes ensayados el metanol fue el mejor tolerado, además de ser el empleado habitualmente para la extracción de sulfonamidas en mieles. Por otro lado, el metanol también se recomienda para eluir estos analitos de los cartuchos SPE, utilizados para la preparación de la muestra en la siguiente etapa. Por ello, se llevo a cabo un ensayo competitivo en PBS-T/MeOH $10 \%$ utilizando STZ como analito. En la Figura 55 se muestran las curvas de calibrado para STZ en PBS-T y PBS-T/MeOH $10 \%$. 

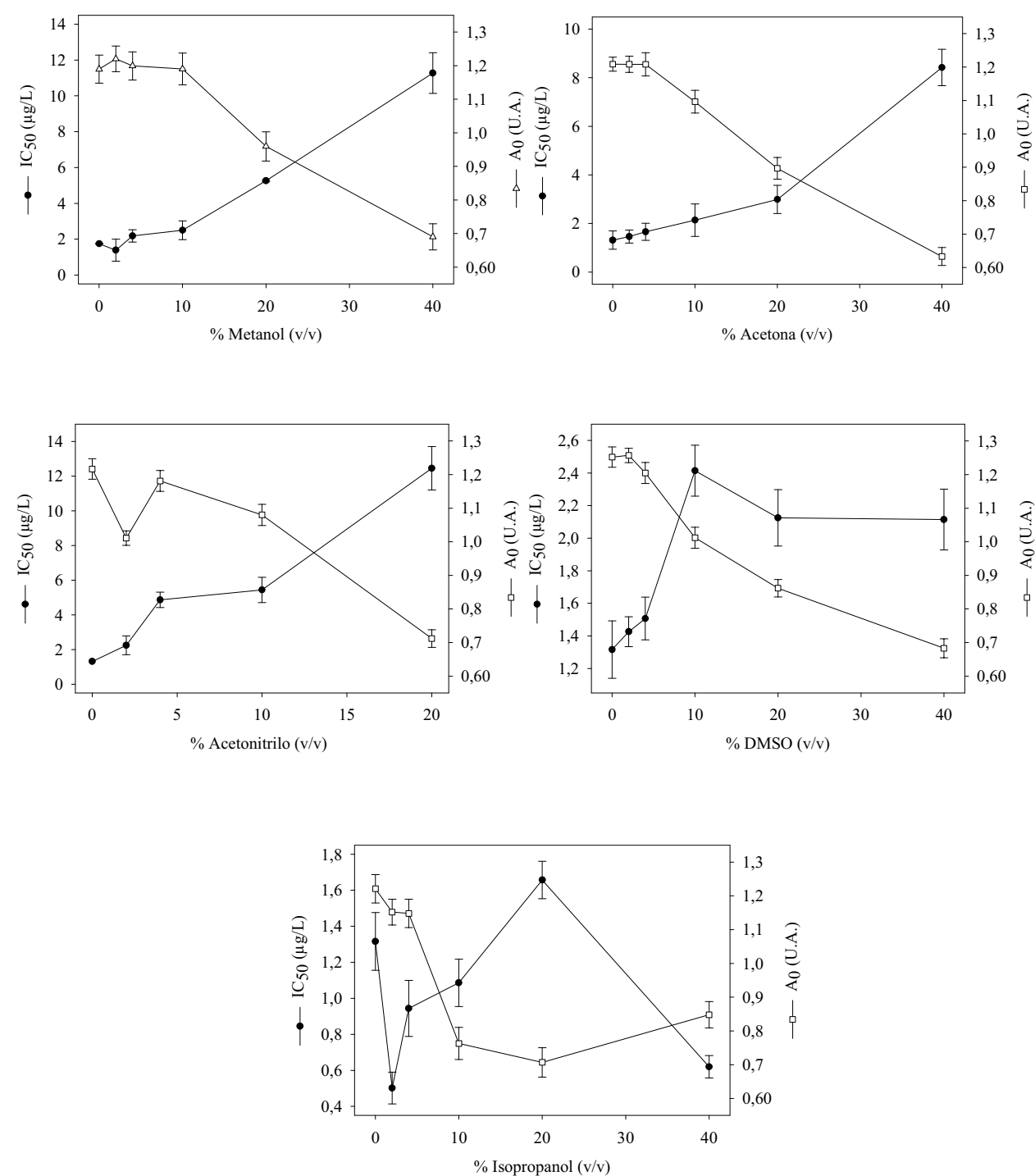

Figura 54. Tolerancia a disolventes orgánicos del inmunoensayo para STZ 


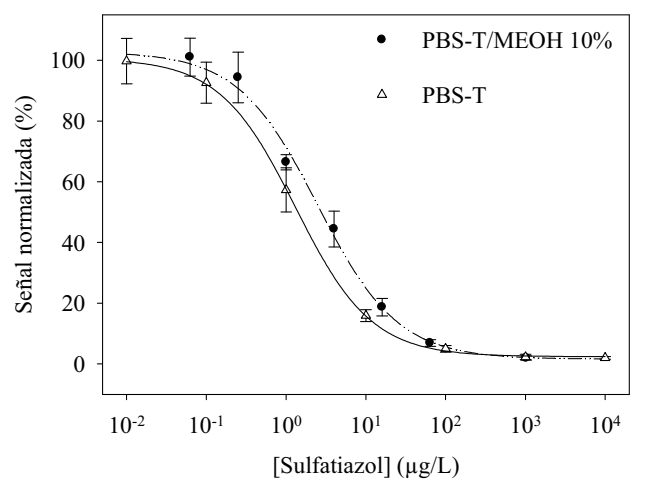

Figura 55. Curvas de calibrado de STZ en PBS-T y PBS-T/MeOH al $10 \%$ v/v (media y desviación de tres réplicas)

Los resultados obtenidos demuestran que existen diferencias significativas entre el calibrado obtenido en tampón fosfato y en PBS-T/MeOH al 10\% v/v, obteniendo menor sensibilidad en este último medio. En consecuencia, la cuantificación de los extractos metanólicos se realizó empleando un calibrado en disolución reguladora conteniendo un $10 \%$ de metanol. Las características analíticas de ambos inmunoensayos se resumen en la Tabla 33.

Tabla 33. Parámetros analíticos de los ELISAs desarrollados para STZ

\begin{tabular}{ccccc}
\hline Medio & $\begin{array}{c}\mathbf{I C}_{\mathbf{5 0}}{ }^{a} \\
(\boldsymbol{\mu g} / \mathbf{L})\end{array}$ & $\begin{array}{c}\mathbf{A}_{\mathbf{0}}{ }^{b} \\
(\mathbf{U . A .})\end{array}$ & $\begin{array}{c}\mathbf{R D}^{c} \\
(\boldsymbol{\mu g} / \mathbf{L})\end{array}$ & $\begin{array}{c}\mathbf{L D}^{d} \\
(\boldsymbol{\mu g} / \mathbf{L})\end{array}$ \\
\hline Tampón & 1,32 & 1,21 & $0,29-7,00$ & 0,13 \\
$10 \%$ metanol & 2,50 & 0,81 & $0,57-13,60$ & 0,25 \\
\hline
\end{tabular}

${ }^{a} \mathrm{IC}_{50}:$ sensibilidad

${ }^{b} \mathrm{~A}_{0}$ : absorbancia máxima; U.A.: unidades de absorbancia ${ }^{c} \mathrm{RD}$ : intervalo de trabajo o rango dinámico

${ }^{d} \mathrm{LD}$ : límite de detección

Como puede observarse, el ELISA llevado a cabo en presencia de metanol muestra una ligera disminución de la señal máxima, un menor límite de detección y sensibilidad, y un mayor intervalo de trabajo. El ensayo en tampón fosfato resultó ser 1,9 veces más sensible comparado con el resultado obtenido en medio metanólico, no obstante este último puede utilizarse para la determinación de residuos de sulfonamidas en miel. 
En este caso, dado que se trata de un ensayo multianalito y teniendo en cuenta que las sulfonamidas en mayor o menor extensión reaccionan con los azúcares reductores de la miel ${ }^{175}$, se llevó a cabo su extracción mediante hidrólisis, siguiendo el procedimiento descrito por Posyniak et al. ${ }^{132}$. Para ello, se utilizaron muestras de miel exentas de sulfonamidas, las cuales fueron fortificadas con STZ a nivel de $24 \mu \mathrm{g} / \mathrm{kg}$ de miel.

Para evaluar el método de extracción se compararon dos tipos de fases estacionarias: un cartucho de SPE basado en partículas de sílice funcionalizadas con octadecil (Strata C18-E $500 \mathrm{mg}$, recomendado para la extracción de compuestos orgánicos polares o hidrofóbicos en muestras acuosas), y otro relleno de un polímero de estireno-divinilbenceno químicamente modificado con grupos pirrolidona (Strata-X $200 \mathrm{mg}$, adecuado para analitos polares y no polares). Los cartuchos Strata-X se probaron con dos procedimientos diferentes de elución, metanol o una mezcla metanol/acetonitrilo/agua/ácido acético glacial en proporción 60:30:10:0,1 (v/v). Los resultados obtenidos mostraron un elevado efecto matriz en ambos casos, con valores de recuperación superiores al $120 \%$.

La evaluación de los cartuchos Strata C18-E se llevó a cabo de acuerdo con la metodología descrita por diferentes autores ${ }^{132,176}$, la cual incluía una etapa de hidrólisis con tampón acetato y elución con acetonitrilo. Se obtuvieron también resultados con recuperaciones que excedieron el $120 \%$, por lo que no se consideró un tratamiento adecuado. Sin embargo, cuando la elución se realizó con metanol los resultados fueron buenos, con valores de recuperación alrededor del 100\%.

El estudio de recuperación se llevó a cabo utilizando muestras de miel dopadas y extraídas empleando cartuchos Strata C18-E y metanol como eluyente (Figura 21, Experimental). Para ello, se analizaron diez submuestras de una misma miel (exenta de sulfonamidas), fortificadas con STZ a una concentración de $24 \mu \mathrm{g} / \mathrm{kg}$, las cuales fueron extraídas por separado y, posteriormente, analizadas mediante ELISA. En la tabla 34 se muestran los valores de recuperación obtenidos para las diez submuestras de miel. 
Tabla 34. Determinación de STZ mediante ELISA en miel

\begin{tabular}{ccc}
\hline Muestra $^{a}$ & $\begin{array}{c}\text { [STZ] determinada } \\
(\text { media } \pm \text { SD) }\end{array}$ & $\begin{array}{c}\text { Recuperación } \\
\mathbf{( \% )}\end{array}$ \\
\hline 1 & $3,60 \pm 0,34$ & 120 \\
2 & $3,54 \pm 0,37$ & 118 \\
3 & $3,76 \pm 0,50$ & 125 \\
4 & $3,67 \pm 0,10$ & 122 \\
5 & $3,32 \pm 0,21$ & 111 \\
6 & $2,95 \pm 0,43$ & 98 \\
7 & $2,62 \pm 0,14$ & 87 \\
8 & $2,53 \pm 0,24$ & 84 \\
9 & $2,91 \pm 0,43$ & 97 \\
10 & $2,74 \pm 0,27$ & 91 \\
\hline
\end{tabular}

${ }^{a}$ Muestras dopadas con STZ a $24 \mu \mathrm{g} / \mathrm{kg}$

Concentraciones en $\mu \mathrm{g} / \mathrm{L}$

SD desviación estándar para $\mathrm{n}=3$

Los resultados demuestran la efectividad del tratamiento seleccionado, alcanzándose valores de recuperación entre el 84 y $125 \%$, con un valor medio del $105 \%$, indicando que el procedimiento de extracción presentaba una buena recuperación a la concentración de analito estudiada, con un CV del 16\%.

A fin de evaluar la aplicabilidad del inmunoensayo desarrollado, se seleccionaron seis muestras comerciales de miel de diferente origen exentas de sulfonamidas y se enriquecieron con STZ, SMP, SP, SMT, SSZ y PSTZ, a tres niveles: 12, 24 y $36 \mu \mathrm{g} \mathrm{STZ/kg} \mathrm{miel} \mathrm{(expresada} \mathrm{como} \mathrm{equivalentes} \mathrm{de} \mathrm{STZ).} \mathrm{En} \mathrm{la}$ Tabla 35 se muestra el esquema del procedimiento de dopaje. La concentración de cada sulfonamida se seleccionó en base a su reactividad cruzada, expresando los resultados como equivalentes de STZ (Eq STZ), calculados de acuerdo a la siguiente ecuación: $\mathrm{Eq} \mathrm{STZ}=\mathrm{C} \times(\mathrm{RC} / 100)$, donde $\mathrm{C}$ es la concentración del analito y $\mathrm{RC}$ es el porcentaje de reactividad cruzada.

Las muestras se analizaron por triplicado mediante el ELISA desarrollado, siguiendo el procedimiento de extracción descrito previamente. Las recuperaciones fueron calculadas utilizando la ecuación: recuperación $=\mathrm{R} \times 100 / \Sigma$ Eq STZ, donde $\mathrm{R}$ es la concentración de STZ obtenida al interpolar el resultado en la curva de calibrado obtenida en PBS-T/MeOH al 10\% v/v. 
Tabla 35. Composición de las muestras de miel fortificadas

\begin{tabular}{lcccccc}
\hline \multirow{2}{*}{ Analito } & \multicolumn{5}{c}{ Nivel de fortificación } \\
\cline { 2 - 6 } & [Sulfonamida] & Eq STZ & [Sulfonamida] & Eq STZ & [Sulfonamida] & Eq STZ \\
\hline STZ & 0,43 & 0,43 & 0,85 & 0,85 & 1,28 & 1,28 \\
SMP & 1,50 & 0,15 & 3,00 & 0,31 & 4,50 & 0,46 \\
SP & 1,50 & 0,24 & 3,00 & 0,48 & 4,50 & 0,72 \\
SMT & 1,50 & 0,28 & 3,00 & 0,56 & 4,50 & 0,84 \\
SSZ & 0,42 & 0,18 & 0,85 & 0,36 & 1,28 & 0,54 \\
PSTZ & 1,50 & 0,22 & 3,00 & 0,44 & 4,50 & 0,66 \\
\cline { 1 - 3 }$\Sigma$ Eq STZ & & 1,50 & & 3,00 & & 4,50 \\
\hline
\end{tabular}

Concentraciones en $\mu \mathrm{g} / \mathrm{L}$

Como puede observarse en la Tabla 36, el valor de la recuperación osciló entre 80 y $130 \%$, obteniendo una media del 106\% para el conjunto de las muestras analizadas. Los mejores resultados se obtuvieron al analizar las muestras dopadas a $3 \mu \mathrm{g} / \mathrm{L}$ Eq STZ, probablemente por ser la concentración más próxima al valor de $\mathrm{IC}_{50}$ en medio metanólico $\left(\mathrm{IC}_{50}=2,50 \mu \mathrm{g} / \mathrm{L}\right)$. Los coeficientes de variación oscilaron entre 3 y $22 \%$, con un valor medio del $14 \%$.

Tabla 36. Recuperaciones obtenidas en el análisis de muestras de miel comercial dopadas con una mezcla de STZ, SMP, SP, SMT, SSZ y PSTZ

\begin{tabular}{ccccccc}
\hline Muestra $^{a}$ & $\begin{array}{c}\text { Eq STZ }_{\text {determinado }}{ }^{b} \\
(\mathbf{m e d i a} \pm \mathbf{S D})\end{array}$ & $\begin{array}{c}\mathbf{R} \\
(\%)\end{array}$ & $\begin{array}{c}\text { Eq STZ }_{\text {determinado }}{ }^{c} \\
(\mathbf{m e d i a} \pm \mathbf{S D})\end{array}$ & $\begin{array}{c}\mathbf{R} \\
(\%)\end{array}$ & $\begin{array}{c}\mathbf{E q ~ S T Z}_{\text {determinado }}{ }^{\boldsymbol{d}} \\
(\mathbf{m e d i a} \pm \mathbf{S D})\end{array}$ & $\begin{array}{c}\mathbf{R} \\
(\%)\end{array}$ \\
\hline $\mathrm{A}$ & $1,56 \pm 0,21$ & 104 & $3,24 \pm 0,10$ & 108 & $5,56 \pm 0,36$ & 124 \\
$\mathrm{~B}$ & $1,70 \pm 0,11$ & 113 & $3,27 \pm 0,14$ & 109 & $5,84 \pm 0,63$ & 130 \\
$\mathrm{C}$ & $1,36 \pm 0,23$ & 91 & $2,76 \pm 0,17$ & 92 & $4,92 \pm 0,56$ & 109 \\
$\mathrm{D}$ & $1,39 \pm 0,03$ & 93 & $2,73 \pm 0,31$ & 91 & $5,37 \pm 0,71$ & 119 \\
$\mathrm{E}$ & $1,20 \pm 0,16$ & 80 & $2,94 \pm 0,37$ & 98 & $4,83 \pm 0,77$ & 107 \\
$\mathrm{~F}$ & $1,93 \pm 0,28$ & 129 & $3,21 \pm 0,70$ & 107 & $5,03 \pm 0,33$ & 112 \\
\hline
\end{tabular}

${ }^{a}$ Mieles españolas de diferentes flores (todas las muestras son comerciales: A, B, D, E y F poliflora; C romero), dopadas a: ${ }^{b} 1,5 \mu \mathrm{g} / \mathrm{L} \mathrm{Eq} \mathrm{STZ;}{ }^{C} 3,0 \mu \mathrm{g} / \mathrm{L} \mathrm{Eq} \mathrm{STZ;}{ }^{d} 4,5 \mu \mathrm{g} / \mathrm{L} \mathrm{Eq} \mathrm{STZ.}$ Resultados expresados como Eq STZ; Concentraciones en $\mu \mathrm{g} / \mathrm{L}$

$\mathrm{SD}$ desviación estándar para $\mathrm{n}=3$

El inmunoensayo muestra un límite de detección de $0,25 \mu \mathrm{g} / \mathrm{L}$, correspondiente a $2 \mu \mathrm{g} / \mathrm{kg}$ Eq STZ en miel, lo cual lo hace muy adecuado para determinar 
simultáneamente residuos de sulfonamidas (STZ, SMP, SP, SMT, SSZ y PSTZ ) por debajo de los LMRs permitidos por la legislación $(100 \mu \mathrm{g} / \mathrm{kg})$, sin necesidad de preconcentración previa.

\subsubsection{Ensayo para TCs}

Las tetraciclinas comprenden un grupo de antibióticos que se han utilizado en medicina y veterinaria con fines terapéuticos y profilácticos. Entre los más utilizados se encuentran la oxitetraciclina, la tetraciclina y la clortetraciclina. A pesar de la prohibición de estos antibióticos como promotores del crecimiento, la utilización de tetraciclinas en veterinaria aún sigue siendo habitual debido a su alta eficacia y bajo coste. Existe una preocupación de la posible presencia de residuos de estos antibióticos en alimentos de consumo humano, como carnes (músculo) de ganado bovino, porcino y ovino, carne de aves de corral (pollo), leche y miel, lo que puede provocar graves problemas de salud pública. Entre estos problemas cabe destacar el desarrollo de resistencias, alergias, trastornos en la osificación y efectos carcinógenos.

Por ello, se consideró de interés estudiar la aplicación del inmunoensayo desarrollado para TCs (KLH-OTC-3-III/OVA-TC-1) a la determinación de residuos de este tipo de antibióticos en miel.

En una primera etapa se evaluó el efecto matriz con el fin de evitar interferencias potenciales en el ensayo desarrollado. Para realizar este estudio, se utilizaron muestras comerciales de miel -libres de TCs, previo análisis por HPLC-, dopadas con TC, diluidas en PBS-T y filtradas a través de una membrana de nitrocelulosa. Se prepararon cinco curvas patrón, cuatro de ellas con diferentes diluciones de miel en tampón PBS-T -1:10, 1:20, 1:25, y 1:50 (p/v)- y una quinta, en PBS-T. Todos los ensayos se efectuaron por triplicado. Los valores de sensibilidad y absorbancia máxima de las curvas realizadas con miel diluida se compararon con los obtenidos en PBS-T. La Figura 56 muestra la influencia de la matriz en la intensidad de la señal y los valores de $\mathrm{IC}_{50}$. Como puede observarse, la señal analítica disminuye a medida que el porcentaje de miel aumenta. Este efecto matriz es menos acusado a diluciones altas; por ejemplo, la dilución 1:50 (p/v) alcanza un $93 \%$ de la señal normalizada. Sin embargo, cuando comparamos los valores de $\mathrm{IC}_{50}$ obtenidos en PBS-T con las de miel diluida, se observa que la sensibilidad disminuye ( $\mathrm{IC}_{50}$ aumenta) a medida que el factor de dilución de la 
matriz es mayor. El ensayo más sensible y con una mayor relación $\mathrm{A}_{0} / \mathrm{IC}_{50}$ se obtuvo con la curva de calibrado llevada a cabo con una dilución 1:20 (p/v) de la matriz en PBS-T.

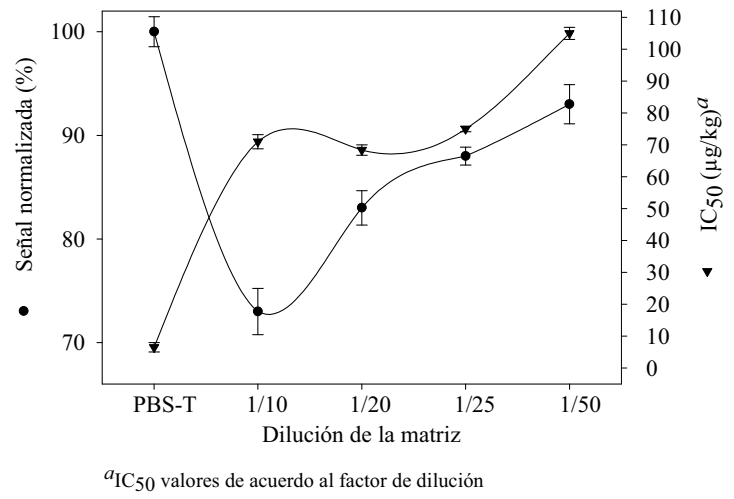

Figura 56. Efecto matriz en la señal y sensibilidad del ensayo

Una vez evaluado el efecto matriz, se estimó la idoneidad de la metodología propuesta para la determinación de residuos de tetraciclinas en miel analizando ocho muestras de diferente procedencia, libres de TCs. Para ello, las muestras se doparon con TC a tres niveles (5, 10 y $15 \mu \mathrm{g} / \mathrm{kg}$ ), se diluyeron 1:20 (p/v) en PBS-T y se filtraron, tal y como se ha descrito previamente. La curva de calibrado se preparó utilizando una matriz modelo, mezcla proporcional de diferentes muestras de miel, diluida 1:20 en PBS-T. Las muestras fueron directamente analizadas mediante el ELISA para TC, sin previa extracción. Tanto los patrones como las muestras se analizaron por triplicado. La curva de calibrado preparada utilizando esta matriz modelo alcanzó un LD de $0,40 \mu \mathrm{g} / \mathrm{kg}$ y una sensibilidad $\left(\mathrm{IC}_{50}\right)$ de 3,42 $\mu \mathrm{g} / \mathrm{kg}$. La aplicación del ensayo desarrollado a la determinación de residuos de tetracicinas en mieles proporcionó resultados analíticos muy interesantes, como se muestra en la Tabla 37, con recuperaciones entre $73 \%$ y $112 \%$, indicando que la interpolación de los resultados en una curva base, preparada con un conjunto de diferentes mieles (exentas de TCs), corrige la interferencia de la matriz, permitiendo analizar directamente mieles sin más que diluirlas en PBS-T.

Los resultados obtenidos muestran el potencial de las técnicas inmunoquímicas y lo que éstas pueden aportar en el campo agroalimentario, especialmente en lo que respecta a la implementación de Planes de Vigilancia efectivos. 


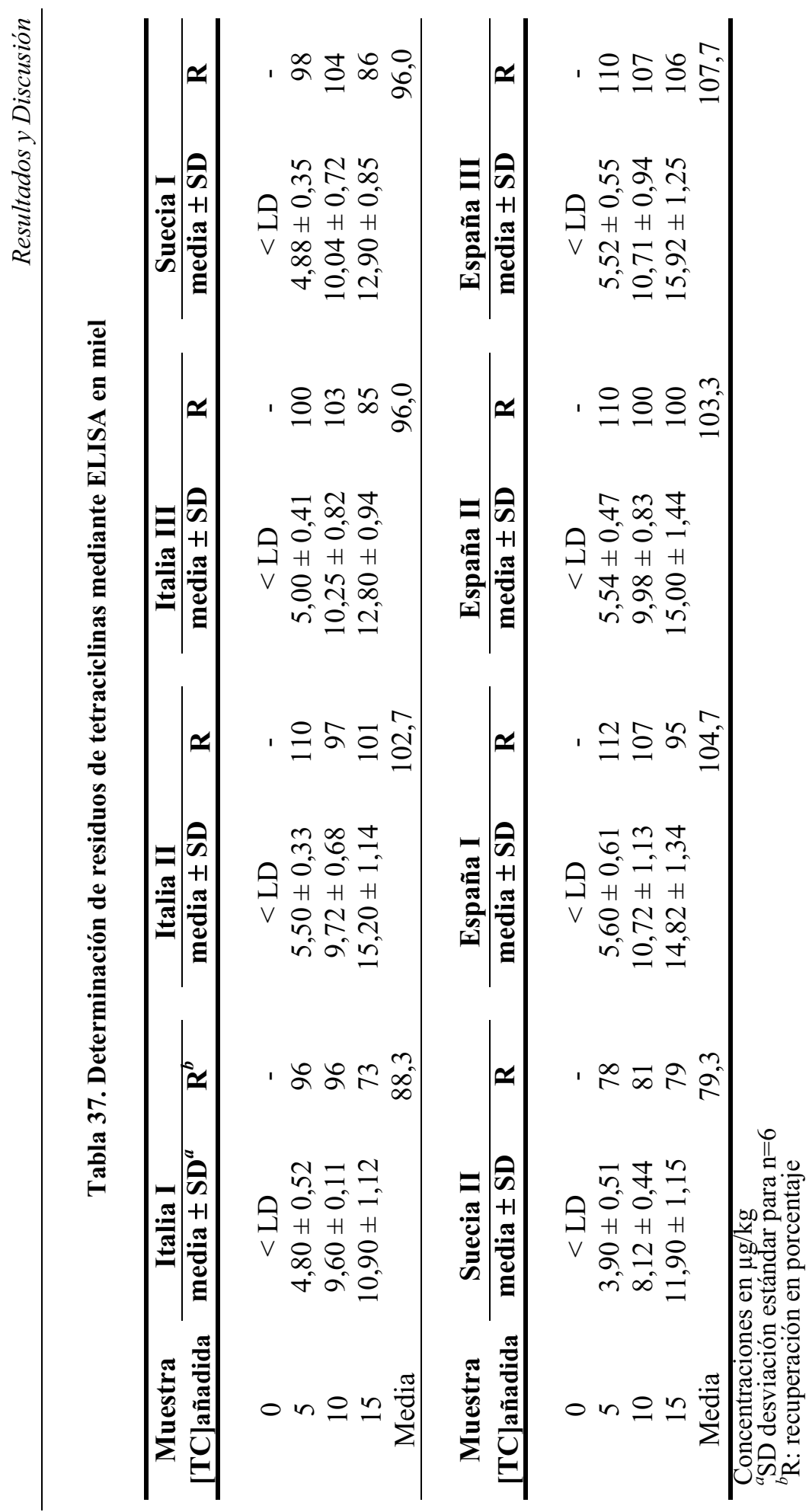

$\infty$ 



\section{CONCLUSIONES}



De acuerdo a las investigaciones llevadas a cabo y a los resultados obtenidos se pueden extraer las siguientes conclusiones:

- Se han optimizado rutas sintéticas para algunos haptenos de sulfonamidas (tipo I y III) modificando la estrategia descrita previamente en la literatura, utilizando reactivos con menores problemas de manipulación y toxicidad. En todos los casos se han alcanzado rendimientos globales más elevados

- Se ha demostrado que la síntesis de haptenos tipo II (para sulfonamidas y tetraciclinas) mediante reacciones de acoplamiento diazo es una estrategia muy adecuada para obtener anticuerpos de elevada afinidad

- Se ha comprobado que la preparación de un azocompuesto de OTC mediante la nueva ruta sintética propuesta es muy efectiva. En general, la preparación de los azocompuestos ha demostrado ser la vía más adecuada para la síntesis de haptenos de tetraciclinas

- Se ha constatado que la hidrólisis ácida o básica del grupo amida, así como la esterificación del fenol presente en la tetraciclina no son rutas sintéticas adecuadas para la preparación de derivados de dicho compuesto

- Por primera vez se ha descrito una ruta sintética para la obtención de haptenos de tetraciclinas tipo carboxamida. Dichos haptenos no proporcionaron anticuerpos con propiedades adecuadas cuando se utilizaron como inmunógenos, aunque resultaron muy apropiados como conjugados de tapizado

- Dado que todos los compuestos de la familia de las sulfonamidas poseen una región constante, la especificidad de los ensayos depende en gran medida del conjugado de tapizado utilizado. Así, usando el antisuero S3-I con el conjugado de tapizado OVA-S2 se obtiene un ensayo específico para STZ, mientras que empleando el mismo anticuerpo policlonal y el conjugado OVA-S8 el ensayo es capaz de reconocer simultáneamente a seis sulfonamidas 
- Con independencia del tipo de hapteno, todos los anticuerpos obtenidos contra sulfonamidas reconocen a varios conjugados de tapizado. Para el caso del formato directo, únicamente los haptenos tipo I (caracterizados por mantener intacta la región constante y poseer la región variable funcionalizada) han permitido desarrollar ELISAs para este formato en condiciones de homología

- Los haptenos de sulfonamidas tipo III, haptenos fragmentarios, preparados manteniendo la región constante de las sulfonamidas y un brazo espaciador alifático de longitud variable (S10, S11, S12 y S13), deberían producir anticuerpos policlonales con elevada afinidad para los distintos compuestos de la familia. Los ensayos de competición revelaron que S11 y S13 presentaron baja afinidad, S12 fue altamente específico para SMX y únicamente S10 cumple esta hipótesis. Este hecho pone de nuevo de manifiesto la aleatoriedad de la respuesta. Sin embargo, se ha confirmado (STZ y SSZ) la importancia de utilizar un hapteno inmunizante que preserve al máximo la estructura del analito, para obtener anticuerpos de alta afinidad frente a una única sulfonamida

- Dada la similitud estructural entre los compuestos de la familia de las tetraciclinas, la obtención de inmunorreactivos que permitan el desarrollo de ensayos específicos no es tarea fácil. Sin embargo, el ensayo desarrollado para CTC es altamente selectivo, siendo el primero reportado en la bibliografía

- Las prestaciones del ELISA desarrollado para STZ han permitido la determinación de residuos de este analito directamente en muestras de miel, con un tratamiento de muestra mínimo y elevada selectividad y sensibilidad

- La elevada sensibilidad del ELISA puesto a punto para SSZ ha hecho posible la determinación de residuos de este analito en plasma humano, obteniéndose incluso mejores resultados que por HPLC. La utilización del ELISA para el control de esta sulfonamida en pacientes tratados permitirá 
reducir el tiempo y el coste de los análisis, así como el consumo de disolventes orgánicos

- El ELISA genérico I permite la determinación simultánea de STZ, PSTZ, SMP, SSZ, SP y SMT con independencia de la proporción en la que se encuentran dichas sulfonamidas. Su aplicación al análisis de miel ha proporcionado excelentes resultados, por lo que será posible realizar el control simultáneo de las sulfonamidas más comunes en mieles de una forma rápida y económica

- El ELISA genérico desarrollado para tetraciclinas permite determinar simultáneamente TC, CTC, MC, OTC y RTC (tetraciclinas más utilizadas en el campo agroalimentario) en muestras de miel por debajo de los LMRs, sin más que diluirlas en PBS-T

- En general, todos los ELISAs desarrollados para sulfonamidas y tetraciclinas presentan buena sensibilidad (inferiores a los LMRs establecidos por la legislación), por lo que podrían ser utilizados en los laboratorios de control de calidad para la identificación rápida de residuos de estos antibióticos en alimentos y muestras medioambientales 

6. BIBLIOGRAFÍA 

${ }^{1}$ Cordiés, L., Machado, L.A., Hamilton, M.L. (1998) Principios generales de la terapéutica antimicrobiana. Acta Med., 8, 13-27.

2 Sande, M.A., Kapusnik-Uner, J.E., Mandell, G.L. Agentes antimicrobianos. Consideraciones generales. En: Las Bases Farmacológicas de la Terapéutica (A., Goodman, T.W., Rall, A.S., Nies, P., Taylor, eds.) 8 a ed. Parte XI, capítulo 44, Médica Panamericana, México DF, 1993, pp. 991-1017.

${ }^{3}$ Quimioterapia antimicrobiana. En: Manual de Microbiología Médica (E., Jawetz, J.L., Melnick, E.A., Alderberg, eds.) 12 ${ }^{\mathrm{a}}$ ed., El manual moderno, México DF, 1988, pp. 110-135.

${ }^{4}$ Di Corcia, A., Nazzari, M. (2002) Liquid chromatographic-mass spectrometric methods for analyzing antibiotic and antibacterial agents in animal food products. J. Chromatogr. A, 974, 53-89.

${ }^{5}$ Strohl, W.R. Industrial Antibiotics: Today and the future En: Biotechnology of Antibiotics (W.R., Strohl, ed.) Drugs and the pharmaceutical sciences, vol. 82, $2^{\text {nd }}$ ed., Marcel Dekker Inc., New York, 1997, pp. 1-49.

${ }^{6}$ Basco, S. (2008) Antibióticos que curan y matan. Ciencia y Futuro, ABC, 92.

${ }^{7}$ Errecalde, J.O. (2004) Uso de antimicrobianos en animales de consumo. Incidencia del desarrollo de resistencias en salud pública. ONU. FAO. Producción y Salud Animal, 162, 1-57.

${ }^{8}$ García-Rodriguez, J.A. Antimicrobianos. En: Microbiología y Parasitología Médica (A., Pumarola, A., Rodríguez, J.A., García, G., Piédrola, eds.) 2a ed. Parte I, capítulo 12, Salvat, Barcelona, 1987, pp. 120-152.

${ }^{9}$ Roca Marugán, M.I. Termoestabilidad de sustancias antimicrobianas en la leche (Tesis doctoral), UPV, Valencia, 2008, pp. 6. 
${ }^{10}$ Antibacterial agents. En: An Introduction to Medicinal Chemistry (G.L., Patrick, ed.) capítulo 10, Oxford University Press Inc., New York, 1995, pp. 154-166.

${ }^{11}$ Agentes quimioterápicos. Sulfonamidas. En: Compendio Esencial de Química Farmacéutica (A. Korolkovas, J.H. Burckhalter, eds.) Parte V, capítulo 31, Reverté S.A., Barcelona, 1983, pp. 587-606.

${ }^{12}$ García-Rodríguez, J.A., Gomis, M., González, J., Prieto J. La quimioterapia antimicrobiana y el milagro de la penicilina. De Ehrlich a Fleming. En: Historia de la Antibioterapia, pp. 41-59.

http://www.sepeap.org/archivos/libros/antibioticos/1.pdf. Último acceso 6 de septiembre de 2011.

${ }^{13}$ Malgor-Valsecia. Quimioterápicos: sulfonamidas, nitrofuranos, derivados de la naftiridina y quinolonas

http://www.med.unne.edu.ar/catedras/farmacologia/temas_farma/volumen3/cap33_ sulfyquinol.pdf. Último acceso 10 de agosto de 2011.

${ }^{14}$ Botsoglou, N.A., Fletouris D.J. Analysis of drug residues. En: Drug Residues in Foods: Fharmacology, Food Safety and Analysis (D.J., Fletouris, ed.) Parte III, capítulo 29, Marcel Dekker Inc., New York, 2001, pp. 961-985.

15 Mandell, G.L., Petri, W.A. Fármacos antimicrobianos. Sulfonamidas, trimetoprim-sulfametoxazol, quinolonas y fármacos contra infecciones de vías urinarias. En: Goodman \& Gilman's. Las bases Farmacológicas de la Terapéutica (J.G., Hardman, L., Limbird, R., Molinoff, R., Ruddon, A., Goodman, eds.) $9^{\text {a }}$ ed., capítulo 44, McGraw-Hill Interamericana, México DF, 1996, pp. 1123-1132.

${ }^{16}$ Morejón García, M., Salup Díaz, R., Cué Brugueras, M. (2003) Actualización en tetraciclinas. Rev. Cubana Farm., 37, 1-5.

${ }^{17}$ Bosó-Ribelles, V., Romá-Sánchez, E., Salavert-Lleti, M., Hernández-Marti, V., Poveda-Andrés, J.L. (2007) La tigeciclina, el primer antibiótico de una nueva clase: las glicilciclinas. Rev. Esp. Quimioterap., 20, 19-35. 
${ }^{18}$ Parida, R.K., Nayak, J.R., Biswal, B., Karna, N. (2010) Glycylcyclines - the new class of antimicrobial. Der Pharmacia Lettre, 2, 180-185.

${ }^{19}$ Chopra, I., Roberts, M. (2001) Tetracycline antibiotics: mode of action, applications, molecular biology, and epidemiology of bacterial resistance. Microbiol. Mol. Biol. Rev., 65, 232-260.

${ }^{20}$ Botsoglou, N.A., Fletouris D.J. Analysis of drug residues. En: Drug Residues in Foods: Fharmacology, Food Safety and Analysis (D.J., Fletouris, ed.) Parte III, capítulo 29, Marcel Dekker Inc., New York, 2001, pp. 985-1002.

${ }^{21}$ Nelson, M.L. (1998) Chemical and biological dynamics of tetracyclines. $A d v$. Dent. Res., 12, 5-11.

${ }^{22}$ Vicente, D., Pérez-Trallero, E. (2010) Tetraciclinas, sulfamidas y metronidazol. Enferm. Infecc. Microbiol. Clin., 28, 122-130.

${ }^{23}$ Zakeri, B., Wright, G.D. (2008) Chemical biology of tetracycline antibiotics. Biochem. Cell Biol., 86, 124-136.

${ }^{24}$ Torres, C., Zarazaga, M. (2002) Antibióticos como promotores del crecimiento en animales. ¿Vamos por el buen camino?. Gac. Sanit., 16, 109-112.

${ }^{25}$ Díez, P., Calderón, V. (1997) Empleo de antibióticos en veterinaria. Rev. Esp. Quimioterap., 10, 275-280.

${ }^{26}$ Nunnery, J., Angulo, F.J., Tollefson, L. (2006) Public health and policy. Prev. Vet. Med., 73, 191-195.

${ }^{27}$ Chafer-Pericas, C., Maquieira, A., Puchades, R. (2010) Fast screening methods to detect antibiotic residues in food samples. TrAC, Trends Anal. Chem., 29, 10381049 . 
Bibliografía

${ }^{28}$ Önal, A. (2011) Overview on liquid chromatographic analysis of tetracycline residues in food matrices. Food Chem., 127, 197-203.

29 Blanco, P.J., Medel, P. (2009) Residuos de sustancias medicamentosas en productos de origen animal: control de los procesos de contaminación cruzada en la fabricación de pienso. Cría y Salud, 27, 50-52.

${ }^{30}$ Anadón, A. Antibióticos de Uso Veterinario y su Relación con la Seguridad Alimentaria y Salud Pública. Real Academia de Ciencias Veterinarias, Instituto de España, 2007, pp. 1-134.

${ }^{31}$ Sanderson, J.P., Naisbitt, D.J., Park, B.K. (2006) Role of bioactivation in druginduced hypersensitivity reactions. AAPS J., 8, E55-E64.

${ }^{32}$ Raison-Peyron, N., Messaad, D., Bousquet, J., Demoly, P. (2001) Anaphylaxis to beef in penicillin-allergic patient. Allergy, 56, 796-797.

${ }^{33}$ Tollefson, L., Karp, B.E. (2004) Human health impact from antimicrobial use in food animals. Med. Maladies Infect., 34, 514-521.

${ }^{34}$ Nunnery, J., Angulo, F.J., Tollefson, L. (2006) Public health and policy. Prev. Vet. Med., 73, 191-195.

${ }^{35}$ Codex Alimentarius, 2009. Informe de la tercera reunión del grupo de acción intergubernamental especial del codex sobre la resistencia a los antimicrobianos. Codex Alimentarius, 1. Programa conjunto FAO/OMS sobre Normas Alimentarias. FAO. Jeju (República de Corea).

${ }^{36}$ Magariños, H. Contaminación de la leche por antibióticos. En: Producción Higiénica de la Leche Cruda. Capítulo 6, Edición Producción y Servicios Incorporados S.A., Guatemala, 2001, pp. 53-62. 
37 Díaz-Cruz, M.S., López de Alda, M.J., Barceló, D. (2003) Environmental behaviour and analysis of veterinary and human drugs in soils, sediments and sludge. TrAC, Trends Anal. Chem., 22, 340-351.

${ }^{38}$ Díaz-Cruz M.S., Barceló, D. (2005) LC-MS ${ }^{2}$ trace analysis of antimicrobials in water, sediment and soil. TrAC, Trends Anal. Chem., 24, 645-657.

${ }^{39}$ Richardson, S.D. (2009) Water analysis: emerging contaminants and current issues. Anal. Chem., 81, 4645-4677.

${ }^{40}$ Garcia-Galan, M.J., Díaz-Cruz, M.S., Barceló, D. (2009) Combining chemical analysis and ecotoxicity to determine environmental exposure and to assess risk from sulfonamides. TrAC, Trends Anal. Chem., 28, 804-819.

${ }^{41}$ Kuster, M., López de Alda, M.J., Barceló, D. Estrogens and progestogens in wastewater, sludge, sediments, and soil En: The Handbook of Environmental Chemistry (D., Barceló, ed.) vol. 5, Part O, Springer-Verlag Berlin Heidelberg, 2005, pp. 1-24.

${ }^{42}$ Health Canada (2011) Administrative maximum residue limits (AMRLS) and maximum residue Limits (MRLS) set by Canada.

http://www.hc-sc.gc.ca/dhp-mps/alt_formats/pdf/vet/mrl-lmr/mrl-lmr_versus_newnouveau-eng.pdf. Último acceso 6 de septiembre de 2011.

${ }^{43}$ US Food and Drug Administration (2003) Code of Federal Regulations title 21, part 556. US Government Printing Office, Washington, Chap 1.

${ }^{44}$ The Japan Food Chemical Research Foundation (2006) Positive list system for agricultural chemical residues in foods.

http://www.ffcr.or.jp/zaidan/FFCRHOME.nsf/pages/MRLs-p. Último acceso 10 de agosto de 2011. 
Bibliografia

45 Heitzman, R.J. (Ed.), Veterinary drug residues, Report Eur 15127-EN, Commission of the EC, Brussels-Luxemburg, 1994.

${ }^{46}$ Stolker, A.A.M., Brinkman, U.A.Th. (2005) Analytical strategies for residue analysis of veterinary drugs and growth-promoting agents in food-producing animals-a review. J. Chromatogr. A, 1067, 15-53.

${ }^{47}$ Garrido Frenich, A., Plaza-Bolanos, P., Aguilera-Luiz, M.M., Martinez-Vidal, J.L. Recent advances in the analysis of veterinary drugs and growth-promoting agents by chromatographic techniques. En: Chromatography: Types, Techniques and Methods (Chemical Engineering Methods and Technology) (T.J., Quintin, ed.) Nova Science Publishers Inc., New York, 2010, pp. 1-101.

48 Samanidou, V.F., Tolika, E.P., Papadoyannis, I.N. (2008) Chromatographic residue analysis of sulfonamides in foodstuffs of animal origin. Separ. Purif. Rev., $37,325-371$.

${ }^{49}$ Wang, S., Zhang, H.Y., Wang, L., Duan, Z.J., Kennedy, I. (2006) Analysis of sulphonamide residues in edible animal products: A review. Food Addit. Contam., $23,362-384$.

${ }^{50}$ Oka, H., Ito, Y., Matsumoto, H. (2000) Chromatographic analysis of tetracycline antibiotics in foods. J. Chromatogr. A, 882, 109-133.

${ }^{51}$ Barker, S.A., Walker, C.C. (1992) Chromatographic methods for tetracycline analysis in foods. J. Chromatogr., 624, 195-209.

52 Jimenez, V., Companyo, R., Guiteras, J. (2009) Preparation of quality control materials for the determination of sulfonamides in animal feed. Food Addit. Contam., 26, 969-977. 
${ }^{53}$ Granja, R.H.M.M., Niño, A.M.M., Rabone, F., Salerno, A.G. (2008) A reliable high-performance liquid chromatography with ultraviolet detection for the determination of sulfonamides in honey. Anal. Chim. Acta, 613, 116-119.

${ }^{54}$ Tsai, W.H., Huang, T.C., Chen, H.H., Wu, Y.W., Huang, J.J., Chuang, H.Y. (2010) Determination of sulfonamides in swine muscle after salting-out assisted liquid extraction with acetonitrile coupled with back-extraction by a water/acetonitrile/dichloromethane ternary component system prior to highperformance liquid chromatography. J. Chromatogr. A, 1217, 250-255.

55 Vargas Mamani, M.C., Reyes Reyes, F.G., Rath, S. (2009) Multiresidue determination of tetracyclines, sulphonamides and chloramphenicol in bovine milk using HPLC-DAD. Food Chem., 117, 545-552.

${ }^{56}$ Pena, A., Paulo, M., Silva, L.J., Seifrtová, M., Lino, C.M., Solich, P. (2010) Tetracycline antibiotics in hospital and municipal wastewaters: a pilot study in Portugal. Anal. Bioanal. Chem. 396, 2929-2936.

${ }^{57}$ Gehring, T.A., Griffin, B., Williams, R., Geiseker, C., Rushing, L.G., Siitonen, P.H. (2006) Multiresidue determination of sulfonamides in edible catfish, shrimp and salmon tissues by high-performance liquid chromatography with postcolumn derivatization and fluorescence detection. J. Chromatogr. B, 840, 132-138.

${ }^{58}$ Koesukwiwat, U., Jayanta, S., Leepipatpiboon, N. (2007) Validation of a liquid chromatography-mass spectrometry multi-residue method for the simultaneous determination of sulfonamides, tetracyclines, and pyrimethamine in milk. $J$. Chromatogr. A, 1140, 147-156.

59 Dasenaki, M.E., Thomaidis, N.S. (2010) Multi-residue determination of seventeen sulfonamides and five tetracyclines in fish tissue using a multi-stage LCESI-MS/MS approach based on advanced mass spectrometric techniques. Anal. Chim. Acta., 672, 93-102. 
Bibliografia

${ }^{60}$ Kantiani, L., Farré, M., Freixiedas, J.M., Barceló, D. (2010) Development and validation of a pressurised liquid extraction liquid chromatography-electrospraytandem mass spectrometry method for $\beta$-lactams and sulfonamides in animal feed. J. Chromatogr. A, 1217, 4247-4254.

${ }^{61}$ Reeves, V.B. (1999) Confirmation of multiple sulfonamide residues in bovine milk by gas chromatography-positive chemical ionization mass spectrometry. $J$. Chromatogr. B, 723, 127-137.

62 Chiavarino, B., Crestoni, M.E., Di Marzio, A., Fornarini, S. (1998) Determination of sulfonamide antibiotics by gas chromatography coupled with atomic emission detection. J. Chromatogr. B, 706, 269-277.

${ }^{63}$ Mineo, H., Kaneko, S., Koizumi, I., Asida, K., Akahori, F. (1992) An analytical study of antibacterial residues in meat: the simultaneous determination of 23 antibiotics and 13 drugs using gas chromatography. Vet. Hum. Toxicol., 34, 393397.

${ }^{64}$ Dagan, S., Amirav, A. (1996) Fast, very fast, and ultra-fast gas chromatographymass spectrometry of thermally labile steroids, carbamates, and drugs in supersonic molecular beams. J. Am. Soc. Mass Spectrom., 7, 737-752.

${ }^{65}$ Petkovska, E., Slaveska-Raicki, R., Rafajlovska, V. (2006) Determination of tetracycline, oxytetracycline, and chlortetracycline in milk by TLC and column chromatography using Amberlite XAD-2. Chem. Anal. (Warsaw), 51, 275-283.

${ }^{66}$ Babic, S., Asperger, D., Mutavdzic, D., Horvat, A.J.M., Kastelan-Macan, M. (2005) Determination of sulfonamides and trimethoprim in spiked water samples by solid-phase extraction and thin-layer chromatography. J. Planar Chromatogr. Mod. TLC, 18, 423-426.

${ }^{67}$ De Brabander, H.F., Noppe, H., Verheyden, K., Vanden Bussche, J., Wille, K., Okerman, L., Vanhaecke, L., Reybroeck, W., Ooghe, S., Croubels, S. (2009) 
Residue analysis: Future trends from a historical perspective. J. Chromatogr. A, 1216, 7964-7976.

${ }^{68}$ Pikkemaat, M.G. (2009) Microbial screening methods for detection of antibiotic residues in slaughter animals. Anal. Bioanal. Chem., 395, 893-905.

${ }^{69}$ Stead, S., Sharman, M., Tarbin, J.A., Gibson, E., Richmond, S., Stark, J., Geijp, E. (2004) Meeting maximum residue limits: an improved screening technique for the rapid detection of antimicrobial residues in animal food products. Food Addit. Contam., 21, 216-221.

${ }^{70} \mathrm{http}: / /$ www.microkit.es/index.htm. Último acceso 10 de agosto de 2011.

${ }^{71}$ Kurittu, J., Lonnberg, S., Virta, M., Karp, M. (2000) Qualitative detection of tetracycline residues in milk with a luminescence-based microbial method: the effect of milk composition and assay performance in relation to an immunoassay and a microbial inhibition assay. J. Food Prot., 63, 953-957.

${ }^{72}$ Pastor-Navarro, N., Gallego-Iglesias, E., Maquieira, A., Puchades, R. (2007) Immunochemical method for sulfasalazine determination in human plasma. Anal. Chim. Acta, 583, 377-383.

${ }^{73}$ Muldoon, M.T., Holtzapple, C.K., Deshpande, S.S., Beier, R.C., Stanker, L.H. (2000) Development of a monoclonal antibody-based cELISA for the analysis of sulfadimethoxine. 1. Development and characterization of monoclonal antibodies and molecular modeling studies of antibody recognition. J. Agric. Food Chem., 48, 537-544.

${ }^{74}$ Lee, N., Holtzapple, C.K., Muldoon, M.T., Deshpande, S.S., Stanker, L.H. (2001) Immunochemical approaches to the detection of sulfathiazole in animal tissues. Food Agric. Immunol., 13, 5-17. 
Bibliografia

75 Dixon-Holland, D.E., Katz, S.E. (1991) Competitive direct enzyme-linked immunosorbent screening assay for the detection of sulfamethazine contamination of animal feeds. J. Assoc. Off. Anal. Chem., 74, 784-789.

76 Fleeker, J.R., Lovett, L.J. (1985) Enzyme immunoassay for screening sulfamethazine residues in swine blood. J. Assoc. Off. Anal. Chem., 68, 172-174.

${ }^{77}$ Singh, P., Ram, B.P., Sharkov, N. (1989) Enzyme immunoassay for screening of sulfamethazine in swine. J. Agric. Food Chem., 37, 109-114.

78 Sheth, H.B., Sporns, P. (1990) Enzyme immunoassay for screening of sulfathiazole in honey. J. Assoc. Off. Anal. Chem., 73, 871-874.

79 Renson, C., Degand, G., Maghum-Roglster, G. (1993) Determination of sulphamethazine in animal tissues by enzyme immunoassay. Anal. Chim. Acta, 275, 323-328.

80 Franek, M., Kolar, V., Deng, A., Crooks, S. (1999) Determination of sulfadimidine (sulfamethazine) residues in milk, plasma, urine and edible tissues by sensitive ELISA. Food Agric. Immunol., 11, 339-349.

81 Wang, L., Wang, S., Zhang, J., Liu, J., Zhang, Y. (2008) Enzyme-linked immunosorbent assay and colloidal gold immunoassay for sulphamethazine residues in edible animal foods: Investigation of the effects of the analytical conditions and the sample matrix on assay performance. Anal. Bioanal. Chem., $390,1619-1627$.

${ }^{82}$ Märltbauer, E., Meier, R., Usleber, E.,Terplan, G. (1992) Enzyme immunoassays for the detection of sulfamethazine, sulfadiazine, sulfamethoxypyridazine and trimethoprim in milk. Food Agric. Immunol., 4, 219-228. 
${ }^{83}$ Ostermaier, S., Schneider, E., Usleber, E., Märltbauer, E., Terplan, G. (1995) Rapid enzyme immunoassays for the detection of three sulphonamides in milk. Food Agric. Immunol., 7, 253-258.

${ }^{84}$ Jackman, R., Brown, A.J., Dell, A.N., Everest, S.J. Production of antisera to 12 sulphonamides and their use in enzyme immunoassays. En: Proceedings of EuroResidues II Conference (N., Haagsma, A., Ruiter, P.B., Czedik-Eysenberg, eds.), Veldhoven, The Netherlands, 1993, pp. 391-394.

${ }^{85}$ Haasnoot, W., Korsrud, G.O., Cazemier, G., Maneval, F., Keukens, H., Nouws, J.F.M. (1996) Application of an enzyme immunoassay for the determination of sulphamethazine (sulphadimidine) residues in swine urine and plasma and their use as predictors of the level in edible tissue. Food Addit. Contam., 13, 811-822.

${ }^{86}$ Sheth, H.B., Sporns, P. (1991) Development of a single ELISA for detection of sulfonamides, J. Agric. Food Chem., 39, 1696-1700.

87 Spinks, C.A., Wyatt, G.M., Lee, H.A., Morgan, M.R.A. (1999) Molecular modeling of hapten structure and relevance to broad spectrum specificity immunoassay of sulfonamide antibiotics. Bioconjugate Chem., 10, 583-588.

${ }^{88}$ Muldoon, M.T., Font, I.A., Beier, R.C., Holtzapple, C.K., Young, C.R., Stanker, L.H. (1999) Development of a cross-reactive monoclonal antibody to sulfonamide antibiotics: evidence for structural conformation-selective hapten recognition. Food Agric. Immunol., 11, 117-134.

${ }^{89}$ Assil, H.I., Sheth, H., Sporns, P. (1992) An ELISA for sulfonamide detection using affinity-purified polyclonal antibodies. Food Res. Int., 25, 343-353.

${ }^{90}$ Haasnoot, W., Cazemier, G., Du Pré J., Kemmers-Voncken, A., BienenmannPloum, M., Verheijen, R. (2000) Sulphonamide antibodies: from specific polyclonals to generic monoclonals. Food Agric. Immunol., 12, 15-30. 
91 Haasnoot, W., Du Pre J., Cazemier, G., Kemmers-Voncken, A., Verheijen, R., Jansen, B.J.M. (2000) Monoclonal antibodies against a sulfathiazole derivative for the immunochemical detection of sulfonamides. Food Agric. Immunol., 12, 127-138.

92 Korpimäki, T., Rosenberg, J., Virtanen, P., Karskela, T., Lamminmäki, U., Tuomola, M., Vehniäinen, M., Saviranta, P. (2002) Improving broad specificity hapten recognition with protein engineering. J. Agric. Food Chem., 50, 4194-4201.

93 Korpimäki, T., Rosenberg, J., Virtanen, P., Lamminmäki, U., Tuomola, M., Saviranta, P. (2003) Further improvement of broad specificity hapten recognition with protein engineering. Protein Eng., 16, 37-46.

${ }^{94}$ Korpimäki, T., Brockmann, E.C., Kuronen, O., Saraste, M., Lamminmäki, U., Tuomola, M. (2004) Engineering of a broad specificity antibody for simultaneous detection of 13 sulfonamides at the maximum residue level. J. Agric. Food Chem., $52,40-47$.

${ }^{95}$ Franek, M., Diblikova, I., Cernoch, I., Vass, M., Hruska, K. (2006) Broadspecificity immunoassays for sulfonamide detection: immunochemical strategy for generic antibodies and competitors. Anal. Chem., 78, 1559-1567.

${ }^{96}$ Zhang, H., Duan, Z., Wang, L., Zhang, Y., Wang, S. (2006) Hapten synthesis and development of polyclonal antibody-based multi-sulfonamide immunoassays. J. Agric. Food Chem., 54, 4499-4505.

97 Pastor-Navarro, N., García-Bover, C., Maquieira, A., Puchades, R. (2004) Specific polyclonal-based immunoassays for sulfathiazole. Anal. Bioanal. Chem., 379, 1088-1099.

${ }^{98}$ Ermolenko, D.N., Eremin, S.A., Mart'ianov, A.A., Zherdev, A.V., Dzantiev, B.B. (2007) A new generic enzyme immunoassay for sulfonamides. Anal. Lett., 40, 1047-1062. 
${ }^{99}$ Eremin, S.A., Murtazina, N.R., Ermolenko, D.N., Zherdev, A.V., Mart'ianov, A.A., Yazynina, E.V., Michura, I.V., Formanovsky, A.A., Dzantiev, B.B. (2005) Production of polyclonal antibodies and development of fluorescence polarization immunoassay for sulphanilamide. Anal. Lett., 38, 951-969.

100 Adrian, J., Font, H., Diserens, J.M., Sánchez-Baeza, F., Marco, M.P. (2009) Generation of broad specificity antibodies for sulfonamide antibiotics and development of an enzyme-linked immunosorbent assay (ELISA) for the analysis of milk samples. J. Agric. Food Chem., 57, 385-394.

101 Faraj, B.A., Ali, F.M. (1981) Development and application of a radioimmunoassay for tetracycline. J. Pharmacol. Exp. Ther., 217, 10-14.

102 Lang, B., Märtlbauer, E., Terplan, G. (1992) Ein enzymimmunologischer Nachweis von. Tetracyclinen in Milch. Arch. Lebensm. hyg., 43, 77-80.

${ }^{103}$ Goldring, J.P.D., Thobakgale, C., Hiltunen, T., Coetzer, T.H.T. (2005) Raising antibodies in chickens against primaquine, pyrimethamine, dapsone, tetracycline, and doxycycline. Immunol. Invest., 34, 101-114.

${ }^{104}$ Everest, S.J., Cobb, A.L., Courboin, G.M., Jackman, R. (1994) Development of an ELISA for the detection of chlortetracycline, oxytetracycline and tetracycline residues. Food Agric. Immunol., 6, 55-61.

105 Zhang, Y., Lu, S., Liu, W., Zhao, C., Xi, R. (2007) Preparation of antitetracycline antibodies and development of an indirect heterologous competitive enzyme-linked immunosorbent assay to detect residues of tetracycline in milk. $J$. Agric. Food Chem., 55, 211-218.

106 Franek, M., Kolar, V., Deng; A., Crooks, S. (1999) Determination of sulphadimidine (sulfamethazine) residues in milk, plasma, urine and edible tissues by sensitive ELISA. Food Agric. Immunol., 11, 339-349. 
${ }^{107}$ Thomson, C.A., Sporns, P. (1995) Direct ELISAs for sulfathiazole in milk and honey with special emphasis on enzyme conjugate preparation. J. Food Sci., 60, 409-415.

${ }^{108}$ Garden, S.W., Sporns, P. (1994) Development and evaluation of an enzyme immunoassay for sulfamerazine in milk. J. Agric. Food Chem., 42, 1379-1391.

${ }^{109}$ Muldoon, M.T., Buckley, S.A., Deshpande, S.S., Holtzapple, C.K., Beier, R.C., Stanker, L.H. (2000) Development of a monoclonal antibody-based cELISA for the analysis of sulfadimethoxine. 2. Evaluation of rapid extraction methods and implications for the analysis of incurred residues in chicken liver tissue. J. Agric. Food Chem., 48, 545-550.

${ }^{110}$ Spinks, C.A., Schut, C.G., Wyatt, G.M., Morgan, M.R.A. (2001) Development of an ELISA for sulphachlorpyridazine and investigation of matrix effects from different sample extraction procedures. Food Addit. Contam., 18, 11-18.

${ }^{111}$ Tafintseva, I.Yu., Zherdev, A.V., Eremin, S.A., Dzantiev, B.B. (2010) Enzyme immunoassay for determination of sulfamethoxypyridazine in honey. Appl. Biochem. Microbiol., 46, 216-220.

112 Cliquet, P., Cox, E., Haasnoot, W., Schacht, E., Goddeeris, B.M. (2003) Generation of group-specific antibodies against sulphonamides. J. Agric. Food Chem., 51, 5835-5842.

113 Cliquet, P., Cox, E., Haasnoot, W., Schacht, E., Goddeeris, B.M. (2003) Extraction procedure for sulfachloropyridazine in porcine tissues and detection in a sulfonamide-specific enzyme-linked immunosorbent assay (ELISA). Anal. Chim. Acta, 494, 21-28.

114 Adrian, J., Pinacho, D.G., Granier, B., Diserens, J.-M., Sánchez-Baeza, F., Marco, M.P. (2008) A multianalyte ELISA for immunochemical screening of sulfonamide, fluoroquinolone and ß-lactam antibiotics in milk samples using classselective bioreceptors. Anal. Bioanal. Chem., 391, 1703-1712. 
${ }^{115}$ Adrian, J., Font, H., Diserens, J.M., Sanchez-Baeza, F., Marco, M.P.. (2009) Generation of broad specificity antibodies for sulfonamide antibiotics and development of an enzyme-linked immunosorbent assay (ELISA) for the analysis of milk samples. J. Agric. Food Chem., 57, 385-394.

${ }^{116}$ Münstedt, T., Rademacher, E., Petz, M. (2005) HPLC, Charm II and ELISA: advantages and disadvantages for the analysis of tetracyclines in Honey. Apiacta, 40, 5-9.

117 Jeon, M., Kim, J., Paeng, K.J., Park, S.W., Rhee Paeng, I. (2008) Biotin-avidin mediated competitive enzyme-linked immunosorbent assay to detect residues of tetracyclines in milk. Microchem. J., 88, 26-31.

118 Jeon, M., Rhee Paeng, I. (2008) Quantitative detection of tetracycline residues in honey by a simple sensitive immunoassay. Anal. Chim. Acta, 626, 180-185.

119 R-Biopharm (2001) Operator's manual Ridascreen sulfonamide. Article $\mathrm{n}^{\mathrm{o}}$ R3004. R-Biopharm, Darmstadt.

${ }^{120}$ Aga, D.S., O'Connor, S., Ensley, S., Payero, J.O., Snow, D., Tarkalson, D. (2005) Determination of the persistence of tetracycline antibiotics and their degradates in manure-amended soil using enzyme-linked immunosorbent assay and liquid chromatography-mass spectrometry. J. Agric. Food Chem., 53, 7165-7171.

${ }^{121}$ Croubels, S., Okerman, L., Vanoosthuyze, K., van Hoof, J., van Peteghem, C. En: Euroresidue III: Conference on Residues of Veterinary Drugs in Foods (N., Haagsma, A., Ruiter, eds.). University of Utrecht, Utrecht, 1996, pp. 362-366.

${ }^{122}$ Okerman, L., De Wasch, K., Van Hoof, J., Smedts, W. (2003) Simultaneous determination of different antibiotic residues in bovine and in porcine kidneys by solid-phase fluorescence immunoassay. J. AOAC Int., 86, 236-240. 
Bibliografia

${ }^{123}$ Alfredsson, G., Branzell, C., Granelli, K., Lundström, A. (2005) Simple and rapid screening and confirmation of tetracyclines in honey and egg by a dipstick test and LC-MS/MS. Anal. Chim. Acta, 529, 47-51.

${ }^{124}$ Kolloff, H.G. (1938) Water-soluble derivatives of $p$-aminobenzenesulfonamide. I. J. Am. Chem. Soc., 60, 950-951.

${ }^{125}$ Adams, R., Long, P.H., Johanson, A.J. (1939) Sulfanilamide derivatives. I. J. Am. Chem. Soc., 61, 2342-2346.

126 Lazareva, E.N., Kutskaya, I.P., Sitnikova, L.V., Krjuchkova, A.P. (1970) Nouveau dérivé carboxamidé de la tetracycline. Institut National de la Proprieté Industrielle 1.591.985.

${ }^{127}$ Langone, J.J., van Vunakis, H. (1982) Radioimmunoassay of nicotine, cotinine, and $\gamma$-(3-piridyl)- $\gamma$-oxo-N-methylbutyramide. Meth. Enzymol., 84, 628-640.

${ }^{128}$ Erlanger, B.F. (1980) The preparation of antigenic hapten-carrier conjugates: a survey. Meth. Enzymol., 70, 85-104.

${ }^{129}$ Beasley, H.L., McAdam, D.P., Larkin, K.A., Ferguson, B.S., Bushway, R.J., Skerritt, J.H. (1997) Laboratory and field enzyme-immunoassays for diazinon and their application to residue analysis in lanolin, water, and fruit juice. Bull. Environ. Contam. Toxicol., 59, 375-382.

${ }^{130}$ Bradford, M.M. (1976) A rapid and sensitive method for the quantitation of microgram quantities of protein utilizing the principle of protein dye binding. Anal. Biochem., 72, 248-254.

131 Catty, D., Raykundalia, C. Production and quality control of polyclonal antibodies. En: Antibodies, A Practical Approach (D., Catty, ed.) vol. I, IRL Press, Oxford, 1989, pp. 149-157. 
${ }^{132}$ Posyniak, A., Zmudzki, J., Niedzielska, J., Sniegocki, T., Grzebalska, A. (2003) Sulfonamide residues in honey. Control and development of analytical procedure. Apiacta, 38, 249-256.

${ }^{133}$ Palumbo, G., Bacchi, S., Primavera, L., Palumbo, P., Carlucci, G. (2005) A validated HPLC method with electrochemical detection for simultaneous assay of 5 -aminosalicylic acid and its metabolite in human plasma. Biomed. Chromatogr., $19,350-354$.

${ }^{134}$ Huq, S., Dixon, A., Teuscher, J., Kallury, K. (2003) High recoveries and superior clean-up of sulpha drugs from plasma using a new polymeric ion exchange sorbent-strata ${ }^{\mathrm{TM}}-\mathrm{X}-\mathrm{C}$. LC-GC Europe, 16, part. 9, 16-17.

135 Hansen, S.H. (1989) Simple and rapid method for the simultaneous determination of the eight main metabolites and conjugates of sulphasalazine in human plasma, urine and faeces using dynamically modified silica. $J$. Chromatogr., 491, 175-185.

${ }^{136}$ Goodrow, M.H., Sanborn, J.R., Stoutamire, D.W., Gee, S.J., Hammock, B.D. Strategies for immunoassay hapten design. En: Immunoanalysis of Agrochemicals: Emerging Technologies (J.O., Nelson, A.E., Karu, R.B., Wong, eds.) ACS Symposium Series, vol. 586, American Chemical Society, Washington, DC, 1995, pp. 119-139.

${ }^{137}$ Marco, M.-P., Gee, S., Hammock, B.D. (1995) Immunochemical techniques for environmental analysis. Part II. Antibody production and immunoassay development. TrAC, Trends Anal. Chem., 14, 415-425.

${ }^{138}$ Franek, M., Hruska, K. (2005) Antibody based methods for environmental and food analysis: a review. Vet. Med.-Czech, 50, 1-10.

139 Oubiña, A., Ballesteros, B., Bou, P., Galve, R., Gascón, J., Iglesias, F., Sanvicens, N., Marco, M.-P. Immunoassays for environmental analysis. En: 
Sample Handling and Trace Analysis of Pollutants: Techniques, Applications and Quality Assurance. (D., Barcelo, ed.) Techniques and Instrumentation in Analytical Chemistry, vol 21, Elsevier, Amsterdam, NL, 2000, pp. 289-339.

${ }^{140}$ Lee, N., McAdam, D.P., Skerritt, J.H. (1998) Development of immunoassays for type II synthetic pyrethroids. 1. Hapten design and application to heterologous and homologous assays. J. Agric. Food Chem., 46, 520-534.

141 Galve, R., Sanchez-Baeza, F., Camps, F., Marco, M.P. (2002) Indirect competitive immunoassay for trichlorophenol determination. Rational evaluation of the competitor heterology effect. Anal. Chim. Acta, 452, 191-206.

${ }^{142}$ Zhang, Q., Wang, L., Ahn, K.C., Sun, Q., Hu, B., Wang, J., Liu, F. (2007) Hapten heterology for a specific and sensitive indirect enzyme-linked immunosorbent assay for organophosphorus insecticide fenthion. Anal. Chim. Acta, 596, 303-311.

${ }^{143}$ Barton, S.D., Ollis W.D. Comprehensive Organic Chemistry. The Synthesis and Reactions of Organic Compounds. (D.N., Jones, ed.) Sulphur, selenium, silicon, boron, organometallic compounds, vol. 3, Pergamon Press, Oxford, 1979, pp. 345 362.

144 Sprague, J.M., Lincoln, R.M., Ziegler, C. (1946) Carboxy derivatives of sulfonamidothiazoles. J. Am. Chem. Soc., 68, 266-269.

${ }^{145}$ Li, J.S., Li, X.W., Yuan, J.X., Wang, X. (2000) Determination of sulfonamides in swine meat by immunoaffinity chromatography. J. AOAC Int., 83, 830-836.

146 Mayfield, C.A., DeRuiter, J. (1987) Novel inhibitors of rat lens aldose reductase: N-[[(substituted amino)phenyl]sulfonyl]glycines. J. Med. Chem., 30, 1595-1598. 
${ }^{147}$ Deng, X., Mani, N.S. (2006) A facile, environmentally benign sulfonamide synthesis in water. Green Chem., 8, 835-838.

148 Barton, D.H.R., Magnus, P.D. (1971) Experiments on the synthesis of tetracycline. Part I. Introduction to the series. J. Chem. Soc. C, 2164-2166.

${ }^{149}$ Oka, H., Ikai, Y., Kawamura, N., Yamada, M., Harada, K., Ito, S., Suzuki, M. (1989) Photodecomposition products of tetracycline in aqueous solution. J. Agric. Food Chem., 37, 226-231.

150 Anderson, C.R., Rupp, H.S., Wu, W.-H. (2005) Complexities in tetracycline analysis: chemistry, matrix extraction, cleanup, and liquid chromatography. $J$. Chromatogr. A, 1075, 23-32.

151 Gentili, A., Perret, D., Marchese, S. (2005) Liquid chromatography-tandem mass spectrometry for performing confirmatory analysis of veterinary drugs in animal-food products. TrAC, Trends Anal. Chem., 24, 704-733.

152 Jacobsen, A.M., Halling-Sørensen, B. (2006) Multi-component analysis of tetracyclines, sulfonamides and tylosin in swine manure by liquid chromatographytandem mass spectrometry. Anal. Bioanal. Chem., 384, 1164-1174.

153 Carson, M., Ngoh, M.A., Hadley, S.W. (1998) Confirmation of multiple tetracycline residues in milk and oxytetracycline in shrimp by liquid chromatography-particle beam mass spectrometry. J. Chromatogr. B, 712, 113128.

154 Debayle, D., Dessalces, G., Grenier-Loustalot, M.F. (2008) Multi-residue analysis of traces of pesticides and antibiotics in honey by HPLC-MS-MS. Anal. Bioanal. Chem., 391, 1011-1020.

155 Wan, G.-H., Cui, H., Zheng, H.-S., Zhou, J., Liu, L.-J., Yu, X.-F. (2005) Determination of tetracyclines residues in honey using high-performance liquid 
chromatography with potassium permanganate-sodium sulfite- $\beta$-cyclodextrin chemiluminescence detection. J. Chromatogr. B, 824, 57-64.

${ }^{156}$ Ferraz Spisso, B., de Oliveira e Jesus, A.L., Gonçalves de Araújo Júnior, M.A., Alves Monteiro, M. (2007) Validation of a high-performance liquid chromatographic method with fluorescence detection for the simultaneous determination of tetracyclines residues in bovine milk. Anal. Chim. Acta, 581, 108117.

${ }^{157}$ Posyniak, A., Mitrowska, K., Zmudzki, J., Niedzielska, J. (2005) Analytical procedure for the determination of chlortetracycline and 4-epi-chlortetracycline in pig kidneys. J. Chromatogr. A, 1088, 169-174.

${ }^{158}$ Pouliquen, H., Gouelo, D., Larhantec, M., Pilet, N., Pinault, L. (1997) Rapid and simple determination of oxolinic acid and oxytetracycline in the shell of the blue mussel (Mytilus edulis) by high-performance liquid chromatography. $J$. Chromatogr. B, 702, 157-162.

159 Jefferis, R., Deverill, I. The antigen antibody reaction. En: Principles and Practice of Immunoassay, (C.P., Price, D.J., Newman, eds.) Chapter 1, Stockton Press, New York, 1991, pp. 1-18.

${ }^{160}$ Li, Q.X., Zhao, M.S., Gee, S.J., Kurth, M.J., Seiber, J.N., Hammock, B.D. (1991) Development of enzyme-linked immunosorbent assays for 4-nitrophenol and subtituted 4-nitrophenols. J. Agric. Food Chem., 39, 1685-1692.

${ }^{161}$ Rona, K., Winkler, V., Riesz, T., Gachalyi, B. (1987) Liquid chromatographic method for the simultaneous determination of sulfasalazine and its main metabolites in biological fluids. Chromatographia, 24, 720-724.

${ }^{162}$ Gu, G.-Z., Xia, H.-M., Pang, Z.-Q., Liu, Z.-Y., Jiang, X.-G., Chen, J. (2011) Determination of sulphasalazine and its main metabolite sulphapyridine and 5aminosalicylic acid in human plasma by liquid chromatography/tandem mass 
spectrometry and its application to a pharmacokinetic study. J. Chromatogr. B, $879,449-456$.

${ }^{163}$ Elmasry, M.S., Blagbrough, I.S., Rowan, M.G., Saleh, H.M., Kheir, A.A., Rogers, P.J. (2011) Quantitative HPLC analysis of mebeverine, mesalazine, sulphasalazine and dispersible aspirin stored in a Venalink monitored dosage system with co-prescribed medicines. J. Pharmaceut. Biomed. Anal., 54, 646-652.

164 Jornet, D., González-Martínez, M.A., Puchades, R., Maquieira, A. (2010) Antibiotic immunosensing: determination of sulfathiazole in water and honey. Talanta, 81, 1585-1592.

${ }^{165}$ Guillen, I., Gabaldon, J.A., Nunez-Delicado, E., Puchades, R., Maquieira, A., Morais, S. (2011) Detection of sulphathiazole in honey samples using a lateral flow immunoassay. Food Chem., 129, 624-629.

${ }^{166}$ Pastor-Navarro, N., Brun, E.M., Gallego-Iglesias, E., Maquieira, A., Puchades, R. (2009) Development of immunoassays to determinate sulfamethoxazole residues in wastewaters. J. Environ. Monit., 11, 1094-1100.

${ }^{167}$ Cháfer-Pericás, C., Maquieira, A., Puchades, R., Miralles, J., Moreno, A. (2010) Fast screening immunoassay of sulfonamides in commercial fish samples. Anal. Bioanal. Chem., 396, 911-921.

${ }^{168}$ Cháfer-Pericás, C., Maquieira, A., Puchades, R., Miralles, J., Moreno, A. (2011) Multiresidue determination of antibiotics in feed and fish samples for food safety evaluation. Comparison of immunoassay vs LC-MS-MS. Food Control, 22, 993999.

${ }^{169}$ Pastor-Navarro, N., Gallego-Iglesias, E., Brun, E.M., Maquieira, A., Puchades Pla, R. The immunoassay, a reliable tool for screening sulfonamide residues in honey. I Congreso Iberoamericano sobre Seguridad Alimentaria (CIBSA), Sevilla, España, 2006. 
Bibliografía

${ }^{170}$ Cháfer-Pericás, C., Maquieira, A., Puchades, R., Miralles, J., Moreno, A., Pastor-Navarro, N., Espinós, F. (2010) Immunochemical determination of oxytetracycline in fish: comparison between enzymatic and time-resolved fluorometric assays. Anal. Chim. Acta, 662, 177-185.

${ }^{171}$ EC Regulation (2001) Directive 2001/110, L10 (12-1-2002):47-52.

${ }^{172}$ Sandborn, W.J., Hanauer, S.B. (2003) Systematic review: the pharmacokinetic profiles of oral mesalazine formulations and mesalazine pro-drugs used in the management of ulcerative colitis. Aliment. Pharmacol. Ther., 17, 29-42.

173 Alegre De Miguel, C., Santos Ramírez, C., Barceló Bru, M. (2008) Susceptibilidad de la población española a los efectos adversos por sulfasalazina: revisión sistemática. Reumatol. Clin., 4, 132-135.

${ }^{174}$ Kaufmann, A., Kaenzig, A. (2004) Contamination of honey by the herbicide asulam and its antibacterial active metabolite sulfanilamide. Food Addit. Contam., $21,564-571$.

175 Sheth, H.B., Yaylayan, V.A., Low, N.H., Stiles, M.E., Sporns, P. (1990) Reaction of reducing sugars with sulfathiazole and importance of this reaction to sulfonamide residue analysis using chromatographic, colorimetric, microbiological, or ELISA methods. J. Agric. Food Chem., 38, 1125-1130.

${ }^{176}$ Heering, W., Usleber, E., Dietrich, R., Märtlbauer, E. (1998) Immunochemical screening for antimicrobial drug residues in commercial honey. Analyst, 123, 27592762 . 


\section{APÉNDICE I}

ESPECTROS RMN, IR Y MS 



\section{SULFONAMIDAS}

\section{ESPECTROS DE LOS HAPTENOS TIPO I}

\section{Hapteno S2- Ácido 4-(4-amino-bencenosulfonilamino)benzoico}

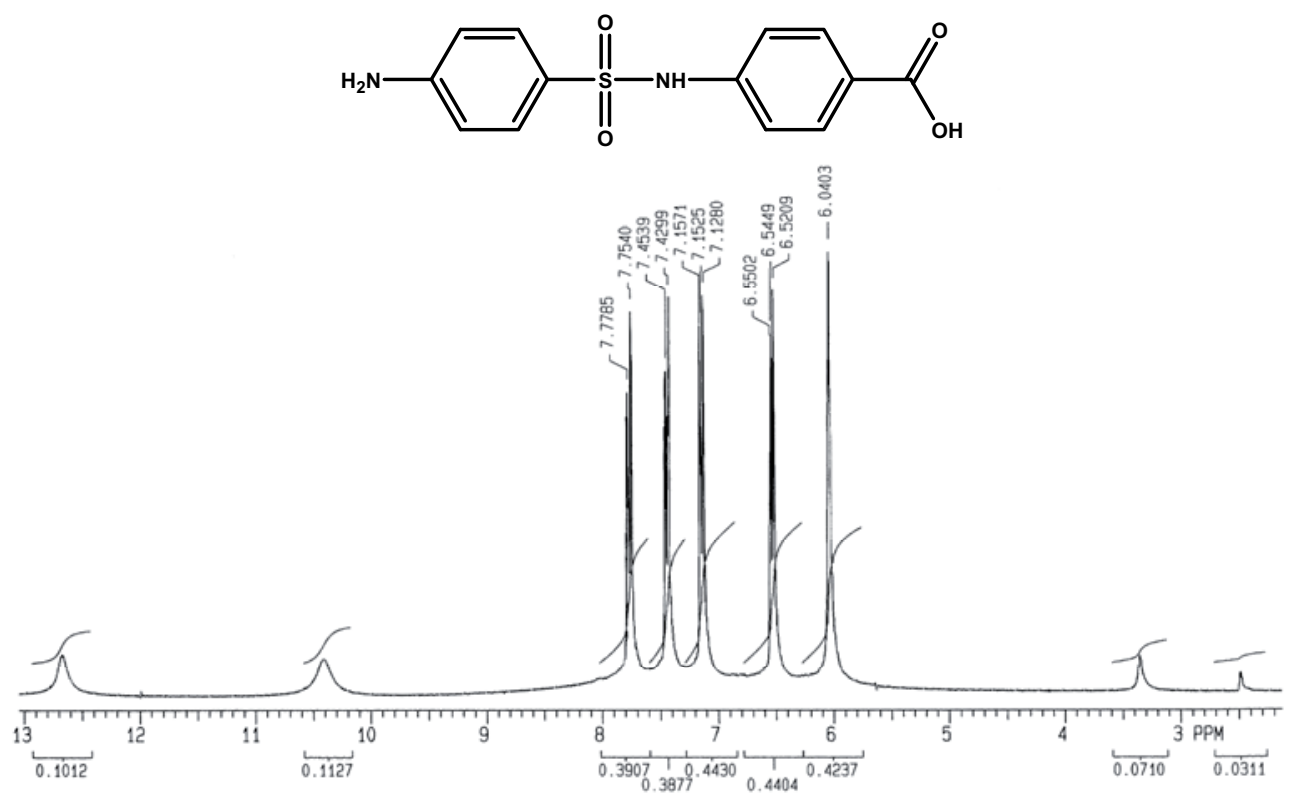

Espectro 1: ${ }^{1} \mathrm{H}-\mathrm{RMN}\left(300 \mathrm{MHz}, \mathrm{DMSO}-\mathrm{d}_{6}\right)$

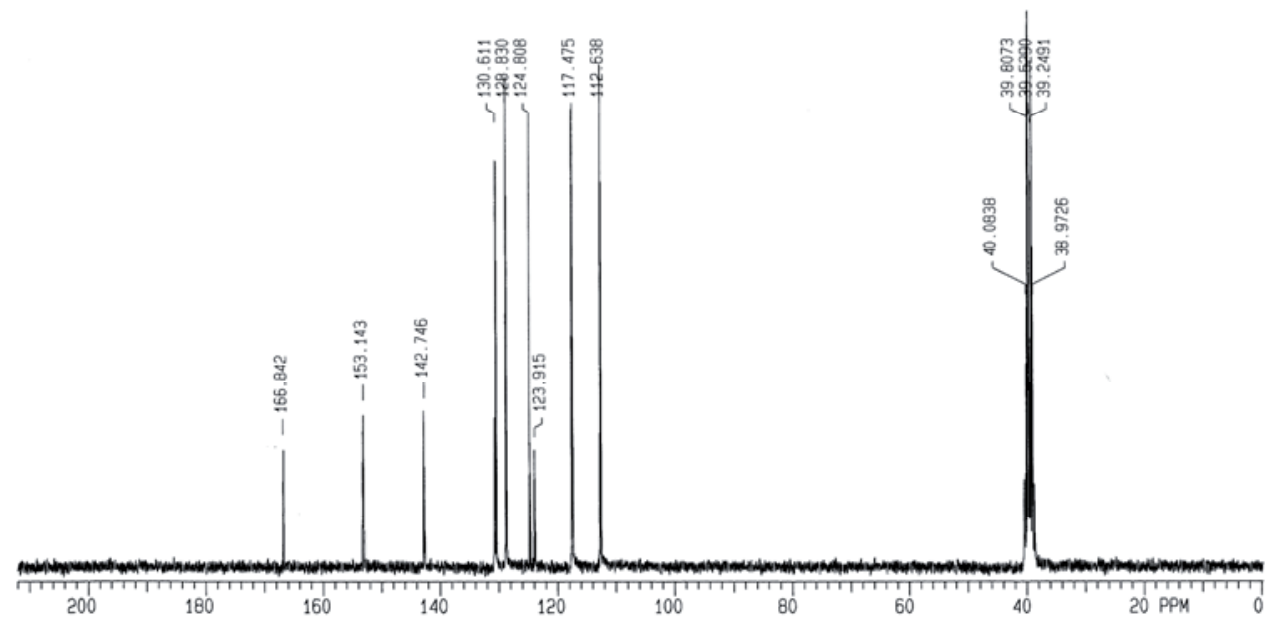

Espectro 2: ${ }^{13} \mathrm{C}-\mathrm{RMN}\left(75,4 \mathrm{MHz}, \mathrm{DMSO}-\mathrm{d}_{6}\right)$ 

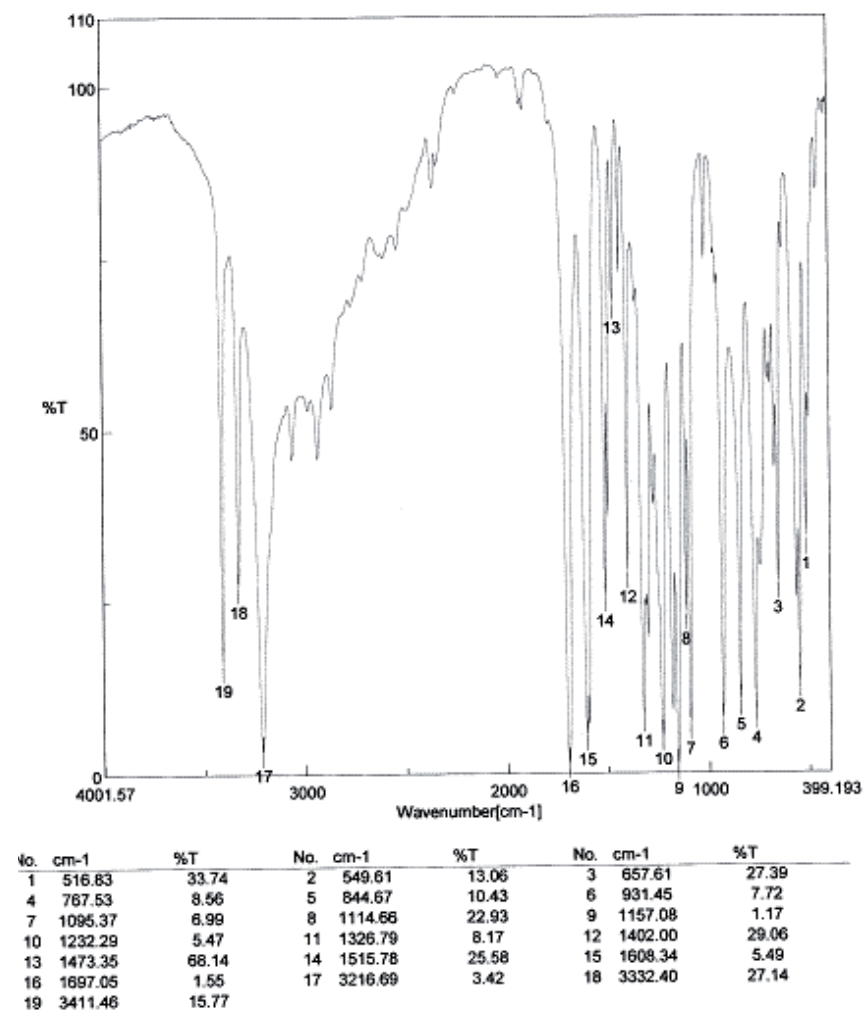

Espectro 3: IR ( $\mathrm{KBr})$

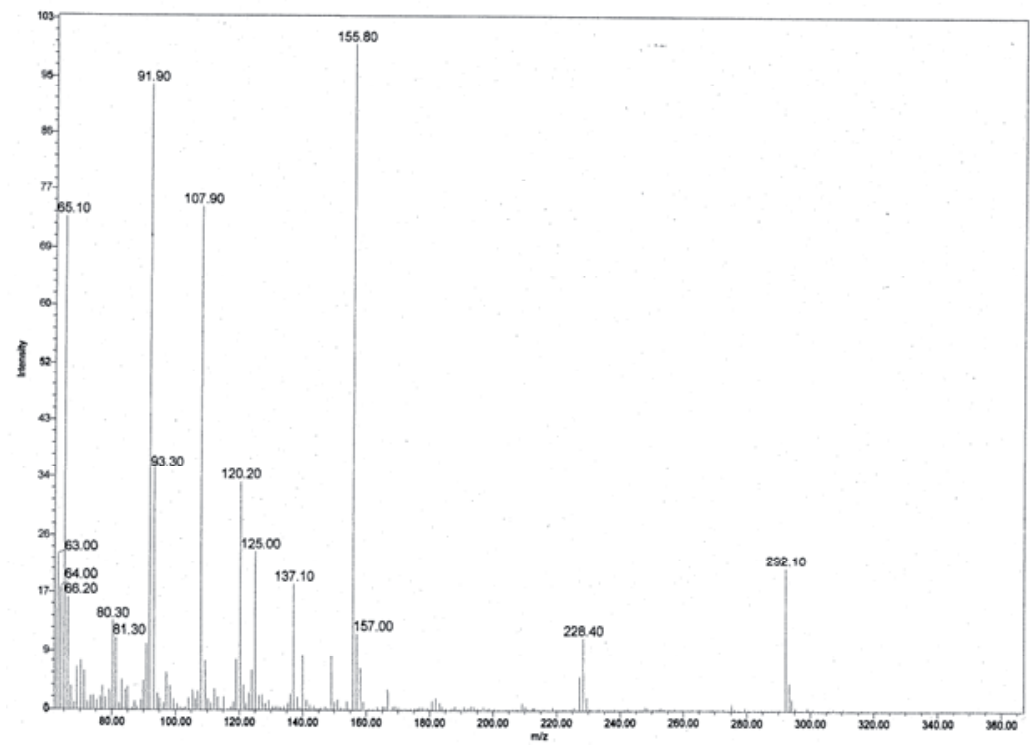

Espectro 4: MS (fragmento, intensidad relativa) 
Hapteno S3- Ácido [2-(4-amino-bencenosulfonilamino)-1,3-tiazol-4-il]acético<smiles>Nc1ccc(S(=O)(=O)Nc2nc(CC(=O)O)cs2)cc1</smiles>

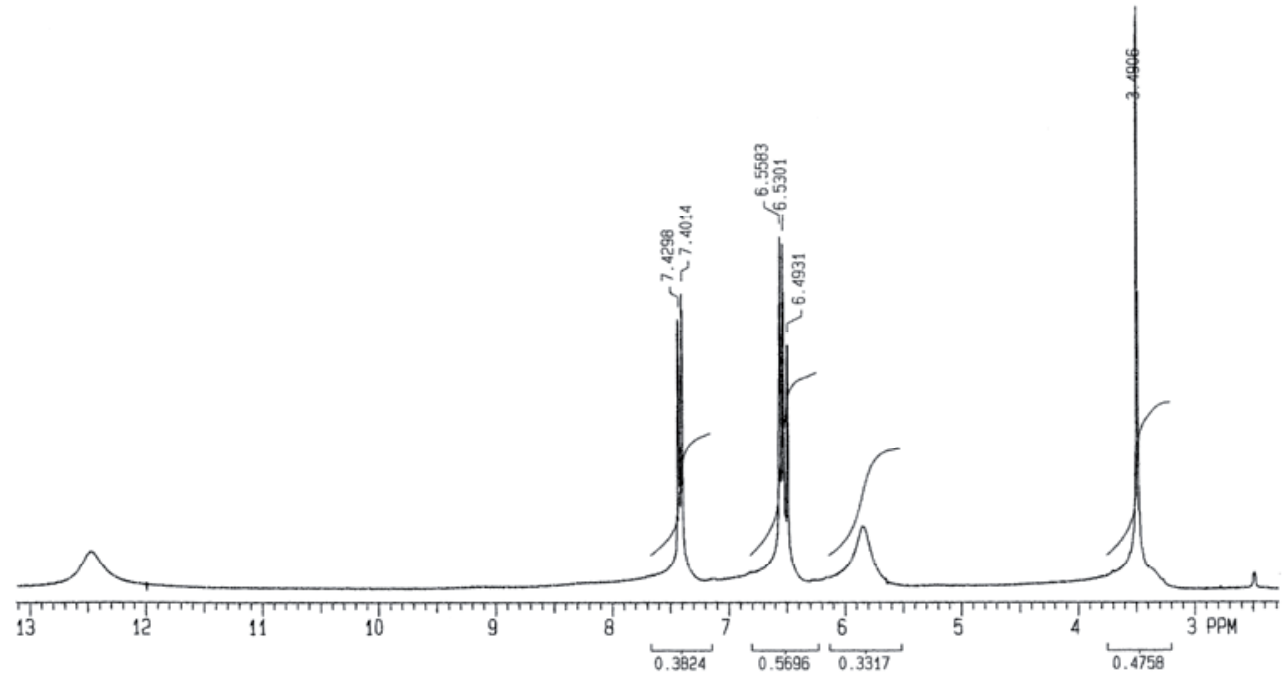

Espectro 5: ${ }^{1} \mathrm{H}-\mathrm{RMN}\left(300 \mathrm{MHz}, \mathrm{DMSO}-\mathrm{d}_{6}\right)$

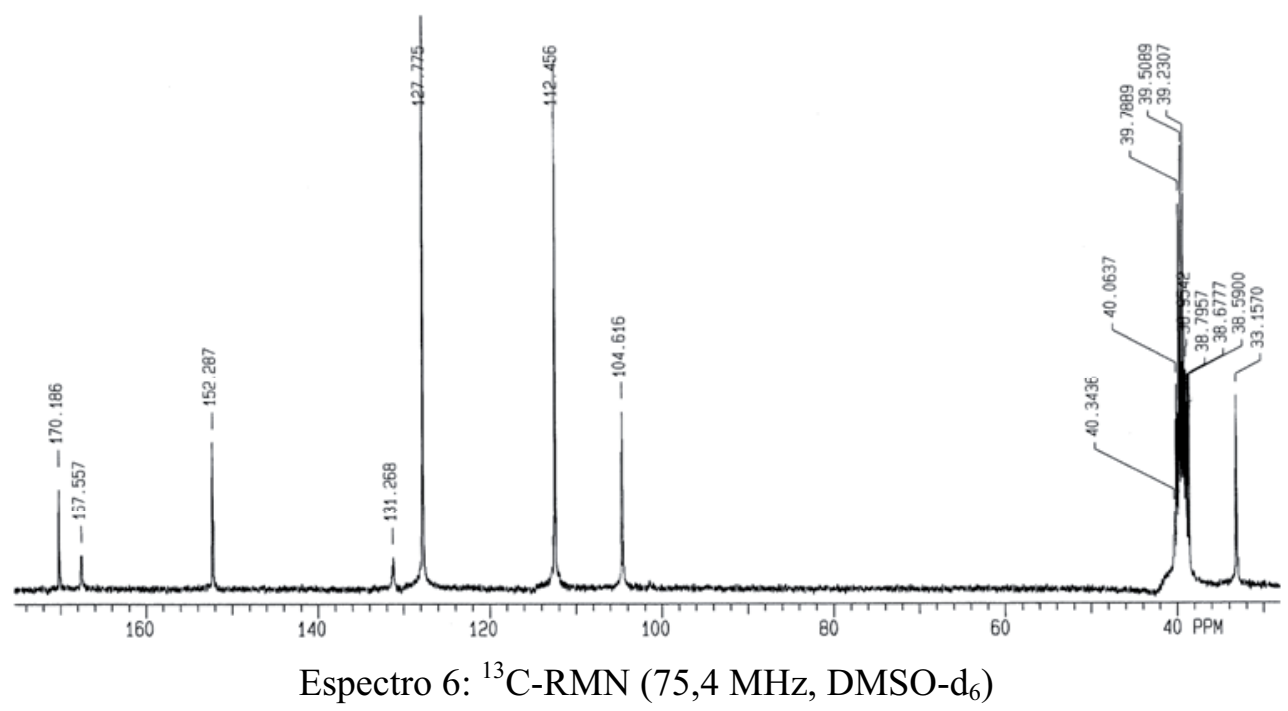



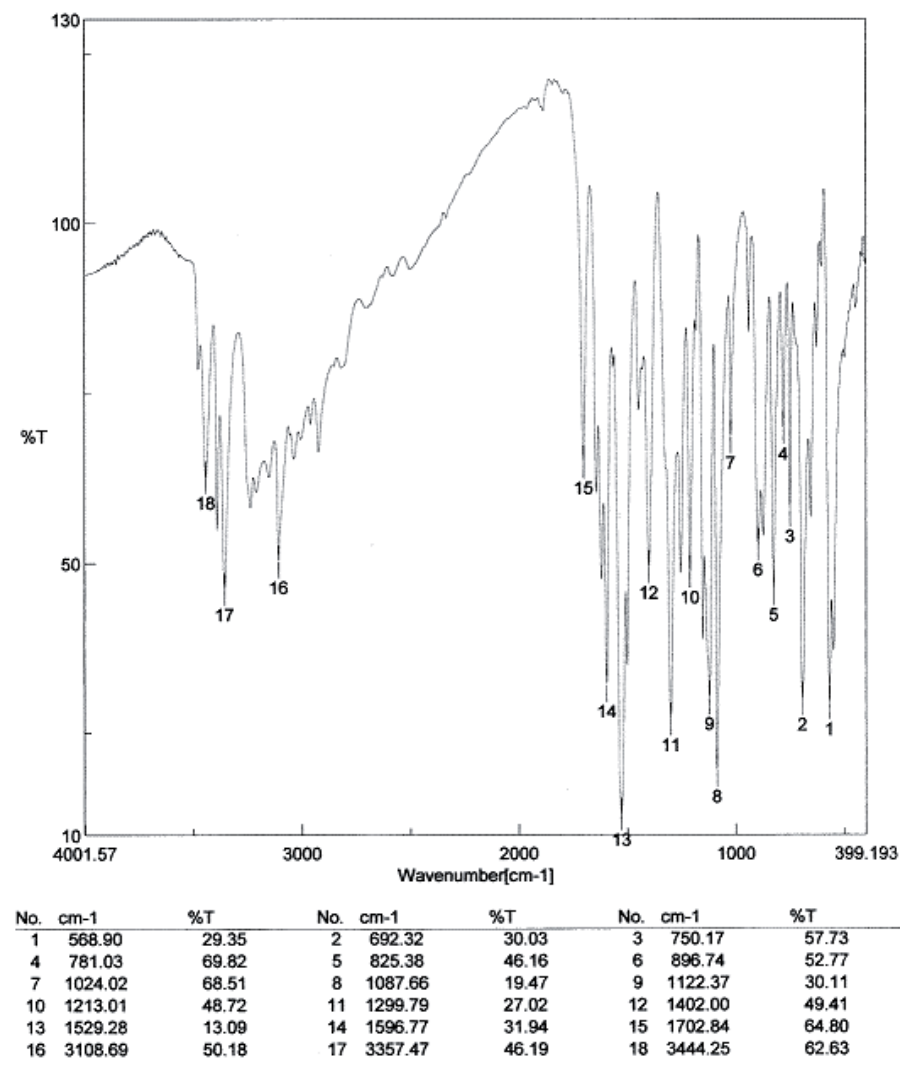

Espectro 7: IR (KBr)

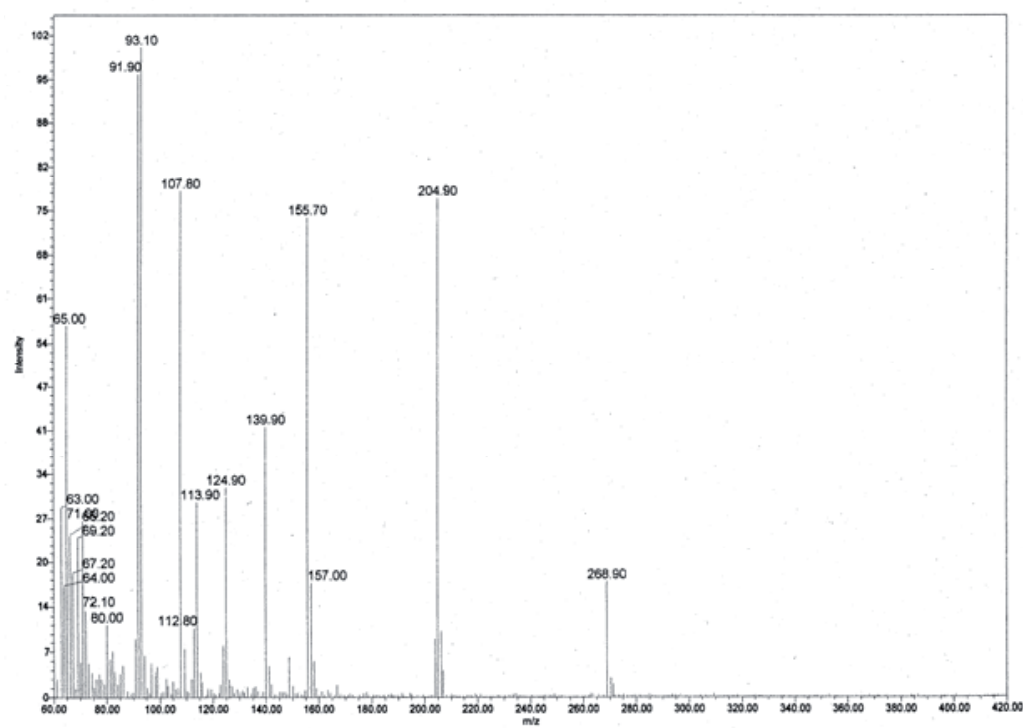

Espectro 8: MS (fragmento, intensidad relativa) 
Hapteno S4- Ácido 6-(4-amino-bencenosulfonilamino)nicotínico<smiles>Nc1ccc(S(=O)(=O)Nc2ccc(C(=O)O)cn2)cc1</smiles>

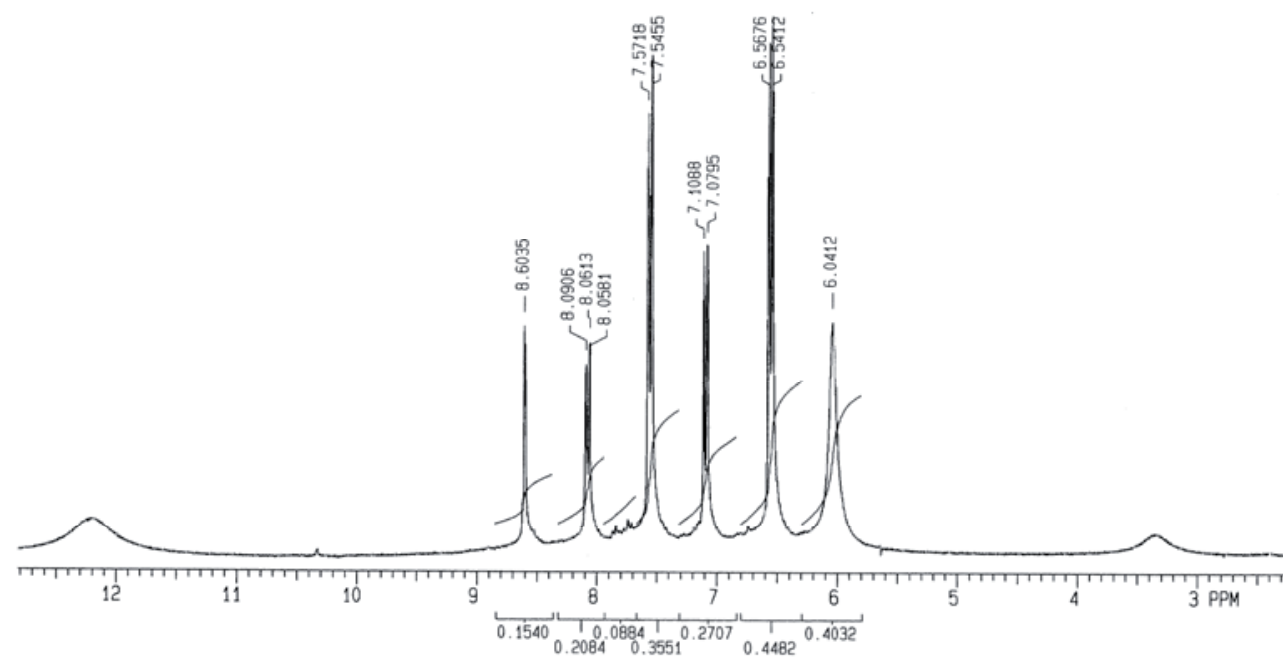

Espectro 9: ${ }^{1} \mathrm{H}-\mathrm{RMN}\left(300 \mathrm{MHz}, \mathrm{DMSO}-\mathrm{d}_{6}\right)$

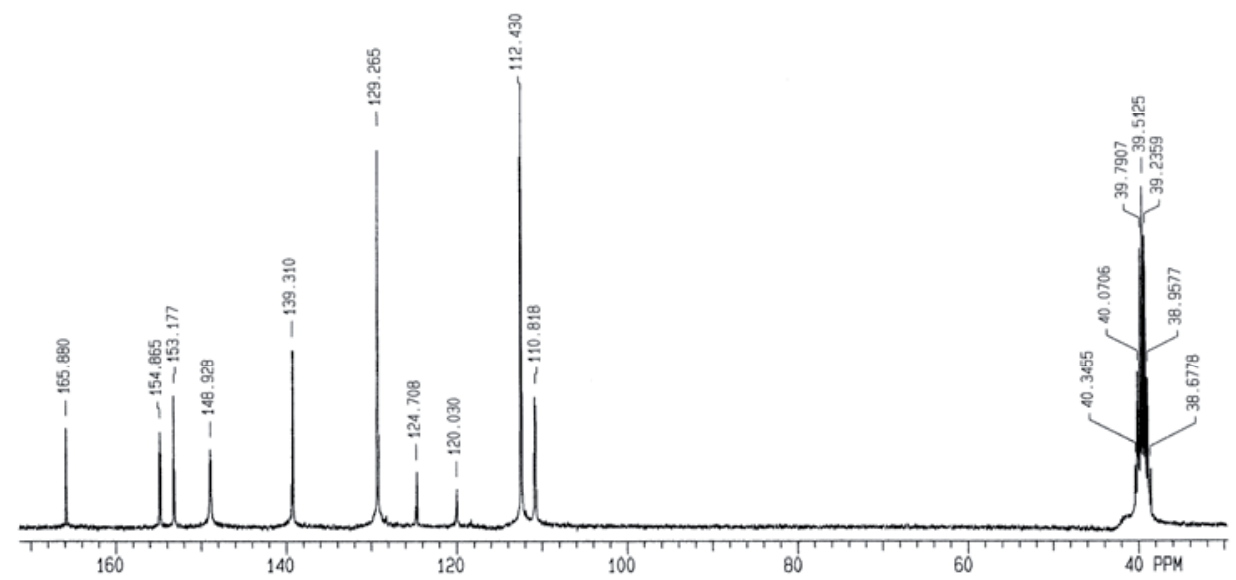

Espectro 10: ${ }^{13} \mathrm{C}-\mathrm{RMN}\left(75,4 \mathrm{MHz}, \mathrm{DMSO}-\mathrm{d}_{6}\right)$ 


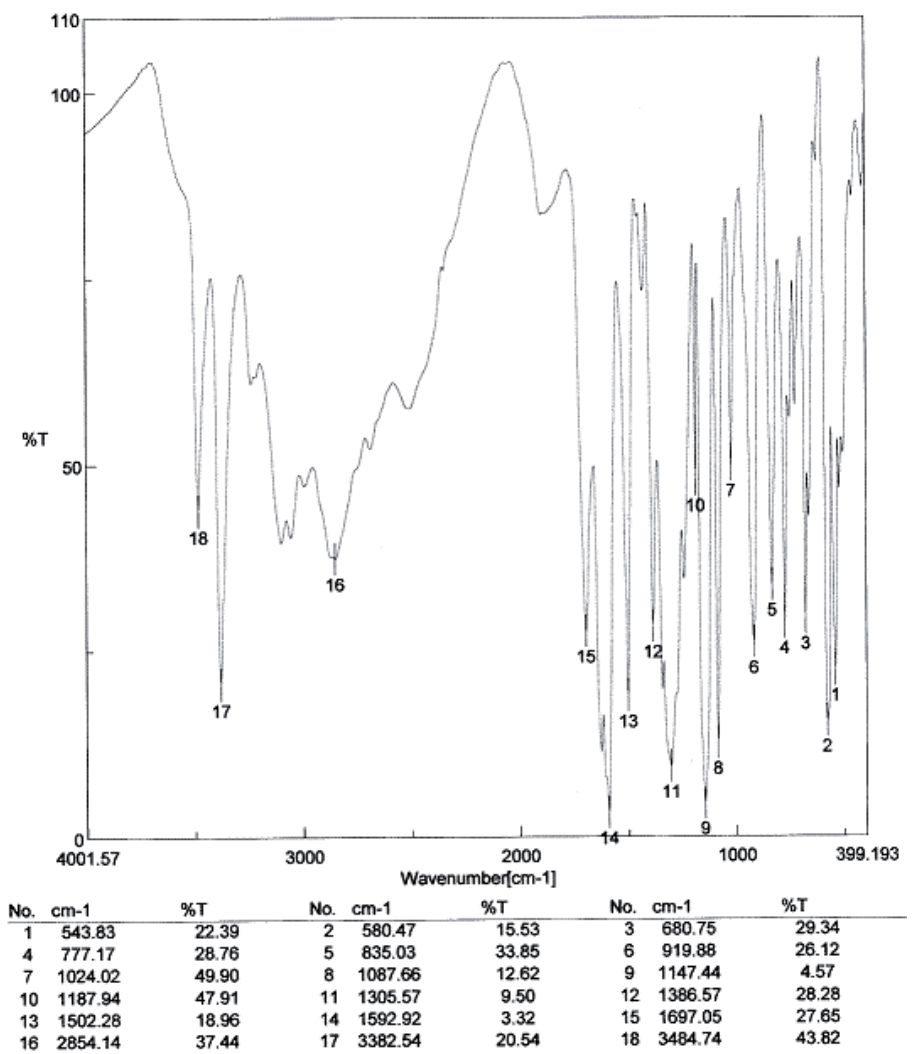

Espectro 11: IR (KBr)

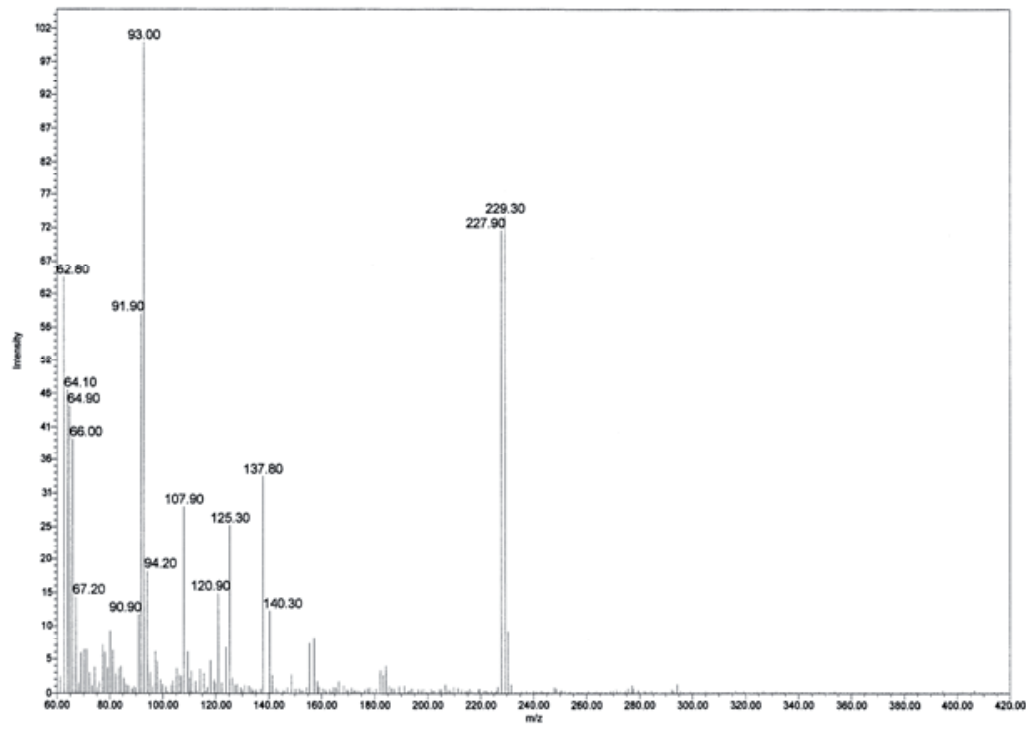

Espectro 12: MS (fragmento, intensidad relativa) 
Hapteno S9- Ácido [4-(4-amino-bencenosulfonilamino)fenil]acético<smiles>Nc1ccc(S(=O)(=O)Nc2ccc(CC(=O)O)cc2)cc1</smiles>

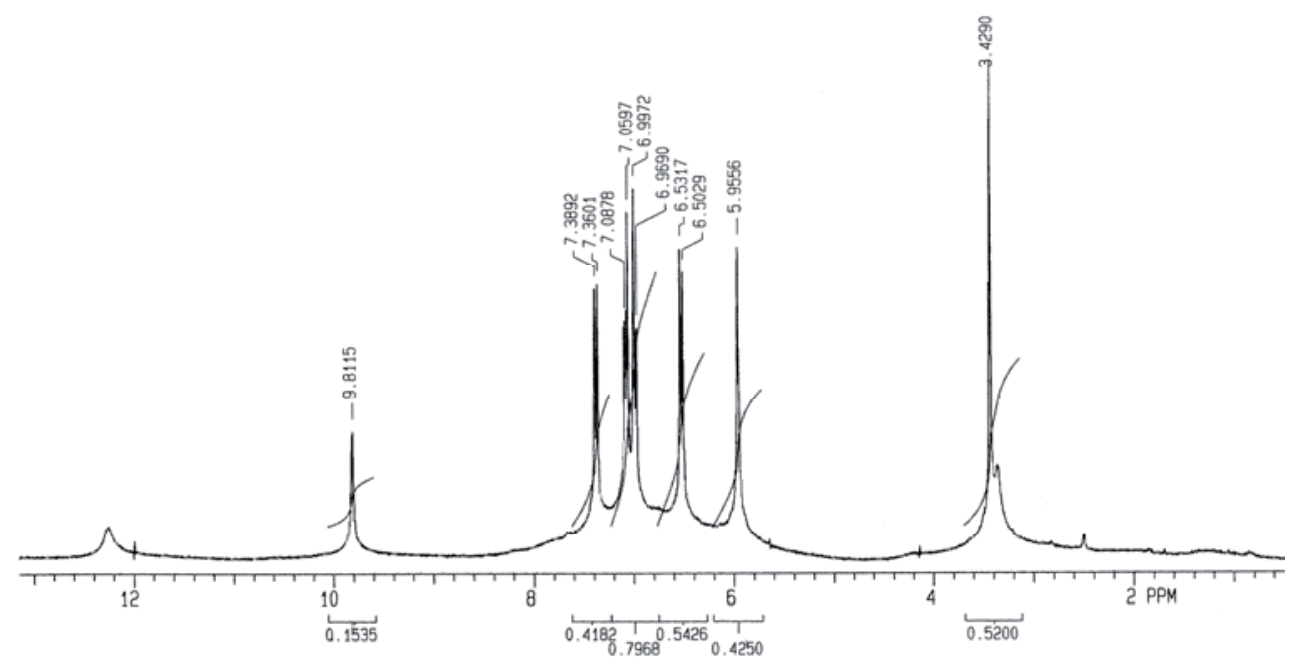

Espectro 13: ${ }^{1} \mathrm{H}-\mathrm{RMN}\left(300 \mathrm{MHz}, \mathrm{DMSO}-\mathrm{d}_{6}\right)$

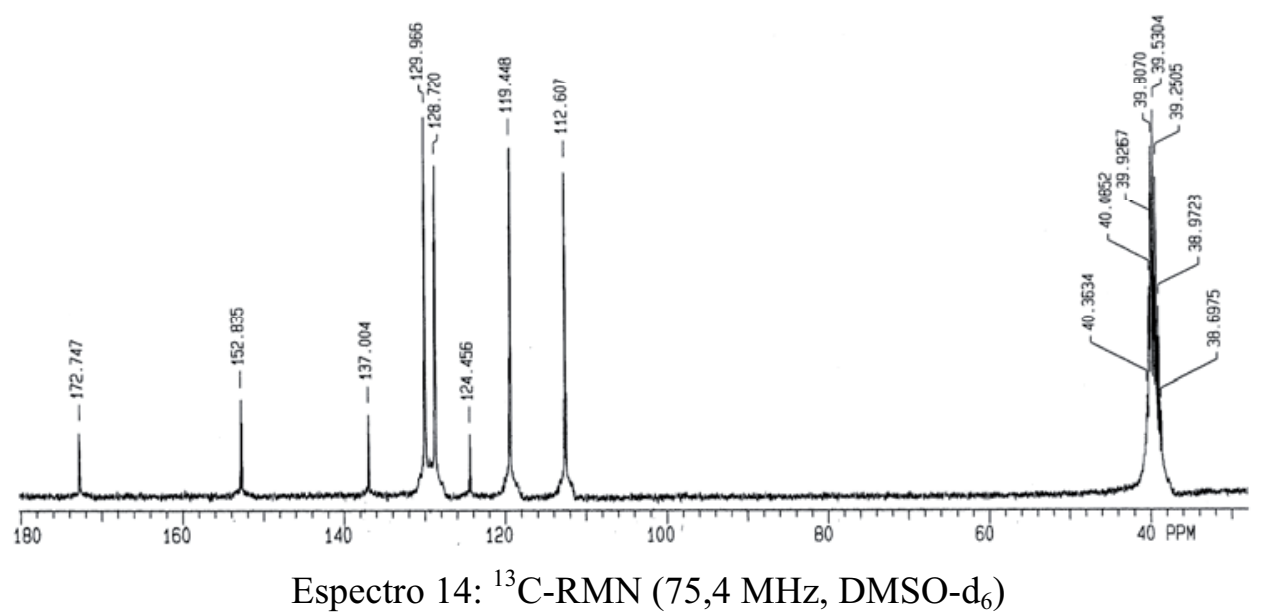




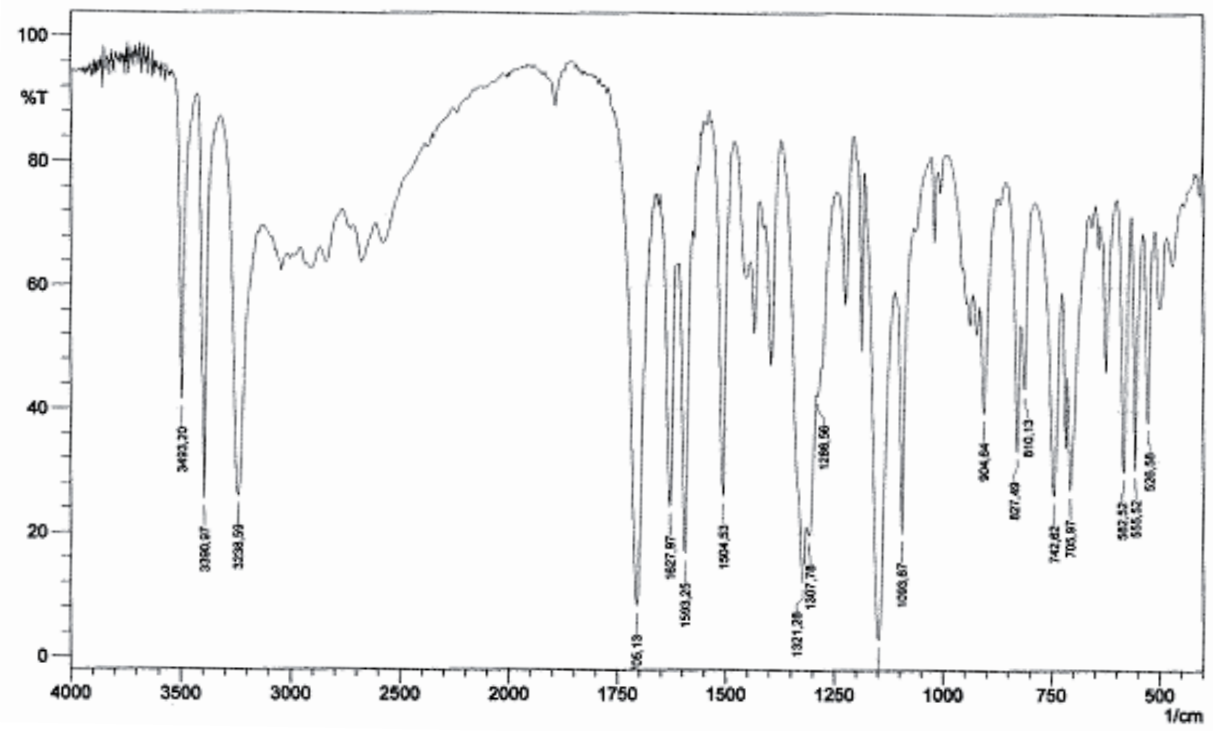

Espectro 15: IR (KBr)

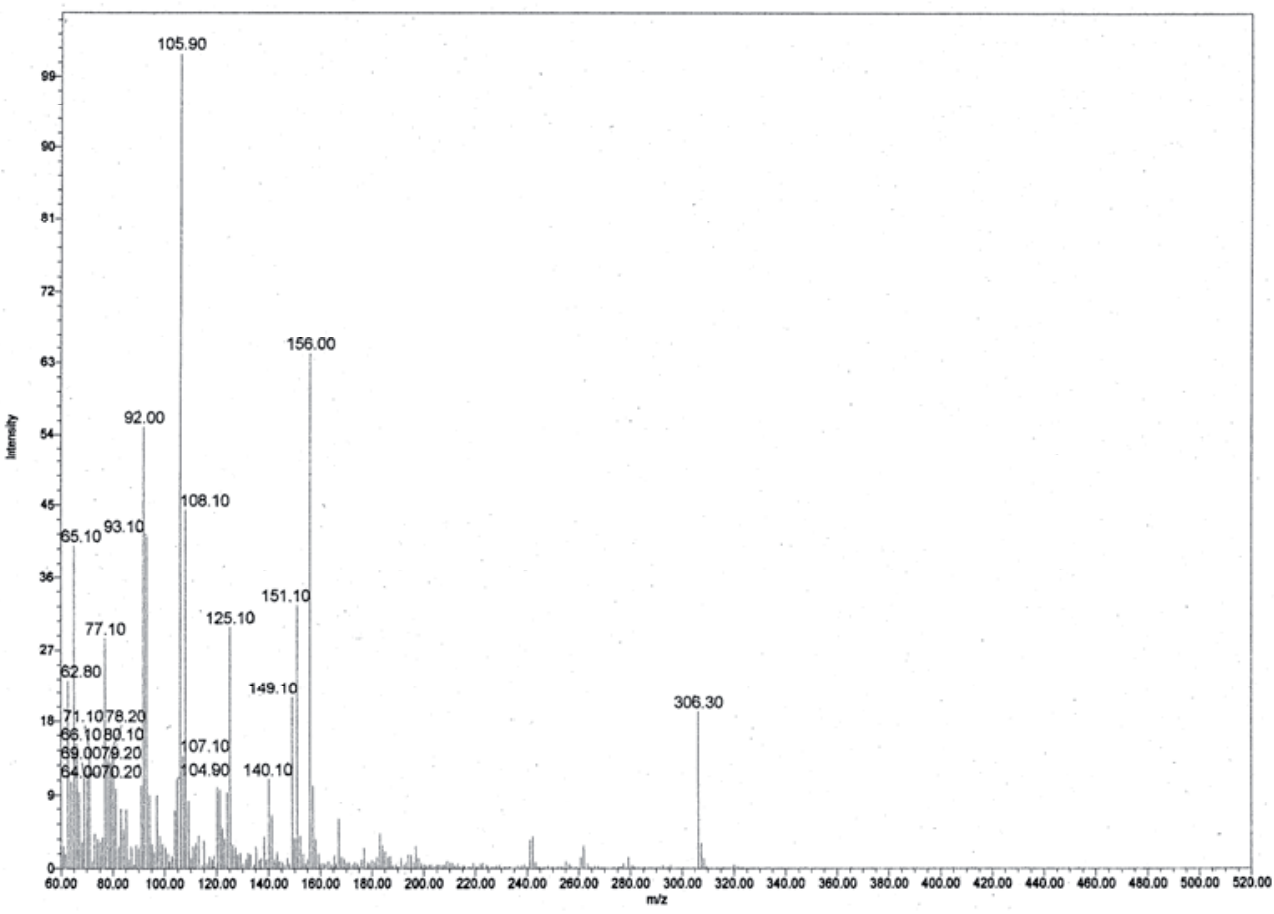

Espectro 16: MS (fragmento, intensidad relativa) 
Hapteno S14- Ácido 4-[4-(4-amino-bencenosulfonilamino)benceno sulfonilamino]benzoico
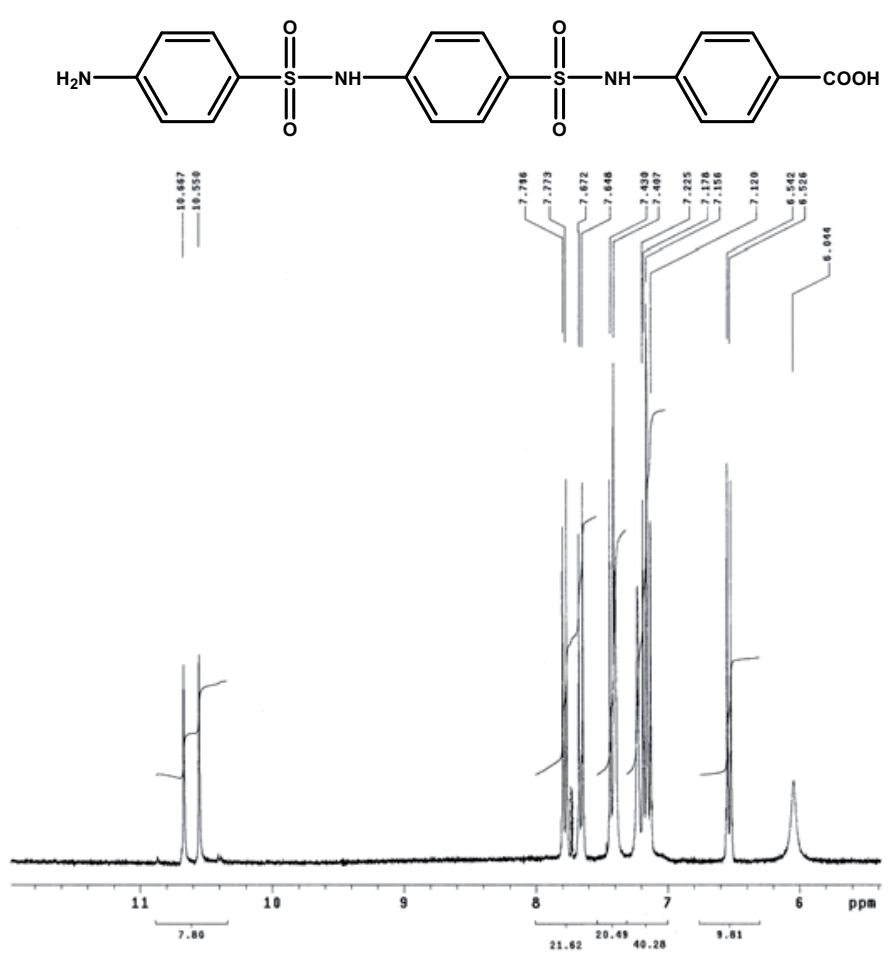

Espectro 17: ${ }^{1} \mathrm{H}-\mathrm{RMN}\left(300 \mathrm{MHz}, \mathrm{DMSO}-\mathrm{d}_{6}\right)$

$$
\text { | }
$$

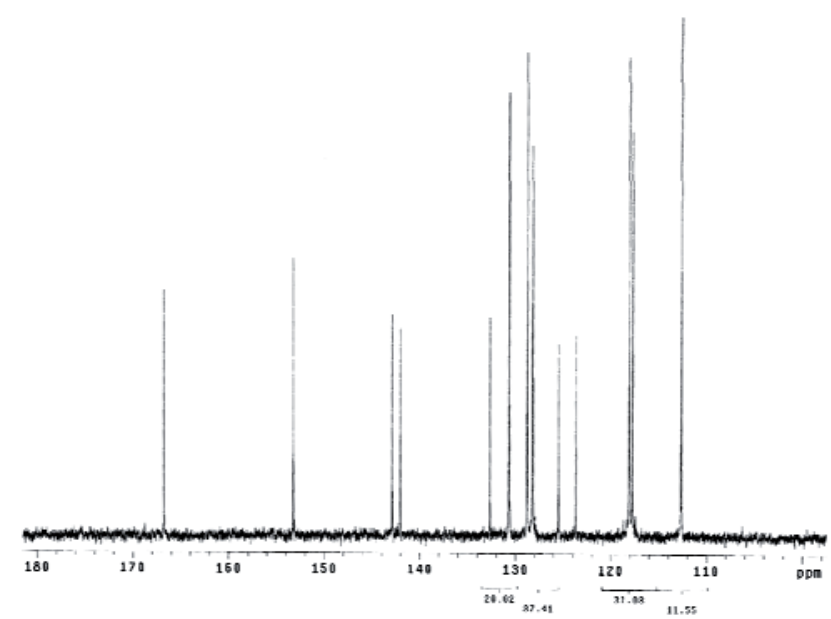

Espectro 18: ${ }^{13} \mathrm{C}-\mathrm{RMN}\left(75,4 \mathrm{MHz}, \mathrm{DMSO}-\mathrm{d}_{6}\right)$ 


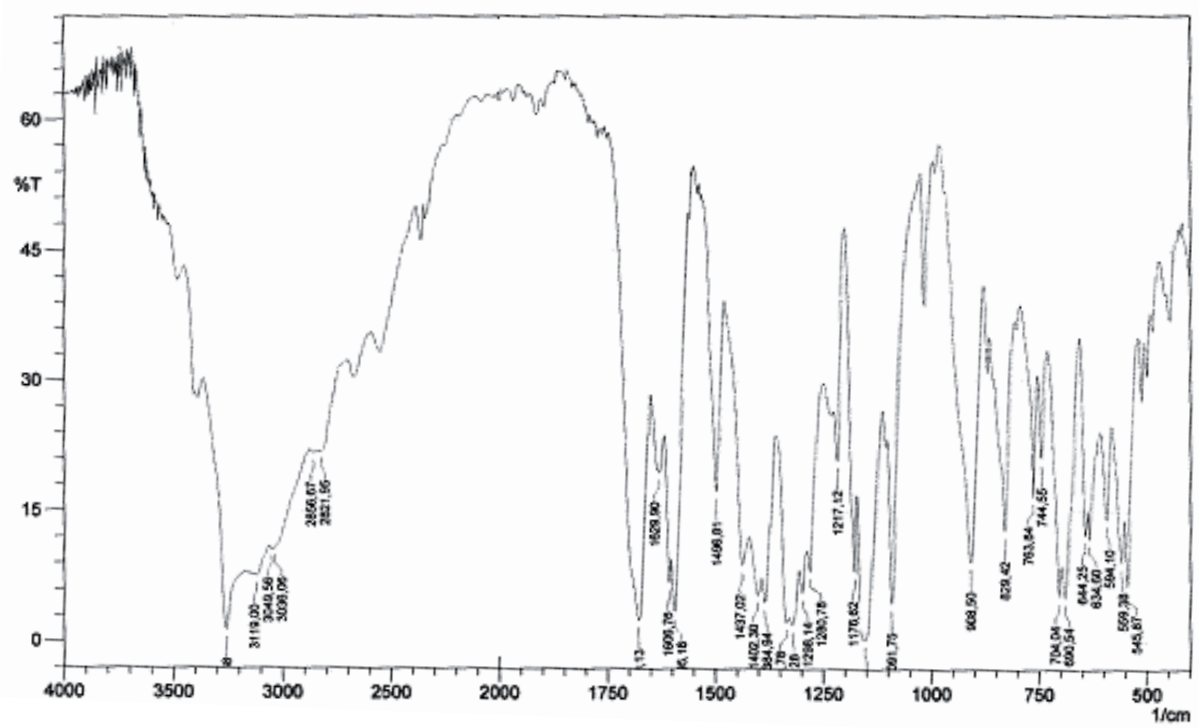

Espectro 19: IR (KBr)

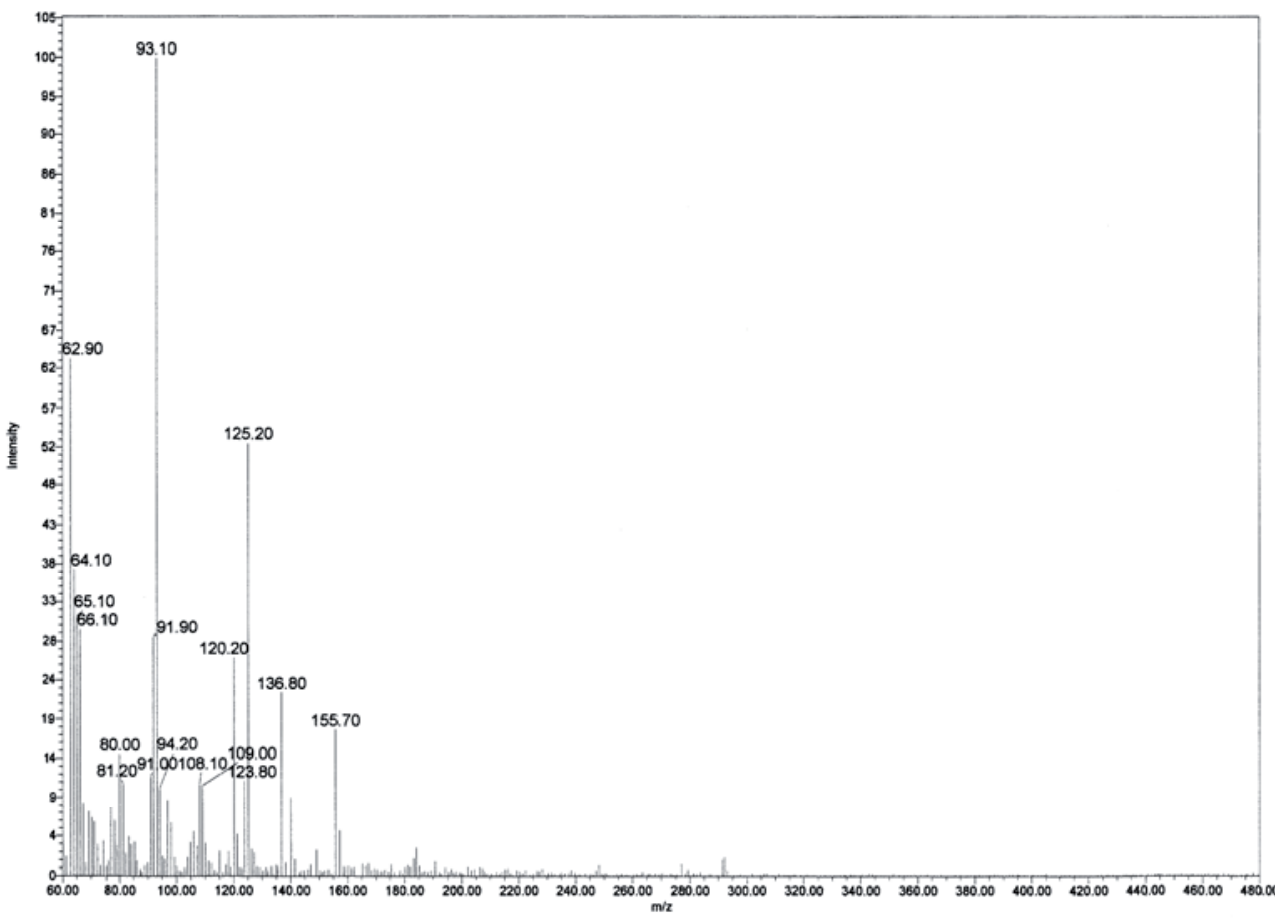

Espectro 20: MS (fragmento, intensidad relativa) 


\section{ESPECTROS DE LOS HAPTENOS TIPO II}

Hapteno S7- Ácido 3-\{4-hidroxi-3-[4-(tiazol-2-ilsulfamoil)fenilazo]fenil\} propanoico
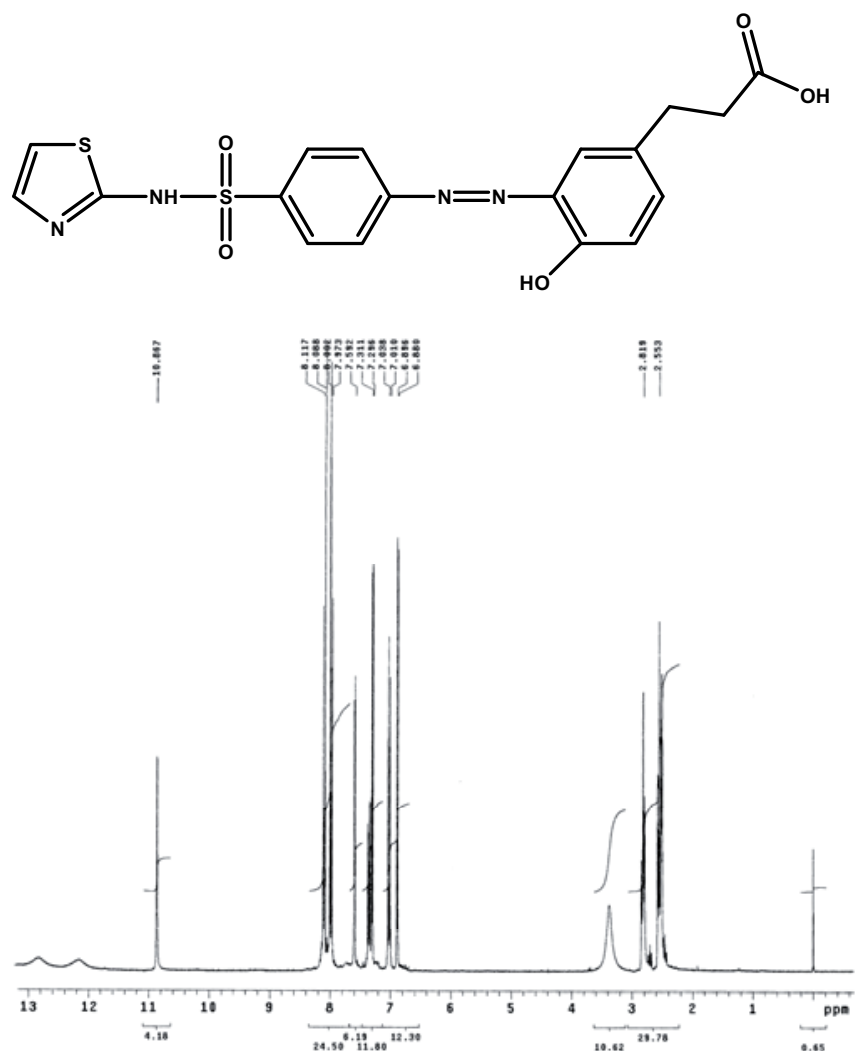

Espectro 21: ${ }^{1} \mathrm{H}-\mathrm{RMN}\left(300 \mathrm{MHz}, \mathrm{DMSO}-\mathrm{d}_{6}\right)$

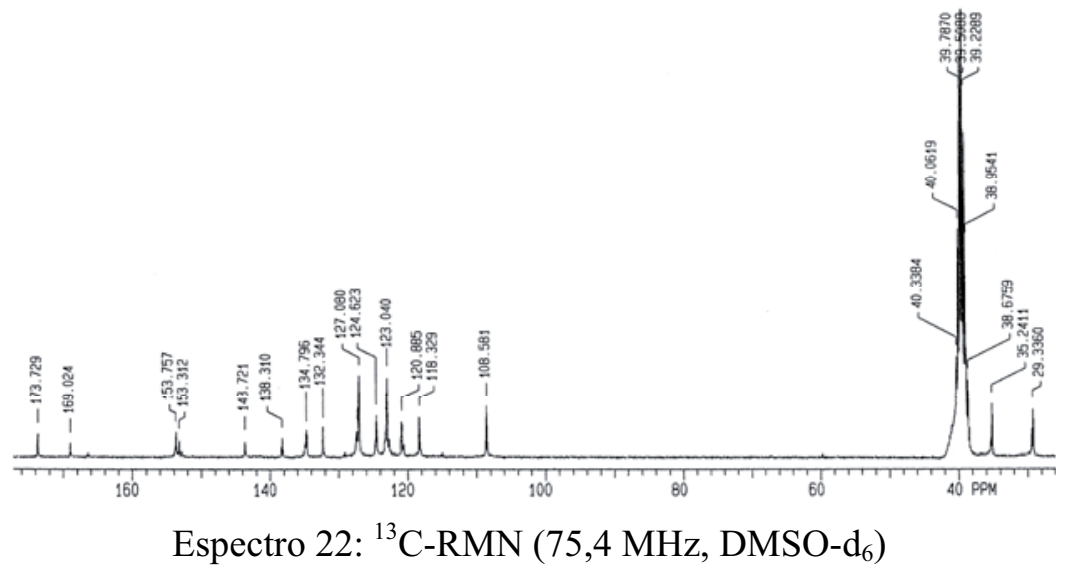



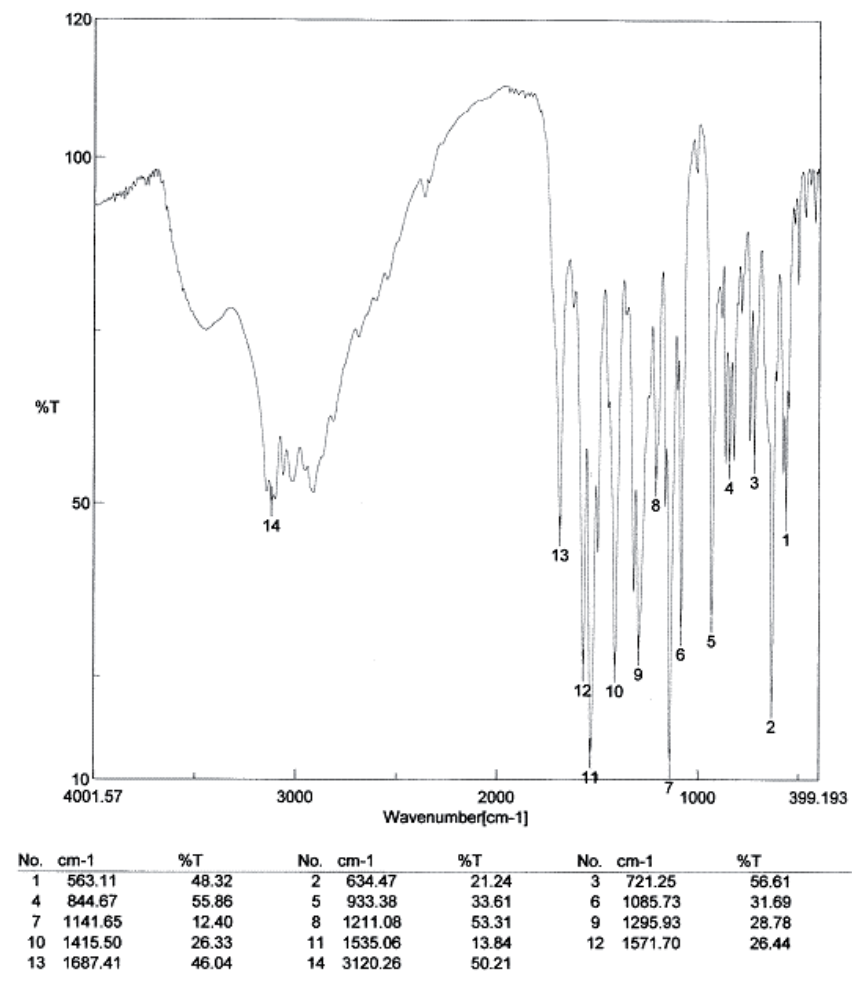

Espectro 23: IR (KBr)

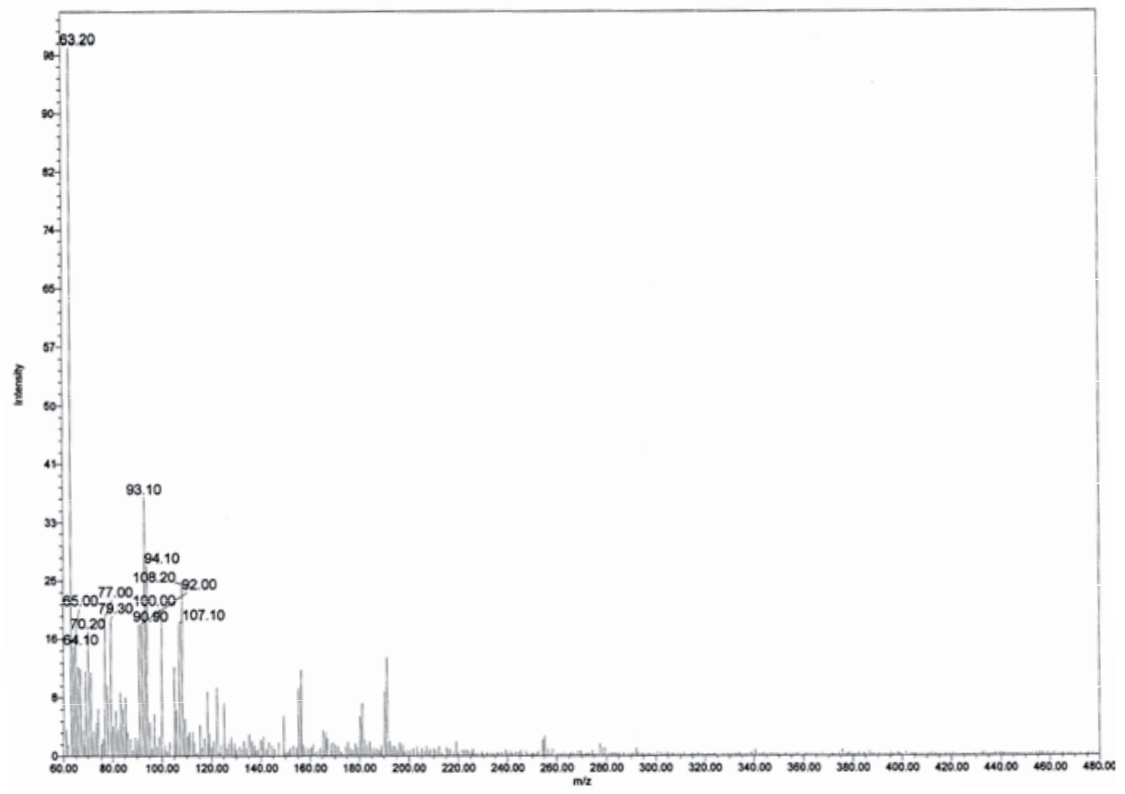

Espectro 24: MS (fragmento, intensidad relativa) 
Hapteno S8- Ácido 3-\{4-hidroxi-3-[4-(pirimidin-2-ilsulfamoil)fenilazo]fenil\} propanoico
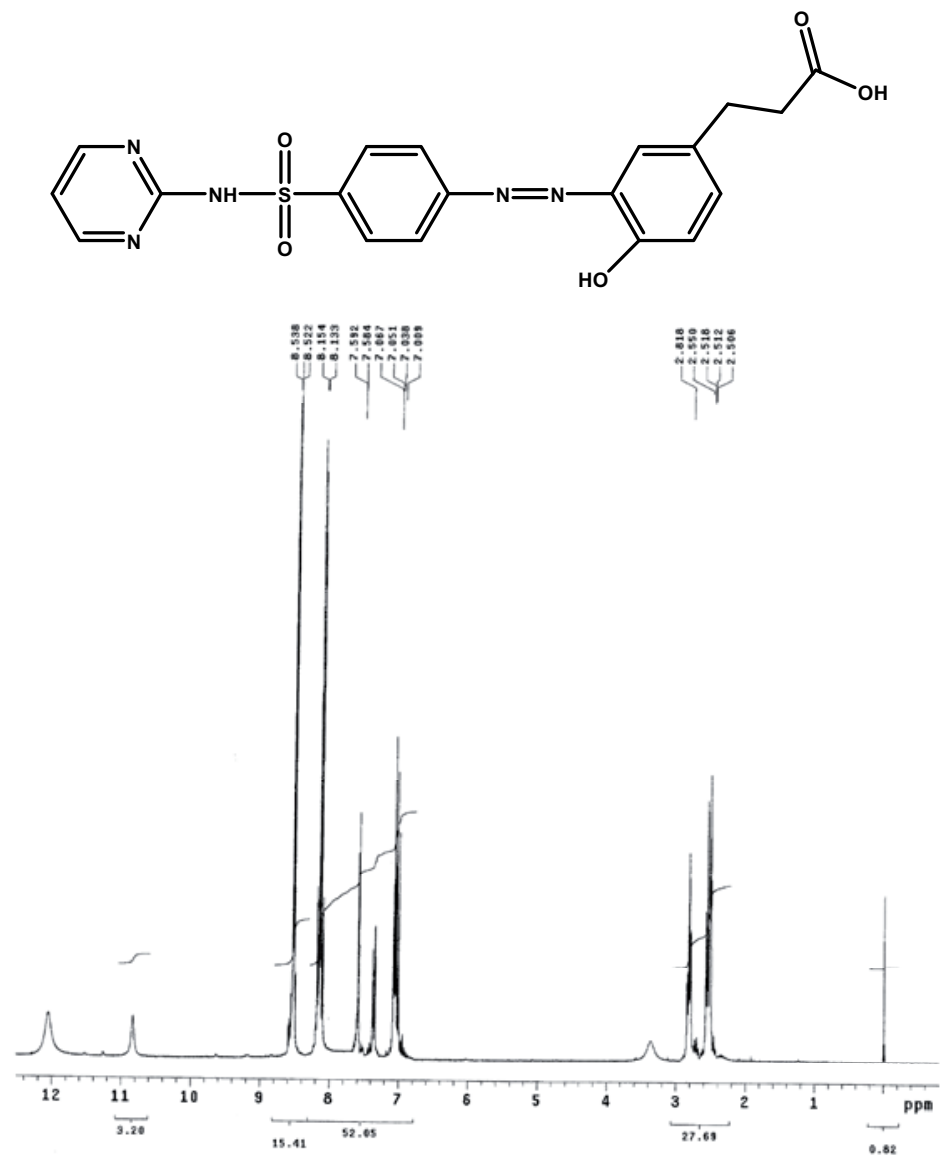

Espectro 25: ${ }^{1} \mathrm{H}-\mathrm{RMN}\left(300 \mathrm{MHz}, \mathrm{DMSO}-\mathrm{d}_{6}\right)$

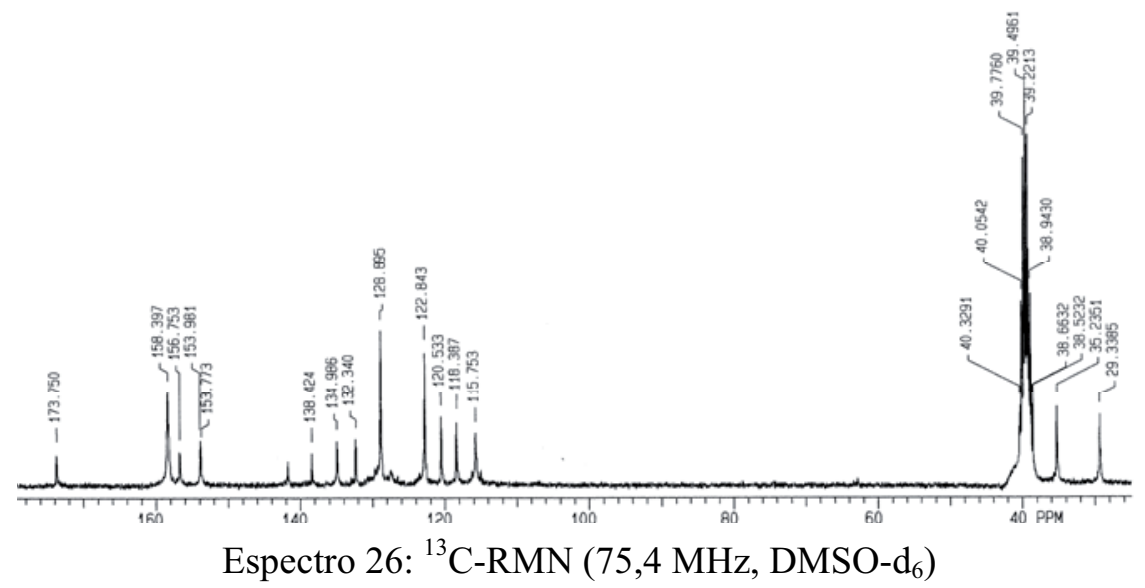




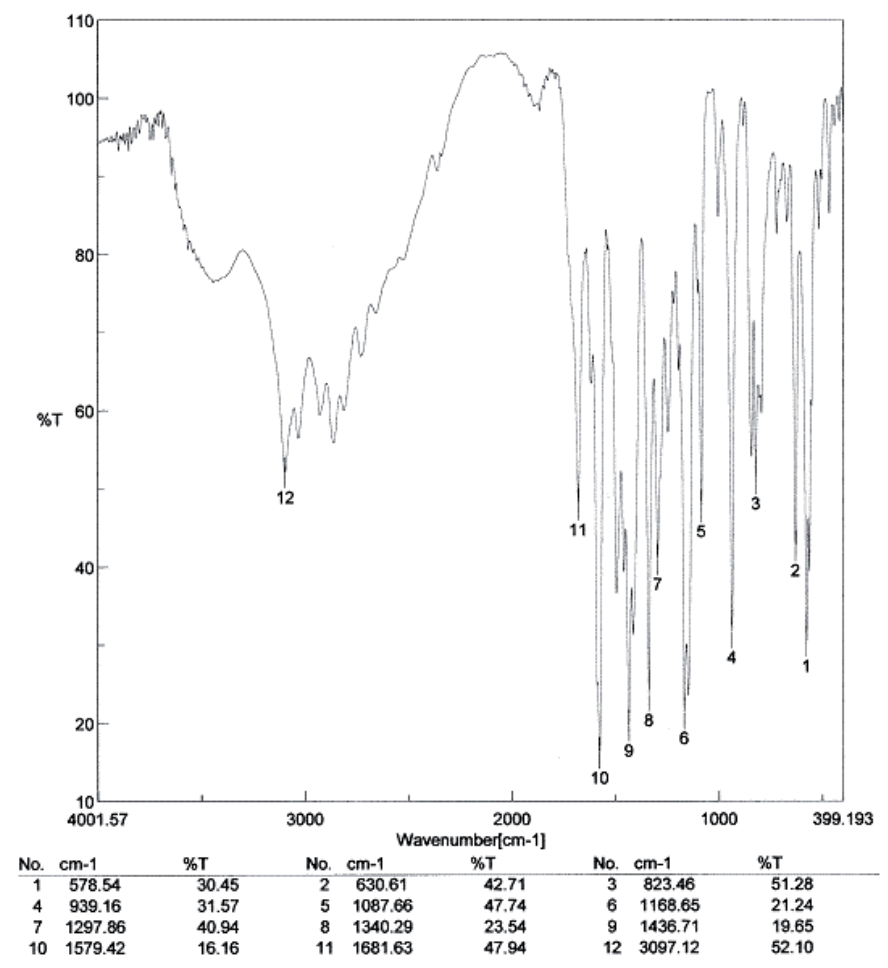

Espectro 27: IR (KBr)

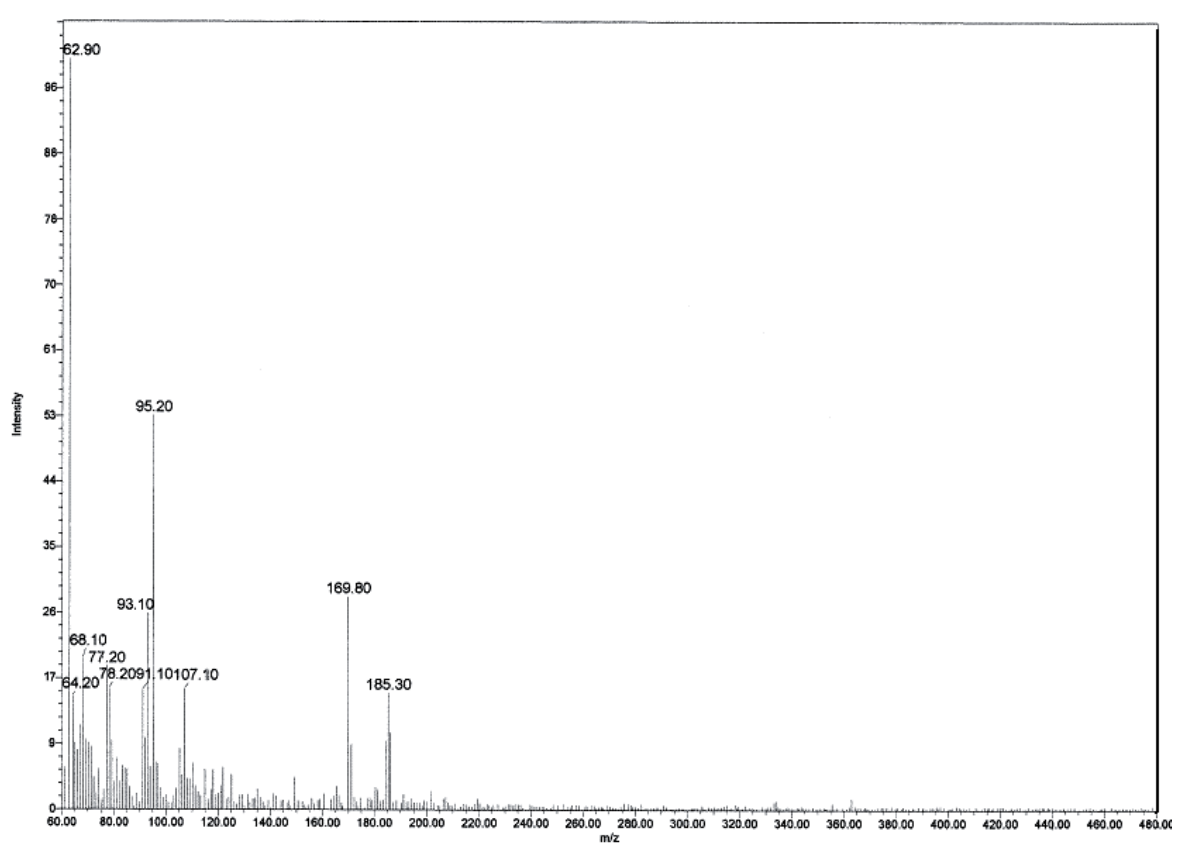

Espectro 28: MS (fragmento, intensidad relativa) 


\section{ESPECTROS DE LOS HAPTENOS TIPO III}

Hapteno S10- Ácido (4-amino-bencenosulfonilamino)acético
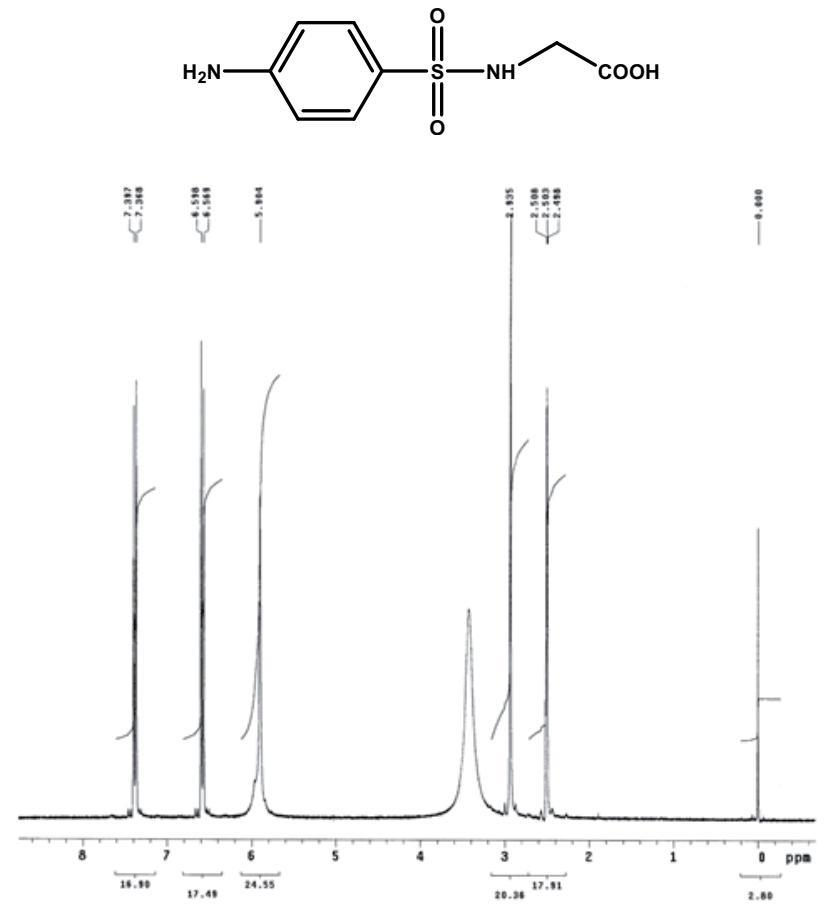

Espectro 29: ${ }^{1} \mathrm{H}-\mathrm{RMN}\left(300 \mathrm{MHz}, \mathrm{DMSO}-\mathrm{d}_{6}\right)$

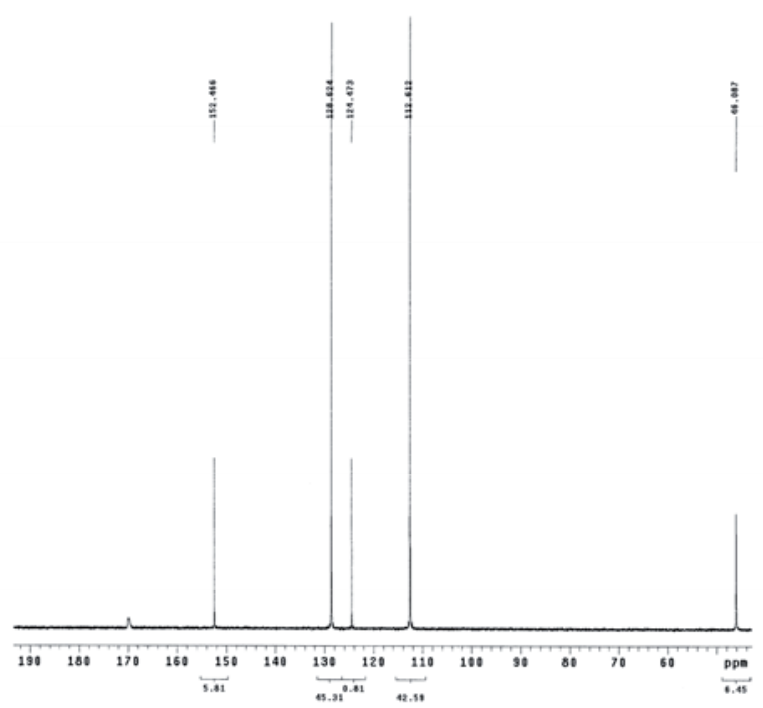

Espectro 30: ${ }^{13} \mathrm{C}-\mathrm{RMN}\left(75,4 \mathrm{MHz}, \mathrm{DMSO}-\mathrm{d}_{6}\right)$ 


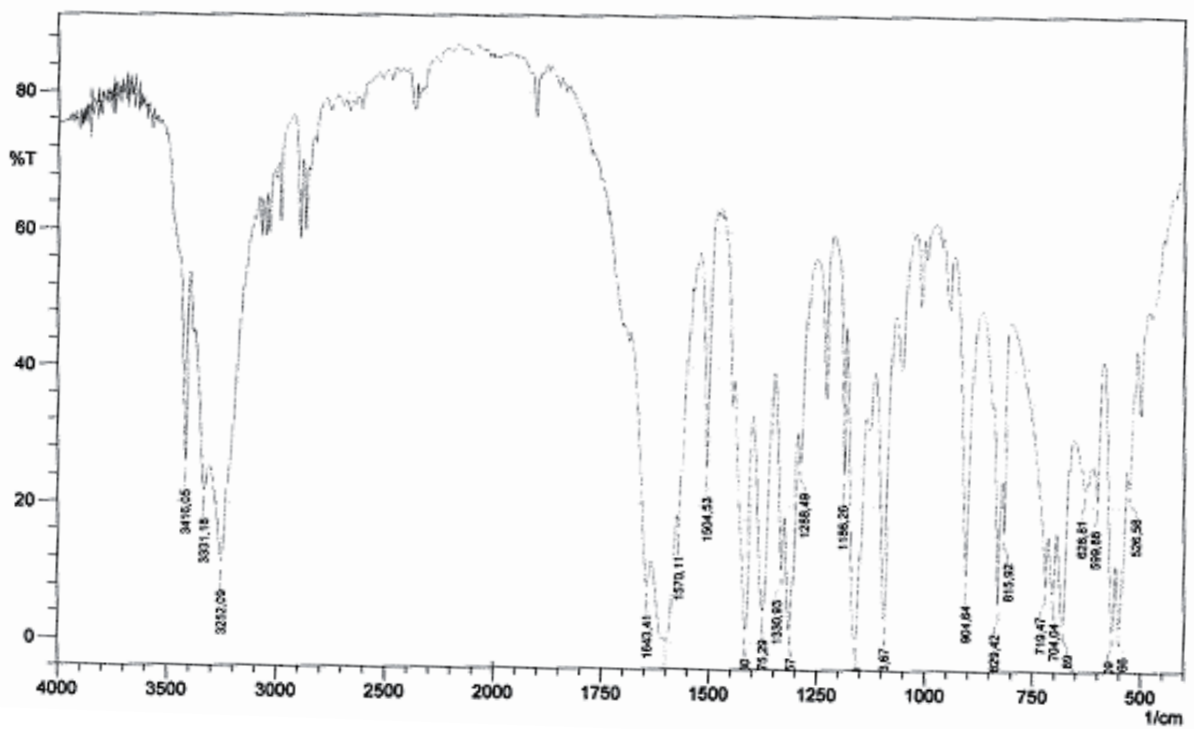

Espectro 31: IR (KBr)

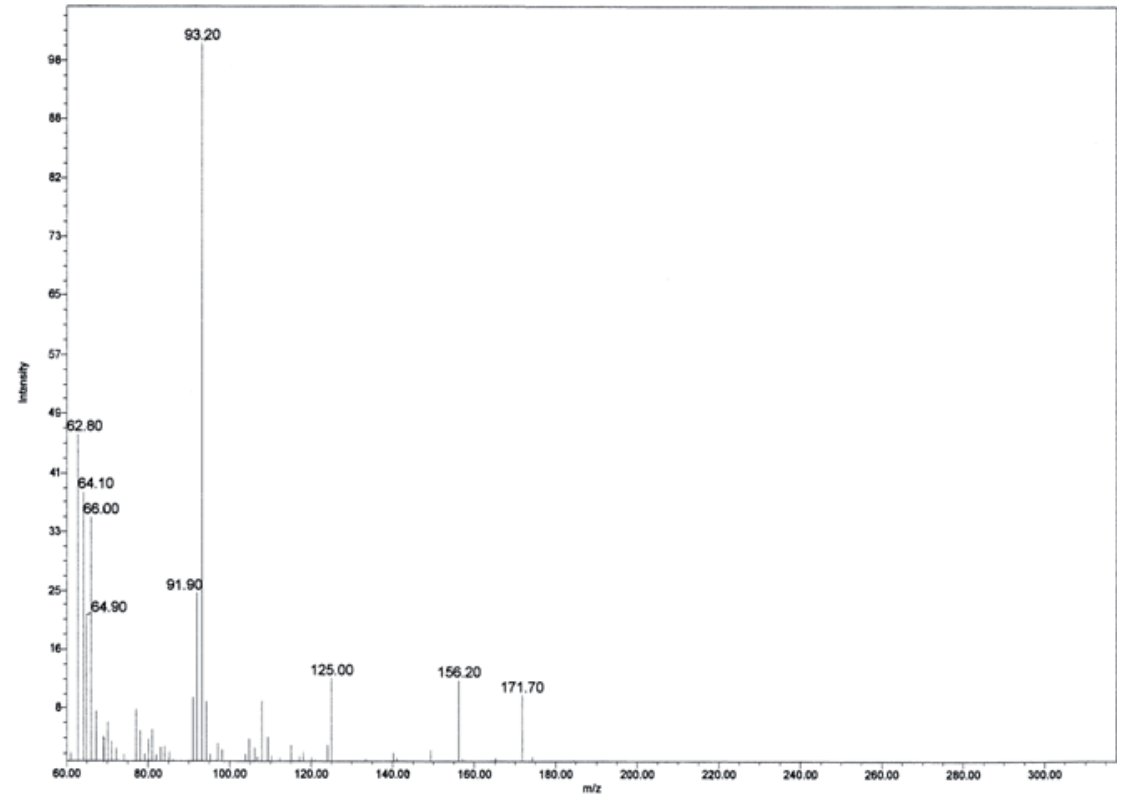

Espectro 32: MS (fragmento, intensidad relativa) 


\section{Hapteno S11- Ácido 6-(4-amino-bencenosulfonilamino)hexanoico}<smiles>Nc1ccc(S(=O)(=O)NCCCCCC(=O)O)cc1</smiles>

翌

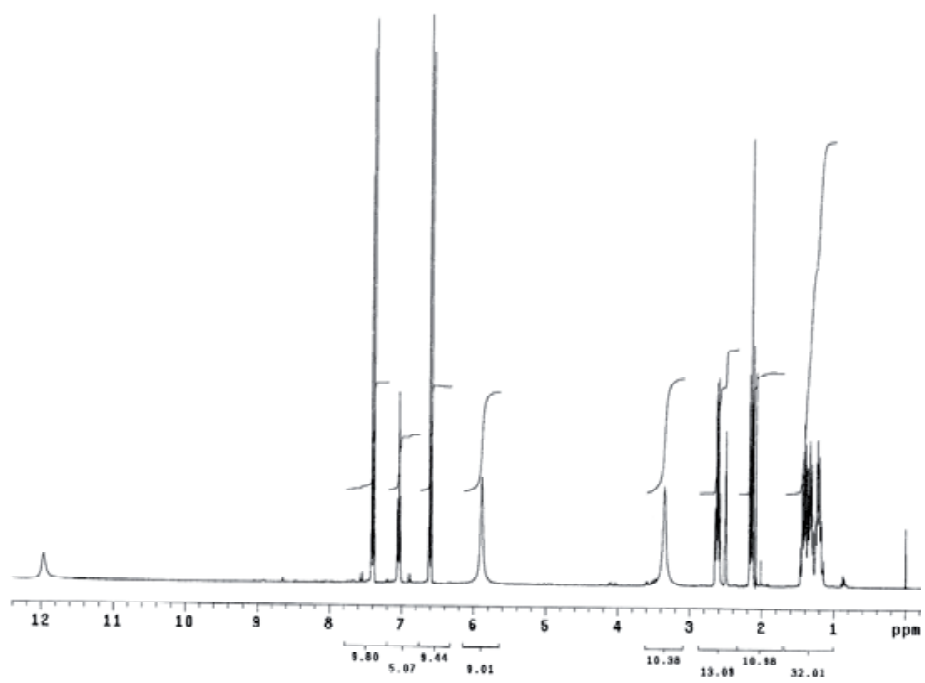

Espectro 33: ${ }^{1} \mathrm{H}-\mathrm{RMN}\left(300 \mathrm{MHz}, \mathrm{DMSO}-\mathrm{d}_{6}\right)$

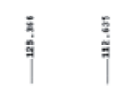

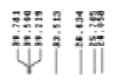

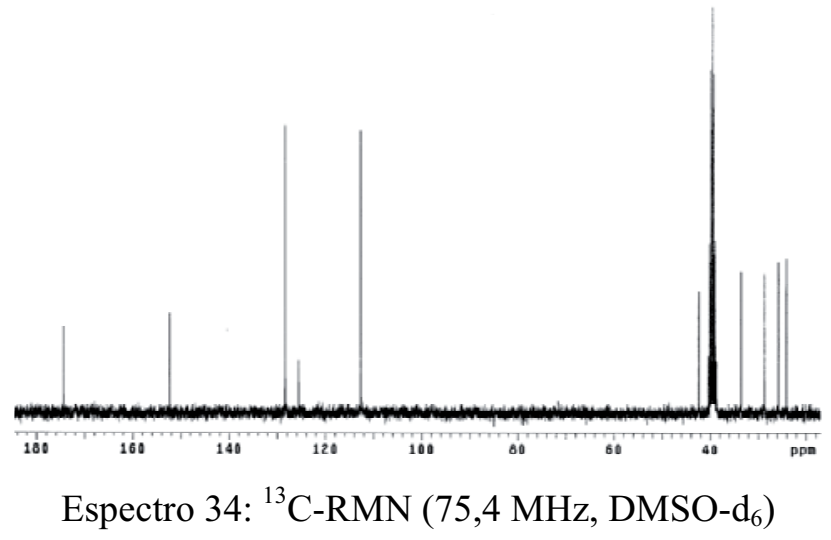




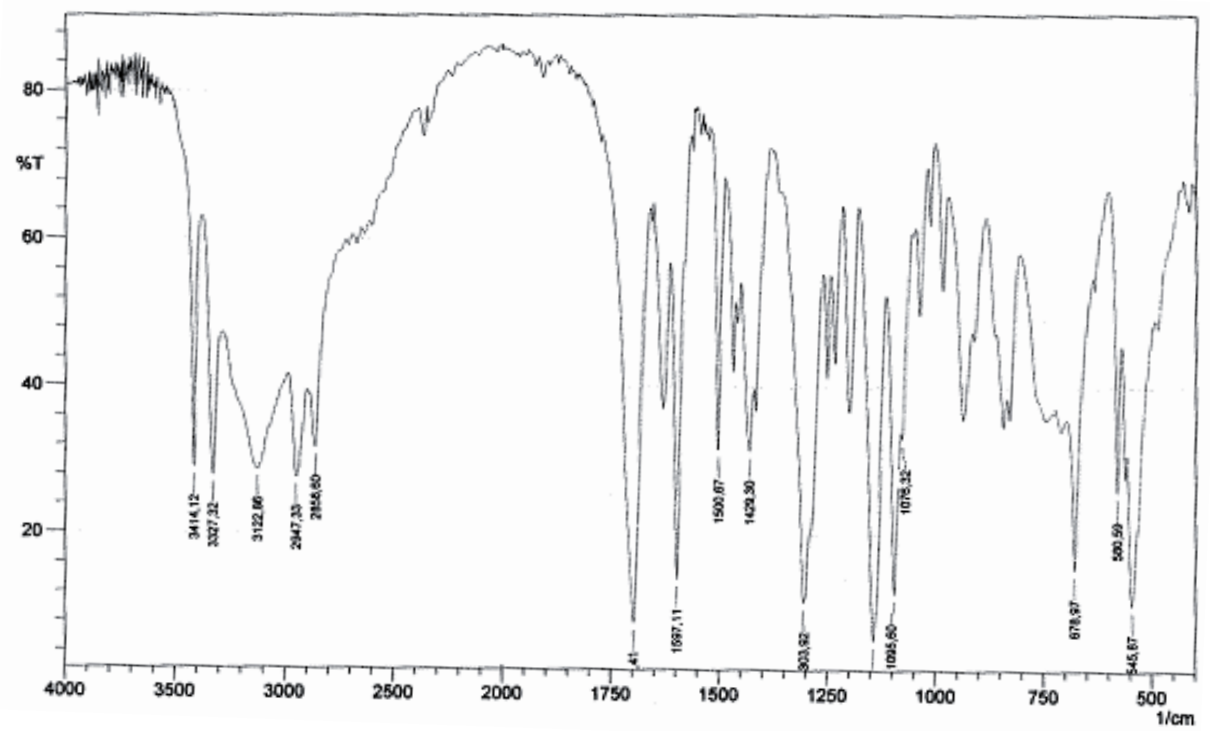

Espectro 35: IR (KBr)

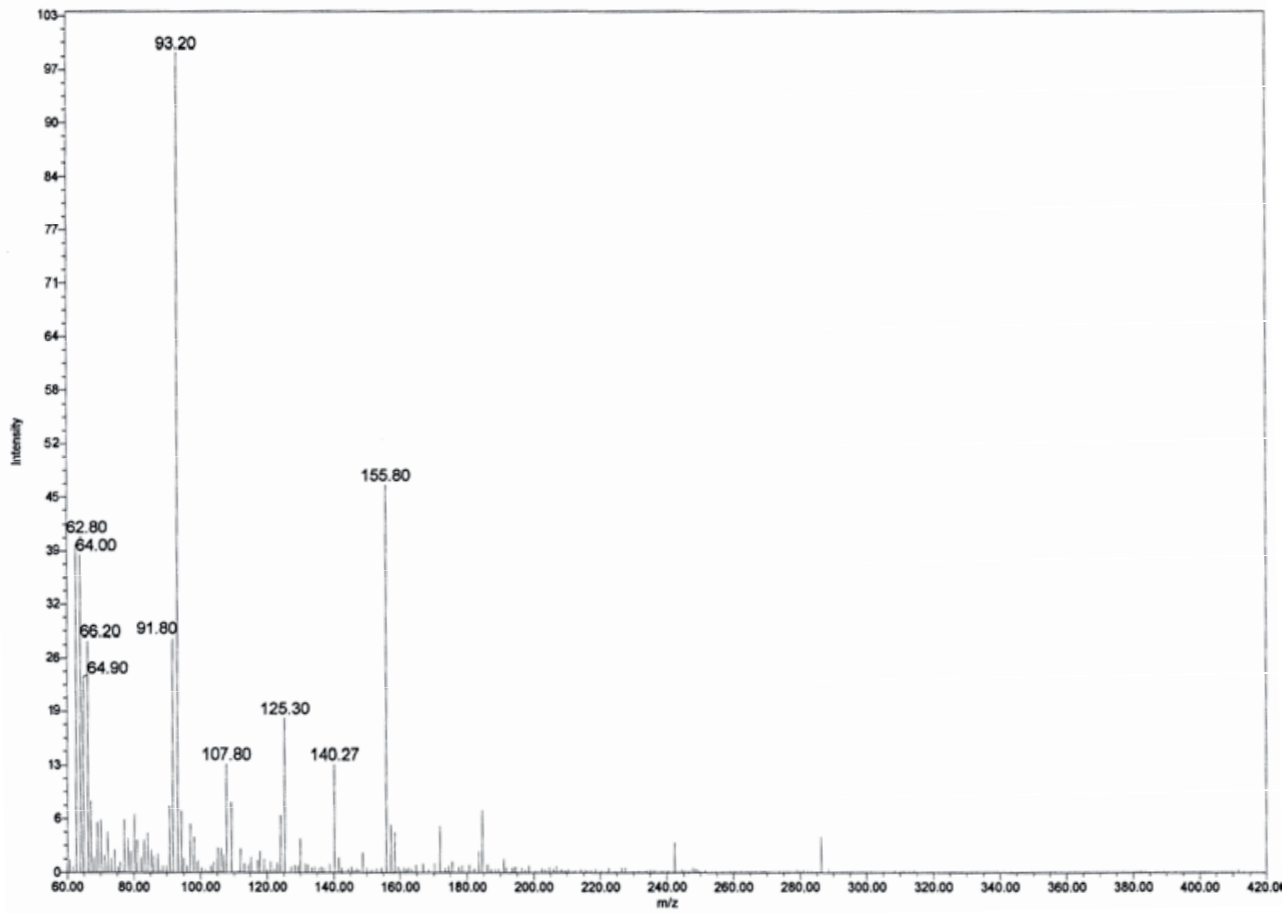

Espectro 36: MS (fragmento, intensidad relativa) 
Hapteno S12- 4-Amino- $N$-(3-hidroxipropil)bencenosulfonamida<smiles>Nc1ccc(S(=O)(=O)NCCCO)cc1</smiles>

ไู่
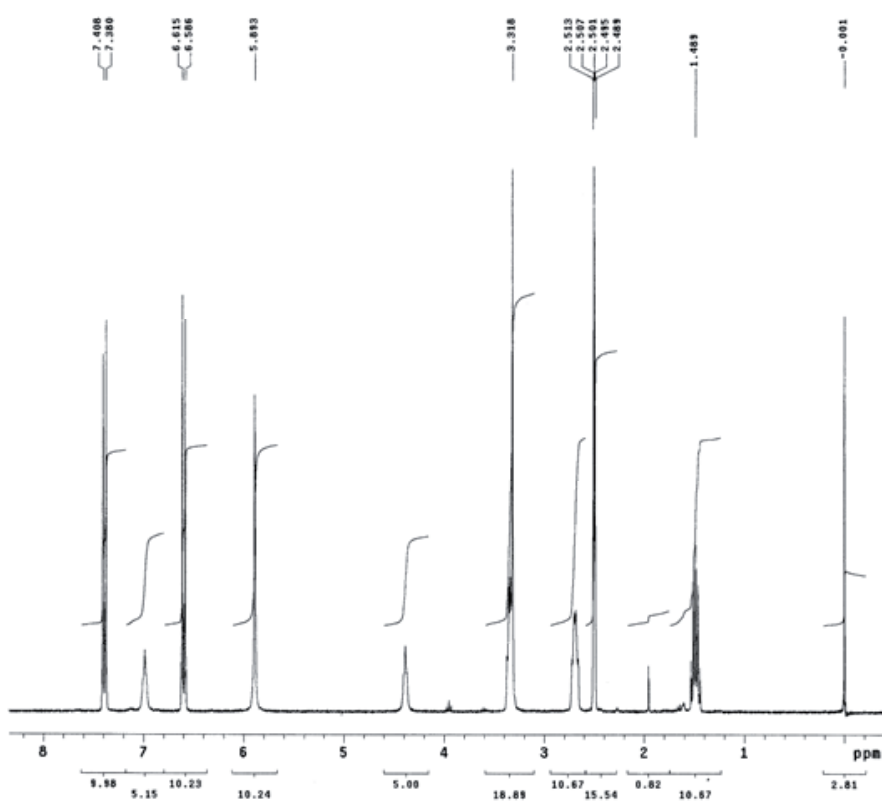

Espectro 37: ${ }^{1} \mathrm{H}-\mathrm{RMN}\left(300 \mathrm{MHz}, \mathrm{DMSO}-\mathrm{d}_{6}\right)$

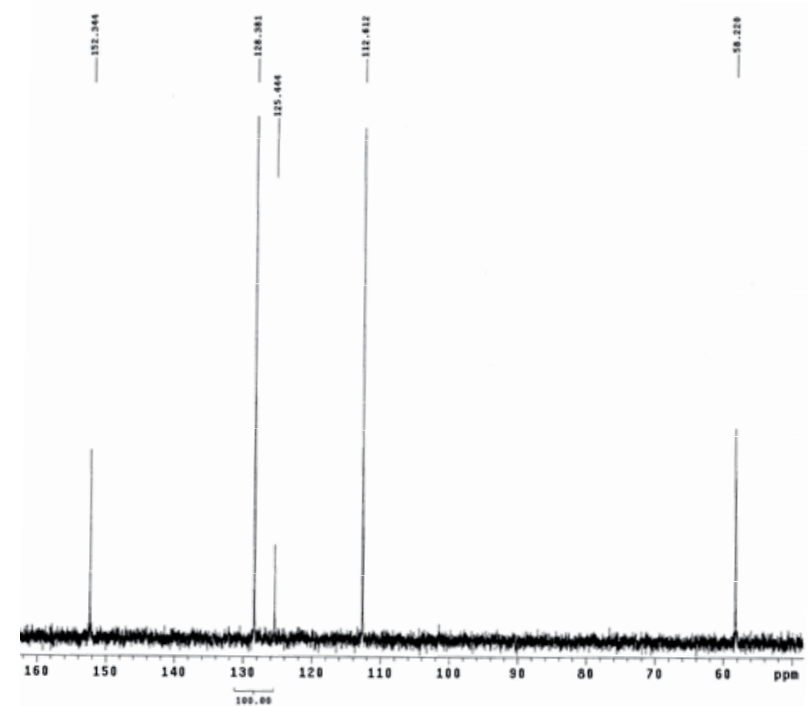

Espectro 38: ${ }^{13} \mathrm{C}-\mathrm{RMN}\left(75,4 \mathrm{MHz}, \mathrm{DMSO}-\mathrm{d}_{6}\right)$ 


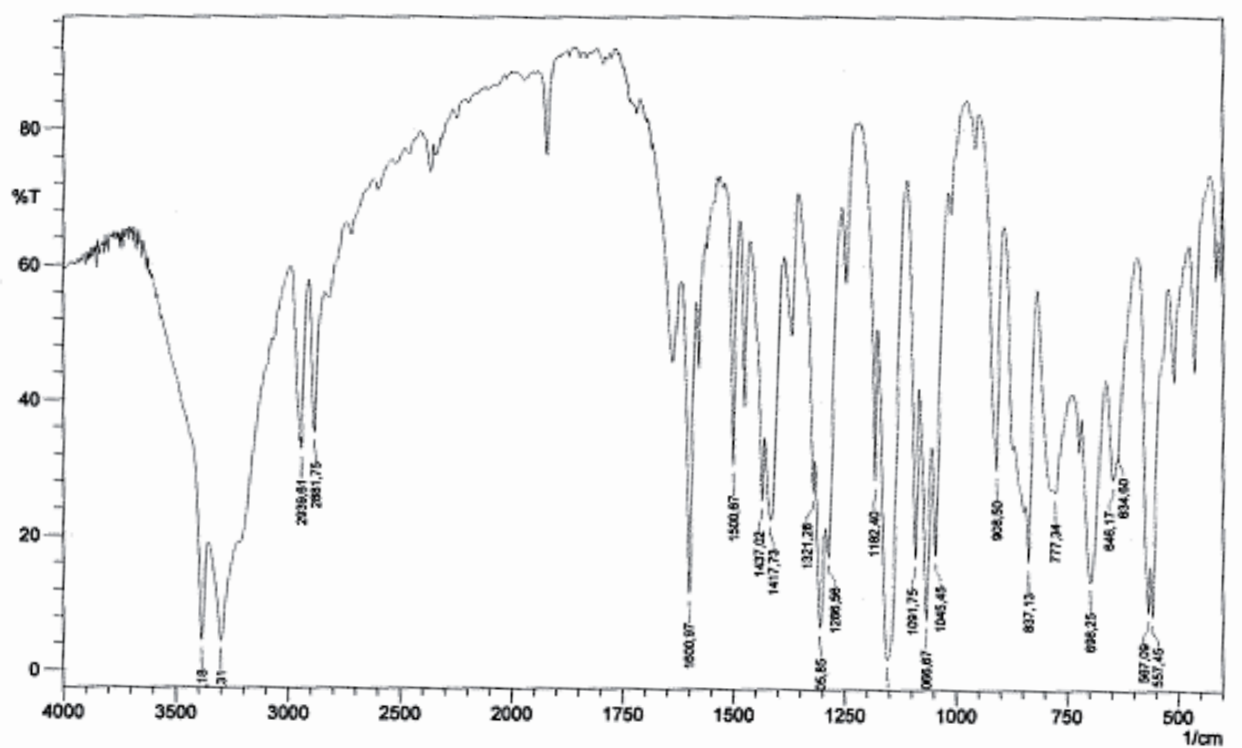

Espectro 39: IR (KBr)

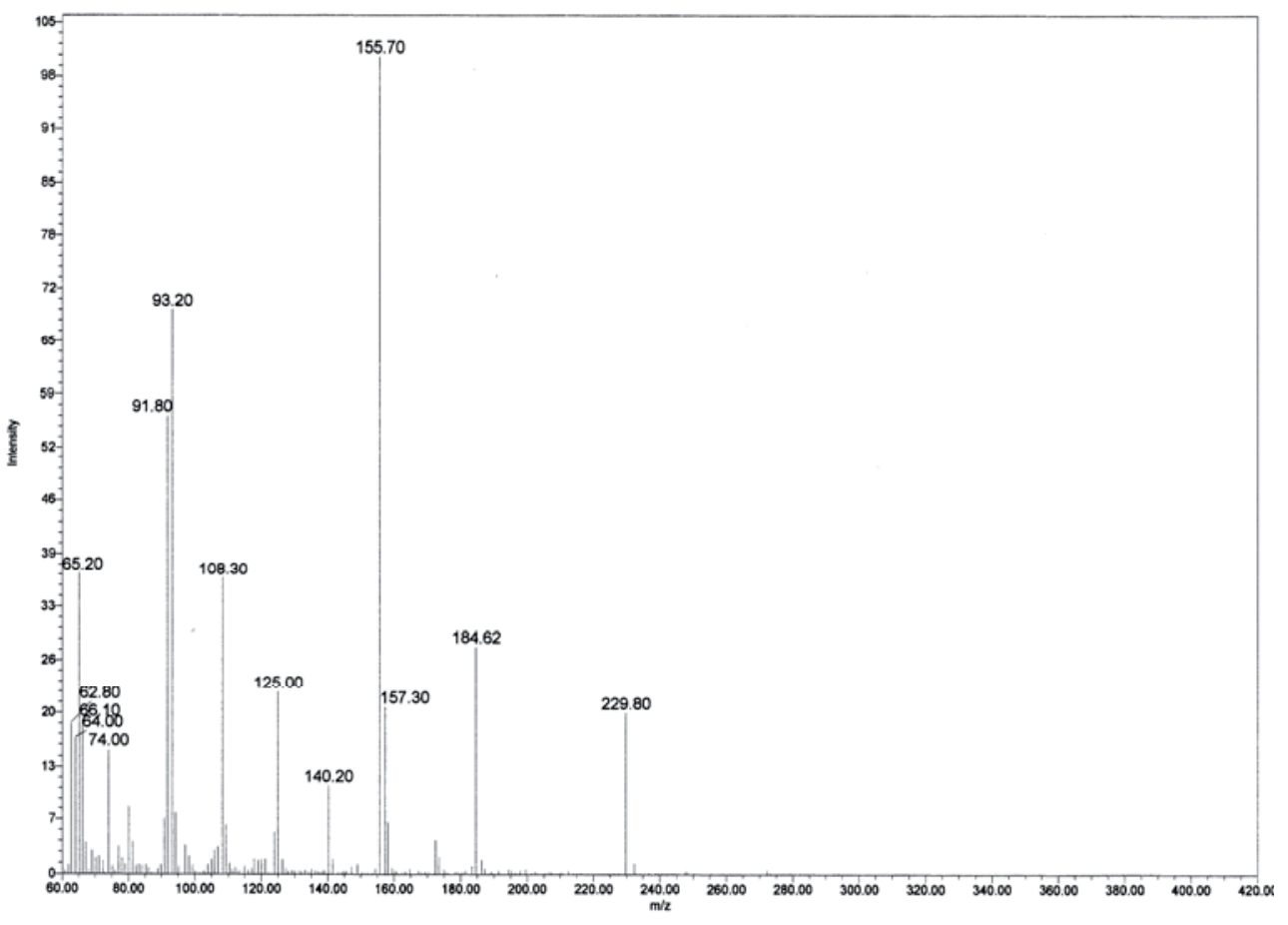

Espectro 40: MS (fragmento, intensidad relativa) 
Hapteno S13- Ácido 4-(4-amino-bencenosulfonilamino)butanoico<smiles>Nc1ccc(S(=O)(=O)NCCCC(=O)O)cc1</smiles>

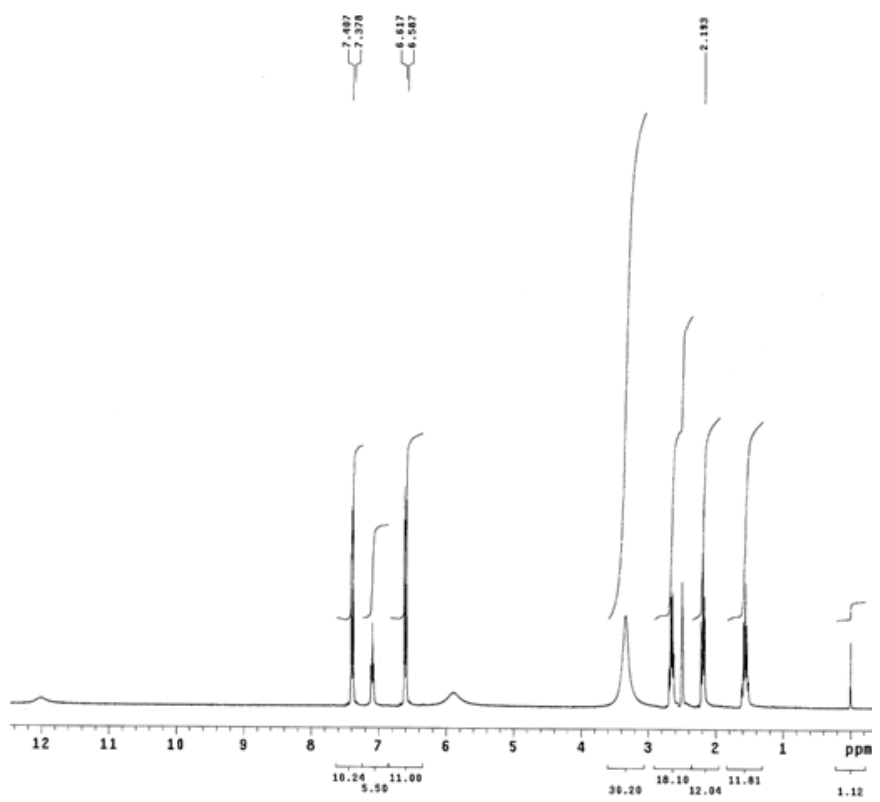

Espectro 41: ${ }^{1} \mathrm{H}-\mathrm{RMN}\left(300 \mathrm{MHz}, \mathrm{DMSO}-\mathrm{d}_{6}\right.$ )

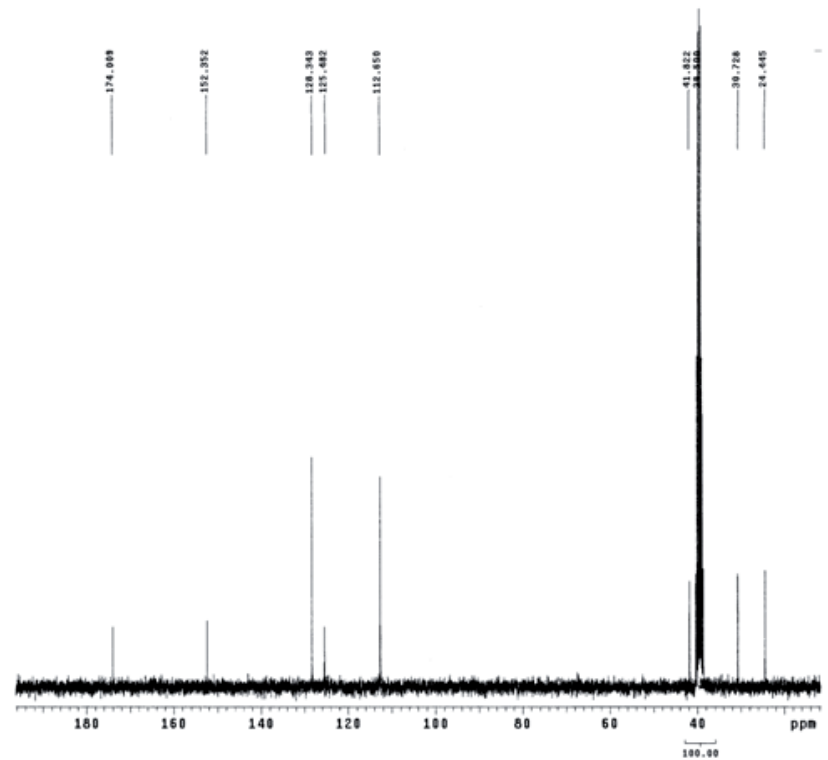

Espectro 42: ${ }^{13} \mathrm{C}-\mathrm{RMN}\left(75,4 \mathrm{MHz}, \mathrm{DMSO}-\mathrm{d}_{6}\right)$ 


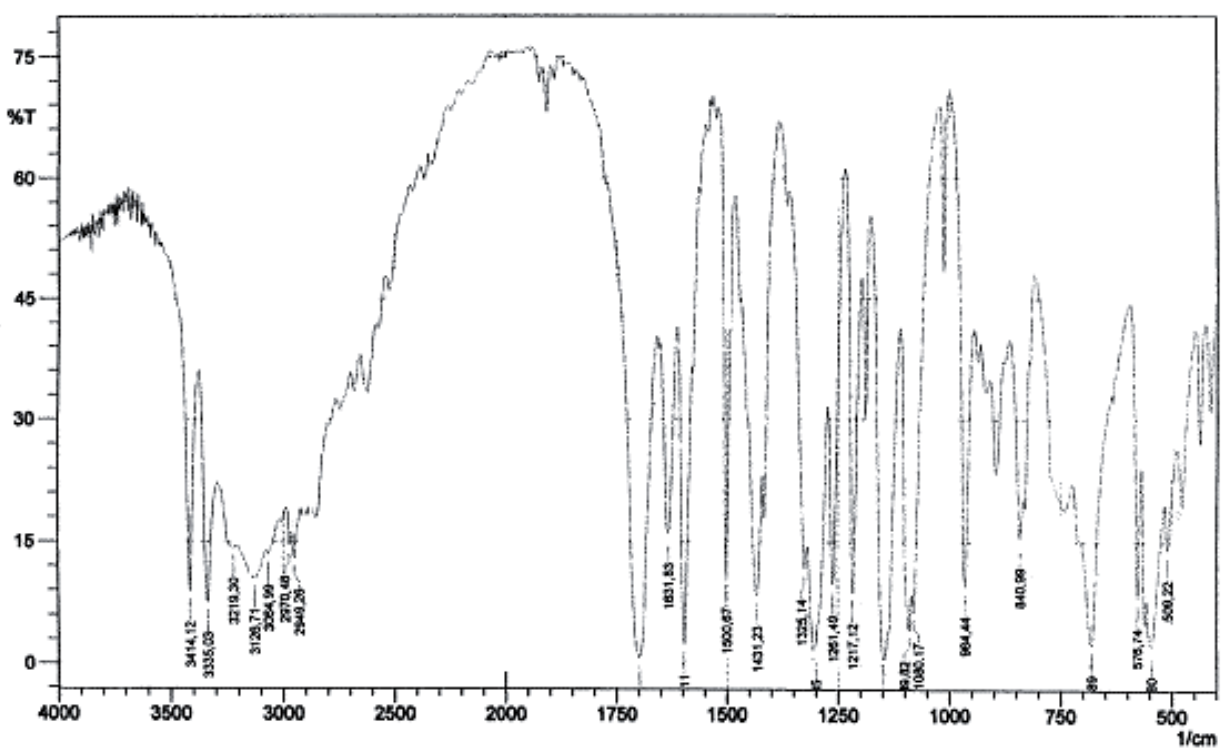

Espectro 43: IR (KBr)

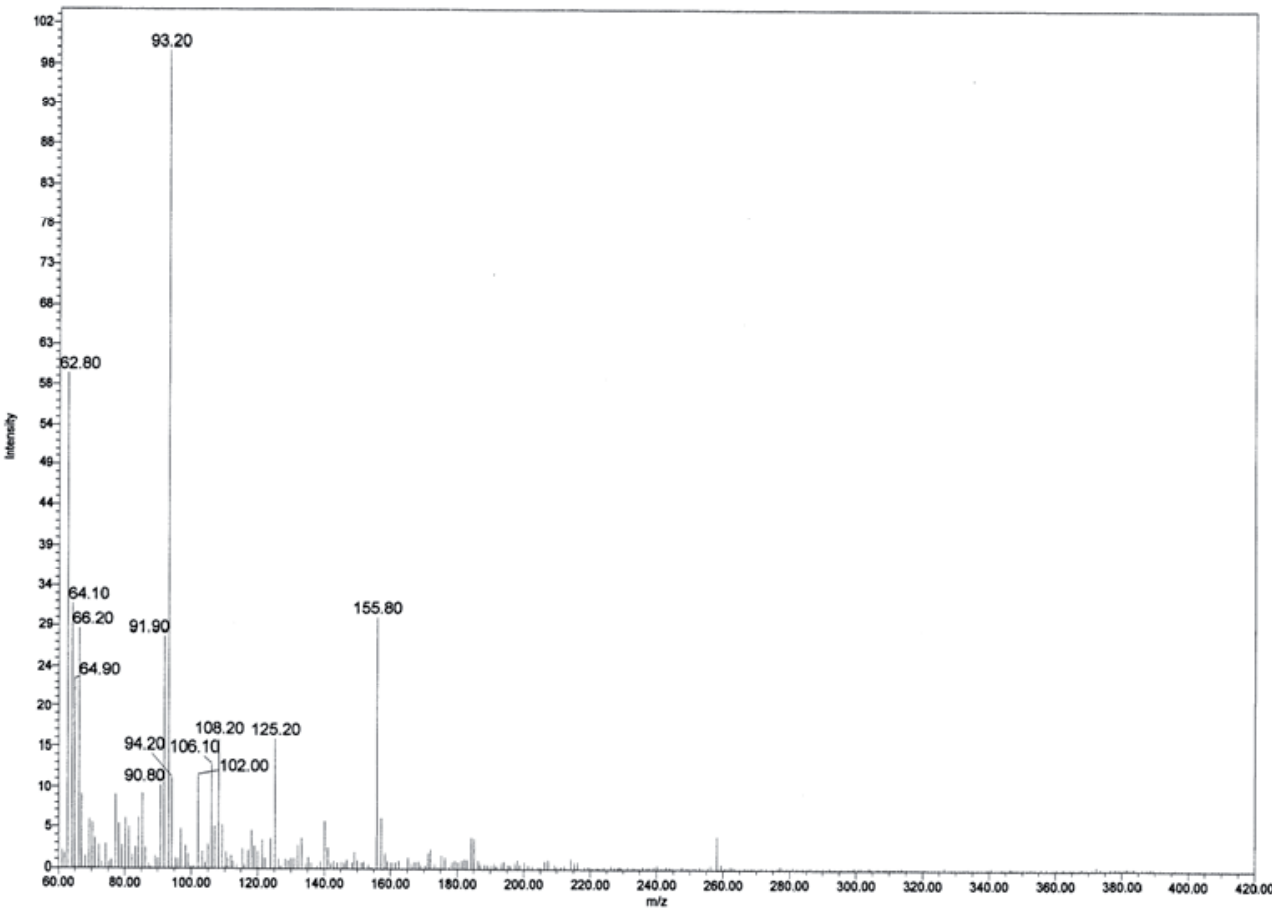

Espectro 44: MS (fragmento, intensidad relativa) 


\section{TETRACICLINAS}

\section{ESPECTROS DE LOS HAPTENOS TIPO I}

CTC- Clortetraciclina<smiles>CCOC1=C(O)C([N+](=O)[O-])C2CC3C(=O)c4c(O)ccc(Cl)c4C(C)(O)C3=C(O)C2(O)C(=O)C1=O</smiles>

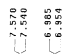

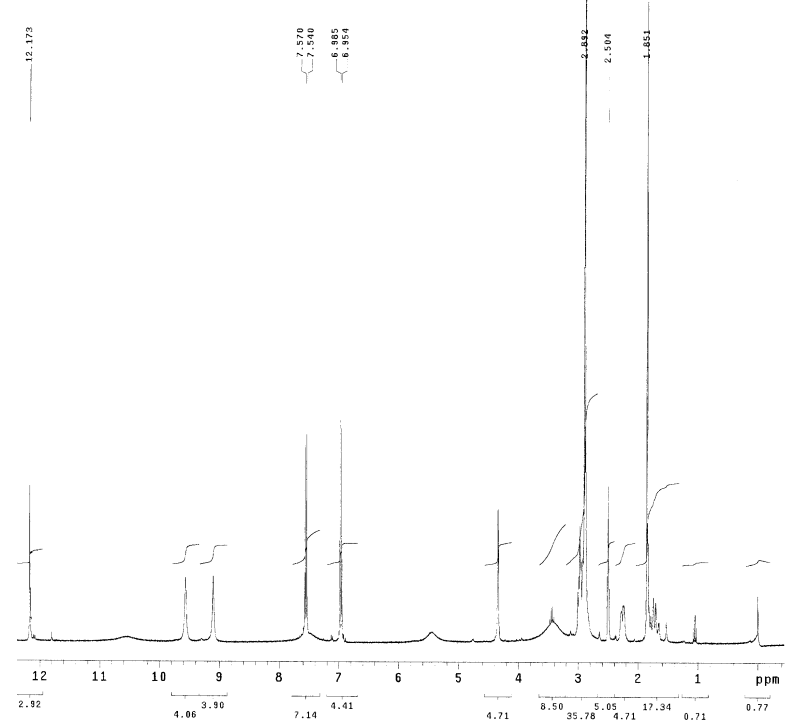

Espectro 45: ${ }^{1} \mathrm{H}-\mathrm{RMN}\left(300 \mathrm{MHz}, \mathrm{DMSO}-\mathrm{d}_{6}\right.$ )

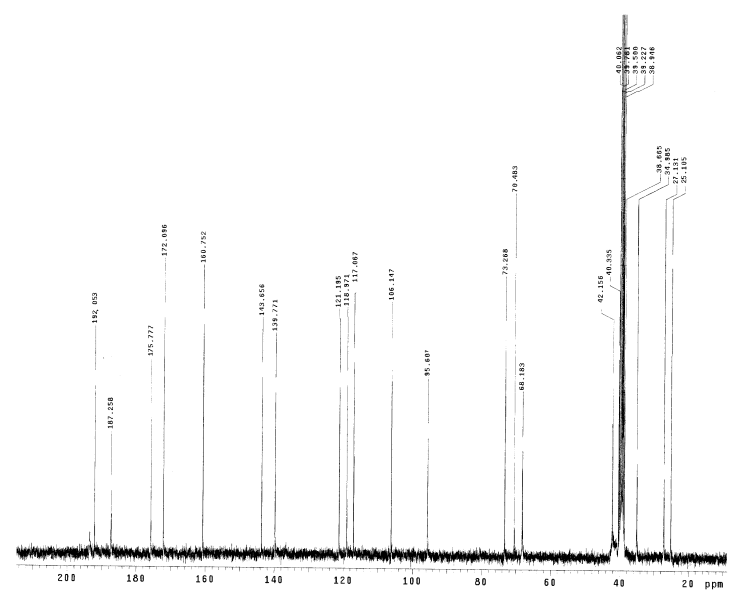

Espectro 46: ${ }^{13} \mathrm{C}-\mathrm{RMN}\left(75,4 \mathrm{MHz}, \mathrm{DMSO}-\mathrm{d}_{6}\right)$ 
Hapteno CTC-2- Glicinametilclortetraciclina

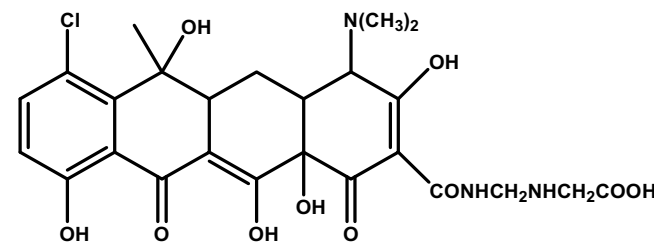

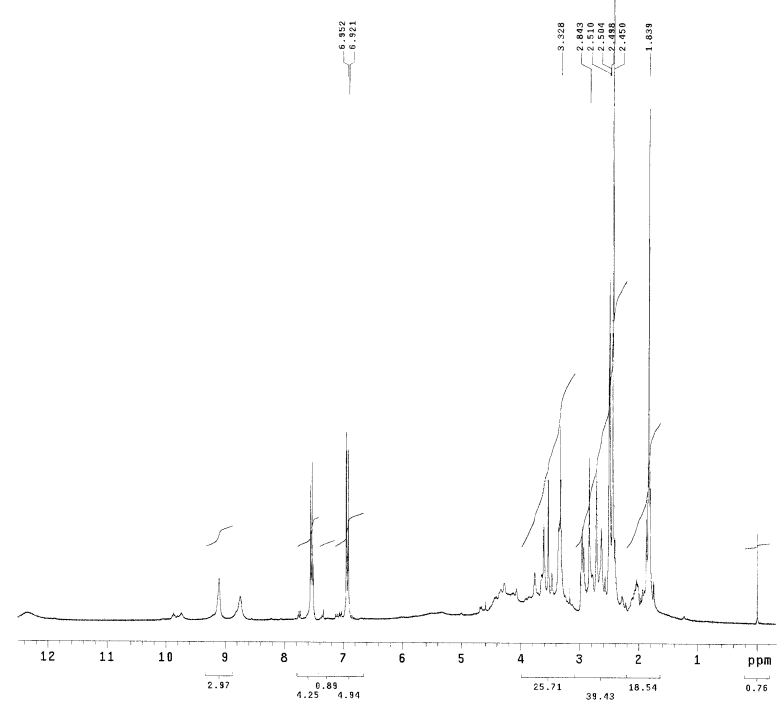

Espectro 47: ${ }^{1} \mathrm{H}-\mathrm{RMN}$ (300 MHz, DMSO-d ${ }_{6}$ )

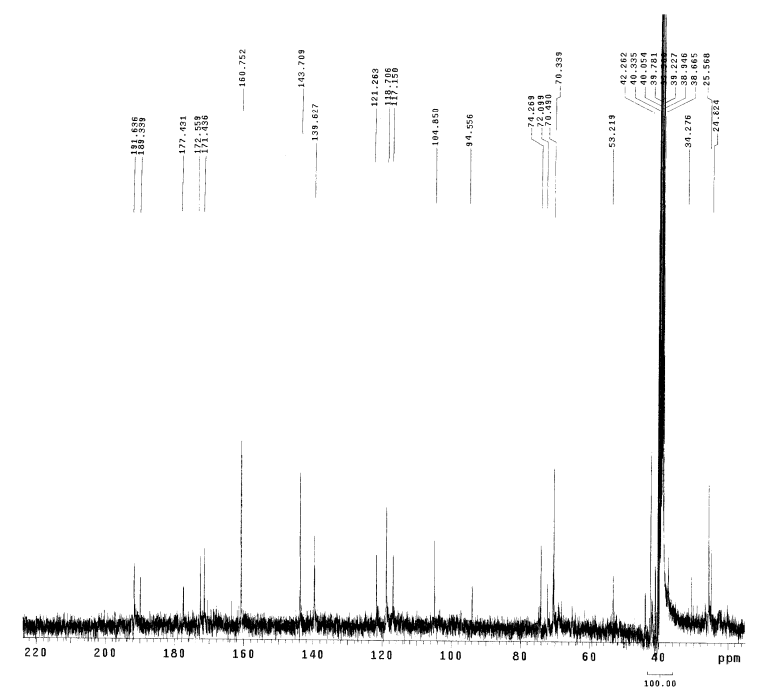

Espectro $48:{ }^{13} \mathrm{C}-\mathrm{RMN}\left(75,4 \mathrm{MHz}, \mathrm{DMSO}^{-} \mathrm{d}_{6}\right)$ 

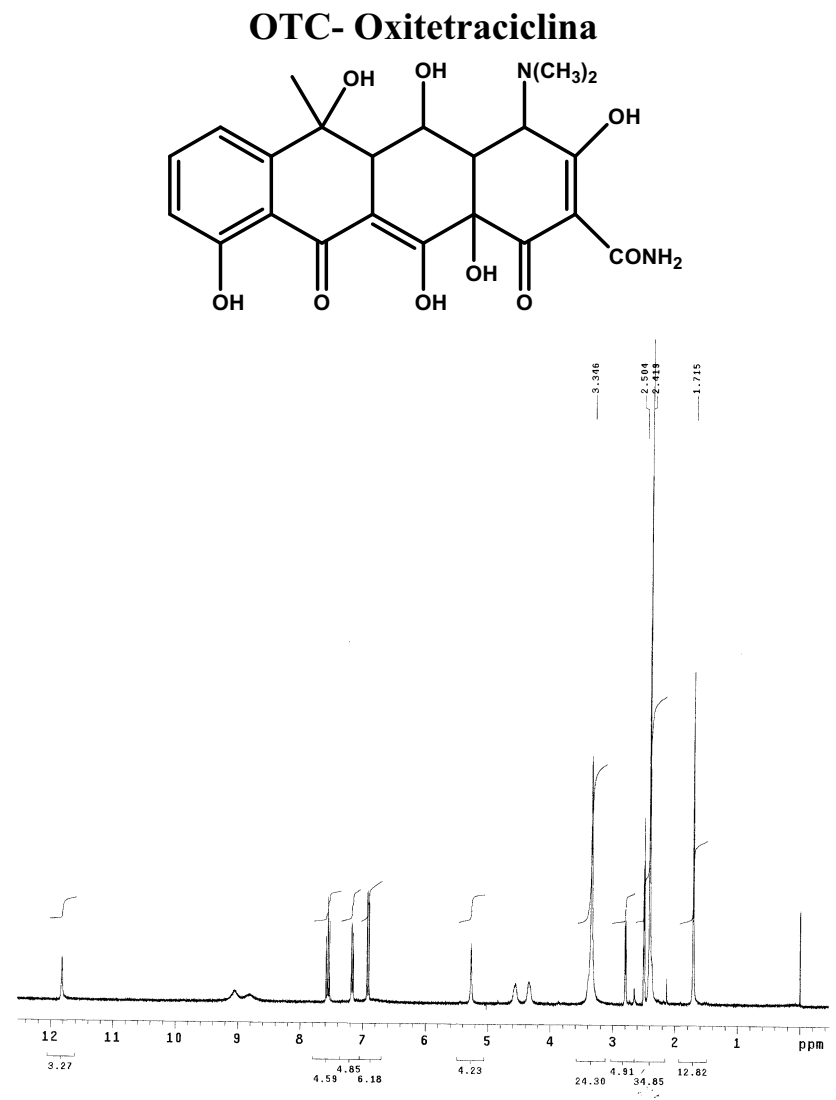

Espectro 49: ${ }^{1} \mathrm{H}-\mathrm{RMN}\left(300 \mathrm{MHz}, \mathrm{DMSO}-\mathrm{d}_{6}\right.$ )

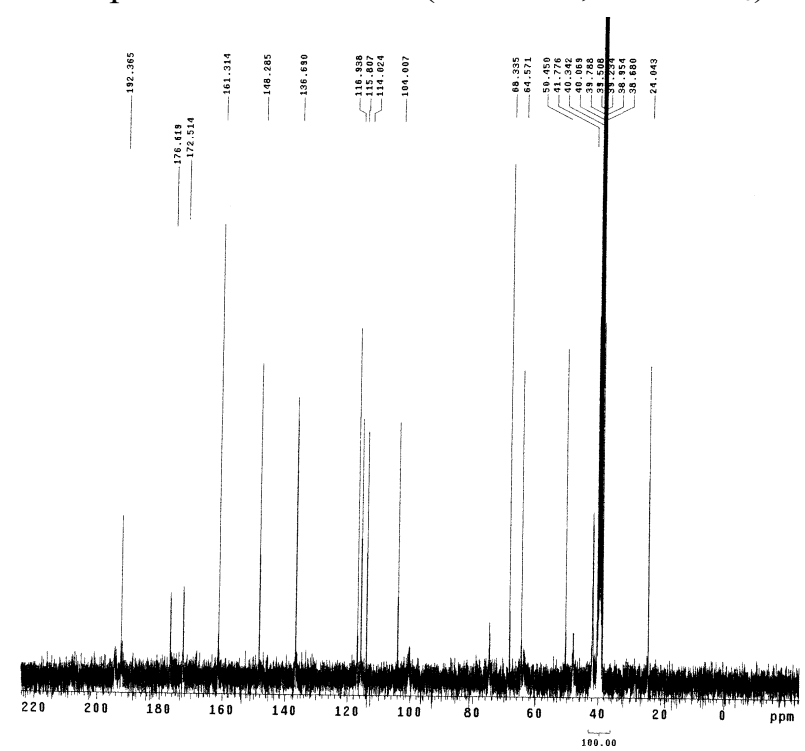

Espectro 50: ${ }^{13} \mathrm{C}-\mathrm{RMN}\left(75,4 \mathrm{MHz}, \mathrm{DMSO}^{-\mathrm{d}_{6}}\right)$ 
Hapteno OTC-2- Hidrocloruro de glicinametiloxitetraciclina<smiles>CC1(O)c2cccc(O)c2C(=O)C2=C(O)C3(O)C(=O)C(OCCCO)=C(O)C(O)C3C(O)C21</smiles>

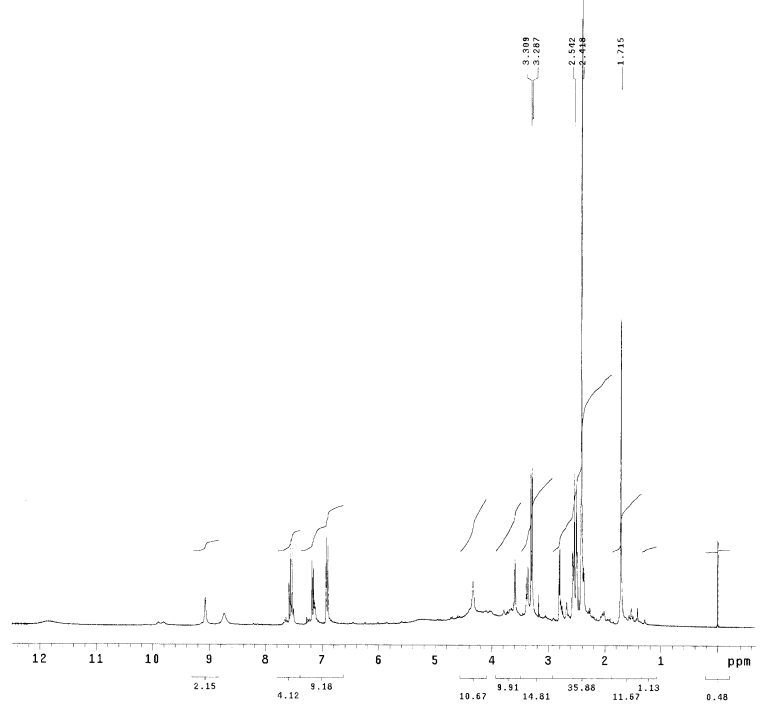

Espectro 51: ${ }^{1} \mathrm{H}-\mathrm{RMN}\left(300 \mathrm{MHz}, \mathrm{DMSO}-\mathrm{d}_{6}\right)$

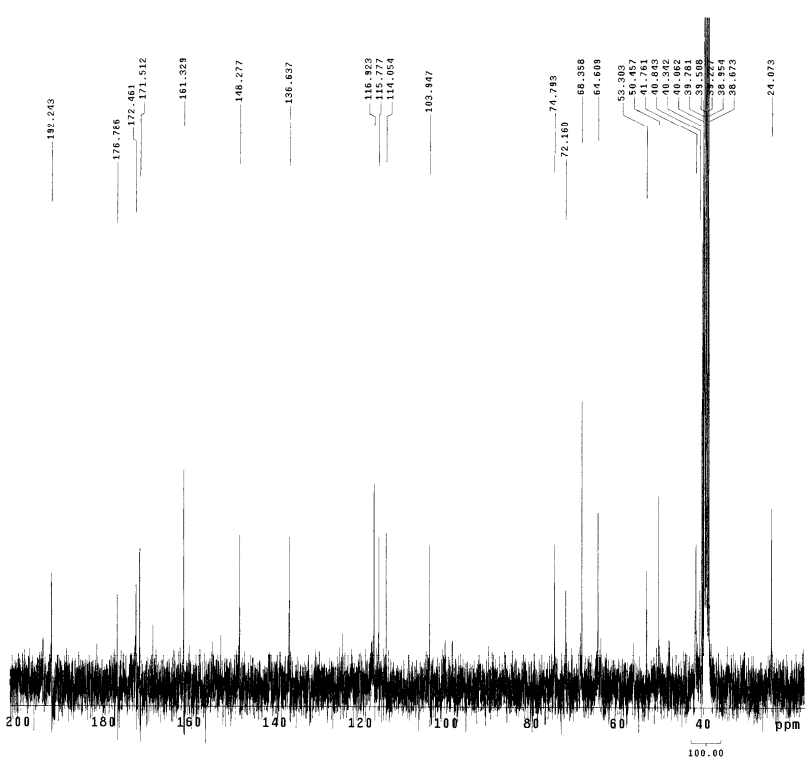

Espectro 52: ${ }^{13} \mathrm{C}-\mathrm{RMN}\left(75,4 \mathrm{MHz}, \mathrm{DMSO}-\mathrm{d}_{6}\right)$ 


\section{ESPECTROS DE LOS HAPTENOS TIPO II}

Hapteno OTC-3- Hidrocloruro de 7 y 9-(4'-carboxifenilazo)oxitetraciclina

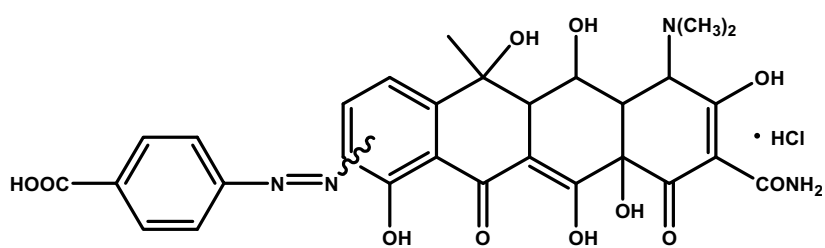

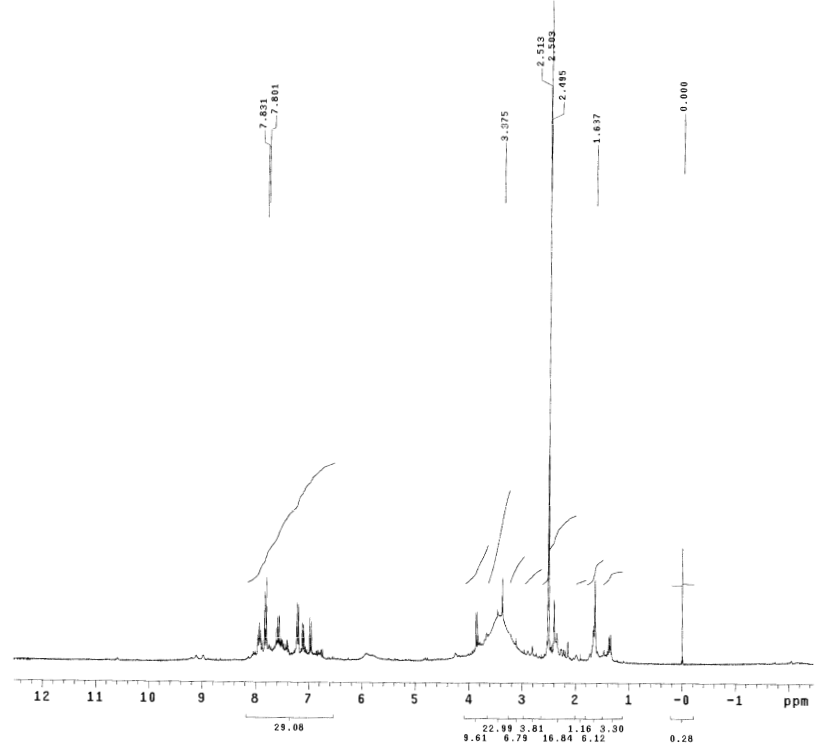

Espectro 53: ${ }^{1} \mathrm{H}-\mathrm{RMN}\left(300 \mathrm{MHz}, \mathrm{DMSO}-\mathrm{d}_{6}\right)$

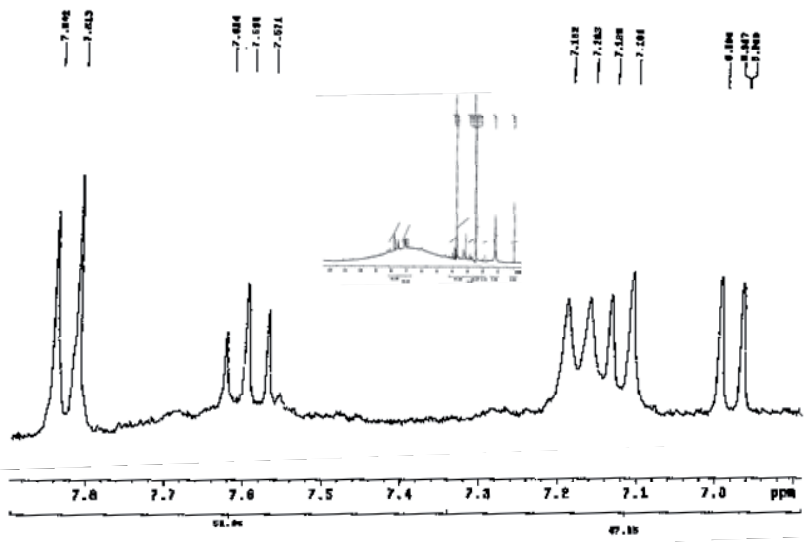

Espectro 54: Ampliación de la zona aromática del ${ }^{1} \mathrm{H}-\mathrm{RMN}$ (300 MHz, DMSO-d ${ }_{6}$ ). La inserción muestra el espectro completo 
Hapteno CTC-3- Hidrocloruro de 9-(4'-carboxifenilazo)clortetraciclina<smiles></smiles>

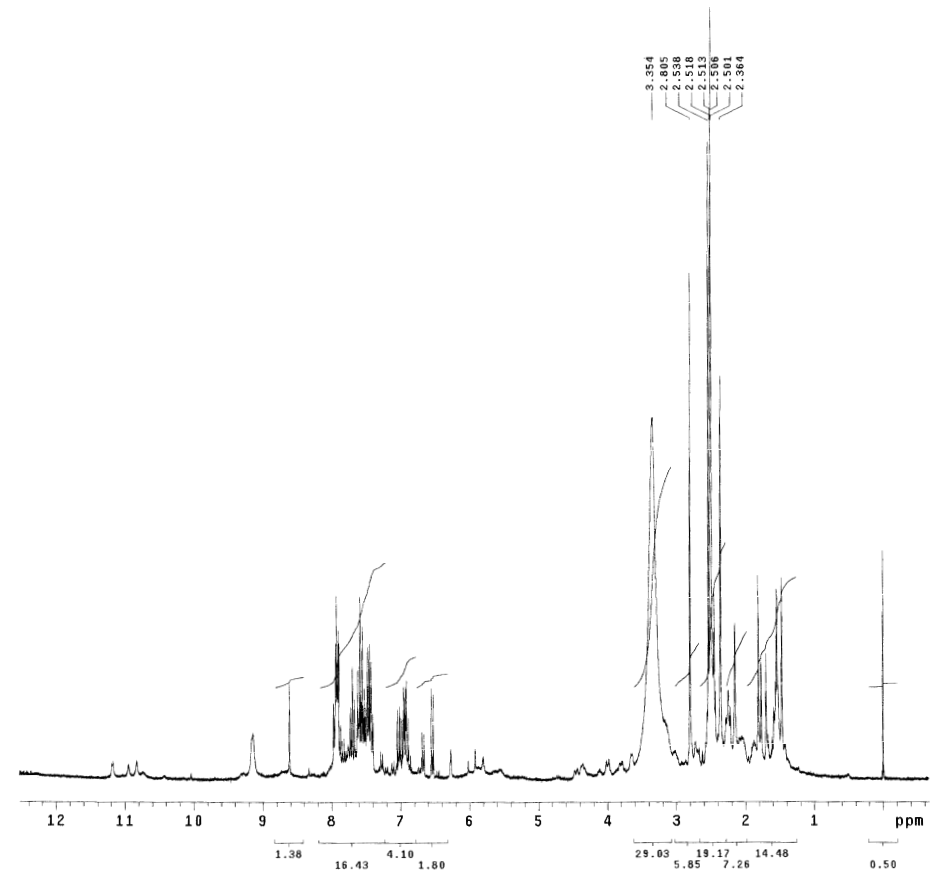

Espectro 55: ${ }^{1} \mathrm{H}-\mathrm{RMN}\left(300 \mathrm{MHz}, \mathrm{DMSO}-\mathrm{d}_{6}\right)$ 
Hapteno TC-4- Hidrocloruro de 7 y 9-(4'-carboxifenilazo)tetraciclina<smiles>CC1(O)C(O)=C(O)C(=O)C2(O)C(O)=C3C(=O)c4c(O)cccc4C(C)(O)C3CC12</smiles>

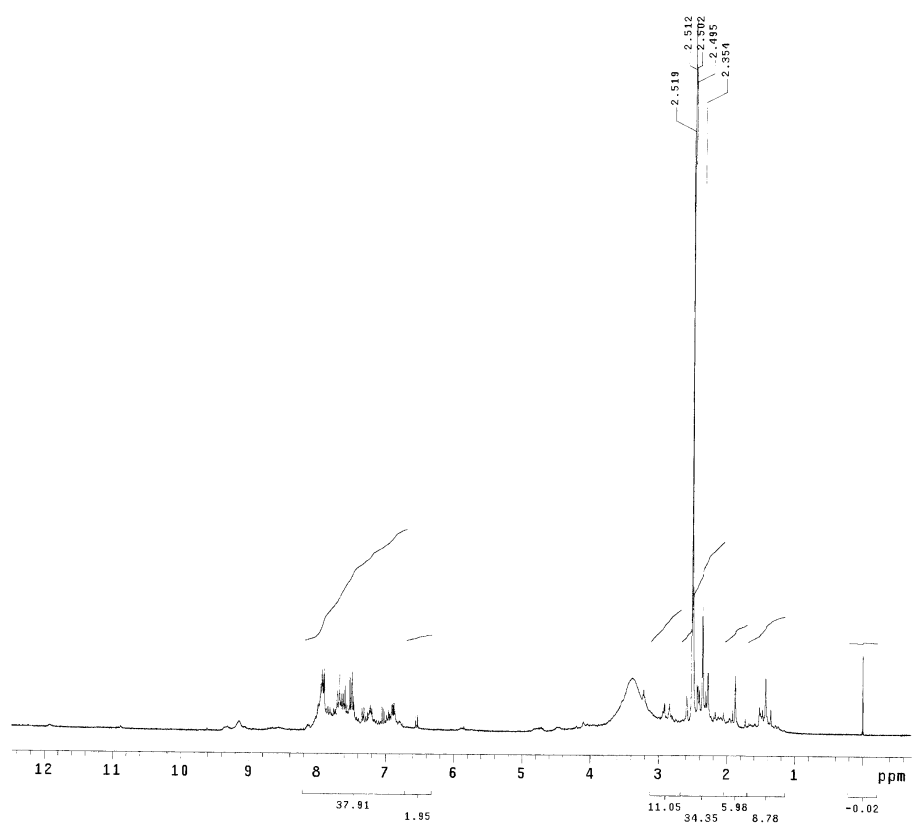

Espectro 56: ${ }^{1} \mathrm{H}-\mathrm{RMN}\left(300 \mathrm{MHz}, \mathrm{DMSO}-\mathrm{d}_{6}\right)$ 



\section{APÉNDICE II}

PUBLICACIONES DERIVADAS DE ESTA TESIS DOCTORAL 

Dd Pastor-Navarro, N., García-Bover, C., Maquieira, A., Puchades, R. (2004) Specific polyclonal-based immunoassays for sulfathiazole. Anal. Bioanal. Chem., 379, 1088-1099.

Da Pastor-Navarro, N., Gallego-Iglesias, E., Maquieira, A., Puchades, R. (2007) Development of a group-specific immunoassay for sulfonamides. Application to bee honey analysis. Talanta, 71, 923-933.

[D] Pastor-Navarro, N., Gallego-Iglesias, E., Maquieira, A., Puchades, R. (2007) Immunochemical method for sulfasalazine determination in human plasma. Anal. Chim. Acta, 583, 377-383.

D] Pastor-Navarro, N., Morais, S., Maquieira, A., Puchades, R. (2007) Synthesis of haptens and development of a sensitive immunoassay for tetracycline residues. Application to honey samples generic. Anal. Chim. Acta, 594, 211-218.

Pastor-Navarro, N., Maquieira, A., Puchades, R. (2009) Immunoanalytical determination of tetracycline and sulfonamide residues in edible products: a review. Anal. Bioanal. Chem., 395, 907920.

[D] Pastor-Navarro, N., Brun, E.M., Gallego-Iglesias, E., Maquieira, A., Puchades, R. (2009) Development of immunoassays to determinate sulfamethoxazole residues in wastewaters. J. Environ. Monit., 11, 10941100 .

Climent, E., Bernardos, A., Martínez-Mañez, R., Maquieira, A., Marcos, M.D., Pastor-Navarro, N., Puchades, R., Sancenón, F., Soto, J., Amorós, P. (2009) Controlled delivery systems using antibody-capped mesoporous nanocontainers. J. Am. Chem. Soc., 131, 14075-14080.

[Dd Cháfer-Pericás, C., Maquieira, A., Puchades, R., Miralles, J., Moreno, A., Pastor-Navarro, N., Espinós, F. (2010) Immunochemical 
determination of oxytetracycline in fish: comparison between enzymatic and time-resolved fluorometric assays. Anal. Chim. Acta, 662, 177-185.

Artículos de divulgación

[D] Pastor-Navarro, N., Maquieira, A., Puchades, R. (2007) Nuevos inmunoensayos para el análisis de residuos de tetraciclinas en mieles. CTC Alimentación,, 32, 12-17.

[1] González Martínez, M. A., Pastor-Navarro, N., Maquieira, A., Puchades, R. (2007) Aplicación de inmunosensores a la determinación de sulfatiazol en agua. CTC Alimentación, 32, 7-11. 


\section{APÉNDICE III}

PUBLICACIONES BASADAS EN INMUNORREACTIVOS DESARROLLADOS EN ESTA TESIS DOCTORAL 

Dd Pastor-Navarro, N., Gallego-Iglesias, E., Brun, E.M., Maquieira, A., Puchades Pla, R. The immunoassay, a reliable tool for screening sulfonamide residues in honey. I Congreso Iberoamericano sobre Seguridad Alimentaria (CIBSA), Sevilla, España, 2006.

Dastor-Navarro, N., Brun, E.M., Gallego-Iglesias, E., Maquieira, A., Puchades, R. (2009) Development of immunoassays to determinate sulfamethoxazole residues in wastewaters. J. Environ. Monit., 11, 10941100 .

[d] Climent, E., Bernardos, A., Martínez-Mañez, R., Maquieira, A., Marcos, M.D., Pastor-Navarro, N., Puchades, R., Sancenón, F., Soto, J., Amorós, P. (2009) Controlled delivery systems using antibody-capped mesoporous nanocontainers. J. Am. Chem. Soc., 131, 14075-14080.

[ㅁ] Cháfer-Pericás, C., Maquieira, A., Puchades, R., Miralles, J., Moreno, A. (2010) Fast screening immunoassay of sulfonamides in commercial fish samples. Anal. Bioanal. Chem., 396, 911-921.

[D] Cháfer-Pericás, C., Maquieira, A., Puchades, R., Miralles, J., Moreno, A., Pastor-Navarro, N., Espinós, F. (2010) Immunochemical determination of oxytetracycline in fish: comparison between enzymatic and time-resolved fluorometric assays. Anal. Chim. Acta, 662, 177-185.

Jornet, D., González-Martínez, M.A., Puchades, R., Maquieira, A. (2010) Antibiotic immunosensing: determination of sulfathiazole in water and honey. Talanta, 81, 1585-1592.

[D] Cháfer-Pericás, C., Maquieira, A., Puchades, R., Miralles, J., Moreno, A. (2011) Multiresidue determination of antibiotics in feed and fish samples for food safety evaluation. Comparison of immunoassay vs LC-MS-MS. Food Control, 22, 993-999. 
[L] Guillen, I., Gabaldon, J.A., Nunez-Delicado, E., Puchades, R., Maquieira, A., Morais, S. (2011) Detection of sulphathiazole in honey samples using a lateral flow immunoassay. Food Chem., 129, 624-629.

Aplicación de ensayos ELISA optimizados utilizando inmunorreactivos desarrollados en esta Tesis Doctoral

\begin{tabular}{|c|c|c|c|c|}
\hline Inmunorreactivos & Analito & Muestra & LD & Ref. \\
\hline BSA-S10-I/OVA-S2 & 9 sulfonamidas & miel & $2,35 \mu \mathrm{g} / \mathrm{L}$ & 171 \\
\hline BSA-S12-II/OVA-S8 & SMX & agua & $0,001 \mu \mathrm{g} / \mathrm{L}$ & 168 \\
\hline BSA-S4-II/OVA-S6 & $\begin{array}{l}\text { SMR } \\
\text { SDM } \\
\text { SDZ }\end{array}$ & $\begin{array}{l}\text { dorada } \\
\text { dorada } \\
\text { dorada }\end{array}$ & $\begin{array}{r}3,6 \mu \mathrm{g} / \mathrm{Kg} \\
6 \mu \mathrm{g} / \mathrm{Kg} \\
6 \mu \mathrm{g} / \mathrm{Kg}\end{array}$ & 169 \\
\hline BSA-S3-I/HRP-S4 & STZ & $\begin{array}{l}\text { agua } \\
\text { miel }\end{array}$ & $\begin{array}{r}0,11 \mu \mathrm{g} / \mathrm{L} \\
2,2 \mu \mathrm{g} / \mathrm{L}\end{array}$ & 166 \\
\hline KLH-OTC-3-III/OVA-TC-1 & $\begin{array}{c}\text { OTC } \\
\text { TC } \\
\text { CTC }\end{array}$ & $\begin{array}{l}\text { dorada } \\
\text { dorada } \\
\text { dorada }\end{array}$ & $\begin{array}{r}16 \mu \mathrm{g} / \mathrm{Kg} \\
7,7 \mu \mathrm{g} / \mathrm{Kg} \\
54 \mu \mathrm{g} / \mathrm{Kg}\end{array}$ & $\begin{array}{l}172 \\
170\end{array}$ \\
\hline BSA-S3-I/OVA-S2 & STZ & miel & $15 \mu \mathrm{g} / \mathrm{Kg}$ & 167 \\
\hline
\end{tabular}


